\title{
DOE/NV/10872.-T268
}

\section{IDENTIFICATION AND CHARACTERIZATION OF CONSERVATIVE ORganic TRaCERS FOR USE AS HydRologic Tracers For the YuCCa MoUntain SITE CharaCterization STUdY}

FINAL REPORT

\section{DOE Cooperative Agreement No. DE-FC 08-90NV10872}

\author{
Klaus Stetzenbach \\ Irene Farnham
}

\section{MASTER}

\section{Harry Reid Center For Environmental Studies University of Nevada - Las Vegas}

\begin{abstract}
This report was prepared as an account of work sponsored by an agency of the United States Government. Neither the United States Government nor any agency thereof, nor any of their employees, makes any warranty, express or implied, or assumes any legal liability or responsibility for the accuracy, completeness, or usefulness of any information, apparatus, product, or process disclosed, or represents that its use would not infringe privately owned rights. Reference herein to any specific commercial product, process, or service by trade name, trademark, manufacturer, or otherwise does not necessarily constitute or imply its endorsement, recommendation, or favoring by the United States Government or any agency thereof. The views and opinions of authors expressed herein do not necessarily state or reflect those of the United States Government or any agency thereof.
\end{abstract}




\section{SUMMARY of RESULTS}

This is the final report for Identification and Characterization of Conservative Organic Tracers for Use as Hydrologic Tracers for the Yucca Mountain Site Characterization Study. This report contains only major findings and conclusions resulting from this project. Detailed reports of all activities performed for this project were provided to the Project Office every quarter since the beginning of the project.

All of the fluorinated benzoic acids tested behave conservatively in three types of tuff.

The fluorocinnamic acids are not stable enough to be used as tracers.

The fluoro- and chloro-salicylic acids do not behave conservatively in the tuffs.

The pyridone, 2-oxynicotinamide, behaves conservatively in the tuffs.

The fluorobenzoates have relatively low toxicity.

The fluorobenzoates are not mutagens.

lodide was used successfully as a tracer at the C-wells. 


\section{INTRODUCTION}

Understanding the three-dimensional movement of ground water is essential from the standpoint of evaluating health risks and also for the remediation of contaminated waters, or waters moving through contaminated soils. Water level measurements provide a general sense of speed and direction, but are too coarse to provide detailed pathways and vertical movement information. Ground water tracers can be used to provide information on direction and speed of water movement, and contaminants that might be conveyed by the water. Tracers can also be used to measure effective porosity, hydraulic conductivity, and dispersivity.

In general, conservative groundwater tracers must be non-sorbing, stable for the duration of the tracer test, non-toxic, and have solubilities several orders of magnitude higher than the detection limit. Although inorganic ions such as chloride, bromide, and iodide are considered to be the best conservative tracers, other classes of tracers are often required to allow for more extensive tracer tests.

Extensive tracer testing is expected to take place at the C-well complex in the Nevada Test Site as part of the Yucca Mountain Site Characterization Project (YMSCP). The C-well complex consists of one pumping well, $\mathrm{C} 3$, and two injection wells, $\mathrm{C} 1$ and $\mathrm{C} 2$, into which tracer will be introduced. Since numerous tracer tests are planned at the C-well complex, more tracers with the above stated properties must be identified. The goal of the research performed at HRC was to provide USGS with numerous tracers to complete these tests.

Several classes of fluorinated organic acids have been evaluated. These include numerous isomers of fluorinated benzoic acids, cinnamic acids, and salicylic acids. Also, several derivatives of 2-hydroxy nicotinic acid (pyridone) have been tested. The stability of these compounds was determined using batch and column tests. Ames testing (mutagenicity/carcinogenicity) was conducted on the fluorinated benzoic acids and a literature review of toxicity of the fluorobenzoates and three perfluoro aliphatic acids was prepared. Solubilities were measured and method development work was performed to optimize the detection of these compounds.

A Quality Assurance (QA) Program was developed under existing DOE and USGS guidelines. The program includes QA procedures and technical standard operating procedures (SOPs). Criteria for field and laboratory tracer activities were established concerning sample storage, calibrations, replicate analyses, and blank determinations.

A tracer test, using sodium iodide, was performed at the C-well complex. HRC chemists performed analyses on site, to provide real time data for the USGS hydrologists, and in the laboratories at UNLV. Over 2,500 analyses were performed.

This report provides the results of the laboratory experiments and literature reviews used to evaluate the potential tracers and reports on the results of the iodide $\mathrm{C}$-well tracer test. 


\section{STATEMENT OF PROBLEM}

The purpose of this work was to identify and characterize compounds that would act as conservative tracers for use as hydrologic tracers for experiments to be conducted at the C-well complex.

General Outline of Tasks as received from the Department of Energy:

1) Identify candidate tracers for use as conservative tracers.

2) Conduct analytical chemical evaluation of promising candidate tracers by evaluating detection limits with respect to the Yucca Mountain environment.

3) Conduct batch tests on promising candidate tracers to evaluate suitability using a mass balance approach with consideration for time dependence.

4) Conduct column tests on promising candidate tracers with crushed core material and provide qualitative evaluations relative to bromide.

5) Conduct tests for degradation of candidate tracer compounds due to microbial action and chemical reactions under the environmental conditions anticipated at the $\mathrm{C}$ well complex. Provide evidence for non-toxicity.

6) Prepare an appropriate level quality assurance program.

7) Report recommendations for field application of conservative organic tracers for hydrologic testing. 


\section{RATIONALE FOR CHOOSING POTENTIAL TRACERS}

Tracers must have a number of properties to be functional. Regardless of the desired properties, the chemical and physical behavior of a tracer in ground water and the porous medium under study must be understood. Good estimates of tracer behavior can be obtained from laboratory studies. Tracers should have the following properties:

1) Must be water soluble.

2) Should not sorb on the aquifer material (i.e., be conservative).

3) Should be chemically and biologically stable for the duration of the test.

4) Should be foreign to the environment.

5) Should have excellent analytical sensitivity.

6) Should be non-toxic.

There are a relatively limited number of chemicals that meet all of the above described criteria. In general, any organic compound that is ionic or can be ionized at ground water $\mathrm{pH}$ values will be soluble enough to be used as a tracer. Most organic acids meet the requirements except for stability. Benzoic acid, an aromatic acid, meets all the above requirements except the one for stability. By substituting halogens, specifically fluorine, for the ring hydrogens, stability can be improved dramatically. Aromatic compounds that have halogen atoms attached to the ring have short and therefore strong bonds between the carbon and halide atom. Carbon-fluorine bonds are the shortest of the carbon halide bonds and are therefore expected to be the strongest and least reactive. As a general rule, it can be stated that more halogen atoms on a molecule, especially fluorine, further increase their stability. Teflon is an example of a perfluorinated compound that is virtually resistant to all chemical attack. Fluorine atoms are similar in size to hydrogens and are therefore not expected to appreciably alter the toxicity of the isomers with respect to the parent compound. Benzoic acid, cinnamic acid, and salicylic acid all occur naturally and are relatively safe when ingested in low quantities. Salicylic acid fluoresces and is therefore expected to have better sensitivity.

Three perfluorinated aliphatic acids, trifluoroacetic acid, pentafluoropropionic acid and heptafluorobutyric acid, meet most of the criteria but, for reasons explained in the toxicity report for perfluorinated aliphatic acids, they were not chosen and will not be discussed further in this report.

\section{METHOD DEVELOPMENT}

All the potential tracers tested can be analyzed by high performance liquid chromatography (HPLC). This method was chosen not only because it is precise and sensitive, but also the instruments are field portable and the ground water samples can be injected directly into the instrument with only filtration required. This allows analyses to 
be conducted in the field for immediate test results. All the assays for the potential tracers use reversed phase HPLC (C-18) columns, but the solvent compositions and the detectors are specific to each class or sub-class of compounds. A variable wavelength $\mathrm{UV}$ detector set between 200 and $230 \mathrm{~nm}$ is used for the fluorinated benzoates; the UV detector set at $270 \mathrm{~nm}$ is used for the fluorinated cinnamic acids; and a fluorescence detector set at $314 \mathrm{~nm}$ (excitation) and $360 \mathrm{~nm}$ (emission) is used for the pyridone compounds.

The fluorinated benzoic acids were shown through batch and column tests as well as

the toxicity review to be the best candidates for tracer field use. Because of this, a significant effort was placed on optimizing the analytical procedures for these compounds. Ultraviolet detector and liquid chromatographic parameters were determined that provide detection limits within the range required for the analysis of field samples and also to maximize the chromatographic separation of these compounds.

Analytical procedures for the analysis of iodide in field samples were developed. Generally, iodide is quantified using an iodide electrode. This method often does not allow the high precision and accuracy required for the analysis of tracer field samples. A method was developed at the HRC that allows for the use of reverse phase HPLC with UV detection.

\section{HPLC Optimization}

Multiple well tracer tests, requiring the use of several tracers, are anticipated at the C-well complex. In order to quantify multiple tracers, each tracer compound must be chromatographically separated from all of the other tracer compounds found within the sample. HPLC conditions were found that allowed for the separation of 15 of the 17 commercially available fluorinated benzoic acids. This separation is shown in the chromatogram in Figure 1. The HPLC conditions are as follows:

Column: Supelco LC-18 reverse phase column $(15 \mathrm{~cm} \times 4.6 \mathrm{~mm})$

Solvents: $\quad \mathrm{KH}_{2} \mathrm{PO}_{4}$ Buffer (adjusted to $\mathrm{pH}=2.7$ with $\mathrm{H}_{3} \mathrm{PO}_{4}$ ) Methanol

Gradient: $95 \% \mathrm{KH}_{2} \mathrm{PO}_{4}$ buffer : $5 \%$ Methanol to $35 \% \mathrm{KH}_{2} \mathrm{PO}_{4}$ buffer : $65 \%$ Methanol over 100 minutes; hold at $35 \% \mathrm{KH}_{2} \mathrm{PO}_{4}$ buffer : $65 \%$ Methanol for 20 minutes

Flow Rate: $1.4 \mathrm{~mL} / \mathrm{min}$. 
Figure 1. HPLC Chromatograms of all commercially available fluorinated and chlorinated benzoic acids. 


\section{BATCH TESTING}

The batch tests provide information on the stabilities of the potential tracers in an environment that closely simulates that of the C-wells. Mixtures containing these compounds in J-13 water are exposed to three types of tuffs (light, medium, and dark). A 1 to ratio of mass of water to mass of rock was used. The tracer concentrations were at about 5 ppm to allow accurate quantitation.

The tuff material has been identified by DOE geologists as Bullfrog Tuff, a crystal rich, pumiceous, rhyolitic (silica rich) tuff which underlies the Topopah Spring tuff in Yucca Mountain. The samples referred to as light, medium, and dark have been classified as follows: Un-welded "light" tuff, which is light weight, porous, and easily broken; Moderatelywelded "medium" tuff, which is semi-porous and contains some dense areas of collapsed pumice fragments; and the Densely-welded "dark" tuff which is hard, very dense, and vitrophyric in nature, and can be classified as an obsidian.

A control is also prepared which contains each of the tracers in J-13 water but no tuff. The concentration of each compound is measured periodically to determine changes that occur with time. High performance liquid chromatography (HPLC) is used to separate each of the compounds within the mixture, and an ultraviolet (UV) or fluorescence detector is used for detection and quantitation.

The results for each class of compounds tested are as follows.

\section{Fluorinated Benzoic Acids}

All commercially available fluorinated benzoic acids have been batch tested over sixty days. HPLC with UV detection was used for all analyses.

These compounds exhibit excellent stability with changes in concentration of less than $5 \%$ in each tuff type for most compounds. The concentrations for each of the compounds in each of the tuff types from day 0 to day 60 are shown in the following tables. These data are also presented in the graphs in Appendix A. These results not only show the high stability of these compounds but also demonstrate the excellent precision available through the HPLC/UV methods. 
Table 1 Concentrations of Tracers in the Control Samples

\begin{tabular}{|c|c|c|c|c|c|c|c|}
\hline \multirow[b]{2}{*}{ Compound } & \multicolumn{7}{|c|}{ Concentration (ppm) } \\
\hline & 0 & 1 & 5 & 10 & 20 & 30 & 60 \\
\hline 2,3-Difluorobenzoic Acid & 5.15 & 5.19 & 5.09 & 5.11 & 5.13 & 5.21 & 5.12 \\
\hline 2,4-Difluorobenzoic Acid & 5.33 & 5.32 & 5.35 & 5.38 & 5.25 & 5.34 & 5.37 \\
\hline 2,5-Difluorobenzoic Acid & 5.14 & 5.15 & 5.14 & 5.18 & 5.13 & 5.17 & 5.15 \\
\hline 2,6-Difluorobenzoic Acid & 4.99 & 4.97 & 5.03 & 5.01 & 5.02 & 5.17 & 5.06 \\
\hline 3,4-Difluorobenzoic Acid & 5.05 & 5.06 & 5.01 & 5.13 & 5.04 & 5.07 & 5.01 \\
\hline 3,5-Difluorobenzoic Acid & 5.06 & 5.20 & 5.01 & 5.15 & 5.05 & 5.20 & 5.03 \\
\hline 2,3,4-Trifluorobenzoic Acid & 4.95 & 4.92 & 4.92 & 5.06 & 4.90 & 5.01 & 4.98 \\
\hline 2,3,6-Trifluorobenzoic Acid & 5.10 & 5.13 & 5.04 & 5.07 & 5.06 & 5.18 & 5.13 \\
\hline 2,4,5-Trifluorobenzoic Acid & 5.92 & 5.94 & 5.94 & 6.03 & 6.08 & 6.02 & 5.90 \\
\hline 2,4,6-Trifluorobenzoic Acid & 5.74 & 5.77 & 5.79 & 5.78 & 5.84 & 5.75 & 5.72 \\
\hline 3,4,5-Trifluorobenzoic Acid & 5.14 & 5.16 & 5.02 & 5.06 & 5.31 & 5.20 & 5.06 \\
\hline 2,3,4,5-Tetrafluorobenzoic Acid & 5.74 & 5.71 & 5.66 & 5.70 & 5.73 & 5.65 & 5.60 \\
\hline 2,3,5,6-Tetrafluorobenzoic Acid & 6.20 & 6.22 & 6.29 & 6.26 & 6.21 & 6.27 & 6.24 \\
\hline Pentafluorobenzoic Acid & 5.62 & 5.64 & 5.67 & 5.71 & 5.67 & 5.65 & 5.59 \\
\hline$\alpha, \alpha, \alpha$-Trifluoro-o-toluic acid & 5.14 & 5.15 & 5.00 & 5.07 & 4.96 & 5.09 & 5.05 \\
\hline$\alpha, \alpha, \alpha$-Trifluoro-m-toluic acid & 5.13 & 5.12 & 5.02 & 5.06 & 5.18 & 5.12 & 5.06 \\
\hline$\alpha, \alpha, \alpha$-Trifluoro-p-toluic acid & 5.28 & 5.29 & 5.19 & 5.22 & 5.23 & 5.26 & 5.14 \\
\hline
\end{tabular}


Table 2 Concentrations of Tracers in the Light Tuff Samples

\begin{tabular}{|c|c|c|c|c|c|c|c|}
\hline & & Conc & ion & & & & \\
\hline Compound & 0 & 1 & 5 & 10 & 20 & 30 & 60 \\
\hline 2,3-Difluorobenzoic Acid & 5.15 & 5.19 & 5.07 & 5.02 & 5.00 & 5.09 & 5.09 \\
\hline 2,4-Difluorobenzoic Acid & 5.43 & 5.45 & 5.43 & 5.35 & 5.23 & 5.35 & 5.49 \\
\hline 2,5-Difluorobenzoic Acid & 5.19 & 5.18 & 5.19 & 5.18 & 5.10 & 5.19 & 5.28 \\
\hline 2,6-Difluorobenzoic Acid & 4.77 & 4.78 & * & $*$ & *6.58 & 4.96 & \\
\hline 3,4-Difluorobenzoic Acid & 5.07 & 5.14 & 5.06 & 5.10 & 4.99 & 5.06 & 5.18 \\
\hline 3,5-Difluorobenzoic Acid & 5.07 & 5.08 & 5.03 & 5.04 & 5.08 & 5.11 & 5.10 \\
\hline 2,3,4-Trifluorobenzoic Acid & 4.98 & 5.04 & 5.08 & 5.11 & 4.94 & 5.06 & 5.11 \\
\hline 2,4,5-Trifluorobenzoic Acid & 5.97 & 5.99 & 5.95 & 5.97 & 6.01 & 6.02 & 6.08 \\
\hline 3,4,5-Trifluorobenzoic Acid & 5.05 & 5.08 & 5.08 & 5.13 & 5.18 & 5.25 & 5.35 \\
\hline 2,3,4,5-Tetrafluorobenzoic Acid & 5.78 & 5.81 & 5.75 & 5.69 & 5.67 & 5.65 & 5.71 \\
\hline Pentafluorobenzoic Acid & 5.53 & 5.58 & 5.55 & 5.16 & 5.27 & 4.96 & 5.55 \\
\hline$\alpha, \alpha, \alpha$-Trifluoro-o-toluic acid & 4.97 & 5.02 & 4.98 & 5.03 & 4.91 & 5.06 & 5.29 \\
\hline$\alpha, \alpha, \alpha$-Trifluoro-m-toluic acid & 5.06 & 5.17 & 5.14 & 5.14 & 5.13 & 5.26 & 5.10 \\
\hline$\alpha, \alpha, \alpha$-Trifluoro-p-toluic acid & 5.16 & 5.28 & 5.25 & 5.28 & 5.23 & 5.33 & 5.31 \\
\hline
\end{tabular}

*A large interference was observed in all of the light tuff samples. This interfered with the quantitation of 2,3,5,6-Tetrafluorobenzoic acid, 2,4,6-Trifluorobenzoic acid, 2,3,6-Trifluorobenzoic acid and $t 5-t 30$ for 2,6Difluorobenzoic acid. These data are therefore not reported. 
Table 3 Concentrations of Tracers in the Medium Tuff Samples

\begin{tabular}{llllllll}
\hline \multicolumn{1}{c}{ Compound } & & \multicolumn{5}{c}{ Concentration (ppm) } \\
& 0 & 1 & 5 & 10 & 20 & 30 & 60 \\
\hline 2,3-Difluorobenzoic Acid & 5.17 & 5.18 & 5.11 & 5.15 & 5.11 & 5.14 & 5.10 \\
2,4-Difluorobenzoic Acid & 5.41 & 5.41 & 5.37 & 5.39 & 5.25 & 5.36 & 5.45 \\
2,5-Difluorobenzoic Acid & 5.19 & 5.18 & 5.20 & 5.18 & 5.14 & 5.21 & 5.24 \\
2,6-Difluorobenzoic Acid & 5.05 & 5.14 & 5.28 & 5.21 & 5.18 & 5.17 & 4.99 \\
3,4-Difluorobenzoic Acid & 5.12 & 5.08 & 5.06 & 5.10 & 5.07 & 5.03 & 4.99 \\
3,5-Difluorobenzoic Acid & 5.18 & 5.10 & 5.08 & 5.10 & 5.06 & 5.13 & 5.11 \\
2,3,4-Trifluorobenzoic Acid & 4.98 & 5.01 & 5.02 & 5.13 & 4.96 & 5.10 & 5.11 \\
2,3,6-Trifluorobenzoic Acid & 5.05 & 5.15 & 4.97 & 5.02 & 4.94 & 4.99 & 4.53 \\
2,4,5-Trifluorobenzoic Acid & 5.99 & 5.97 & 5.96 & 6.04 & 6.12 & 6.11 & 6.09 \\
2,4,6-Trifluorobenzoic Acid & 6.01 & 6.03 & $*$ & 6.01 & 5.68 & 5.67 & 5.62 \\
3,4,5-Trifluorobenzoic Acid & 5.18 & 5.14 & 5.15 & 5.12 & 5.10 & 5.18 & 5.25 \\
2,3,4,5-Tetrafluorobenzoic Acid & 5.74 & 5.74 & 5.76 & 5.71 & 5.76 & 5.70 & 5.68 \\
2,3,5,6-Tetrafluorobenzoic Acid & 6.29 & 6.30 & 6.40 & 6.36 & 6.19 & 6.26 & 6.29 \\
Pentafluorobenzoic Acid & 5.59 & 5.64 & 5.73 & 5.64 & 5.68 & 5.69 & 5.69 \\
$\alpha, \alpha, \alpha$-Trifluoro-o-toluic acid & 5.04 & 5.13 & 5.07 & 5.17 & 5.07 & 5.21 & 5.04 \\
$\alpha, \alpha, \alpha$-Trifluoro-m-toluic acid & 5.08 & 5.15 & 5.13 & 5.19 & 5.05 & 5.22 & 5.19 \\
$\alpha, \alpha, \alpha$-Trifluoro-p-toluic acid & 5.25 & 5.30 & 5.25 & 5.34 & 5.19 & 5.31 & 5.34
\end{tabular}

*2,4,6-Trifluorobenzoic acid could not be quantitated at $\mathrm{T}=5$ due to the presence of an interference in the chromatogram. 
Table 4 Concentrations of Tracers in the Dark Tuff Samples

\begin{tabular}{|c|c|c|c|c|c|c|c|}
\hline \multirow{2}{*}{ Compound } & \multirow[b]{2}{*}{$\Omega$} & \multirow[b]{2}{*}{1} & \multicolumn{3}{|c|}{ Concentration (ppm) } & \multirow[b]{2}{*}{30.} & \multirow[b]{2}{*}{60} \\
\hline & & & 5 & 10 & 20 & & \\
\hline 2,3-Difluorobenzoic Acid & 5.26 & 5.23 & 5.10 & 5.12 & 5.13 & 5.10 & 5.15 \\
\hline 2,4-Difluorobenzoic Acid & 5.38 & 5.44 & 5.35 & 5.36 & 5.29 & 5.41 & 5.47 \\
\hline 2,5-Difluorobenzoic Acid & 5.17 & 5.20 & 5.16 & 5.18 & 5.16 & 5.25 & 5.25 \\
\hline 2,6-Difluorobenzoic Acid & 5.07 & 5.22 & 5.40 & 5.41 & 5.50 & 5.73 & 5.04 \\
\hline 3,4-Difluorobenzoic Acid & 5.07 & 5.09 & 5.09 & 5.10 & 5.09 & 5.06 & 4.98 \\
\hline 3,5-Difluorobenzoic Acid & 5.06 & 5.22 & 5.01 & 5.04 & 5.02 & 5.13 & 5.12 \\
\hline 2,3,4-Trifluorobenzoic Acid & 4.96 & 5.06 & 5.05 & 5.14 & 5.05 & 5.18 & 5.12 \\
\hline 2,3,6-Trifluorobenzoic Acid & 5.07 & 5.13 & 4.93 & 4.99 & 4.99 & 5.03 & 5.02 \\
\hline 2,4,5-Trifluorobenzoic Acid & 5.95 & 5.97 & 5.96 & 5.99 & 6.12 & 6.14 & 6.11 \\
\hline 2,4,6-Trifluorobenzoic Acid & 5.85 & 5.92 & * & $* 7.00$ & 5.67 & 5.65 & 5.70 \\
\hline 3,4,5-Trifluorobenzoic Acid & 5.07 & 5.10 & 5.08 & 5.16 & 5.20 & 5.13 & 5.39 \\
\hline 2,3,4,5-Tetrafluorobenzoic Acid & 5.74 & 5.76 & 5.80 & 5.68 & 5.79 & 5.72 & 5.62 \\
\hline 2,3,5,6-Tetrafluorobenzoic Acid & 6.29 & 6.33 & 6.22 & 6.13 & 6.18 & 6.23 & 6.32 \\
\hline Pentafluorobenzoic Acid & 5.58 & 5.63 & 5.69 & 5.60 & 5.62 & 5.66 & 5.62 \\
\hline$\alpha, \alpha, \alpha$-Trifluoro-o-toluic acid & 5.00 & 5.08 & 5.04 & 5.04 & 5.02 & 5.04 & 5.09 \\
\hline$\alpha, \alpha, \alpha$-Trifluoro-m-toluic acid & 5.11 & 5.14 & 5.09 & 5.10 & 5.04 & 5.25 & 5.02 \\
\hline$\alpha, \alpha, \alpha$-Trifluoro-p-toluic acid & 5.24 & 5.31 & 5.25 & 5.27 & 5.09 & 5.28 & 5.25 \\
\hline
\end{tabular}

*2,4,6-Trifluorobenzoic acid could not be quantitated at $T=5$ due to the presence of an interference in the chromatogram. The high concentration reported on $T=10$ is also due to an interference. 


\section{Pyridones}

2-Hydroxynicotinic acid (pyridone) and three of its derivatives were batch tested. The pyridone compounds are of interest as groundwater tracers because of their fluorescence properties. Because these compounds fluoresce, they can be detected at low ppb levels. This becomes necessary when dilution exceeds several orders of magnitude during the tracer test. These compounds were quantified over 118 days using HPLC with fluorescence detection. The compounds tested and the results for each of the tuff types and control are listed in Table 5 - 8 . 
Table 5 Concentrations of Pyridones in the Light Tuff Samples

\begin{tabular}{|c|c|c|c|c|c|c|c|}
\hline \multirow{2}{*}{ Compound } & \multirow[b]{2}{*}{0} & \multirow[b]{2}{*}{1} & \multicolumn{5}{|c|}{ Concentration (ppb) } \\
\hline & & & 5 & 11 & 18 & 32 & 118 \\
\hline 2-Oxynicotinamide & 49.22 & 49.56 & 49.05 & 49.29 & 48.36 & 45.63 & 20.75 \\
\hline 2-Hydroxynicotinic acid & 88.94 & 120.32 & 138.74 & 151.72 & 158.34 & 149.34 & $<$ DL \\
\hline N-Methyl-2-oxynicotinamide & 47.20 & 46.67 & 46.51 & 46.75 & 45.94 & 56.13 & 53.09 \\
\hline Methyl 2-Hydroxynicotinate & 93.36 & 41.26 & 29.56 & 14.46 & 4.99 & $<\mathrm{DL}$ & $<\mathrm{DL}$ \\
\hline
\end{tabular}


Table 6 Concentrations of Pyridones in the Medium Tuff Samples

\begin{tabular}{lrrrrrrrr}
\hline \multicolumn{1}{c}{ Compound } & \multicolumn{10}{c}{ Concentration (ppb) } \\
& 0 & 1 & 5 & 11 & 18 & 32 & 118 \\
\hline & 48.20 & 44.49 & 42.88 & 40.93 & 39.27 & 38.68 & 42.75 \\
2-Oxynicotinamide & 56.37 & 57.77 & 56.51 & 54.14 & 53.77 & 61.76 & 37.25 \\
2-Hydroxynicotinic acid & 45.60 & 38.19 & 33.96 & 29.91 & 26.30 & 27.16 & 20.42 \\
N-Methyl-2-oxynicotinamide & Methyl 2-Hydroxynicotinate & 127.80 & 77.13 & 56.17 & 38.46 & 25.24 & $13.26<$ DL
\end{tabular}


Table 7 Concentrations of Pyridones in the Dark Tuff Samples

\begin{tabular}{lrrrrrrr}
\hline \multicolumn{1}{c}{ Compound } & \multicolumn{1}{c}{ Concentration (ppb) } \\
& \multicolumn{1}{c}{0} & \multicolumn{1}{c}{1} & \multicolumn{1}{c}{5} & \multicolumn{1}{c}{11} & \multicolumn{1}{c}{18} & \multicolumn{1}{c}{32} & \multicolumn{1}{c}{118} \\
\hline 2-Oxynicotinamide & 49.22 & 48.88 & 48.36 & 47.84 & 46.70 & 45.56 & 45.29 \\
2-Hydroxynicotinic acid & 61.71 & 63.78 & 65.80 & 82.65 & 1.84 & ND & -7.60 \\
N-Methyl-2-oxynicotinamide & 47.00 & 46.67 & 46.40 & 46.42 & 44.87 & 41.92 & 45.39 \\
Methyl 2-Hydroxynicotinate & 131.51 & 121.07 & 110.49 & 81.41 & 49.88 & 15.10 & 0.00
\end{tabular}


Table 8 Concentrations of Pyridones in the Control

\begin{tabular}{|c|c|c|c|c|c|c|c|}
\hline \multirow[t]{2}{*}{ Compound } & \multirow[b]{2}{*}{0} & \multicolumn{6}{|c|}{ Concentration (ppb) } \\
\hline & & 1 & 5 & 11 & 18 & 32 & 118 \\
\hline 2-oxynicotinamide & 49.42 & 49.22 & 49.21 & 49.62 & 48.97 & 49.82 & 58.64 \\
\hline 2-Hydroxynicotinic acid & 50.70 & 53.93 & 49.90 & 53.08 & 59.19 & 80.20 & 73.34 \\
\hline N-Methyl-2-oxynicotinamide & 48.44 & 48.12 & 48.14 & 49.01 & 47.49 & 51.60 & 65.60 \\
\hline Methyl 2-Hydroxynicotinate & 193.17 & 187.57 & 194.47 & 187.32 & 178.12 & 143.37 & -9.14 \\
\hline
\end{tabular}




\section{Cinnamic Acids}

Four cinnamic acids (3,5-difluorocinnamic acid, 2,5-Difluorocinnamic acid, 2fluorocinnamic acid, and $\alpha$-cinnamic acid) were batch tested. The cinnamic acids were found to be unstable in all three tuffs. These compounds were therefore found to be unsuitable for use as groundwater tracers.

\section{Salicylic Acids}

Two salicylic acids, 5-fluorosalicylic acid and 3,5-dichlorosalicylic acid, were tested. 5-fluorosalicylic acid was unstable in all three tuffs. 3,5-Dichlorosalicylic acid was stable for 90 days in the light tuff and to 250 days in the medium and dark tuffs. The 3,5dichlorosalicylic acid was not chosen as a possible tracer because its fluorescent characteristics were poor and there was no increase in sensitivity over the fluorinated benzoates, and its toxicology properties were unknown.

\section{COLUMN TESTING}

Another method used to measure the sorption of the tracer compounds to tuff material is the column test. The tracer is injected into a column containing ground tuff, and the time required for its elution is measured. The elution volume, calculated by multiplying the elution time by the measured flow rate, is compared to that of bromide. Bromide, which is considered to be a conservative tracer, is used as a reference for each compound. All fluorinated benzoates have been tested on columns containing each of the tuffs (see the previous report for column dimensions and detection methods). The mean elution volume, the standard deviation, and the percent relative standard deviation (\%RSD) for each compound are listed in Tables $9-11$. Three injections of potassium bromide were made per day and the ratios of the elution volumes, analyte/bromide, were calculated. This ratio is also listed along with the mean, standard deviation (SD), and percent relative standard deviation (\%RSD) for the $\mathrm{KBr}$ elution volumes.

The elution volumes for all acids are very similar to bromide and are generally within one standard deviation. The ratios, Tracer $/ \mathrm{KBr}$, are also very close to one, and in fact in the light and medium tuff most are less than one. This indicates faster travel through the column than bromide. The Tracer $/ \mathrm{KBr}$ in the dark tuff are slightly higher than in the light and medium tuff, but the elution volumes for $\mathrm{KBr}$ injections are still within one standard deviation of the benzoates. If it is assumed that bromide (potassium bromide) does not sorb to the tuff, then all the benzoic and toluic acids also behave conservatively. 
Table 9 Column Test Results for the Medium Tuff

\begin{tabular}{lccccccc}
\hline \hline & $\begin{array}{c}\text { Mean } \\
\text { Compound }\end{array}$ & $\begin{array}{c}\text { Standard } \\
\text { Deviation }\end{array}$ & $\begin{array}{c}\text { Tracer } \\
\text { \%RSD }\end{array}$ & $\begin{array}{c}\text { Tracer/ } \\
\text { KBr }\end{array}$ & $\begin{array}{c}\mathrm{KBr} \\
\text { Mean }\end{array}$ & $\begin{array}{c}\mathrm{KBr} \\
\text { SD }\end{array}$ & $\begin{array}{l}\mathrm{KBr} \\
\text { \%RSD }\end{array}$ \\
\hline 2,3-difluorobenzoic acid & 206.6 & 2.00 & 0.97 & 0.99 & 208.1 & 0.82 & 0.39 \\
2,4-difluorobenzoic acid & 162.6 & 4.77 & 2.93 & 0.96 & 169.5 & 2.52 & 1.49 \\
2,5-difluorobenzoic acid & 158.2 & 7.74 & 4.89 & 0.98 & 161.5 & 2.64 & 1.64 \\
2,6-difluorobenzoic acid & 161.0 & 5.81 & 3.61 & 1.00 & 160.6 & 2.53 & 1.58 \\
3,4-difluorobenzoic acid & 209.3 & 5.48 & 2.62 & 0.98 & 212.9 & 4.05 & 1.90 \\
2,3,4-trifluorobenzoic acid & 156.4 & 1.65 & 1.05 & 0.99 & 157.5 & 6.18 & 3.92 \\
2,3,6-trifluorobenzoic acid & 206.6 & 3.74 & 1.81 & 0.99 & 208.6 & 3.08 & 1.48 \\
2,4,5-trifluorobenzoic acid & 201.4 & 1.67 & 0.83 & 0.98 & 205.5 & 1.60 & 0.78 \\
2,4,6-trifluorobenzoic acid & 158.3 & 9.81 & 6.20 & 0.98 & 161.5 & 3.73 & 2.31 \\
3,4,5-trifluorobenzoic acid & 210.8 & 2.02 & 0.96 & 1.00 & 211.7 & 2.34 & 1.11 \\
2,3,4,5-tetrafluorobenzoic acid & 191.6 & 7.83 & 4.09 & 0.99 & 193.7 & 0.00 & 0.00 \\
2,3,5,6-tetrafluorobenzoic acid & 213.0 & 1.44 & 0.68 & 1.00 & 212.4 & 2.38 & 1.12 \\
pentafluorobenzoic acid & 207.4 & 1.26 & 0.61 & 1.00 & 206.5 & 1.41 & 0.68 \\
m-toluic acid & 210.4 & 3.34 & 1.59 & 0.97 & 215.9 & 4.45 & 2.06 \\
0-toluic acid & 205.7 & 1.20 & 0.58 & 0.98 & 209.7 & 0.52 & 0.25 \\
p-toluic acid & 212.5 & 2.42 & 1.14 & 1.01 & 210.5 & 0.60 & 0.29
\end{tabular}


Table 10 Column Test Results for the Light Tuff

\begin{tabular}{lccccccc}
\hline \hline Compound & $\begin{array}{c}\text { Mean } \\
(\mathrm{mL})\end{array}$ & $\begin{array}{c}\text { Standard } \\
\text { Deviation }\end{array}$ & $\begin{array}{c}\text { Tracer } \\
\text { \%RSD }\end{array}$ & $\mathrm{KBr} / \mathrm{KBr}$ & $\mathrm{KBr}$ & $\mathrm{KBBr}$ \\
mean & SD & \%RSD \\
\hline 2,3-difluorobenzoic acid & 301.7 & 6.16 & 2.04 & 0.95 & 316.4 & 7.91 & 2.50 \\
2,4-difluorobenzoic acid & 288.4 & 13.0 & 4.51 & 0.92 & 312.0 & 21.3 & 6.84 \\
2,5-difluorobenzoic acid & 292.7 & 5.34 & 1.82 & 0.99 & 296.7 & 3.30 & 1.11 \\
2,6-difluorobenzoic acid & 287.0 & 10.2 & 3.56 & 0.95 & 302.3 & 3.74 & 1.24 \\
3,4-difluorobenzoic acid & 292.6 & 14.7 & 5.04 & 0.98 & 298.2 & 12.7 & 4.26 \\
3,5-difluorobenzoic acid & 302.5 & 5.13 & 1.70 & 0.95 & 317.8 & 11.4 & 3.59 \\
2,3,4-trifluorobenzoic acid & 292.7 & 7.31 & 2.50 & 0.95 & 309.5 & 7.02 & 2.27 \\
2,3,6-trifluorobenzoic acid & 292.9 & 5.54 & 1.89 & 0.94 & 312.9 & 14.1 & 4.51 \\
2,4,5-trifluorobenzoic acid & 282.0 & 9.07 & 3.21 & 0.92 & 305.1 & 3.65 & 1.20 \\
2,4,6-trifluorobenzoic acid & 287.1 & 13.9 & 4.84 & 0.95 & 302.8 & 3.64 & 1.20 \\
3,4,5-trifluorobenzoic acid & 292.8 & 3.77 & 1.29 & 0.95 & 308.0 & 3.76 & 1.22 \\
2,3,4,5-tetrafluorobenzoic acid & 292.1 & 13.9 & 4.77 & 0.93 & 315.2 & 12.4 & 3.95 \\
2,3,5,6-tetrafluorobenzoic acid & 292.4 & 10.3 & 3.51 & 0.92 & 316.3 & 18.0 & 5.70 \\
pentafluorobenzoic acid & 292.6 & 28.3 & 9.67 & 0.98 & 299.1 & 19.9 & 6.66 \\
m-toluic acid & 294.3 & 12.3 & 4.19 & 0.96 & 306.0 & 25.6 & 8.36 \\
o-toluic acid & 287.4 & 11.9 & 4.14 & 0.93 & 309.2 & 3.85 & 1.25 \\
p-toluic acid & 285.5 & 13.9 & 4.87 & 0.90 & 316.1 & 16.8 & 5.30
\end{tabular}


Table 11 Column Test Results for the Dark Tuff

\begin{tabular}{lccccccl}
\hline \hline & $\begin{array}{c}\text { Mean } \\
\text { Compound }\end{array}$ & $\begin{array}{c}\text { Standard } \\
\text { Deviation }\end{array}$ & $\begin{array}{c}\text { Tracer } \\
\text { \%RSD }\end{array}$ & Tracer/ & KBr & KBr & KBr \\
mean & SD & \%RSD \\
\hline 2,3-difluorobenzoic acid & 177.4 & 7.29 & 4.11 & 1.03 & 171.4 & 2.49 & 1.46 \\
2,4-difluorobenzoic acid & 269.9 & 6.55 & 2.43 & 1.01 & 266.5 & 9.96 & 3.73 \\
2,5-difluorobenzoic acid & 237.6 & 20.2 & 8.51 & 0.98 & 242.1 & 28.9 & 11.9 \\
2,6-difluorobenzoic acid & 152.8 & 4.68 & 3.06 & 1.00 & 152.8 & 3.79 & 2.48 \\
3,4-difluorobenzoic acid & 159.1 & 0.56 & 1.61 & 1.02 & 155.4 & 0.85 & 0.55 \\
3,5-difluorobenzoic acid & 245.1 & 10.3 & 4.22 & 1.02 & 240.2 & 6.74 & 2.81 \\
2,3,4-trifluorobenzoic acid & 250.2 & 9.55 & 3.82 & 1.04 & 240.0 & 14.0 & 5.82 \\
2,3,6-trifluorobenzoic acid & 152.8 & 4.68 & 3.06 & 1.00 & 152.8 & 3.79 & 2.48 \\
2,4,5-trifluorobenzoic acid & 163.0 & 6.05 & 3.71 & 1.00 & 162.2 & 10.5 & 6.47 \\
2,4,6-trifluorobenzoic acid & 135.2 & 3.49 & 2.58 & 0.96 & 140.5 & 4.05 & 2.88 \\
3,4,5-trifluorobenzoic acid & 169.4 & 1.51 & 0.89 & 1.01 & 168.0 & 0.21 & 0.12 \\
2,3,4,5-tetrafluorobenzoic acid & 162.2 & 2.51 & 1.54 & 0.99 & 164.7 & 3.43 & 2.08 \\
2,3,5,6-tetrafluorobenzoic acid & 170.9 & 1.07 & 0.63 & 1.01 & 169.7 & 2.23 & 1.31 \\
pentafluorobenzoic acid & 241.9 & 10.3 & 4.22 & 1.05 & 230.2 & 9.72 & 4.22 \\
m-toluic acid & 243.1 & 2.96 & 1.22 & 1.06 & 230.4 & 4.65 & 2.02 \\
o-toluic acid & 138.4 & 3.19 & 2.31 & 0.98 & 141.4 & 5.96 & 4.22 \\
p-toluic acid & 165.5 & 9.18 & 5.55 & 0.99 & 167.0 & 13.1 & 7.85
\end{tabular}




\section{SOLUBILITY}

\section{pH testing:}

Solutions of one, ten, and twenty percent concentrations were tested for solubility. The $\mathrm{pH}$ of each solution was recorded. If the acid was not completely dissolved, then small increments of sodium hydroxide were added until it dissolved. The solution pH was recorded when all the tracer was dissolved and is listed below in Table 12.

The one and ten percent solutions consisted of 0.1 and 1 gram, respectively, of acid in ten milliliters of J-13 water. The twenty percent solution was made using 0.5 grams of the tracer in 2.5 milliliters of $\mathrm{J}-13$ water. 
Table 12. Solubility and $\mathrm{pH}$

\begin{tabular}{lccc}
\hline \hline Tracer & $\mathrm{pH}$ & $\mathrm{pH}$ & $\mathrm{pH}$ \\
& $1 \%$ & $10 \%$ & $20 \%$ \\
\hline 2,3-difluorobenzoic acid & 14 & 13 & 14 \\
2,4-difluorobenzoic acid & 14 & 13 & 14 \\
2,5-difluorobenzoic acid & 4 & 7 & 14 \\
2,6-difluorobenzoic acid & $14^{*}$ & 5 & 14 \\
3,4-difluorobenzoic acid & 14 & 13 & 14 \\
3,5-difluorobenzoic acid & 12 & 13 & 14 \\
2,3,4-trifluorobenzoic acid & 13 & 12 & 14 \\
2,3,6-trifluorobenzoic acid & 1 & 3 & 14 \\
2,4,5-trifluorobenzoic acid & 4 & 9 & 14 \\
2,4,6-trifluorobenzoic acid & $10^{*}$ & 7 & 14 \\
3,4,5-trifluorobenzoic acid & $14^{*}$ & 5 & 14 \\
2,3,4,5-tetrafluorobenzoic acid & 2 & 3 & 14 \\
2,3,5,6-tetrafluorobenzoic acid & 2 & 3 & 14 \\
pentafluorobenzoic acid & 2 & 3 & 14 \\
m-toluic acid & 14 & 14 & 14 \\
o-toluic acid & $12^{*}$ & 11 & 14 \\
p-toluic acid & $14^{*}$ & 12 & 14
\end{tabular}

* the increment of $\mathrm{NaOH}$ used was larger than necessary to dissolve the tracer. 


\section{TOXICITY}

\section{Ames Testing}

The compounds listed in Table 13 were tested for mutagenicity using the Ames test. Ames testing uses specific strains of bacterium Salmonella typherium selected for its inability to grow without the addition of a specific amino acid. When exposed to a mutagen, the selected bacterium reverts to wild type and can grow in the absence of the amino acid. Mutagenicity is suspected when the number of revertants enumerated from the test compound plates exceeds the number of spontaneous revertants in the negative control plate by a minimum of two-fold.

Five concentrations levels between $0.5 \mu \mathrm{g} /$ plate and $500 \mu \mathrm{g} /$ plate were tested in three bacterial strains, TA 97A, TA 98, and TA 100 . No mutagenic activity was observed with any of the 19 tracers with or without S9 amendment. S9 is used for the metabolism of the compound. These results indicate that neither the parent compound or its metabolites are mutagens. A complete listing of the results is shown in Appendix A. 
2,3-Difluorobenzoic acid 2,3,4-Trifluorobenzoic acid

o-Trifluoromethylbenzoic acid 2,4-Difluorobenzoic acid 2,4,5-Trifluorobenzoic acid $\mathrm{m}$-Trifluoromethylbenzoic acid 2,5-Difluorobenzoic acid 3,4,5-Trifluorobenzoic acid p-Trifluoromethylbenzoic acid 2,6-Difluorobenzoic acid 2,3,4,5-Tetrafluorobenzoic acid Trifluoroacetic acid 3,4-Difluorobenzoic acid 2,3,5,6-Tetrafluorobenzoic acid Pentafluoropropionic acid 3,5-Difluorobenzoic acid Pentafluorobenzoic acid Heptafluorobutyric acid 


\section{Toxicity Literature Review}

A literature review of the toxicity of the fluorobenzoates and the perfluorinated aliphatic acids is presented in Appendix B. A synopsis of the results follows.

Very little information regarding the toxicity of the fluorobenzoates was found. A significant body of data exits on the parent compound, benzoic acid, and it is generally recognized as safe. It is used in numerous pharmaceutical preparations and as a preservative in food stuffs. Some studies exist that indicate that the mono- and difluorobenzoates are not significantly more toxic than the parent compound.

Health effects data were found for trifluoroacetic acid, but not for pentafluoropropionic acid and heptafluorobutyric acid. Although TFAA has a low human toxicity, about 1 in 10,000 persons can develop a hepatitis with a 50\% mortality. For this reason none of the aliphatic compounds were recommended for use as tracers.

\section{QUALITY ASSURANCE PROGRAM}

A Quality Assurance Program was developed for both the laboratory testing of potential tracer compounds and the analysis of the field samples collected during the tracer tests at the C-well complex. QA procedures written by HRC, effective 05/10/95 and approved by the USGS Yucca Mountain QA Branch, include:

$\begin{array}{ll}\text { 1.0 } & \text { Management QA Requirements } \\ 2.0 & \text { QA Program } \\ 3.0 & \text { Procurements } \\ 4.0 & \text { Instructions, Procedures, Plans, and Drawings } \\ 5.0 & \text { Document Control } \\ 6.0 & \text { Identification and Control of Items } \\ 7.0 & \text { Control of Processes } \\ 8.0 & \text { Control of Measuring and Test Equipment } \\ 9.0 & \text { Handling, Storage, and Shipping } \\ 10.0 & \text { Control of Nonconformance and Corrective Action } \\ 11.0 & \text { Quality Assurance Records } \\ 12.0 & \text { Surveillances } \\ 13.0 & \text { Software Quality Assurance }\end{array}$

Standard operating procedures (SOPs) (detailed technical procedures), written and used for the field and laboratory tracer tests, include:

Batch Testing of Organic Tracers, Revision 0, effective 5/10/95.

Batch Testing of Organic Tracers, Revision 1, effective 8/1/95.

Organic Tracer Extraction Procedures, Revision 0, effective 8/1/95.

High Pressure Liquid Chromatograph (HPLC) Operation, Revision 0, effective 4/8/95. 
High Pressure Liquid Chromatograph (HPLC) Operation, Revision 1, effective $8 / 1 / 95$.

High Pressure Liquid Chromatograph (HPLC) Operation, Revision 2, effective 12/26/95.

Purchase Inspection, Revision 0, effective 4/8/95.

Purchase Inspection, Revision 1, effective 7/18/95.

Document Control, Revision 0, effective 4/8/95.

Document Control, Revision 1, effective 8/1/95.

Scientific Notebooks, Revision 1, effective 3/31/93.

Scientific Notebooks, Revision 2, effective 5/3/95.

Organic Tracer Scientific Notebooks and Instrument Logs, Revision 0, effective $8 / 1 / 95$.

Sartorius 2432 Analytical Balance, Revision 0, effective 4/2/92.

Analytical Balance Use, Revision 1, effective 4/8/95.

Analytical Balance Use for the Tracer Project, Revision 2, effective 5/8/95.

Analytical Balance Use for the Tracer Project, Revision 3, effective 8/1/95.

Top-Loading Balance Use for the Tracer Projects, Revision 0, effective 12/26/95.

Data Verification/Validation, Revision 0, effective 4/8/95.

Data Verification/Validation, Revision 1, effective 8/1/95.

Data Verification/Validation, Revision 2, effective 12/26/95.

\section{Internal Assessments}

Scientific notebooks and instrument logs are to be evaluated using the scientific notebook SOP applicable by effective date as listed. These evaluations are documented on the associated forms. Batch test data, field tracer-test data, and laboratory tracer-test data are evaluated using the verification/validation SOP applicable by effective date as listed. These evaluations are documented on the associated verification forms and ase included with the data packages. In addition, the field instrument $\log$ was surveyed in the field. These evaluations are documented in the form of comments in the notebooks.

\section{External Assessments}

On 3/3/95, Mr. David Erdmann of the USGS performed a preliminary evaluation of the HRC laboratory. Suggestions from his report, with the exception of the use of control charts, were utilized by HRC.

On 8/9/95, Mr. Pete Rodriguez of the USGS Yucca Mountain QA Branch audited the HRC for compliance to its QA program. Due to a transition in the qualification of suppliers process, rather than a YMP-USGS surveillance report, an OCRWM supplier evaluation report form was received by HRC on 11/22/95 indicating satisfactory review of the HRC QA program and recommendation of HRC placement on the OCRWM QSL. As a result of the audit, the QA procedure 3.0 Procurements was edited for clarification only. 


\section{C-WELL TRACER TEST}

A preliminary tracer test was started at the C-wells in February 1996. Iodide was chosen as the tracer because of its solubility and excellent sensitivity. We were able to detect iodide levels as low as 3 parts per billion (ppb) using HPLC with a UV detector. During the course of the test, 3124 samples were collected and over 2,500 analyses were performed by HRC personnel. Some of the analyses were conducted in the field to provide real time information to the hydrologist. However, because of the large number of samples collected, most were analyzed in our laboratory facilities.

From an analytical chemistry standpoint, the tracer test was highly successful. The injectate concentration was $10,000 \mathrm{ppm}$ (a $1 \%$ solution) and the breakthrough curve peak concentration was approximately 95 parts per billion (ppb). That is a difference of about 5 orders of magnitude. Even with this reduction in concentration, we were able to successfully pinpoint the arrival of the tracer five days after injection and provide sample concentrations with excellent precision given the low concentrations and less than ideal conditions in the field.

Appendix $C$ lists the results of each sample analyzed as well as the injectate concentration, the standard deviation for the method, and a tracer breakthrough curve. 
APPENDIX A 


\section{MATERIALS AND METHODS}

Mutagenicity assays. Mutagenicity assays were performed on the 19 potential tracers as described by Marion and Ames (1983). The assays consisted of tests conducted with buffer and with a hepatic post-mitochondrial supernatant (S9) metabolizing amendment at $4 \%$ and at $9 \%$ (final concentration). Each tracer was tested with three bacterial strains of Salmonella typhimurium (TA97A, TA98, and TA100). Tracer concentrations tested were dependent on the solubility of the compound. Eighteen of the tracers were tested at five concentrations ranging from $500 \mu \mathrm{g} / \mathrm{plate}$ to $0.5 \mu \mathrm{g} / \mathrm{plate}$, final concentration depending on the tracer. An exception was $p$-trifluoromethylbenzoic acid which was tested at four concentrations ranging from 0.0625 to $1.25 \mu \mathrm{g} /$ plate, final concentration. All assays were conducted with positive controls dependent on the bacterial strain and the presence or absence of the $S 9$ amendment (Table 1). Negative controls for all assays consisted of distilled water.

Table 1. Experimental design for the positive control.

\begin{tabular}{||c|c|c|c|}
\hline \multirow{2}{*}{ Strain } & Amendment & $\begin{array}{c}\text { Positive } \\
\text { Control }\end{array}$ & $\begin{array}{c}\text { Final } \\
\text { Concentration }\end{array}$ \\
\hline \multirow{2}{*}{ TA 97A } & buffer & ICR-191 & $1.0 \mu \mathrm{g} / \mathrm{plate}$ \\
\cline { 2 - 4 } & S9 & 2-aminofluorene & $5.0 \mu \mathrm{g} / \mathrm{plate}$ \\
\hline \multirow{2}{*}{ TA 98 } & buffer & daunomycin & $5.0 \mu \mathrm{g} / \mathrm{plate}$ \\
\cline { 2 - 4 } & S9 & 2-aminofluorene & $5.0 \mu \mathrm{ug} / \mathrm{plate}$ \\
\hline \multirow{2}{*}{ TA 100 } & buffer & sodium azide & $1.5 \mu \mathrm{g} / \mathrm{plate}$ \\
\hline
\end{tabular}


For each assay, $0.05 \mathrm{ml}$ of tracer solution was mixed with $0.1 \mathrm{ml}$ of an eleven hour culture of one of the $S$. typhimurium strains. The bacterial/tracer suspension was mixed with a $0.5 \mathrm{ml}$ amendment (buffer, $4 \% \mathrm{~S} 9$ or $9 \% \mathrm{~S} 9$ ) and $2 \mathrm{ml}$ of molten top agar $(50 \mu \mathrm{ML}$-histidine, $50 \mu \mathrm{M}$ biotin, $0.5 \% \mathrm{NaCl}, 0.6 \%$ agar). The mixture was then plated to Petri plates containing minimal salts agar with glucose. All assays were performed in duplicate. The plates were incubated inverted in the dark at $37^{\circ} \mathrm{C}$ for 48 hours and the revertant colonies were enumerated visually and recorded. The mean of the duplicate measurements \pm 1 standard deviation of the mean were calculated.

\section{RESULTS}

The potential mutagenicity of the 19 tracers were measured with $S$. typhimurium strains TA97A, TA98, and TA100 in the presence of $4 \%$ or $9 \% \mathrm{~S} 9$ and in the absence of any post-mitochondrial metabolizing amendment (Tables 2-20). Mutagenicity is suspected when the number of revertants enumerated from test compound plates exceeds the number of spontaneous revertants in the negative control plates by a minimum of two-fold (Cerniglia et al., 1985). At the concentrations tested, no two-fold increase in the number of revertants was detected for any of the 19 tracers for any of the three bacterial strains. Therefore, no mutagenic activity was observed with any of the tester strains with or without S9 amendment.

Cerniglia, C.E., J.P. Freeman, G.L. White, R.H. Heflich, and D.W. Miller. 1985. Fungal metabolism and detoxification of the nitropolycyclic aromatic hydrocarbon 1-nitropyrene. Appl. Environ. Microbiol. 50:649-655.

Marion, D.M. and B.N. Ames. 1983. Revised methods for the Salmonella mutagenicity test. Mutat. Res. 113:173-215. 
Tracer: 2,6-DIFLUOROBENZOIC ACID

\begin{tabular}{|c|c|c|c|c|c|c|}
\hline \multirow{2}{*}{ Strain } & \multirow{2}{*}{ Trial } & \multirow{2}{*}{$\begin{array}{l}\text { neg. } \\
\text { control }\end{array}$} & \multicolumn{4}{|c|}{ Tracer Concentration ( $\mu \mathrm{g} /$ plate $)$} \\
\hline & & & 5 & 15 & 50 & 150 \\
\hline \multirow{3}{*}{ TA97A* } & Buffer & $176 \pm 15$ & $209 \pm 21$ & $215 \pm 12$ & $200 \pm 1$ & $154 \pm 30$ \\
\hline & $4 \% \mathrm{~S} 9$ & $218 \pm 7$ & $223 \pm 4$ & $220 \pm 1$ & $239 \pm 1$ & $221 \pm 21$ \\
\hline & $10 \% \mathrm{~S} 9$ & $215 \pm 18$ & $241 \pm 17$ & $234 \pm 11$ & $251 \pm 35$ & $253 \pm 13$ \\
\hline \multirow{3}{*}{ TA98 } & Buffer & $31 \pm 4$ & $28 \pm 1$ & $34 \pm 10$ & $24 \pm 1$ & $24 \pm 2$ \\
\hline & $4 \% \mathrm{~S} 9$ & $42 \pm 11$ & $49 \pm 0$ & $37 \pm 13$ & $44 \pm 5$ & $42 \pm 4$ \\
\hline & $10 \% \mathrm{~S} 9$ & $48 \pm 7$ & $50 \pm 1$ & $51 \pm 4$ & $46 \pm 7$ & $51 \pm 4$ \\
\hline \multirow{3}{*}{ TA100 } & Buffer & $280 \pm 19$ & $233 \pm 17$ & $253 \pm 17$ & $227 \pm 20$ & $214 \pm 23$ \\
\hline & $4 \% \mathrm{~S} 9$ & $229 \pm 16$ & $260 \pm 11$ & $223 \pm 6$ & $250 \pm 23$ & $210 \pm 1$ \\
\hline & $10 \% \mathrm{~S} 9$ & $227 \pm 19$ & $260 \pm 2$ & $236 \pm 1$ & $251 \pm 4$ & $235 \pm 24$ \\
\hline
\end{tabular}

* Strain TA97A Tracer Concentration for S-9 trials $=0.5,1.5,5,15,50$ 
Tracer: ORTHO-TRIFLUOROMETHYLBENZOIC ACID

\begin{tabular}{|c|c|c|c|c|c|c|c|c|}
\hline \multirow{2}{*}{ Strain } & \multirow{2}{*}{ Trial } & \multirow{2}{*}{$\begin{array}{c}\text { neg. } \\
\text { control }\end{array}$} & \multicolumn{5}{|c|}{ Tracer Concentration ( $\mu \mathrm{g} / \mathrm{plate})$} & \multirow{2}{*}{$\begin{array}{c}\text { pos. } \\
\text { control }\end{array}$} \\
\hline & & & 1.5 & 5 & 15 & 50 & 150 & \\
\hline \multirow{3}{*}{ TA97A } & Buffer & $176 \pm 15$ & $221 \pm 8$ & $211 \pm 5$ & $186 \pm 18$ & $191 \pm 4$ & $214 \pm 32$ & $>3000$ \\
\hline & $4 \% \mathrm{~S} 9$ & $218 \pm 7$ & $258 \pm 13$ & $238 \pm 40$ & $227 \pm 11$ & $243 \pm 2$ & $253 \pm 10$ & $892 \pm 72$ \\
\hline & $10 \% \mathrm{~S} 9$ & $215 \pm 18$ & $268 \pm 22$ & $263 \pm 0$ & $253 \pm 2$ & $224 \pm 14$ & $228 \pm 3$ & 585 \\
\hline \multirow{3}{*}{ TA98 } & Buffer & $31 \pm 4$ & $30 \pm 1$ & $26 \pm 11$ & $29 \pm 2$ & $27 \pm 4$ & $20 \pm 8$ & $730 \pm 147$ \\
\hline & $4 \% \mathrm{~S} 9$ & $42 \pm 11$ & $36 \pm 6$ & $46 \pm 1$ & $39 \pm 8$ & $38 \pm 3$ & $37 \pm 2$ & $1448 \pm 68$ \\
\hline & $10 \% \mathrm{~S} 9$ & $48 \pm 7$ & $55 \pm 1$ & $45 \pm 8$ & $44 \pm 6$ & $48 \pm 8$ & $46 \pm 20$ & $416 \pm 71$ \\
\hline \multirow{3}{*}{ TA100 } & Buffer & $280 \pm 19$ & $265 \pm 21$ & $249 \pm 9$ & $262 \pm 30$ & $254 \pm 19$ & $253 \pm 13$ & $1145 \pm 211$ \\
\hline & $4 \%$ S9 & $229 \pm 16$ & $261 \pm 5$ & $265 \pm 2$ & $270 \pm 18$ & $251 \pm 17$ & $242 \pm 1$ & $1237 \pm 107$ \\
\hline & $10 \% \mathrm{~S} 9$ & $227 \pm 19$ & $244 \pm 6$ & $243 \pm 4$ & $276 \pm 13$ & $253 \pm 14$ & $231 \pm 1$ & $630 \pm 71$ \\
\hline
\end{tabular}

* Strain TA97A Tracer Concentration for S-9 trials $=0.15,0.5,1.5,5.0,15.0$ 
Tracer: META-TRIFLUOROMETHYLBENZOIC_ACID

\begin{tabular}{|c|c|c|c|c|c|c|c|c|}
\hline \multirow{2}{*}{ Strain } & \multirow{2}{*}{ Trial } & \multirow{2}{*}{$\begin{array}{l}\text { neg. } \\
\text { control }\end{array}$} & \multicolumn{5}{|c|}{ Tracer Concentration ( $\mu \mathrm{g} / \mathrm{plate})$} & \multirow{2}{*}{$\begin{array}{l}\text { pos. } \\
\text { control }\end{array}$} \\
\hline & & & 1.5 & 5 & 15 & 50 & 150 & \\
\hline \multirow{3}{*}{ TA97A } & Buffer & $176 \pm 15$ & $198 \pm 25$ & $195 \pm 18$ & $200 \pm 6$ & $218 \pm 16$ & $189 \pm 17$ & $>3000$ \\
\hline & $4 \%$ S9 & $218 \pm 7$ & $253 \pm 4$ & $227 \pm 8$ & $238 \pm 1$ & $253 \pm 0$ & $231 \pm 21$ & $892 \pm 72$ \\
\hline & $10 \% \mathrm{~S} 9$ & $215 \pm 18$ & $270 \pm 22$ & $227 \pm 6$ & $226 \pm 3$ & $247 \pm 3$ & $246 \pm 4$ & 585 \\
\hline \multirow{3}{*}{ TA98 } & Buffer & $31 \pm 4$ & & $35 \pm 4$ & $28 \pm 4$ & $33 \pm 4$ & $28 \pm 4$ & $730 \pm 147$ \\
\hline & $4 \% S 9$ & $42 \pm 11$ & & $52 \pm 8$ & $55 \pm 7$ & $40 \pm 9$ & $47 \pm 6$ & $1448 \pm 68$ \\
\hline & $10 \% S 9$ & $48 \pm 7$ & & $48 \pm 6$ & $59 \pm 8$ & $57 \pm 5$ & $58 \pm 14$ & $416 \pm 71$ \\
\hline \multirow{3}{*}{ TA100 } & Buffer & $280 \pm 19$ & $268 \pm 18$ & $269 \pm 11$ & $249 \pm 13$ & $250 \pm 16$ & $248 \pm 27$ & $1145 \pm 211$ \\
\hline & $4 \%$ S 9 & $229 \pm 16$ & $240 \pm 5$ & $255 \pm 13$ & $244 \pm 5$ & $262 \pm 22$ & $246 \pm 24$ & $1237 \pm 107$ \\
\hline & $10 \% \mathrm{~S} 9$ & $227 \pm 19$ & $239 \pm 4$ & $280 \pm 2$ & $256 \pm 4$ & $235 \pm 32$ & $260 \pm 17$ & $630 \pm 71$ \\
\hline
\end{tabular}

* Strain TA97A Tracer Concentration for $S-9$ trials $=0.15,0.5,1.5,5.0,15.0$ 
Tracer: PARA-TRIFLUOROMETHYLBENZOIC ACID

\begin{tabular}{|c|c|c|c|c|c|c|c|}
\hline \multirow{2}{*}{ Strain } & \multirow{2}{*}{ Trial } & \multirow{2}{*}{$\begin{array}{l}\text { neg. } \\
\text { control }\end{array}$} & \multicolumn{4}{|c|}{ Tracer Concentration $(\mu \mathrm{g} /$ plate) } & \multirow{2}{*}{$\begin{array}{l}\text { pos. } \\
\text { control }\end{array}$} \\
\hline & & & .0625 & .125 & .625 & 1.25 & \\
\hline \multirow{3}{*}{ TA97A } & Buffer & $202 \pm 8$ & $202 \pm 30$ & $165 \pm 24$ & $188 \pm 5$ & $183 \pm 24$ & $>3000$ \\
\hline & $4 \% S 9$ & $230 \pm 23$ & $247 \pm 13$ & $229 \pm 31$ & $230 \pm 9$ & $220 \pm 2$ & $821 \pm 43$ \\
\hline & $10 \% \$ 9$ & $238 \pm 10$ & $257 \pm 10$ & $235 \pm 21$ & $238 \pm 35$ & $211 \pm 27$ & $642 \pm 10$ \\
\hline \multirow{3}{*}{ TA98 } & Buffer & $45 \pm 3$ & $57 \pm 13$ & $39 \pm 4$ & $42 \pm 1$ & $50 \pm 12$ & $960 \pm 116$ \\
\hline & $4 \%$ S9 & $65 \pm 10$ & $66 \pm 13$ & $72 \pm 8$ & $74 \pm 17$ & $61 \pm 4$ & $1076 \pm 47$ \\
\hline & $10 \%$ S9 & $72 \pm 4$ & $63 \pm 5$ & $74 \pm 12$ & $80 \pm 9$ & $67 \pm 8$ & $464 \pm 78$ \\
\hline \multirow{3}{*}{ TA100 } & Buffer & $222 \pm 30$ & $225 \pm 4$ & $247 \pm 30$ & $254 \pm 1$ & $236 \pm 6$ & $2000 \pm 0$ \\
\hline & $4 \% S 9$ & $231 \pm 15$ & $222 \pm 35$ & $220 \pm 13$ & $233 \pm 22$ & $210 \pm 13$ & $1150 \pm 14$ \\
\hline & $10 \% \$ 9$ & $219 \pm 7$ & $208 \pm 14$ & $218 \pm 1$ & $228 \pm 18$ & $248 \pm 21$ & $508 \pm 23$ \\
\hline
\end{tabular}


Tracer: 2,3,4-TRIFLUOROBENZOIC ACID

\begin{tabular}{|c|c|c|c|c|c|c|c|c|}
\hline \multirow{2}{*}{ Strain } & \multirow{2}{*}{ Trial } & \multirow{2}{*}{$\begin{array}{l}\text { neg. } \\
\text { control }\end{array}$} & \multicolumn{5}{|c|}{ Tracer Concentration ( $\mu \mathrm{g} / \mathrm{plate})$} & \multirow{2}{*}{$\begin{array}{l}\text { pos. } \\
\text { control }\end{array}$} \\
\hline & & & 1.5 & 5 & 15 & 50 & 150 & \\
\hline \multirow{3}{*}{ TA97A } & Buffer & $202 \pm 8$ & $189 \pm 6$ & $186 \pm 23$ & $185 \pm 12$ & $169 \pm 11$ & $139 \pm 6$ & $>3000$ \\
\hline & $4 \% S 9$ & $230 \pm 23$ & $264 \pm 6$ & $269 \pm 33$ & $207 \pm 6$ & $222 \pm 1$ & $105 \pm 71$ & $821 \pm 43$ \\
\hline & $10 \% \mathrm{~S} 9$ & $238 \pm 10$ & $224 \pm 4$ & $265 \pm 1$ & $238 \pm 4$ & $255 \pm 13$ & $265 \pm 18$ & $642 \pm 10$ \\
\hline \multirow{3}{*}{ TA98 } & Buffer & $45 \pm 3$ & $51 \pm 13$ & $47 \pm 11$ & $51 \pm 11$ & $45 \pm 1$ & $45 \pm 4$ & $960 \pm 116$ \\
\hline & $4 \%$ S9 & $65 \pm 10$ & $67 \pm 11$ & $49 \pm 1$ & $71 \pm 1$ & $130 \pm 98$ & $57 \pm 11$ & $1076 \pm 47$ \\
\hline & $10 \% \mathrm{~S} 9$ & $72 \pm 4$ & $77 \pm 6$ & $70 \pm 11$ & $61 \pm 4$ & $78 \pm 3$ & $66 \pm 9$ & $464 \pm 78$ \\
\hline \multirow{3}{*}{ TA100 } & Buffer & $222 \pm 30$ & $229 \pm 10$ & $239 \pm 1$ & $231 \pm 9$ & $273 \pm 8$ & $234 \pm 12$ & $2000 \pm 0$ \\
\hline & $4 \% \mathrm{~S} 9$ & $231 \pm 15$ & $220 \pm 20$ & $218 \pm 22$ & $228 \pm 13$ & $205 \pm 7$ & $231 \pm 0$ & $1150 \pm 14$ \\
\hline & $10 \% \mathrm{~S} 9$ & $219 \pm 7$ & $249 \pm 1$ & $228 \pm 13$ & $238 \pm 4$ & $239 \pm 10$ & $224 \pm 10$ & $508 \pm 23$ \\
\hline
\end{tabular}

* Strain TA97A Tracer Concentration for S-9 HIGH trials $=0.15,0.5,1.5,5.0,15.0$ 
Tracer: 3,4,5-TRIFLUOROBENZOIC ACID

\begin{tabular}{|c|c|c|c|c|c|c|c|c|}
\hline \multirow{2}{*}{ Strain } & \multirow{2}{*}{ Trial } & \multirow{2}{*}{$\begin{array}{l}\text { neg. } \\
\text { control }\end{array}$} & \multicolumn{5}{|c|}{ Tracer Concentration ( $\mu \mathrm{g} / \mathrm{plate})$} & \multirow{2}{*}{$\begin{array}{l}\text { pos. } \\
\text { control }\end{array}$} \\
\hline & & & 5 & 15 & 50 & 150 & 500 & \\
\hline \multirow{3}{*}{ TA97A } & Buffer & $202 \pm 8$ & $174 \pm 26$ & $200 \pm 4$ & $152 \pm 13$ & $189 \pm 20$ & $149 \pm 1$ & $>3000$ \\
\hline & $4 \% \mathrm{~S} 9$ & $230 \pm 23$ & $213 \pm 6$ & $261 \pm 37$ & $209 \pm 13$ & $174 \pm 38$ & $189 \pm 25$ & $821 \pm 43$ \\
\hline & $10 \% S 9$ & $188 \pm 27$ & $195 \pm 4$ & $265 \pm 1$ & $240 \pm 13$ & $151 \pm 39$ & 158 & $446 \pm 57$ \\
\hline \multirow{3}{*}{ TA98 } & Buffer & $45 \pm 3$ & $56 \pm 15$ & $52 \pm 8$ & $53 \pm 4$ & $46 \pm 4$ & $34 \pm 2$ & $960 \pm 116$ \\
\hline & $4 \%$ S9 & $65 \pm 10$ & $58 \pm 13$ & $58 \pm 11$ & $69 \pm 1$ & $59 \pm 4$ & $592 \pm 7$ & $1076 \pm 47$ \\
\hline & $10 \% \mathrm{~S} 9$ & $72 \pm 4$ & $58 \pm 7$ & $59 \pm 9$ & $57 \pm 3$ & $71 \pm 10$ & $62 \pm 18$ & $464 \pm 78$ \\
\hline \multirow{3}{*}{ TA100 } & Buffer & $222 \pm 30$ & $247 \pm 14$ & $219 \pm 11$ & $254 \pm 21$ & $217 \pm 7$ & $105 \pm 28$ & $2000 \pm 0$ \\
\hline & $4 \% \$ 9$ & $231 \pm 15$ & $215 \pm 10$ & $224 \pm 5$ & $230 \pm 28$ & $213 \pm 4$ & $50 \pm 25$ & $1150 \pm 14$ \\
\hline & $10 \% \mathrm{~S} 9$ & $219 \pm 7$ & $237 \pm 4$ & $248 \pm 14$ & $252 \pm 8$ & $218 \pm 1$ & $22 \pm 15$ & $508 \pm 23$ \\
\hline
\end{tabular}


Tracer: 2,3,4,5-TETRAFLUOROBENZOIC ACID

\begin{tabular}{|c|c|c|c|c|c|c|c|c|}
\hline \multirow{2}{*}{ Strain } & \multirow{2}{*}{ Trial } & \multirow{2}{*}{$\begin{array}{c}\text { neg. } \\
\text { control }\end{array}$} & \multicolumn{5}{|c|}{ Tracer Concentration ( $\mu \mathrm{g} /$ plate) } & \multirow{2}{*}{$\begin{array}{l}\text { pos. } \\
\text { control }\end{array}$} \\
\hline & & & 5 & 15 & 50 & 150 & 500 & \\
\hline \multirow{3}{*}{ TA97A } & Buffer & $202 \pm 8$ & $225 \pm 23$ & $198 \pm 19$ & $156 \pm 11$ & $110 \pm 21$ & $180 \pm 4$ & $>3000$ \\
\hline & $4 \% \mathrm{~S} 9$ & $230 \pm 23$ & $261 \pm 9$ & $250 \pm 7$ & $205 \pm 6$ & $177 \pm 8$ & $217 \pm 0$ & $821 \pm 33$ \\
\hline & $10 \% \mathrm{~S} 9$ & $238 \pm 10$ & $265 \pm 1$ & $232 \pm 11$ & $268 \pm 1$ & $250 \pm 13$ & $205 \pm 8$ & $642 \pm 10$ \\
\hline \multirow{3}{*}{ TA98 } & Buffer & $45 \pm 3$ & $41 \pm 9$ & $48 \pm 1$ & $51 \pm 5$ & $56 \pm 3$ & $38 \pm 9$ & $960 \pm 116$ \\
\hline & $4 \%$ S9 & $65 \pm 10$ & $51 \pm 6$ & $72 \pm 2$ & $72 \pm 5$ & $55 \pm 15$ & $52 \pm 24$ & $1076 \pm 47$ \\
\hline & $10 \% \mathrm{~S} 9$ & $72 \pm 4$ & $57 \pm 11$ & $64 \pm 23$ & $70 \pm 8$ & $74 \pm 6$ & $59 \pm 8$ & $464 \pm 78$ \\
\hline \multirow{3}{*}{ TA100 } & Buffer & $222 \pm 30$ & $227 \pm 1$ & $261 \pm 23$ & $249 \pm 17$ & $240 \pm 21$ & $194 \pm 8$ & $2000 \pm 0$ \\
\hline & $4 \% \mathrm{~S} 9$ & $231 \pm 15$ & $223 \pm 11$ & $222 \pm 18$ & $204 \pm 16$ & $224 \pm 12$ & $177 \pm 8$ & $1150 \pm 14$ \\
\hline & $10 \% \mathrm{~S} 9$ & $219 \pm 7$ & $211 \pm 30$ & $234 \pm 14$ & $217 \pm 7$ & $216 \pm 27$ & $165 \pm 17$ & $508 \pm 23$ \\
\hline
\end{tabular}

* Strain TA97A Tracer Concentration for S-9 HIGH trials $=0.5,1.5,5.0,15.0,50.0$ 
Tracer: 2,3-DIFLUOROBENZOIC ACID

\begin{tabular}{|c|c|c|c|c|c|c|c|c|}
\hline \multirow{2}{*}{ Strain } & \multirow{2}{*}{ Trial } & \multirow{2}{*}{$\begin{array}{l}\text { neg. } \\
\text { control }\end{array}$} & \multicolumn{5}{|c|}{ Tracer Concentration ( $\mu \mathrm{g} /$ plate) } & \multirow{2}{*}{$\begin{array}{l}\text { pos. } \\
\text { control }\end{array}$} \\
\hline & & & 1.5 & 5 & 15 & 50 & 150 & \\
\hline \multirow{3}{*}{ TA97A } & Buffer & $194 \pm 9$ & $174 \pm 23$ & $227 \pm 14$ & $204 \pm 3$ & $204 \pm 21$ & $197 \pm 23$ & $>3000$ \\
\hline & $4 \% \mathrm{~S} 9$ & $231 \pm 13$ & $254 \pm 11$ & $245 \pm 12$ & $255 \pm 12$ & $230 \pm 7$ & $210 \pm 41$ & $596 \pm 18$ \\
\hline & $10 \% \mathrm{~S} 9$ & $237 \pm 20$ & $257 \pm 47$ & $262 \pm 6$ & $258 \pm 2$ & $241 \pm 11$ & $230 \pm 7$ & $403 \pm 18$ \\
\hline \multirow{3}{*}{ TA98 } & Buffer & $38 \pm 2$ & $29 \pm 6$ & $35 \pm 4$ & $41 \pm 13$ & $42 \pm 6$ & $44 \pm 13$ & $516 \pm 76$ \\
\hline & $4 \% S 9$ & $48 \pm 5$ & $58 \pm 7$ & $53 \pm 10$ & $55 \pm 14$ & $57 \pm 6$ & $56 \pm 8$ & $959 \pm 101$ \\
\hline & $10 \% \mathrm{~S} 9$ & $46 \pm 9$ & $66 \pm 5$ & $59 \pm 4$ & $52 \pm 11$ & $61 \pm 1$ & $65 \pm 8$ & $325 \pm 22$ \\
\hline \multirow{3}{*}{ TA100 } & Buffer & $201 \pm 19$ & $225 \pm 23$ & $237 \pm 3$ & $224 \pm 25$ & $197 \pm 11$ & $208 \pm 15$ & $1034 \pm 59$ \\
\hline & $4 \% \mathrm{~S} 9$ & $207 \pm 6$ & $225 \pm 9$ & $222 \pm 12$ & $218 \pm 6$ & $195 \pm 21$ & $199 \pm 1$ & $1070 \pm 11$ \\
\hline & $10 \% \mathrm{~S} 9$ & $218 \pm 12$ & $186 \pm 5$ & $220 \pm 11$ & $220 \pm 23$ & $217 \pm 19$ & $208 \pm 5$ & $495 \pm 27$ \\
\hline
\end{tabular}


Tracer: 2,4-DIFLUOROBENZOIC ACID

\begin{tabular}{|c|c|c|c|c|c|c|c|c|}
\hline \multirow{2}{*}{ Strain } & \multirow{2}{*}{ Trial } & \multirow{2}{*}{$\begin{array}{l}\text { neg. } \\
\text { control }\end{array}$} & \multicolumn{5}{|c|}{ Tracer Concentration ( $\mu \mathrm{g} / \mathrm{plate})$} & \multirow{2}{*}{$\begin{array}{c}\text { pos. } \\
\text { control }\end{array}$} \\
\hline & & & 0.5 & 2.5 & 5 & 25 & 50 & \\
\hline \multirow{3}{*}{ TA97A } & Buffer & $194 \pm 9$ & $203 \pm 12$ & $160 \pm 13$ & $135 \pm 98$ & $213 \pm 5$ & $190 \pm 36$ & $>3000$ \\
\hline & $4 \% \mathrm{~S} 9$ & $231 \pm 13$ & $286 \pm 25$ & $245 \pm 55$ & $285 \pm 10$ & $368 \pm 62$ & $280 \pm 30$ & $596 \pm 18$ \\
\hline & $10 \% \mathrm{~S} 9$ & $238 \pm 10$ & $211 \pm 6$ & $233 \pm 28$ & $261 \pm 20$ & $235 \pm 22$ & $256 \pm 39$ & $642 \pm 10$ \\
\hline \multirow{3}{*}{ TA98 } & Buffer & $38 \pm 2$ & $38 \pm 8$ & $33 \pm 11$ & $25 \pm 11$ & $35 \pm 5$ & $31 \pm 4$ & $516 \pm 76$ \\
\hline & $4 \%$ S9 & $48 \pm 5$ & $49 \pm 4$ & $61 \pm 4$ & $35 \pm 9$ & $52 \pm 4$ & $53 \pm 12$ & $959 \pm 101$ \\
\hline & $10 \% \mathrm{~S} 9$ & $46 \pm 9$ & $63 \pm 6$ & $56 \pm 11$ & $32 \pm 8$ & $62 \pm 20$ & $66 \pm 5$ & $325 \pm 22$ \\
\hline \multirow{3}{*}{ TA100 } & Buffer & $201 \pm 19$ & $207 \pm 19$ & $235 \pm 6$ & $217 \pm 28$ & $219 \pm 7$ & $221 \pm 18$ & $1034 \pm 59$ \\
\hline & $4 \%$ S9 & $207 \pm 6$ & $229 \pm 0$ & $232 \pm 18$ & $224 \pm 8$ & $205 \pm 21$ & $209 \pm 4$ & $1070 \pm 11$ \\
\hline & $10 \% \mathrm{~S} 9$ & $218 \pm 12$ & $247 \pm 8$ & $218 \pm 8$ & $222 \pm 14$ & $234 \pm 13$ & $195 \pm 2$ & $495 \pm 27$ \\
\hline
\end{tabular}


Tracer: 2,5-DIFLUOROBENZOIC ACID

\begin{tabular}{|c|c|c|c|c|c|c|c|c|}
\hline \multirow{2}{*}{ Strain } & \multirow{2}{*}{ Trial } & \multirow{2}{*}{$\begin{array}{l}\text { neg. } \\
\text { control }\end{array}$} & \multicolumn{5}{|c|}{ Tracer Concentration ( $\mu \mathrm{g} / \mathrm{plate})$} & \multirow{2}{*}{$\begin{array}{l}\text { pos. } \\
\text { control }\end{array}$} \\
\hline & & & 3 & 15 & 30 & 150 & 300 & \\
\hline \multirow{3}{*}{ TA97A } & Buffer & $194 \pm 9$ & $177 \pm 29$ & $199 \pm 6$ & $217 \pm 23$ & $209 \pm 24$ & $218 \pm 4$ & $>3000$ \\
\hline & $4 \%$ S9 & $231 \pm 13$ & $229 \pm 1$ & $268 \pm 13$ & $303 \pm 21$ & $252 \pm 0$ & $258 \pm 8$ & $596 \pm 18$ \\
\hline & $10 \% \mathrm{~S} 9$ & $237 \pm 20$ & $284 \pm 0$ & $257 \pm 8$ & $290 \pm 18$ & $272 \pm 4$ & $227 \pm 11$ & $403 \pm 18$ \\
\hline \multirow{3}{*}{ TA98 } & Buffer & $38 \pm 2$ & $31 \pm 1$ & $36 \pm 6$ & $44 \pm 4$ & $32 \pm 13$ & $27 \pm 8$ & $516 \pm 76$ \\
\hline & $4 \% \mathrm{~S} 9$ & $48 \pm 5$ & $55 \pm 6$ & $58 \pm 6$ & $51 \pm 6$ & $47 \pm 4$ & $42 \pm 1$ & $959 \pm 101$ \\
\hline & $10 \% \mathrm{~S} 9$ & $46 \pm 9$ & $47 \pm 7$ & $55 \pm 6$ & $62 \pm 1$ & $57 \pm 1$ & $38 \pm 2$ & $325 \pm 22$ \\
\hline \multirow{3}{*}{ TA100 } & Buffer & $201 \pm 19$ & $230 \pm 28$ & $225 \pm 6$ & $226 \pm 2$ & $194 \pm 13$ & $188 \pm 40$ & $1034 \pm 59$ \\
\hline & $4 \%$ S 9 & $207 \pm 6$ & $251 \pm 3$ & $223 \pm 14$ & $213 \pm 24$ & $231 \pm 2$ & $184 \pm 3$ & $1070 \pm 11$ \\
\hline & $10 \%$ S 9 & $218 \pm 12$ & $223 \pm 17$ & $245 \pm 14$ & $251 \pm 1$ & $218 \pm 19$ & $181 \pm 30$ & $495 \pm 27$ \\
\hline
\end{tabular}


Tracer: 3,4-DIFLUOROBENZOIC ACID

\begin{tabular}{|c|c|c|c|c|c|c|c|c|}
\hline \multirow{2}{*}{ Strain } & \multirow{2}{*}{ Trial } & \multirow{2}{*}{$\begin{array}{l}\text { neg. } \\
\text { control }\end{array}$} & \multicolumn{5}{|c|}{ Tracer Concentration ( $\mu \mathrm{g} / \mathrm{plate})$} & \multirow{2}{*}{$\begin{array}{l}\text { pos. } \\
\text { control }\end{array}$} \\
\hline & & & 1.5 & 5 & 15 & 50 & 150 & \\
\hline \multirow{3}{*}{ TA97A } & Buffer & $194 \pm 9$ & $181 \pm 20$ & $183 \pm 6$ & $194 \pm 15$ & $227 \pm 1$ & $203 \pm 11$ & $>3000$ \\
\hline & $4 \% S 9$ & $222 \pm 15$ & $169 \pm 60$ & $220 \pm 19$ & $217 \pm 13$ & $217 \pm 21$ & $202 \pm 0$ & $947 \pm 65$ \\
\hline & $10 \% \mathrm{~S} 9$ & $237 \pm 20$ & $268 \pm 25$ & $280 \pm 1$ & $282 \pm 74$ & $292 \pm 47$ & $279 \pm 17$ & $403 \pm 18$ \\
\hline \multirow{3}{*}{ TA98 } & Buffer & $26 \pm 4$ & $44 \pm 8$ & $50 \pm 5$ & $41 \pm 0$ & $31 \pm 17$ & $39 \pm 13$ & $171 \pm 50$ \\
\hline & $4 \% S 9$ & $46 \pm 11$ & $45 \pm 2$ & $56 \pm 23$ & $51 \pm 8$ & $52 \pm 5$ & $34 \pm 3$ & $1107 \pm 58$ \\
\hline & $10 \% \mathrm{~S} 9$ & $53 \pm 7$ & $70 \pm 10$ & $59 \pm 3$ & $62 \pm 16$ & $56 \pm 7$ & $49 \pm 2$ & $258 \pm 33$ \\
\hline \multirow{3}{*}{ TA100 } & Buffer & $201 \pm 19$ & $244 \pm 25$ & $247 \pm 16$ & $235 \pm 4$ & $228 \pm 8$ & $216 \pm 14$ & $1034 \pm 59$ \\
\hline & $4 \%$ S9 & $207 \pm 6$ & $246 \pm 30$ & $229 \pm 1$ & $241 \pm 6$ & $223 \pm 24$ & $239 \pm 12$ & $1070 \pm 11$ \\
\hline & $10 \% \mathrm{~S} 9$ & $218 \pm 12$ & $227 \pm 33$ & $235 \pm 39$ & $234 \pm 7$ & $223 \pm 27$ & $223 \pm 8$ & $495 \pm 27$ \\
\hline
\end{tabular}


Tracer: 3,5 -DIFLUOROBENZOIC ACID

\begin{tabular}{|c|c|c|c|c|c|c|c|c|}
\hline \multirow{2}{*}{ Strain } & \multirow{2}{*}{ Trial } & \multirow{2}{*}{$\begin{array}{l}\text { neg. } \\
\text { control }\end{array}$} & \multicolumn{5}{|c|}{ Tracer Concentration ( $\mu \mathrm{g} / \mathrm{plate})$} & \multirow{2}{*}{$\begin{array}{c}\text { pos. } \\
\text { control }\end{array}$} \\
\hline & & & 3 & 15 & 30 & 150 & 300 & \\
\hline \multirow{3}{*}{ TA97A } & Buffer & $187 \pm 32$ & $231 \pm 5$ & $204 \pm 12$ & $229 \pm 8$ & $213 \pm 8$ & $145 \pm 23$ & $>3000$ \\
\hline & $4 \%$ S9 & $222 \pm 15$ & $219 \pm 6$ & $216 \pm 15$ & $222 \pm 1$ & $212 \pm 19$ & $175 \pm 16$ & $947 \pm 65$ \\
\hline & $10 \% \mathrm{~S} 9$ & $238 \pm 10$ & $251 \pm 16$ & $247 \pm 5$ & $237 \pm 6$ & $266 \pm 21$ & $229 \pm 1$ & $642 \pm 10$ \\
\hline \multirow{3}{*}{ TA98 } & Buffer & $26 \pm 4$ & $44 \pm 8$ & $46 \pm 3$ & $49 \pm 6$ & $41 \pm 8$ & $36 \pm 16$ & $171 \pm 50$ \\
\hline & $4 \% \mathrm{~S} 9$ & $46 \pm 11$ & $57 \pm 13$ & $54 \pm 2$ & $56 \pm 6$ & $51 \pm 1$ & $46 \pm 11$ & $1107 \pm 58$ \\
\hline & $10 \% \mathrm{~S} 9$ & $53 \pm 7$ & $65 \pm 13$ & $47 \pm 10$ & $62 \pm 8$ & $63 \pm 7$ & $47 \pm 10$ & $258 \pm 33$ \\
\hline \multirow{3}{*}{ TA100 } & Buffer & $203 \pm 9$ & $195 \pm 23$ & $213 \pm 21$ & $216 \pm 16$ & $196 \pm 6$ & $185 \pm 15$ & $1624 \pm 34$ \\
\hline & $4 \%$ S9 & $204 \pm 17$ & $203 \pm 13$ & $216 \pm 30$ & $197 \pm 37$ & $208 \pm 8$ & $188 \pm 4$ & $1362 \pm 6$ \\
\hline & $10 \% \mathrm{~S} 9$ & $178 \pm 12$ & $222 \pm 5$ & $219 \pm 4$ & $211 \pm 33$ & $210 \pm 5$ & $193 \pm 16$ & $562 \pm 40$ \\
\hline
\end{tabular}


Tracer: 2,3,5,6-TETRAFLUOROBENZOIC ACID

\begin{tabular}{|c|c|c|c|c|c|c|c|c|}
\hline \multirow{2}{*}{ Strain } & \multirow{2}{*}{ Trial } & \multirow{2}{*}{$\begin{array}{l}\text { neg. } \\
\text { control }\end{array}$} & \multicolumn{5}{|c|}{ Tracer Concentration ( $\mu \mathrm{g} / \mathrm{plate})$} & \multirow{2}{*}{$\begin{array}{l}\text { pos. } \\
\text { control }\end{array}$} \\
\hline & & & 5 & 15 & 50 & 150 & 500 & \\
\hline \multirow{3}{*}{ TA97A } & Buffer & $187 \pm 32$ & $190 \pm 33$ & $208 \pm 21$ & $206 \pm 16$ & $199 \pm 26$ & $176 \pm 4$ & $>3000$ \\
\hline & $4 \% \mathrm{~S} 9$ & $222 \pm 15$ & $243 \pm 25$ & $223 \pm 9$ & $227 \pm 9$ & $217 \pm 17$ & $193 \pm 8$ & $947 \pm 65$ \\
\hline & $10 \% \$ 9$ & $238 \pm 10$ & $269 \pm 9$ & $253 \pm 11$ & $262 \pm 27$ & $269 \pm 11$ & $231 \pm 4$ & $642 \pm 10$ \\
\hline \multirow{3}{*}{ TA98 } & Buffer & $26 \pm 4$ & $37 \pm 12$ & $40 \pm 8$ & $49 \pm 1$ & $37 \pm 2$ & $33 \pm 4$ & $171 \pm 50$ \\
\hline & $4 \% \mathrm{~S} 9$ & $46 \pm 11$ & $48 \pm 3$ & $54 \pm 2$ & $72 \pm 25$ & $56 \pm 11$ & $47 \pm 9$ & $1107 \pm 58$ \\
\hline & $10 \% \mathrm{~S} 9$ & $53 \pm 7$ & $54 \pm 1$ & $63 \pm 2$ & $63 \pm 13$ & $66 \pm 8$ & $42 \pm 6$ & $258 \pm 33$ \\
\hline \multirow{3}{*}{ TA100 } & Buffer & $203 \pm 9$ & $212 \pm 1$ & $214 \pm 25$ & $217 \pm 20$ & $226 \pm 22$ & $194 \pm 28$ & $1624 \pm 34$ \\
\hline & $4 \%$ S9 & $204 \pm 17$ & $206 \pm 2$ & $196 \pm 18$ & $227 \pm 14$ & $204 \pm 17$ & $196 \pm 11$ & $1362 \pm 6$ \\
\hline & $10 \% \mathrm{~S} 9$ & $178 \pm 12$ & $217 \pm 10$ & $212 \pm 5$ & $210 \pm 22$ & $223 \pm 23$ & $164 \pm 0$ & $562 \pm 40$ \\
\hline
\end{tabular}


Tracer: 2,4,5-TRIFLUOROBENZOIC ACID

\begin{tabular}{|c|c|c|c|c|c|c|c|c|}
\hline \multirow{2}{*}{ Strain } & \multirow{2}{*}{ Trial } & \multirow{2}{*}{$\begin{array}{l}\text { neg. } \\
\text { control }\end{array}$} & \multicolumn{5}{|c|}{ Tracer Concentration ( $\mu g /$ plate) } & \multirow{2}{*}{$\begin{array}{l}\text { pos. } \\
\text { control }\end{array}$} \\
\hline & & & 5 & 15 & 50 & 150 & 500 & \\
\hline \multirow{3}{*}{ TA97A } & Buffer & $187 \pm 32$ & $207 \pm 13$ & $226 \pm 12$ & $224 \pm 21$ & $209 \pm 6$ & $168 \pm 0$ & $>3000$ \\
\hline & $4 \%$ S9 & $222 \pm 15$ & $229 \pm 1$ & $213 \pm 4$ & $201 \pm 1$ & $217 \pm 8$ & $171 \pm 4$ & $947 \pm 65$ \\
\hline & $10 \% \mathrm{~S} 9$ & $238 \pm 10$ & & & $236 \pm 9$ & $266 \pm 17$ & $172 \pm 21$ & $642 \pm 10$ \\
\hline \multirow{3}{*}{ TA98 } & Buffer & $26 \pm 4$ & $39 \pm 0$ & $43 \pm 8$ & $27 \pm 4$ & $42 \pm 8$ & $24 \pm 4$ & $171 \pm 50$ \\
\hline & $4 \%$ S9 & $46 \pm 11$ & $39 \pm 6$ & $43 \pm 16$ & $44 \pm 0$ & $40 \pm 6$ & $180 \pm 146$ & $1107 \pm 58$ \\
\hline & $10 \% \mathrm{~S} 9$ & $53 \pm 7$ & $43 \pm 0$ & $42 \pm 7$ & $54 \pm 0$ & $47 \pm 9$ & $39 \pm 7$ & $258 \pm 33$ \\
\hline \multirow{3}{*}{ TA100 } & Buffer & $203 \pm 9$ & $223 \pm 8$ & $209 \pm 47$ & $191 \pm 18$ & $204 \pm 13$ & $158 \pm 3$ & $1624 \pm 34$ \\
\hline & $4 \%$ S9 & $204 \pm 17$ & $225 \pm 9$ & $203 \pm 45$ & $195 \pm 28$ & $202 \pm 13$ & $147 \pm 9$ & $1362 \pm 6$ \\
\hline & $10 \%$ S9 & $178 \pm 12$ & $211 \pm 18$ & $182 \pm 0$ & $205 \pm 8$ & $195 \pm 20$ & $169 \pm 7$ & $562 \pm 40$ \\
\hline
\end{tabular}


Tracer: TRIFLUOROACETIC ACID

\begin{tabular}{|c|c|c|c|c|c|c|c|c|}
\hline \multirow{2}{*}{ Strain } & \multirow{2}{*}{ Trial } & \multirow{2}{*}{$\begin{array}{l}\text { neg. } \\
\text { control }\end{array}$} & \multicolumn{5}{|c|}{ Tracer Concentration $(\mu \mathrm{g} / \mathrm{plate})$} & \multirow{2}{*}{$\begin{array}{l}\text { pos. } \\
\text { control }\end{array}$} \\
\hline & & & 5 & 15 & 50 & 150 & 500 & \\
\hline \multirow{3}{*}{ TA97A } & Buffer & $187 \pm 32$ & $183 \pm 8$ & $204 \pm 6$ & $214 \pm 15$ & $209 \pm 44$ & $201 \pm 16$ & $>3000$ \\
\hline & $4 \%$ S9 & $222 \pm 15$ & $255 \pm 12$ & $247 \pm 13$ & $219 \pm 5$ & $234 \pm 16$ & $168 \pm 59$ & $947 \pm 65$ \\
\hline & $10 \%$ S 9 & $182 \pm 9$ & $201 \pm 8$ & $164 \pm 48$ & $180 \pm 26$ & $194 \pm 6$ & $167 \pm 7$ & $432 \pm 21$ \\
\hline \multirow{3}{*}{ TA98 } & Buffer & $50 \pm 4$ & $52 \pm 4$ & $44 \pm 11$ & $41 \pm 2$ & $57 \pm 3$ & $43 \pm 7$ & $370 \pm 59$ \\
\hline & $4 \%$ S9 & $50 \pm 6$ & $70 \pm 4$ & $77 \pm 1$ & $71 \pm 6$ & $56 \pm 8$ & $64 \pm 4$ & $1150 \pm 10$ \\
\hline & $10 \% \mathrm{~S} 9$ & $63 \pm 2$ & $64 \pm 16$ & $69 \pm 18$ & $70 \pm 18$ & $74 \pm 2$ & $74 \pm 1$ & $413 \pm 16$ \\
\hline \multirow{3}{*}{ TA100 } & Buffer & $203 \pm 9$ & $197 \pm 16$ & $211 \pm 36$ & $227 \pm 4$ & $198 \pm 10$ & $209 \pm 5$ & $1624 \pm 34$ \\
\hline & $4 \% S 9$ & $204 \pm 17$ & $227 \pm 25$ & $208 \pm 14$ & $205 \pm 18$ & $199 \pm 13$ & $178 \pm 26$ & $1362 \pm 6$ \\
\hline & $10 \% S 9$ & $178 \pm 12$ & $252 \pm 4$ & $222 \pm 34$ & $216 \pm 14$ & $243 \pm 7$ & $215 \pm 16$ & $562 \pm 40$ \\
\hline
\end{tabular}


Tracer: PENTAFLUOROPROPIONIC ACID

\begin{tabular}{|c|c|c|c|c|c|c|c|c|}
\hline \multirow{2}{*}{ Strain } & \multirow{2}{*}{ Trial } & \multirow{2}{*}{$\begin{array}{l}\text { neg. } \\
\text { control }\end{array}$} & \multicolumn{5}{|c|}{ Tracer Concentration ( $\mu \mathrm{g} / \mathrm{plate})$} & \multirow{2}{*}{$\begin{array}{c}\text { pos. } \\
\text { control }\end{array}$} \\
\hline & & & 5 & 15 & 50 & 150 & 500 & \\
\hline \multirow{3}{*}{ TA97A } & Buffer & $202 \pm 18$ & $190 \pm 12$ & $188 \pm 18$ & $132 \pm 28$ & $136 \pm 8$ & $163 \pm 23$ & $>3000$ \\
\hline & $4 \%$ S9 & $232 \pm 11$ & $204 \pm 9$ & $166 \pm 18$ & $175 \pm 5$ & $185 \pm 4$ & $153 \pm 4$ & $902 \pm 161$ \\
\hline & $10 \% S 9$ & $221 \pm 24$ & $217 \pm 6$ & $200 \pm 3$ & $191 \pm 7$ & $172 \pm 21$ & $171 \pm 5$ & $491 \pm 51$ \\
\hline \multirow{3}{*}{ TA98 } & Buffer & $50 \pm 4$ & $43 \pm 18$ & $38 \pm 7$ & $45 \pm 6$ & $52 \pm 6$ & $43 \pm 2$ & $370 \pm 59$ \\
\hline & $4 \% S 9$ & $50 \pm 6$ & $60 \pm 4$ & $58 \pm 0$ & $57 \pm 6$ & $57 \pm 11$ & $54 \pm 5$ & $1150 \pm 10$ \\
\hline & $10 \% \mathrm{~S} 9$ & $63 \pm 2$ & $69 \pm 5$ & $59 \pm 6$ & $63 \pm 12$ & $69 \pm 20$ & $75 \pm 6$ & $413 \pm 16$ \\
\hline \multirow{3}{*}{ TA100 } & Buffer & $204 \pm 36$ & $221 \pm 18$ & $225 \pm 24$ & $202 \pm 11$ & $192 \pm 33$ & $188 \pm 5$ & $898 \pm 3$ \\
\hline & $4 \%$ S9 & $199 \pm 3$ & $202 \pm 13$ & $194 \pm 23$ & $210 \pm 16$ & $185 \pm 23$ & $178 \pm 29$ & $1111 \pm 16$ \\
\hline & $10 \% \mathrm{~S} 9$ & $215 \pm 12$ & $233 \pm 21$ & $245 \pm 18$ & $223 \pm 35$ & $228 \pm 5$ & $197 \pm 0$ & $515 \pm 8$ \\
\hline
\end{tabular}


Tracer: HEPTAFLUOROBUTYRIC

\begin{tabular}{|c|c|c|c|c|c|c|c|c|}
\hline \multirow{2}{*}{ Strain } & \multirow{2}{*}{ Trial } & \multirow{2}{*}{$\begin{array}{l}\text { neg. } \\
\text { control }\end{array}$} & \multicolumn{5}{|c|}{ Tracer Concentration ( $\mu \mathrm{g} /$ plate) } & \multirow{2}{*}{$\begin{array}{l}\text { pos. } \\
\text { control }\end{array}$} \\
\hline & & & 5 & 15 & 50 & 150 & 500 & \\
\hline \multirow{3}{*}{ TA97A } & Buffer & $202 \pm 18$ & $147 \pm 19$ & $166 \pm 35$ & $174 \pm 1$ & $193 \pm 0$ & $145 \pm 10$ & $>3000$ \\
\hline & $4 \%$ S9 & $232 \pm 11$ & $214 \pm 4$ & $170 \pm 21$ & $222 \pm 12$ & $187 \pm 16$ & $212 \pm 18$ & $902 \pm 161$ \\
\hline & $10 \% S 9$ & $221 \pm 24$ & $241 \pm 1$ & $239 \pm 8$ & $244 \pm 1$ & $163 \pm 30$ & $233 \pm 20$ & $491 \pm 51$ \\
\hline \multirow{3}{*}{ TA98 } & Buffer & $50 \pm 4$ & $48 \pm 6$ & $45 \pm 8$ & $38 \pm 8$ & $41 \pm 2$ & $45 \pm 4$ & $370 \pm 59$ \\
\hline & $4 \%$ S9 & $50 \pm 6$ & $67 \pm 11$ & $55 \pm 1$ & $61 \pm 11$ & $63 \pm 10$ & $61 \pm 10$ & $1150 \pm 10$ \\
\hline & $10 \% \mathrm{~S} 9$ & $63 \pm 2$ & $65 \pm 3$ & $64 \pm 2$ & $75 \pm 4$ & $54 \pm 9$ & $64 \pm 12$ & $413 \pm 16$ \\
\hline \multirow{3}{*}{ TA100 } & Buffer & $204 \pm 36$ & $234 \pm 8$ & $219 \pm 4$ & $218 \pm 18$ & $217 \pm 23$ & $214 \pm 21$ & $898 \pm 3$ \\
\hline & $4 \% \mathrm{~S} 9$ & $199 \pm 3$ & $221 \pm 34$ & $192 \pm 11$ & $181 \pm 23$ & $198 \pm 3$ & $206 \pm 18$ & $1111 \pm 16$ \\
\hline & $10 \% \mathrm{~S} 9$ & $215 \pm 12$ & $213 \pm 22$ & $213 \pm 18$ & $225 \pm 21$ & $239 \pm 15$ & $159 \pm 6$ & $515 \pm 8$ \\
\hline
\end{tabular}


Tracer: 3,5-DICHLOROSALICYLIC ACID

\begin{tabular}{|c|c|c|c|c|c|c|c|c|}
\hline \multirow{2}{*}{ Strain } & \multirow{2}{*}{ Trial } & \multirow{2}{*}{$\begin{array}{l}\text { neg. } \\
\text { control }\end{array}$} & \multicolumn{5}{|c|}{ Tracer Concentration ( $\mu \mathrm{g} / \mathrm{plate})$} & \multirow{2}{*}{$\begin{array}{l}\text { pos. } \\
\text { control }\end{array}$} \\
\hline & & & 0.5 & 2.5 & 5 & 25 & 50 & \\
\hline \multirow{3}{*}{ TA97A } & Buffer & $202 \pm 18$ & $184 \pm 1$ & $197 \pm 9$ & $168 \pm 4$ & $183 \pm 21$ & $216 \pm 1$ & $>3000$ \\
\hline & $4 \% S 9$ & $232 \pm 11$ & $207 \pm 4$ & $240 \pm 1$ & $219 \pm 22$ & $205 \pm 17$ & $215 \pm 13$ & $902 \pm 161$ \\
\hline & $10 \% S 9$ & $221 \pm 24$ & $215 \pm 23$ & $249 \pm 8$ & $217 \pm 9$ & $239 \pm 1$ & $254 \pm 11$ & $491 \pm 51$ \\
\hline \multirow{3}{*}{ TA98 } & Buffer & $50 \pm 4$ & $48 \pm 4$ & $42 \pm 19$ & $41 \pm 1$ & $37 \pm 1$ & $47 \pm 2$ & $370 \pm 59$ \\
\hline & $4 \% S 9$ & $50 \pm 6$ & $60 \pm 8$ & $72 \pm 13$ & $56 \pm 1$ & $56 \pm 11$ & $68 \pm 11$ & $1150 \pm 10$ \\
\hline & $10 \% S 9$ & $63 \pm 2$ & $51 \pm 0$ & $67 \pm 2$ & $75 \pm 10$ & $70 \pm 14$ & $60 \pm 8$ & $413 \pm 16$ \\
\hline \multirow{3}{*}{ TA100 } & Buffer & $204 \pm 36$ & $205 \pm 4$ & $199 \pm 26$ & $207 \pm 8$ & $219 \pm 1$ & $232 \pm 1$ & $898 \pm 3$ \\
\hline & $4 \%$ S9 & $199 \pm 3$ & $211 \pm 3$ & $225 \pm 8$ & $212 \pm 2$ & $207 \pm 21$ & $214 \pm 8$ & $1111 \pm 16$ \\
\hline & $10 \% \mathrm{~S} 9$ & $215 \pm 12$ & $221 \pm 9$ & $217 \pm 45$ & $221 \pm 14$ & $215 \pm 1$ & $225 \pm 33$ & $515 \pm 8$ \\
\hline
\end{tabular}


Tracer: PENTAFLUOROBENZOIC ACID

\begin{tabular}{|c|c|c|c|c|c|c|c|c|}
\hline \multirow{2}{*}{ Strain } & \multirow{2}{*}{ Trial } & \multirow{2}{*}{$\begin{array}{l}\text { neg. } \\
\text { control }\end{array}$} & \multicolumn{5}{|c|}{ Tracer Concentration ( $\mu \mathrm{g} /$ plate) } & \multirow{2}{*}{$\begin{array}{c}\text { pos. } \\
\text { control } \\
+ \\
\end{array}$} \\
\hline & & & 5 & 15 & 50 & 150 & 500 & \\
\hline \multirow{3}{*}{ TA97A* } & Buffer & $176 \pm 15$ & $185 \pm 2$ & $190 \pm 6$ & $191 \pm 2$ & $184 \pm 6$ & $173 \pm 6$ & $>3000$ \\
\hline & $4 \% \mathrm{~S} 9$ & $218 \pm 7$ & $228 \pm 6$ & $200 \pm 21$ & $213 \pm 29$ & $218 \pm 5$ & $188 \pm 7$ & $892 \pm 72$ \\
\hline & $10 \%$ S9 & $215 \pm 18$ & $220 \pm 23$ & $211 \pm 4$ & $237 \pm 18$ & $227 \pm 13$ & $217 \pm 11$ & 585 \\
\hline \multirow{3}{*}{ TA98 } & Buffer & $31 \pm 4$ & $30 \pm 1$ & $37 \pm 1$ & $31 \pm 0$ & $30 \pm 1$ & $25 \pm 9$ & $730 \pm 147$ \\
\hline & $4 \% S 9$ & $42 \pm 11$ & $49 \pm 6$ & $37 \pm 2$ & $45 \pm 2$ & $41 \pm 1$ & $37 \pm 8$ & $1448 \pm 68$ \\
\hline & $10 \%$ S 9 & $48 \pm 7$ & $51 \pm 6$ & $53 \pm 9$ & $58 \pm 12$ & $72 \pm 4$ & $55 \pm 1$ & $416 \pm 71$ \\
\hline \multirow{3}{*}{ TA100 } & Buffer & $280 \pm 19$ & $248 \pm 45$ & $226 \pm 1$ & $216 \pm 32$ & $227 \pm 8$ & $201 \pm 16$ & $1145 \pm 211$ \\
\hline & $4 \% \mathrm{~S} 9$ & $229 \pm 16$ & $239 \pm 35$ & $227 \pm 14$ & $207 \pm 1$ & $234 \pm 22$ & $214 \pm 21$ & $1237 \pm 107$ \\
\hline & $10 \% \mathrm{~S} 9$ & $227 \pm 19$ & $229 \pm 24$ & $238 \pm 25$ & $222 \pm 8$ & $247 \pm 1$ & $206 \pm 5$ & $630 \pm 71$ \\
\hline
\end{tabular}

* Strain TA97A Tracer Concentration for S-9 trials $=0.5,1.5,5,15,50$ 


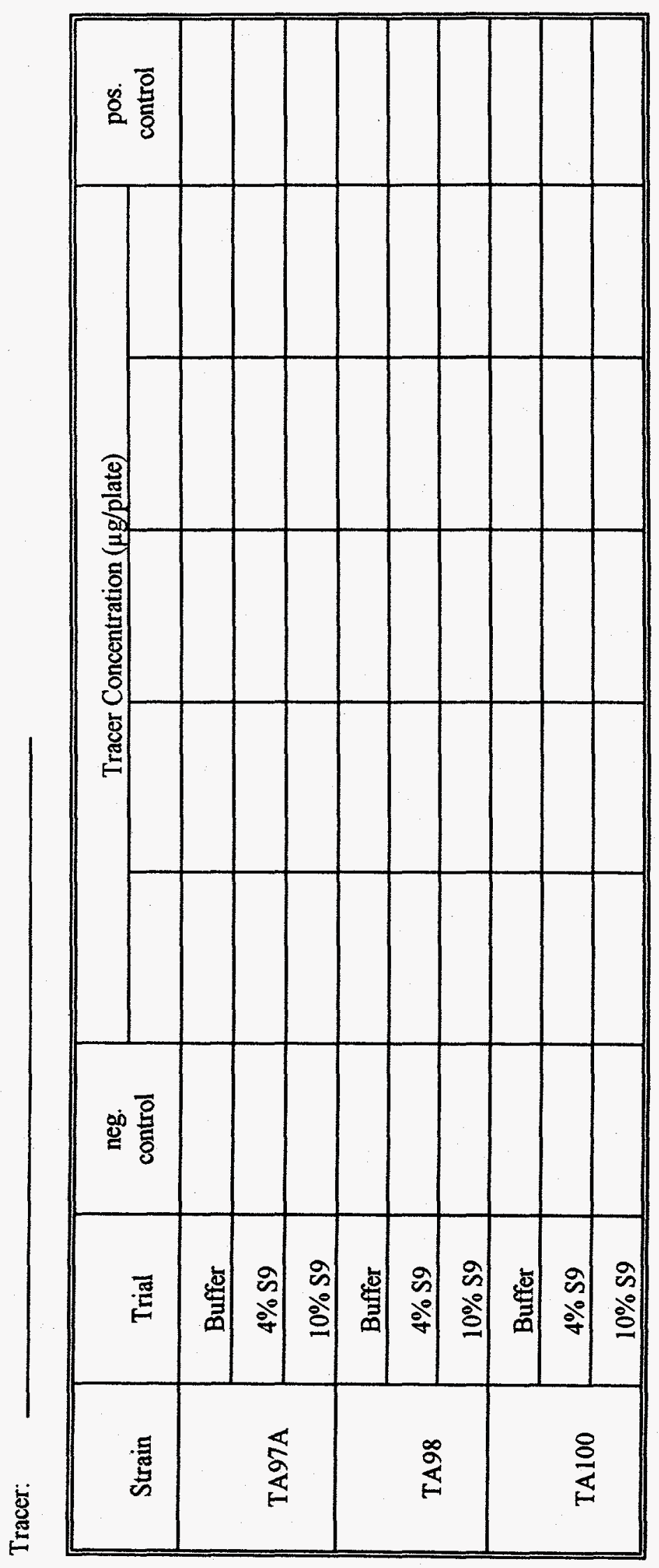


A COMPARISON OF HPLC/MS THERMOSPRAY AND PARTICLE BEAM METHODS OF ANALYSIS

FOR

TFAA/PFPA/HFBA

IN GROUND WATER

BY TONYA DOMBROWSKI

AND KLAUS STETZENBACH

HARRY REID CENTER FOR ENVIRONMENTAL STUDIES

BARRICK MUSEUM OF NATURAL HISTORY

UNIVERSTTY OF NEVADA-LAS VEGAS

LAS VEGAS, NEVADA 
ABSTRACT: A method is described for the qualitative and quantitative identification of three perfluorinated aliphatic acids in ground water. Organic acids are being used as ground-water tracers during hydrologic characterization for the proposed high-level nuclear waste repository at Yucca Mountain, Nevada. Trifluoroacetic, pentafluoropropionic, and heptafluorobutyric acids were evaluated using both HPLC and HPLC/MS methods. The sensitivity of conventional HPLC methods, using a UV-Vis detector, was very poor. Detection limits for this method were around $100 \mathrm{ppm}$ using a $10 \mu \mathrm{L}$ injection volume. Because much greater sensitivity was required for the ground-water tracing project, HPLC/MS methods were evaluated using both particle-beam chemical ionization and thermospray techniques. The results of these two methods were compared for sensitivity and reproducibility, as both are essential for the scope of this project. The thermospray technique showed considerably lower detection limits when compared to the particle beam method of analysis. The detection limit for all three acids using the negative thermospray mode was at about $10 \mathrm{ppb}$ using a $10 \mu \mathrm{L}$ injection volume. The detection limit for the particle-beam analyses was slightly higher. Instrumental settings, sensitivity, and reproducibility for the two HPLC/MS techniques will be discussed.

INTRODUCTION: Yucca Mountain, Nevada, is being evaluated as a potential high-level nuclear waste repository site. The accurate evaluation of ground-water movement is of major importance to the site characterization process. The use of chemical compounds to trace ground-water movement and determine aquifer characteristics such as effective porosity have been widely applied in a number of various circumstances (1-6). To be considered as viable ground-water tracers, however, all compounds used must exhibit certain characteristics. They should:

1) be water soluble

2) not sorb to aquifer material

3) be chemically and biologically stable for the duration of the test

4) be foreign to the local environment

5) be non-toxic

6) have excellent analytical sensitivity

These attributes represent a general case that applies to all tracers, and, while not all of these criteria may be met fully by each tracer compound, they should all be applicable to the fullest possible extent in the initial selection of potential tracer compounds. Their application to the evaluation of ground-water movement is obvious in most cases. If the compounds are to be injected into an aqueous environment, it is clear that they must be soluble in aqueous solutions. The intent of most tracer tests is to determine the direction and speed of the water movement, so it is not desirable to have the tracer sorb to the aquifer material. Since most aquifer materials have a negative charge, anions such as chloride, bromide and organic acids make the best tracers. For accurate interpretation of the results of a tracing test, it is essential that as much as possible of the compound be recovered, and chemical and biological stability will add to the final recovery of the tracer compounds. Typical tracer tests can last from several hours to several weeks. A background contamination of an area by a potential tracing compound will not only add to the difficulty of analytical measurements and interpretation of results but, for organic compounds, may also lead to a higher possibility of biological degradation. The toxicity of a compound is an important consideration whenever chemical compounds are being placed into the natural environment and is therefore a major factor in the selection of potential tracing compounds.

Since the physical and chemical properties of the aquifer and the tracer cannot be changed, the only variable that the researcher has any control over is the analytical sensitivity. The analytical sensitivity will affect and be affected by several of the other areas considered above, as the total amount of a compound being injected into the water system will, to a large extent, be determined by the analytical detection limits for the compound being used. The solubility of the compound will be tied to the amount injected, and this overall amount will influence the potential toxicity, as a large amount of a compound in the natural environment may well exceed the safe, non-toxic levels that a smaller initial concentration would produce. The difference in 
sensitivity from $1 \mathrm{ppm}$ to $1 \mathrm{ppb}$ can be significant. If a tracer test requires $1 \mathrm{ppm}$ sensitivity, and $100 \mathrm{~kg}$ of tracer are required to achieve this concentration, the same test with a $1 \mathrm{ppb}$ sensitivity would only require 100 grams of tracer to be put into the environment.

The first tracer tests for the Yucca Mountain Site Characterization Project are planned in an area called the $\mathrm{C}$-well complex. This consists of a hydropad with 3 wells arranged in a triangle approximately 100 to 200 feet apart. The wells are 3,000 feet deep and the static water level is at approximately 1,300 feet. Twenty to thirty tracer tests are planned to characterize this saturated interval. It is estimated that 15 to 20 tracers are necessary to minimize the potential of interference from foregoing tests. There are not enough inorganic compounds that are acceptable tracers, so organic compounds will have to be used. We are testing 18 organic acids as possible tracers for this location.

Chemistry: Numerous organic compounds have been used to trace ground-water movement. Organic dyes such as fluorescein and rhodamine have been the most common, but these compounds generally sorb to aquifer materials and are readily degraded by microbes. They are best used in non-quantitative tests to trace large flows of water such as underground streams in karst. Optical brighteners (additives to laundry detergents) suffer from the same drawbacks.

Fluorinated benzoic acids have been used successfully for a number of tracing tests (1-5). Their anions are water soluble, they are readily detected by HPLC with UV detection at the 0.1 to $1 \mathrm{ppm}$ level, and, because of the fluorine substitution, they are resistant to chemical and biological degradation. Their major drawbacks are availability and cost ( 7$)$.

Perfluorinated aliphatic acids, such as trifluoroacetic acid (TFAA), pentafluoropropionic acid (PFPA), and heptafluorobutyric acid (HFBA), are more soluble and less expensive than the fluorinated benzoates, but they require more sophisticated instrumentation to be detected at low levels. TFAA, PFPA, and HFBA were used as tracers in trench infiltration studies on Mt. Lemmon, Arizona, at an elevation of 9,000 feet with 40 inches of annual precipitation (6). While these studies cannot be used to obtain quantitative information about degradation of the tracers, they do show that they were still present in detectable amounts more than two years after being placed in the trenches in a moist but unsaturated environment.

Toxicity. TFAA is found in fairly high concentration levels in the blood serum $(\approx 150 \mathrm{ppm})$ and urine $(\approx 300 \mathrm{ppm})$ of patients who have been anesthetized with halothane anesthetics. No negative effects have been attributed to its presence in the body, and therefore it is assumed to be relatively non-toxic at or below these concentration levels. It is expected that typical concentrations in the recovered water will be in the 1 to 10 ppm range, well below the levels found in anesthetized patients. No toxicity data are available for PFPA and HFBA. These compounds have shown very good long-term stability in the environment and, in most cases, appear to be excreted rather than metabolized (8).

Tracers: The tracer compounds chosen for evaluation for this project can be broken down into two major groups: aromatic acids and aliphatic acids. The aromatic acids, because of the ring structure, can be easily and sensitively evaluated using HPLC techniques and a UV detector. The aliphatic acids do not possess a good chromophore and therefore do not lend themselves to routine analytical methods of analysis. Because of the promise shown by these compounds in previous tracer tests, however, it was decided that an HPLC/MS method would be developed to evaluate them for the purpose of this project. It was further hoped that such a method could also be applied to the aromatic acids in the later stages of the project, to provide a means of positive identification in the event that two or more tracers were present in the same aquifer area.

The high sensitivity of environmental HPLC/MS analysis techniques (9.10), and other work done using TFAA as a potential tuning and calibration compound for thermospray HPLC/MS (11-13) showed that these compounds were potentially well suited for HPLCAMS analysis. 
EXPERIMENTAL: An HPLC/MS method for analysis was needed for the aliphatic acid group of the tracer compounds (currently consisting of TFAA, PFPA and HFBA). The bulk of the following discussion will concern this method development and its subsequent evaluation.

Instrumentation: This work was performed with an Extrel Benchmark quadrupole HPLC/MS system (Extrel Corporation, Pittsburgh, PA, USA) configured for both particle-beam and thermospray modes of operation. The MS system was controlled through a Sun Station Sparc I data system which utilized Open Windows ver. 2 and Extrel IONStation software packages. Solvent delivery was performed with a ternary solvent HPLC pump with a flow feedback system to maintain constant flow rate (Spectra-Physics, San Jose, California USA; Model \#SP8800). Reagent gases available included both ammonia and methane.

Operating parameters specific to the particle-beam interface included: pressure: $\approx 3.0 \times 10^{-4}$ torr, source temperature $220^{\circ} \mathrm{C}\left(227-237^{\circ} \mathrm{C}\right)$, nebulizer temperature $110^{\circ} \mathrm{C}\left(110-120^{\circ} \mathrm{C}\right)$, expansion region temperature $55{ }^{\circ} \mathrm{C}$. The solvent, $100 \%$ methanol, was pumped through a reverse-phase $\mathrm{C}-18 \mathrm{column}, 4.6 \mathrm{~mm} \times 15 \mathrm{~cm}$ (Varian/Analytichem International, Harbor City, California USA, P/N 12157017), at $1.00 \mathrm{ml} / \mathrm{min}$ which gave a back-pressure of $\approx 2500$ psi.

Operating parameters specific to the thermospray interface included: pressure: $\approx 3.0 \times 10^{-5}$ torr, source temperature $255^{\circ} \mathrm{C}\left(257-268^{\circ} \mathrm{C}\right)$, nebulizer temperature $178^{\circ} \mathrm{C}\left(173-180^{\circ} \mathrm{C}\right)$, repeller $-21 \mathrm{~V}$. The solvent, $94.5 \% \mathrm{H}_{2} \mathrm{O}$ with $0.1 \mathrm{M}$ ammonium acetate, $1.0 \%$ acetic acid, $4.5 \%$ methanol with $0.1 \mathrm{M}$ ammonium acetate, was pumped through a reverse-phase C-18 column, $4.6 \mathrm{~mm} \times 15 \mathrm{~cm}$ (Varian/Analytichem International, Harbor City, California USA, P/N 12157017), at $1.00 \mathrm{ml} / \mathrm{min}$ which gave a back-pressure of $\approx 2500 \mathrm{psi}$.

The temperature settings shown in the parentheses are the actual values reported by the status screen; those not in parentheses are the set values entered at the start of the analysis.

Reagents: TFAA and HFBA were obtained from Aldrich, $99 \%$ purity. PFPA was obtained from Aldrich, $97 \%$ purity.

\section{RESULTS AND DISCUSSION:}

Particle-beam Evaluation: Initial method development was started using the particle-beam mode of operation. Electron ionization (EI) and both positive and negative chemical ionization (CI) were evaluated. Negative CI was found to be the most sensitive particle-beam mode for these compounds. Ammonia and methane were used initially as reagent gases, and methane was selected for this work. Sensitivity was about the same with both reagent gases, and methane was both less corrosive and much more readily available. Calibration was accomplished using perfluorotributyl-amine (PTA) as a calibration compound. (See figure \#1 for specific operating parameters). On-column injections of the tracer compounds were made over the working range (1.0 to $100 \mathrm{ppm}$ for TFAA, PFPA, HFBA) using a $10 \mu \mathrm{L}$ injection loop. Direct flow (column bypass) injections were made in the working range (1.0 to $100.0 \mathrm{ppm}$ for TFAA, PFPA, HFBA) using a 0.5 $\mu \mathrm{L}$ injection valve.

The ion spectra for these analyses were fairly simple, usually containing only one or two major ions. The parent peak was not observed for any of the acids when evaluated with the particle-beam technique. For all three acids, the major ion was at a mass showing a consistent loss of 20 from the molecular ion mass. This may be the result of a direct loss of HF from the molecular ion; however, such a loss may also be due to a more complicated mechanism which includes the formation of adduct ions, and the subsequent fragmentation of these larger ions into smaller pieces. A further loss of 44 (64 total from parent ion) was also noted under certain conditions, which could be attributed to the loss of $\mathrm{CO}_{2}$. The TFAA signal was very unpredictable, and sensitivity was extremely poor. It is felt that this acid may be too volatile to be accurately analyzed using this technique. The PFPA and HFBA, however, gave good signals with fair sensitivity and good reproducibility throughout the working range of 1.0 to $100.0 \mathrm{ppm}$. Detection limits on column (10 $\mu \mathrm{L}$ loop injection) were at $0.1 \mathrm{ppm}$ for both acids. The methods developed for the evaluation of these acids using negative CI particle-beam MS can most likely be applied to the aromatic acids discussed earlier in this report, 
as the aromatic acids should be good electron capture agents. The sensitivities achieved using negative $\mathrm{CI}$ for the evaluation of the aliphatic acids, however, fell short of the desired detection limits for this project. The goals set for this research required greater sensitivity than that obtained for these acids from the particle-beam evaluations. Thermospray was therefore examined as a means of improving the sensitivity for these specific compounds.

Thermospray Evaluation: Both positive and negative modes of thermospray were evaluated. Initially the signal was very unstable, and both sensitivity and reproducibility were very poor due to an unusual pulsing of the signal which occurred at elevated temperatures (above $200^{\circ} \mathrm{C}$ ). This problem was almost completely corrected by the exchange of the fused silica capillary tubing for stainless steel hypodermic tubing in the Extrel Benchmark nebulizer assembly. However, the placement of the end of the tubing within the source (see figure \#2) was found to have a tremendous influence on the sensitivity of this method. A movement of the end of the tubing by less than $1 \mathrm{~mm}$ was significant in most cases and, at distances very near the optimal placement, could effectively cut off the signal completely. The tubing placement was optimized by watching the height and shape of ammonium adduct ions on the scope screen while making fine adjustments in position. Once the optimal placement was located, the ferrules were tightened to hold the tubing securely in position, and no further placement adjustments were made during the course of the analysis. It is unclear at this time whether this placement sensitivity is a distinct characteristic of the stainless steel tubing, or if its effect can be seen in the fused silica capillary tubing as well. Signal reproducibility with the fused silica tubing was so poor that such adjustments were impossible to evaluate.

Thermospray calibration was done using ammonium adduct ions and a series of PEG injections through the flow injection valve. (See figure \#1 for specific operating parameters.) On- column injections of the tracer compounds were made over the working range $(0.05$ to $1.0 \mathrm{ppm}$ for TFAA, PFPA; 0.1 to $1.0 \mathrm{ppm}$ for $\mathrm{HFBA}$ ) using a $10 \mu \mathrm{L}$ injection loop. Direct flow injections were made in the working range (1.0 to 10.0 ppm for TFAA, PFPA, HFBA) using a $0.5 \mu \mathrm{L}$ injection valve.

Negative thermospray ion spectra yielded one major peak for all three acids. Major ions monitored for all three acids were the molecular ion minus one mass unit (TFAA 113, PFPA 163, HFBA 213). Several adduct ions were visible in all three acids' spectra, but the majority of the ion current was concentrated in those ions listed above. The detection limit was at $0.01 \mathrm{ppm}$ for an on-column injection $(10 \mu \mathrm{L})$ for the TFAA and PFP. This is an order of magnitude better than the results from the negative CI evaluation. For HFBA the detection limit was slightly higher, at $0.05 \mathrm{ppm}$. The HFBA appears to be more affected by the elevated temperatures in the thermospray source, and the signal is slightly unsteady at the temperatures being applied. With further method optimization, the sensitivity of this technique for the HFBA should be comparable to that for the other two acids. Lower source temperatures seem to improve sensitivity and reproducibility for this acid.

Column vs flow injection: On-column injection reproducibility was compared to flow injection reproducibility and detection limits. It was felt that the use of the flow injection valve could greatly reduce the time involved in method development and, later, in initial sample screening and evaluation, if it could be determined that the flow injection results were reproducible to the degree required. The flow injection valve contained a fixed $0.5 \mu \mathrm{L}$ injection loop. This small volume greatly reduced the amount of sample being injected and therefore made detection limits for the valve slightly higher than those for on-column injection.

A comparison is shown below of the reproducibility of the two techniques (negative CI particle-beam and negative ion thermospray) with both on-column injection and flow injection data. The percentages given are percent relative standard deviation (\%rsd) for area counts only, and do not take into account intensity or peak height. They can be useful, however, for identifying trends and relative values.

\section{PARTICLE BEAM:}

\section{Trifluoroacetic acid}

on column: NA Highly unstable

flow injection: NA 
Pentafluoropropionic acid

At Working concentration: (1.0 to $100 \mathrm{ppm})$

on column: $\approx 14.5 \%$

flow injection: $\approx 14.1 \%$

At Detection Limits: (0.1 ppm)

on column: $\approx 50.2 \%$

flow injection: $\approx 33.5 \%$

Heptafluorobutyric acid

At Working concentration: (1.0 to $100 \mathrm{ppm}$ )

on column: $\approx 13.3 \%$

flow injection: $\approx 10.8 \%$

At Detection Limits: $(0.1 \mathrm{ppm})$

on column: $\approx 46.1 \%$

flow injection: $\approx 42.8 \%$

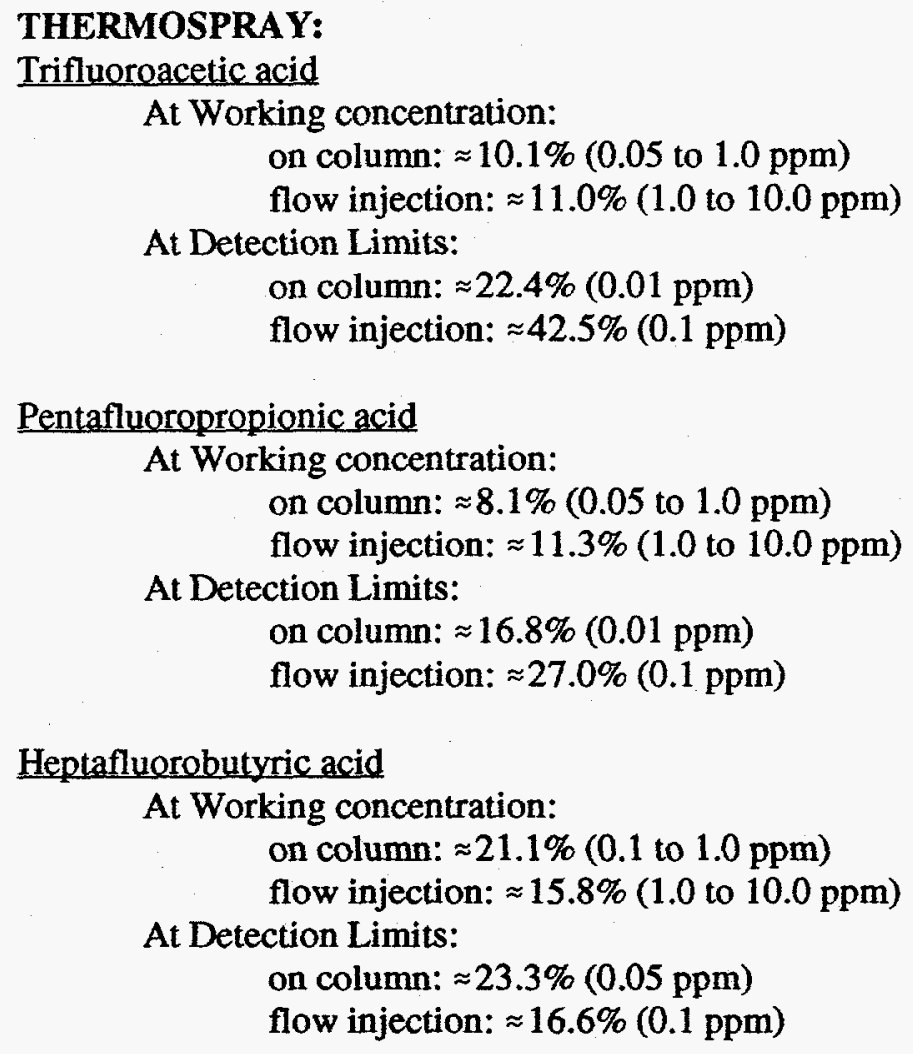

The HFBA values for thermospray show basically the same \%rsd for both the working conditions and the detection limit concentrations. This is felt to be due to the temperature problems discussed earlier.

CONCLUSIONS: Several trends in reproducibility and sensitivity for the negative CI particle-beam compared to the negative ion thermospray technique have been identified by this work to date.

The thermospray mode of analysis has been found to give extremely clean and reproducible ion spectra for all three aliphatic compounds (spectra usually contain only the molecular ion minus one as a major peak). The reproducibility of area counts for thermospray is good for the concentration ranges being used. 
The thermospray method is affected to a much greater extent by temperature fluctuations, however, which have a large effect on both the sensitivity and reproducibility of the method, especially in the case of HFBA.

Negative CI particle-beam yields fairly good reproducibility for PFPA and HFBA and is much more resistant to the effects of temperature fluctuations than the thermospray technique. The reproducibility using negative $\mathrm{Cl}$ is better for HFBA, and approximately the same for PFPA, as that obtained with the thermospray technique. However, negative $\mathrm{Cl}$ particle-beam is not nearly as sensitive overall as thermospray and is not a viable method for the evaluation of TFAA at this time. The thermospray technique is much more sensitive than negative $\mathrm{CI}$ for all three acids (TFAA, PFPA, and HFBA). TFAA is easily seen at very low concentrations; sensitivity for PFPA is at least one order of magnitude better with thermospray than with negative $\mathrm{CI}$, and HFBA sensitivity is at least twice as good with thermospray.

(This research performed under DOE Cooperative Agreement No. DE-FC08-90NV10872.)

\section{REFERENCES}

(1) Barackman, M.L. MS Thesis, University of Arizona, Tucson, 1986.

(2) Stetzenbach, K.J. University of Arizona, Tucson, unpublished data.

(3) Bowman, R.S. Soil Sci. Soc. Am. J 1984a, 48, 987-993.

(4) Bowman, R.S.; Rice, R.C. Water Res. R. 1986, 22, 1531-1536.

(5) Thompson, G.M.; Stetzenbach, K.J. Assessment and Advances in Tracer Technology Topical Report to NRC, Nuclear Regulatory Commission, Washington D.C. 1980.

(6) McCray, J.G.; Nowatzki, E.A.; Stetzenbach, K.J.; Armstrong, G. Low-Level Nuclear Waste Shallow Land Burial Trench Isolation. Final Report to NRC; NUREG/CR-4194; Nuclear Regulatory Commission, Washington D.C. 1985.

(7) Bowman, R.S.; Gibbens, J.F. Ground Water 1992, 30, No.1, 8-13.

(8) Bitner, M.; Thompson, G. Trifluoroacetic Acid as a Safe Tracer, University of Arizona, Department of Hydrology, Tuscon, unpublished report, 1982.

(9) Liquid Chromatography/Mass Spectroscopy: Application in Agricultural, Pharmaceutical, and Environmental Chemistry; Brown, M.A., Ed.; American Chemical Society: Washington D.C. 1990.

(10) Bellar, T.A.; Budde, W.L. Anal. Chem. 1989, 61, 2050-2054.

(11) Stout, S.J.; daCunha, A.R. Anal. Chem. 1989, 61, 2126-2128.

(12) Stout, S.J.; daCunha, A.R. Org. Mass Spectrom. 1990, 25, 187-190.

(13) Heeremans, C.E.M.; Van der Hoeven, R.A.M.; Niessen, W.M.A.; Tjaden, U.R.; Van der Greef, Org. Mass Spectrom. 1988, 24, 109-112. 
FIGURE \# 1

$\begin{array}{lll}\text { Parameter } & \text { Particle-beam setting } & \text { Thermospray setting } \\ \text { Filament } & 300 \mathrm{eV} & 70 \mathrm{eV} \\ \text { Emmission } & 6 \mathrm{~mA} & 6 \mathrm{~mA} \\ \text { Extractor } & 53 \mathrm{~V} & 41 \mathrm{~V} \\ \text { Entrance } & 43 \mathrm{~V} & 8 \mathrm{~V} \\ \text { Ion Energy } & 20 \mathrm{~V} & 10 \mathrm{~V} \\ \text { Exit } & 41 \mathrm{~V} & 70 \mathrm{~V} \\ \text { Dynode } & 5000 \mathrm{~V} & 5000 \mathrm{~V} \\ \text { Multiplier } & 1800 \mathrm{~V} & 1800 \mathrm{~V} \\ \text { Repeller } & \mathrm{N} / \mathrm{A} & -21 \mathrm{~V} \\ \text { Source Temperature } & 220^{\circ} \mathrm{C}\left(227-237^{\circ} \mathrm{C}\right) & 255^{\circ} \mathrm{C}\left(257-268^{\circ} \mathrm{C}\right) \\ \text { Nebulizer Temperature } & 110^{\circ} \mathrm{C}\left(110-120^{\circ} \mathrm{C}\right) & 178^{\circ} \mathrm{C}\left(173-180^{\circ} \mathrm{C}\right) \\ \text { Expansion Region } & 55^{\circ} \mathrm{C} & \mathrm{N} / \mathrm{A} \\ \text { Ion polarity } & \text { Negative } & \text { Negative } \\ \text { Quadrupole DC } & \text { Normal } & \text { Normal } \\ \text { Pressure } & \approx 3.0 \times 10^{-4} \text { torr } & \approx 3.0 \times 10^{-5} \text { tor }\end{array}$

(Note: voltages may differ from day to day by a few settings for maximum sensitivity, but the overall trends stayed the same as those illustrated below.)

The temperature settings shown in parentheses are the actual values reported by the status screen; those not in parentheses are the set values entered at the start of the analysis. The fluctuations may be either the result of the actual instrumental conditions or an artifact of the status update software interfacing with the thermostat electronics. 
APPENDIX B 


\section{ORGANIC TRACER TOXICITY REPORT}

Fluorinated BENZOIC ACIDS

DOE Cooperative Agreement

No. DE-FC 08-90NV10972

Tonya Dombrowski

Klaus J. Stetzenbach PhD.

Harry Reid Center For Environmental Studies

University of Nevada - Las Vegas 


\section{INTRODUCTION}

Ground water tracers are solutes dissolved in or carried by ground water to delineate flow pathways. Tracers provide information on direction and speed of water movement and that of contaminants which might be conveyed by the water. Tracers can also be used to measure effective porosity, hydraulic conductivity, dispersivity and solute distribution coefficients. They can be naturally occurring compounds or elements, or they can be completely foreign to the environment. The latter is generally preferred. For most applications tracers should be conservative, that is, move at the same rate as the water and not adsorb to aquifer materials. Aquifer materials are generally negatively charged, so anionic tracers will not adsorb and will move with the water.

A tracer should behave as follows:

1) Be water soluble.

2) Not adsorb on the aquifer material (i.e., be conservative).

3) Be chemically and biologically stable for the duration of the test.

4) Be foreign to the environment.

5) Have excellent analytical sensitivity.

6) Have a low toxicity.

Fifteen fluorinated organic acids (table 1) are presently being studied as possible tracers for the Yucca Mountain Site Characterization Project. There are two additional isomers of trifluorobenzoic acid, 2,3,6-trifluorobenzoic acid and 2,4,6-trifluorobenzoic acid, that are not presently being studied, but were included in this review of currently available toxicological information. Since these compounds are not used in large quantities in industrial or other processes, only limited data are available, especially human toxicology information.

It should be pointed out here that analytical sensitivity and stability are important adjuncts to the issue of toxicity. Virtually any element or compound that is introduced into an aquifer will cause some degradation of the water quality if the concentration is high enough. Tracers with high analytical sensitivity will permit lower input concentrations and therefore reduce the potential for degradation of the water quality. For example, a difference in sensitivity between $100 \mathrm{ppm}$ and $100 \mathrm{ppb}$ may mean introducing only $1 \mathrm{~kg}$ of tracer into the aquifer instead of $1,000 \mathrm{~kg}$.

All organic chemicals dissolved in water, given enough time, will be degraded to carbon dioxide and inorganic ions (if any are contained in the parent compound) by bacterial action. The time required for this to occur depends on many factors, including lethality to indigenous flora, initial concentration, the capability of the microorganisms to utilize the compound and the probability of contact between a molecule and a degrading organism. Since the majority of microorganisms in the subsurface are associated with the host rock and not the water, strong anions will have limited contact with them, thus increasing their longevity in the environment. The fluorinated organic acids, suggested here as potential tracers, are generally quite resistant to chemical and biological activity. 
Although not totally unreactive, as anions they will have reduced probability of interaction with bacteria.

\section{POTENTIAL for EXPOSURE to TRACER-CONTAINING WATER}

Concerns regarding exposure to pure tracer and the various tracer solutions will depend on the procedures used for transportation, injection and recovery during the tracer tests. For the tracer tests at the c-wells, we anticipate that laboratory space will be available at the site. Therefore, we intend to transport pure tracer to the site and prepare highly concentrated, almost saturated, injection solutions at the site. These highly concentrated solutions will be diluted to approximately $0.1 \%$ to $2 \%$ solutions for injection in the tracer injection apparatus. The concentration of the injection solution will depend upon the analytical sensitivity of the tracer and the estimated dilution that will take place on its migration to and into the recovery well, which will be from 100 to 200 feet away. The actual dilution will depend on several aquifer parameters, which will be measured by the tracing test. Estimated peak tracer recovery concentrations are expected to range from 1 to 20 ppm.

\begin{tabular}{|c|c|c|c|c|}
\hline Location & Physical Form & Amount & Volume & Concentration \\
\hline Laboratory & Solid & $1 \mathrm{~kg}$ & - & _ \\
\hline Lab \& Test Well & Liquid & $1 \mathrm{~kg}$ & $200 \mathrm{~L}$ & $5,000 \mathrm{ppm}(0.5 \%)$ \\
\hline Groundwater & Liquid & $1 \mathrm{~kg}$ & $10^{6} \mathrm{~L}$ & $\begin{array}{l}1.0 \mathrm{ppm} \text { average } \\
\text { 10. } \mathrm{ppm} \text { peak }\end{array}$ \\
\hline
\end{tabular}

There are three exposure scenarios for humans and the environment which may result from the use of these tracer compounds. The first is direct contact with or accidental loss of the pure liquid or solid tracer compound. This would happen if the workers spilled the solid (or pure liquid) material or used poor safety practices in the laboratory. The second scenario would occur if the 200 liters of $0.5 \%$ solution were spilled in the laboratory or on the ground before the solution was introduced into the injection wells. In both of these cases steps can be taken immediately to rectify or remediate the occurrence. The third scenario of contact is the long-term exposure to very low concentrations of the tracer which are not recovered during the study and which migrate out of the study area. In this case, exposed persons may not be aware of their contact with these compounds.

In this report we will address all three scenarios, provide as much toxicity information as is available and give realistic estimates of the probability of contact with the proposed tracers. In the first two scenarios, the exposure will be acute and the actions will be supervised by technical personnel. In the third scenario, the exposure will be sub-chronic and will involve the greatest risk to the general population. 


\section{PURE TRACER}

Current estimates are that $100 \mathrm{~g}$ to $3 \mathrm{~kg}$ of tracer will be used per test. Injection solutions will be prepared on site to minimize possibilities of accidental spills during transport. Handling of the pure tracer to prepare the concentrated injection solution will be limited to trained chemistry personnel. Standard laboratory precautions will be used when these materials are handled. This includes wearing appropriate apparel, safety glasses and respirators if necessary. All warnings noted in the material safety data sheets (MSDS) will be observed.

If the pure tracer is accidentally released into the environment, remediation will depend upon the physical state of the tracer chemical. If the tracer is a solid, remediation will entail removal of the chemical from the ground and any soil that was in contact with the tracer. Since the solid chemical will not react with or penetrate the soil, this should entail only small amounts of soil which may have to be removed. This will be done primarily to prevent contamination so that the tracer can be used without background interference. Liquid tracers may react with and penetrate the soil; this will require more extensive clean-up to prevent contamination.

Potential health effects will be limited to acute toxicity resulting from a single exposure. Since the personnel will be wearing protective clothing and the compounds under consideration have a low volatility, exposure via the normal pathways (ingestion, inhalation or dermal absorption) is expected to be very small.

\section{CONCENTRATED INJECTION SOLUTIONS}

The concentrated tracer solutions which will be injected into the wells will vary between $0.1 \%$ and $2 \%$. Even though the tracers are acids, the injection solution will be basic to increase the solubility of the tracer and to be closer to the ground water $\mathrm{pH}$. Accidental spills of the injection solution will present problems similar to those described above for the liquid tracers, except there will be larger volumes. The larger volumes, 50 to 200 liters, will prevent complete removal of the material if all or a large portion is spilled. The use of that tracer may then be lost to the project, especially if the spill occurs in the immediate area surrounding one of the wells. Over time, bacterial degradation in the root zone will degrade the tracer to fluoride and carbon dioxide and rainwater will eventually carry some of the compound to groundwater.

Accidental ingestion of the tracer injection solutions by humans or animals are highly unlikely due to the limited access to the area and because the tracer injection apparatus will be a closed system. Exposure from other routes is expected to be very small because of the use of protective clothing. Potential health effects will be limited to acute toxicity resulting from a single exposure. 


\section{LOW CONCENTRATION SOLUTIONS}

During the tracing test, the tracer will migrate from the injection well to the pumping well, a distance of approximately 100 to 200 feet. It is anticipated that the tracer injection solution will be reduced in concentration by three to six orders of magnitude during its migration. This will result in estimated peak concentrations of $20 \mathrm{ppb}$ to $20 \mathrm{ppm}$ at the pumping well. The amount of tracer recovered will depend upon the length of the tracing test, as well as specific aquifer conditions. Tracer recoveries can be as high as 70 to 80 percent, but typically average $50 \%$ or less. Recoveries of two fluorinated benzoic acids that were used as ground water tracers at the Waste Isolation Pilot Project (WIPP) site in New Mexico ranged from 15 to 53 percent (Kelly and Pickens, 1986), and when thiocyanate was used as a tracer in Hanford Washington the recovery was $60 \%$ (Thompson, 1982).

If the minimum percent recovery value $(15 \%)$, and the maximum injection mass $(3.0$ $\mathrm{kg}$ ) are used, then $2.55 \mathrm{~kg}$ of tracer will remain in the aquifer per test. The concentration of the tracer, which will have been diluted 3 to 6 orders of magnitude during the tracer test, will be further reduced as the tracer is dispersed as a result of the natural ground water movement. By the time it migrates off-site, or reaches a Nevada Test Site well that is being used to supply drinking water, the tracer concentrations will be at extremely low levels if it has not already been degraded by bacteria.

Potential human health effects would be limited to acute or chronic effects resulting from sub-chronic exposure. The worst case exposure would probably result from the use of the recovery well water for drinking water. Because of the limited access to this site, it is not possible that persons living nearby could use well water for domestic drinking water but we will determine the risk from such a scenario in case other test sites are chosen in the future. The exposure would be sub-chronic because there is a single injection of the tracer which then moves with the groundwater flow $(50-150 \mathrm{~L} / \mathrm{min})$. For persons using water from a well (which is fixed in space), exposure to the tracer would exist during the few weeks required for the tracer plume to pass the well.

\section{CHEMISTRY}

Fluorinated organic compounds were selected as potential tracers because of their long term environmental stability and low reactivity. The carbon-fluorine bonds are the shortest of the carbon-halide bonds and are therefore expected to be the strongest and least reactive. Low reactivity and low toxicity are characteristics of numerous carbon-fluorine compounds. For example, Teflon (polytetrafluoroethylene) is extremely inert and is used in a variety of products that humans are in contact with every day, from containers to GoreTex. Halothane (2-bromo-2-chloro-1,1,1-trifluoroethane) and isofluorane (1-chloro-2,2,2trifluoroethyl difluoromethyl ether) are anesthetics that are used throughout the world. Halons are used as fire extinguishers and freons have been used for many years as refrigerants and propellants because of their stability in the lower atmosphere and low human toxicity. 
As a general rule, it can be stated that the greater the number of halogen atoms on a molecule, especially fluorine, the greater its stability. Perfluorinated acids such as pentafluoro-benzoic acid (PFBA) and trifluoroacetic acid (TFAA) are therefore extremely resistant to chemical attack. Because fluorine is a strong electron withdrawing atom, it also follows that the more fluorine atoms on an organic acid molecule, the stronger that acid becomes.

The acid functional group (carboxyl group), is completely oxidized, difficult to reduce and does not undergo other reactions in aqueous (ground water) solutions. Essentially all of these acids are ionized at typical ground water $\mathrm{pH}$ values. The weakest acids being evaluated have dissociation constants $\left(\mathrm{pK}_{\mathrm{a}}\right)$ values of approximately 4.5 , which means they will all be completely ionized and in their anionic form at water $\mathrm{pH}$ values of six or higher (Freiser and Fernando, 1963). The increasing number of halogens on a compound increase the ionizability, and consequently, the water solubility.

Ionized compounds are generally not able to pass through the microbial cell membranes and therefore are not readily utilized by these systems. However, when they are utilized, the reactions are almost identical to the non-fluorinated parent compound.

In addition to the chemical and microbial stability, the carbon-fluorine bond is also difficult for mammalian enzyme systems to break down, and compounds that contain these bonds are generally excreted without loss of fluoride rather than metabolized. This tends to make such compounds less toxic. These fluorinated acids are among the most polar of the halogenated organic compounds. They contain a polar functional group, the acid or carboxyl group, and the presence of that group facilitates their excretion as the parent compound directly, or as conjugates of the parent compound.

\section{ENVIRONMENTAL BIODEGRADATION Of CONTAMINANTS}

Microorganisms are capable of degrading aromatic hydrocarbons and the aromatic fraction can be used to sustain bacterial growth. Utilization of organic compounds occurs via catabolic pathways catalyzed by a series of enzymes. The product formed may then be utilized by another population of bacteria or the resulting compounds may be resistant to further degradation.

Environmental factors that affect the rate and extent of biodegradation of a chemical tracer are its concentration, the population of microorganisms, presence of other nutrients (including trace metals), dissolved oxygen, $\mathrm{pH}$, temperature salinity and contact time. Another factor which may affect degradation is prior exposure of the microbial population to the tracer or to a similar compound. One must be careful about assumptions made because of similarities between two chemicals or environmental conditions. Differences such as positional isomers, type of halogen or activity of the microbial population may alter the expected results.

The fluorinated aromatic acid tracers have $\mathrm{pK}_{\mathrm{a}}$ values of 4.5 or less, making them anions at normal ground water $\mathrm{pH}$. Ionized compounds are not able to pass through the microbial cell membrane and therefore are not generally utilized. Some bacteria however have acquired or can acquire the ability to transport such compounds as the result of muta- 
tions. It is possible then, during extended tracer tests of 7 to 30 days to lose a small percentage of tracer as the result of bacterial activity. During long tracer tests ( 1 to 1.5 years) all of the tracer may be degraded.

The success of microbial degradation is also related to previous and/or low level chronic exposure to the compound. Chronic sublethal exposure may increase the tolerance of microorganisms and allow for adaptation of the biological community. The microbial population would then more rapidly respond to the presence of that and/or similar compounds, produce the necessary enzymes, and degradation rates would increase. If the compound is chemically analogous to a natural substrate a similar situation may occur with the microbial population readily producing enzymes necessary for degradation. Some chemicals can also act as initiators. These compounds may or may not be degraded in the process, but their presence gives bacteria the ability to degrade compounds of similar chemical structure. Without the presence of the initiator degradation may not take place.

The concentration of the organic compound is also important in determining the rate of biodegradation. Mineralization rates have been shown to be directly proportional to the concentration of the compound over a wide concentration range. The compound may also be in a concentration too low for degradation to occur. The lowest concentration of a compound that will support microbial growth is termed the threshold. At concentrations too low, degradation produces only enough energy for maintenance of the microbial population and growth is absent. Under these conditions degradation rates are retarded due to lack of an actively growing population. At higher concentrations, diffusion provides molecules to the cell surfaces at a rate sufficient to meet the needs of energy of maintenance and cell growth. The microbial population is stimulated and the number of microbes increase with time and degradation rates are enhanced. Thresholds vary with the microbial population involved. If the population is oligotrophic in nature (grows and survives in an environment with a low concentration of available carbon) a lower threshold may exist.

It is not practical to perform field experiments to attempt to estimate the stability of these tracers in the environment. Laboratory stability tests show the mono-fluorinated benzoic acids are not stable for more than 30 days, while some di- and poly-fluorinated benzoates were stable for more than one year (Thompson and Stetzenbach, 1980). Actual field use has also shown that some isomers are more stable than others (Bowman, 1984) and that some are stable for more than one year under saturated (Jones et al, 1992) and unsaturated (McCray et al, 1983) conditions. However, prolonged use of numerous isomers in an area may enhance degradation (Barackman, 1986), presumably by bacteria.

\section{MICROBIAL STUDIES OF FLUOROBENZOIC ACIDS}

All the information related to the microbial degradation of fluorinated benzoic acid is for the mono- and di-fluorobenzoic acid isomers.

A comparison was made of the breakdown of fluorobenzoic acid by Pseudomonas sp. $B 13$, and a similar degradation of benzoic acid. Only ordinary enzymes of the benzoate pathway were detected in 2-fluorobenzoate, 3-fluorobenzoate, and 4-fluorobenzoate-grown cells. The production of these enzymes indicates that the compounds were not treated any 
differently than the non-substituted acid. These compounds were recognized by the bacteria as benzoic acid (Schreiber, 1980). These studies demonstrate that the substitution of a fluorine for a hydrogen atom can create relatively innocuous analogues that proceed along normal metabolic pathways (Goldman, 1967). More recent research using a difluorobenzoic acid yielded similar results. In one study, the biological degradation of both the fluoro-, and chloro-substituted acids was followed using the release of labeled carbon-dioxide as a marker of bacterial degradation activity. In soil containing bacteria known to utilize benzoic acid as a food source, the chlorinated compounds were degraded much more slowly than the fluorinated compounds (Nimmo, 1990). This difference in rate was most likely due to the fact that the much larger chlorine atoms created some stearic hindrance to breakdown, while the smaller fluorine atoms more closely resembled the hydrogens present in the unsubstituted benzoic acid.

Research conducted on the degradation of 2-fluorobenzoic acid by Pseudomonas species isolated from Potomac River mud, showed that over $80 \%$ of the fluorine in the 2fluorobenzoic acid was released as fluoride during the growth of the organism (Goldman, 1967). Similar research using 4-fluorobenzoic acid indicated that nearly $100 \%$ of the organic fluorine was released into the culture medium as fluoride (Harper, 1971), indicating that the fluorobenzoate was utilized by the bacteria the same as benzoic acid.

Similar studies have also been done using Pseudomonas putida bacteria to monitor the degradation of difluoro compounds. Monofluorobenzoates release fluoride when they are degraded by $P$. putida, and although the reactions involved are considerably more complex for difluorobenzoates, about $85 \%$ of the fluorine was mineralized. The degradation potential of $P$. putida was evaluated for six different isomers of difluorobenzoate, and most of the fluorine was eliminated from both positions as $\mathrm{F}$; leaving a catechol and a hydrodiol as major products (Cass, 1987; Milne, 1968).

\section{LITERATURE REVIEW OF TRACER TOXICITY}

No detailed information on the toxicity of the fluorinated benzoic acids was found. Most of the references to toxicology of these compounds were to the mono-fluorinated benzoic acids, which are not being considered as tracers, and some difluorinated benzoates which are being considered. Many references exist for the parent compound, benzoic acid, since it is used extensively as a preservative and antifungal compound. This information, as well as some studies that show similarities in toxicity between fluorinated and nonfluorinated benzoates, are presented as possible evidence of the relatively low toxicity of the fluorinated benzoates.

In the absence of specific toxicology information about fluorinated benzoic acids, some health effects information will be presented for chlorinated benzoic acids even though they are much more toxic compounds. This will permit us to examine a range of potential toxic effects and the dose-response relationships for worst case scenarios. If there is a low risk for the exposure conditions expected from the tracer experiments for the more toxic compounds, then we will have confidence that there will be a low risk from the less toxic compounds. 


\section{BENZOIC ACID}

Benzoic acid is a compound of relatively low toxicity and is used in numerous food (Casarett and Doull, 1980) and pharmaceutical (Tester-Daldrup, 1982) products. It is also found naturally in most berries in concentrations as high as $0.05 \%$ (Merck, 1989). It has an LDLO of $500 \mathrm{mg} / \mathrm{kg}$ (Sigma-Aldrich MSDS) and doses as high as $20 \mathrm{~g}$ have been given to human subjects in toxicological studies (Stewart 1960). A case has been reported of a 67 $\mathrm{kg}$ man ingesting $50 \mathrm{~g}$ doses without ill effects (Gosselin et al. 1984). The lethal dose to $50 \%$ of the test population $\left(\mathrm{LD}_{50}\right)$ in rats has been reported as $1.7 \mathrm{~g} / \mathrm{kg}$ (Merck, 1989). If a "standard adult human" (SAH) weighing $70 \mathrm{~kg}$ (or about 155 pounds) were used, this would amount to a dosage of 119 grams.

Benzoic acid is used as a preservative and an antifungal compound. The acid is used in antifungal preparations, while the sodium or potassium salt, the benzoate ion, is used as a preservative. Benzoic acid is a broad spectrum microbial inhibitor, and is used as a food preservative in a great variety of products ranging from baked goods to jellies to soft drinks. Acid or benzoate concentrations in these products do not exceed one tenth of one per cent or 1,000 ppm (Cassarett and Doull, 1980). The daily acceptable intake is up to $5 \mathrm{mg} / \mathrm{kg}$ of body weight of either the acid (Remington, 1985) or the anion (Casarett and Doull, 1980). Benzoic acid is also used as a preservative in many cosmetics, where concentrations range from 0.1 to $0.5 \%$ (Remington, 1985). The Food and Drug Administration has classified benzoic acid as GRAS (Generally Recognized as Safe) as an antimicrobial (21CFR 181.23) and as a food additive (21CFR 184.1733) with appropriate levels given in 170.3 subparagraph $\mathrm{O}$ subparagraphs 2 and 12 .

The effectiveness of benzoic acid as an antifungal and antimicrobial agent is due to the undissociated form. It is therefore effective at a $\mathrm{pH}$ of 4.0 or lower, but relatively inactive above a pH of 5.0 (Remington, 1985; Krebs, 1983). Benzoic acid is an active ingredient in topical ointments used for the treatment of fungal infections of the skin such as ringworm and athlete's foot. The concentrations of the acid in these ointments can range from $0.5 \%$ to $6.0 \%$ (Martindale, 1989 ).

Benzoic acid is not significantly oxidized in vertebrates. Depending on the species, it conjugated with glycine or glucuronic acid to form hippuric acid or benzoylglucuronic acid which is then excreted in the urine (Neal, 1980). This conjugation with amino acids (Caldwell, 1978) makes the new compound a stronger acid and it is more readily cleared by the kidneys (Jenner, 1980). In humans, benzoic acid taken by mouth is absorbed from the gastro-intestinal tract. It is conjugated with glycine in the liver to form hippuric acid which is rapidly excreted in the urine. Humans can also eliminate benzoic acid as benzoylglucuronic acid (Remington, 1985). In a study, with humans, $96 \%$ of a $20 \mathrm{~g}$ dose was eliminated as hippuric acid within 12 hours (Stewart, 1960). In a study with rabbits, $83 \%$ of the ingested benzoic acid was excreted as the glycine conjugate, $15 \%$ as the glucuronide and only $1 \%$ as the free acid (Caldwell, 1978).

The finding that benzoic acid is excreted as a conjugate is confirmation that benzoic acid can enter cells in the body, presumably by anion transport mechanisms. Thus, benzoic acid and its derivatives have the potential for further metabolism. It also confirms the finding that benzoic acid itself is a poor substrate for the anion secretion pathway in the 
kidney (Ullrich et al., 1988) and must be conjugated to the hippurate before being significantly excreted from the body.

Benzoic acid is readily degraded by microorganisms into $\mathrm{CO}_{2}$. In stability studies, where benzoate solutions are equilibrated with soil, the compound rapidly disappears from solution (Thompson and Stetzenbach, 1980), and when used as a ground water tracer, it was found to readily be degraded by microorganisms (Barackman, 1986).

\section{METABOLIC PRODUCTION OF BENZOIC AND METHYL-BENZOIC ACIDS}

Several chemical compounds are oxidized by the normal metabolic processes to benzoic or toluic acid. By examining their toxicity, additional information can be inferred for the toxicity of benzoic acid. In man, the chief metabolite of inhaled toluene is benzoic acid. Several studies have been done which list the efficiency of this oxidization process at from $62 \%$ (Piotrowski, 1967) to $72 \%$ (Sbrova, 1952) to $80 \%$ (Baseit, third ed.) of the total toluene inhaled. Of the urinary benzoic acid measured, 10 to $20 \%$ is conjugated with glucuronic acid, and the remainder is eliminated in the form of hippurate. The excretion of conjugated benzoic acid is rapid, with an excretion half-time of between 2 and 3 hours. The urinary concentration, which is dependant on initial exposure levels, has been measured as $8650 \mathrm{mg} / \mathrm{L}$ (Baselt, third ed.) with no reported ill effects. At approximately 24 hours after exposure the levels of the metabolite decline to pre-exposure values (Piotrowski, 1977).

Xylene in the human body undergoes oxidation, which leads to the formation of toluic acids. Three isomers are formed, 2-,3-, and 4-toluic acid. Two of these compounds, 3- and 4-toluic acid are conjugated almost exclusively with glycine to form 3- and 4-methyl hippuric acids. The 2-toluic acid undergoes preferential conjugation with glucuronic acid. These processes are highly efficient, and in the case of the 3- and 4-toluic acids, oxidation is on the order of $90 \%$, with all the toluic acid bound to glycine (Piotrowski, 1977).

Toluene and xylene have a very low order of toxicity in humans or in animals. The most common finding is central nervous system (CNS) toxicity after inhalation of high concentrations (Casarett and Doull, 1991), a biological effect shared by all volatile organic solvents. It is not possible for benzoic acid or its congeners to demonstrate this type of toxicity because of their low volatility. In vitro tests with these compounds do not show any potential genotoxic effects.

\section{HALOGENATED BENZOIC ACIDS}

Research done on the relative lethalities of halogenated compounds was conducted using benzoic acid and halogenated benzoic acids. It was shown that the toxicities of benzoic acid and its 4-fluoro substituted derivative are not significantly different. The chloro-, bromo-, and iodo-substituted acids all exhibit similar toxicities, which are greater than those of the unsubstituted or fluoro-substituted acids. This research also demonstrated that a fluorine atom located in the para (4) position on a benzoic acid molecule had no significant effect on its acute lethality in white rats, but a chlorine, bromine, or iodine atom 
in the para position, almost doubled the toxicity of the original benzoic acid compound (Hager and Starkey, 1943). The substitution of a fluorine atom for a hydrogen atom on the compounds evaluated is therefore shown to be the least toxic of all possible halogen substitutions.

Benzoic acids which have a halogen atom in the ortho (2) position on the ring often exhibit herbicidal and/or fungicidal properties (Engesser, 1980). The insecticide 'Dimilin' contains diflubenzuron, which is degraded readily in various agricultural soils and hydro-soils to 2,6-difluorobenzoic acid (Nimmo, 1984). Trichlorobenzoic acid is also used to some extent as an herbicide (Martindale, 1989).

Substantial toxicity data exists for the chlorinated benzoic acids which have found use as herbicides: 2-methoxy-3,6-dichlorobenzoic acid (Dicamba) and 3-amino-2,5dichlorobenzoic acid (Chloramben). Reference doses (RfD) for a lifetime exposure are $3 E$ $2 \mathrm{mg} / \mathrm{kg} /$ day

(2.1 mg/SAH/day for Dicamba (IRIS, 1993) and $1.5 \mathrm{E}-2 \mathrm{mg} / \mathrm{kg} / \mathrm{day}(1.05 \mathrm{mg} / \mathrm{SAH} / \mathrm{day}$ for Chloramben (IRIS, 1993). Unfortunately, these values are used to compute a recommended lifetime dose limit for exposure to these compounds. A more realistic exposure parameter would be a 10-day or longer term Health Advisory (HA) value but neither of these two compounds have such a recommended value. The critical effect used for Dicamba was maternal and fetal toxicity in a rabbit developmental study and a No Observed Adverse Effect Level (NOAEL) of $3 \mathrm{mg} / \mathrm{kg} /$ day $(210 \mathrm{mg} / \mathrm{SAH} /$ day) was used. A 90 day feeding study in the rat showed a NOAEL of $250 \mathrm{mg} / \mathrm{kg} /$ day and a critical effect of a slight decrease in body weight and food consumption. The critical effect for Chloramben was hepatocyte degeneration in an 18 month mouse feeding study and a Lowest Observed Adverse Effect Level was $15 \mathrm{mg} / \mathrm{kg} /$ day $(1050 \mathrm{mg} / \mathrm{SAH} /$ day). No shorter term studies were reported.

\section{FLUORINATED BENZOIC ACIDS}

The fluorinated benzoic acids that are being considered as tracers for the C-well complex fall into two categories. The poly-fluorobenzoates (table 1) have 2,3,4 or 5 fluorine atoms that replace an equivalent number of ring hydrogens. There are sixteen possible isomers of these compounds, fourteen of which are commercially available. (Twelve of these are currently being evaluated, but this report covers all fourteen acids available commercially). The other group is the trifluoromethyl substituted benzoates or trifluorotoluic acids (table 1 ). These compounds substitute a $\mathrm{CF}_{3}$ group for a ring hydrogen. There are only three isomers of trifluorotoluic acid.

The number of compounds that have fluorine substituted rings have been increasing rapidly over the last ten to fifteen years, primarily due to their use as precursors in antibiotics and pesticides. (Schreiber, 1980; O'Reilly, 1990; Domagala, 1991). The metabolic breakdown products from these compounds quite often include some of the acids shown on table 1. This has generated some interest in the biodegradation of these compounds. Very little information exists on the fate of these compounds in man. Some 
work with animals has been done, but most of the research has been with microbial degradation of the fluorobenzoates.

\section{ANIMAL STUDIES}

Studies with rabbits (Caldwell, 1978) exposed to benzoic acid and 2- and 4fluorobenzoic acids show that the fluorinated analogs are excreted as free acids at significantly higher rates than benzoic acid. This is probably due to their somewhat lower pKa values (Benson; Bowman, 1992; Walter, 1982) and their being better substrates for the anion secretion pathway in the kidney (Ullrich et al., 1988). In the study described by Caldwell (1978), $99 \%$ of the benzoic acid dose was recovered; $83 \%$ as the glycine conjugate and $15 \%$ as the glucuronide. The 2-fluorobenzoic acid (o-FBA) and 4-fluorobenzoic acid (p-FBA) were excreted with almost identical ratios: $43 \%$ as the glycine conjugate, $9 \%$ as the glucuronide, and $34 \%$ as the free acid for o-FBA and $35 \%$ for p-FBA. The fate of the other 13 or $14 \%$ is unknown. It could have lost $\mathrm{F}^{-}$, and become benzoic acid as was described for mixed function oxidase enzymes in Pseudomonas bacteria (Goldman, 1967). In another study, rats that were dosed with $100 \mathrm{mg} / \mathrm{kg}$ (intraperitoneal) of 4-trifluoromethylbenzoic acid (p-TFMBA) produced the glucuronide as the main urinary metabolite (Ghauri, 1990).

In a comparative toxicity study by Harger and Starkey using white rats, benzoic acid and para substituted fluoro-, chloro-, bromo- and iodo-benzoic acids, it was shown that the toxicities of benzoic acid and its p-fluoro substituted derivative were not significantly different. In this study solutions of the benzoic acids were injected intravenously and the acute lethality was determined. The $\mathrm{LD}_{50}$ value for benzoic acid was $1.714+/-0.037 \mathrm{~g} / \mathrm{kg}$, while that for p-fluorobenzoic acid was $1.542+/-0.107 \mathrm{~g} / \mathrm{kg}$. The $\mathrm{LD}_{50}$ values for the chloro, bromo-, and iodo-substituted acids were $0.838+/-0.033,0.812+/-0.042$ and $0.786+/-0.037$ $\mathrm{g} / \mathrm{kg}$ respectively. The values for the latter three halogenated acids are essentially the same, but they are twice as toxic as benzoic acid or the fluoro-substituted acid. Generally, acute toxicity determined after intravenous injection shows compounds to be more toxic than would be determined after oral administration because the blood levels reach higher values after injection. Oral $\mathrm{LD}_{50}$ values would be expected to require more compound to cause death than those shown above.

\section{ESTIMATED RISK ASSOCIATED WITH FLUOROBENZOIC ACID EXPOSURE}

A risk analysis is composed of three elements; Exposure to a Hazard results in a Risk. In this project, it has been difficult to construct exposure scenarios. Exposure to the pure tracer and concentrated injection solutions will be minimized by good industrial hygiene practices and by the fact that the proposed tracer chemicals are not volatile or present in water or food consumed by the workers. Any exposure will be from accidents which might result in acute exposure episodes and will occur to trained personnel who are being supervised by knowledgeable persons. 
Likewise, exposure to the tracer chemicals in the groundwater is unlikely because that water will reach the surface at the pumping well. This water will also be handled by the trained personnel. We will assume that this water might be consumed and the potential risk estimated. Also, we will postulate that another well 100 - 200 feet down gradient from the pumping well might be drilled and water used from that well for drinking water purposes.

The hazard has been difficult to determine because health effects of these proposed tracer chemicals have not been studied. The fact that these are uncommon chemicals makes them desirable as tracers because there will be no background levels to interfere with the interpretation of the experimental results. We have attempted to bracket the toxicity of the tracer chemicals by choosing similar compounds which are expected to be less toxic and others which are expected to be more toxic.

\section{Risk from Acute Exposure}

Exposure due to accidents could result in acute effects if the chemical spills on the skin or is accidently ingested. Exposure via skin absorption cannot be estimated for these compounds but their ionic nature makes it unlikely that much will be absorbed. As mentioned earlier, the LDLo of benzoic acid is $500 \mathrm{mg} / \mathrm{kg}$ (35.0 grams per SAH), doses as high as 20 grams have been given to adults without ill effects $(300 \mathrm{mg} / \mathrm{kg})$ and the $\mathrm{LD}_{50}$ in rats is $1.7 \mathrm{~g} / \mathrm{kg}$ (120 grams per $\mathrm{SAH})$. The fluorinated benzoic acid analog was shown to have the same $L_{50}$ as benzoic acid itself after intravenous injection. The daily dose of benzoic acid allowed for adults is $5 \mathrm{mg} / \mathrm{kg}$ ( $350 \mathrm{mg}$ per SAH).

Based on the evidence presented, a single dose of tracer of $5 \mathrm{mg} / \mathrm{kg}$ ( $350 \mathrm{mg}$ per SAH) should present a minimal risk. To derive that the LDLo of $500 \mathrm{mg} / \mathrm{kg}$ was adjusted by a factor of 10 for sensitive human populations and another factor of 10 to adjust for the extrapolation of animals to humans. This is the equivalent of ingesting $70 \mathrm{~mL}$ of the concentrated injection solution. The chances of someone ingesting concentrated tracer solution are extremely small, as all personnel present would be trained in the proper handling and disposal precautions for these compounds, and the injection apparatus is a closed system. However, this evidence seems to indicate a very low toxicity level for these compounds, even at extremely high concentrations.

\section{Risk from Sub-chronic Exposure}

If the pumping well water was used for drinking water, the exposure would not be for an entire lifetime. Exposure to groundwater would occur only as long as the time it would take for the tracer plume to pass the well. Groundwater moves at the rate of 0.14 to $3.4 \mathrm{~m}$ /day (Claassen and Cordes 1975) and it is expected that persons would be exposed for less than 6 months if they drank from a well which had been used for a tracer test. The average tracer concentration would be $1 \mathrm{ppm}$ based on a conservative dilution factor of 5,000 .

If another well was drilled in the pathway of the tracer gradient (approximately 100 200 feet from the pumping well), then another dilution factor of 1,000 should be applied. In this case, groundwater from the well would contain $1 \mathrm{ppb}$ tracer concentration. The 
maximum daily dose for a lifetime exposure to benzoic acid is $5 \mathrm{mg} / \mathrm{kg} /$ day $(350$ $\mathrm{mg} / \mathrm{SAH} /$ day); this equates to a drinking water level of $175 \mathrm{ppm}$ for a water consumption of 2 liters per day. For the chlorinated benzoic acid herbicides, the maximum daily dose for a lifetime exposure is

$2.1 \mathrm{mg} / \mathrm{SAH} /$ day for Dicamba and $1.05 \mathrm{mg} / \mathrm{SAH} /$ day for Chloramben. These equate to drinking water levels of $1 \mathrm{ppm}$ for Dicamba and $0.5 \mathrm{ppm}$ for Chloramben.

The concentration of fluorinated benzoic acids in drinking water that would result in minimal risk lies between $0.5-175 \mathrm{ppm}$ based on the probable toxicity of the compounds. This level has been computed for a lifetime (70 years) exposure to these compounds. To adjust this level for a six month exposure, the upper concentration would be increased by 140 times, resulting in a possible highest range concentration of $24500 \mathrm{ppm}$. It is concluded that the ingestion of water from the pumping well (expected concentration $\approx 1 \mathrm{ppm}$ ) or from another well $100-200$ feet away (expected concentration $\approx 1 \mathrm{ppb}$ ) would not result in a significant risk for any adverse health effects.

\section{CONCLUSIONS}

Several other conclusions can be drawn from the body of literature cited above:

(I) Benzoic and methyl-benzoic acids are widely used in many pharmaceutical preparations and as preservatives in many food products and cosmetics, often at concentrations which exceed those predicted to occur during tracer testing by several orders of magnitude. With such wide spread use and application, especially by the medical industry, any problems associated with exposure to these compounds should be well documented. To date, no serious health problems have been associated with exposure to benzoic and methyl-benzoic acids.

(II) The fluorinated benzoic and methyl-benzoic acids appear to be fairly non-toxic compounds at low to moderate concentrations. Studies have shown that the mono- and difluorinated derivatives of benzoic acid are not significantly more toxic to living systems than the original parent compounds.

(III) Benzoic and methyl-benzoic acids are natural metabolites of toluene and xylene exposure, and even at extremely high concentrations, they have caused no known health problems. Mammalian systems have a well-established pathway using glycine and glucuronic acid conjugation to form hippuric and benzoylglucuronic acids, which are rapidly excreted in the urine. No known health problems have been associated with high concentrations of these acid conjugates.

(IV) Studies of the degradation of fluorinated benzoic acids in soil have shown that defluorination occurs, and nearly all of the organic fluorine is eliminated as fluoride, leaving degradation products which are then broken down further to $\mathrm{CO}_{2}$. 2,6-Difluorobenzoic acid 
has been proven to be stable in a number of tracing experiments, yet it can also be degraded by soil bacteria. This indicates that even highly stable tracers will eventually be degraded.

The above mentioned conclusions, coupled with the fact that potential exposure to these compounds from tracer tests would occur at ultra trace levels, lead to the conclusion that the fluorinated benzoic and methyl-benzoic acids would be relatively safe for use as ground water tracers.

\section{RECOMMENDATIONS}

These conclusions and recommendations were made using a "worst case scenario" exposure assessment of a tracing test conducted in a densely populated area. The application of this point of view to the actual conditions existing in the proposed tracer testing area should be duly noted when any review of this evaluation is performed.

Before any of these compounds are used in populated areas where sub-chronic exposure is likely, further toxicity studies should be done. These studies should be of 90 day duration as a minimum or of 6 months duration. They should involve two animal species with one species being the rat so the results can be compared with similar compounds. They should be done at three dose levels with one level being low enough to insure that a no effect level would be found.

The existing toxicity data for the proposed compounds are so sketchy that there is a low level of confidence in the levels proposed if repeated human exposure is likely. 
Benzoic Acid Reference List:

AHFS Drug Information Formulary, 1992 ed., American Society of Hospital Pharmacies, 1992, pp. 1230, 1263, 1355.

Atlas, R.M.; Bartha, R. Microbial Ecology: Fundamentals and Applications, Second ed., Benjamin/Cummings, Menlo Park, CA, p 370.

Barackman, M.L. Diverging Flow Tracer Tests in Fractured Granite; Equipment Design and Data Collection, Masters Thesis, University of Arizona, Tucson, 1986.

Baselt, R.C.; Cravey, R.H. Disposition of Toxic Drugs in Man, Third ed., Year Book Medical, Chicago, IL, pp 812.

Benson, C.F.; Bowman, R.S. Acid Dissociation Constants of Fluorinated Benzoic Acids Used as Water Tracers, (in submission).

Bowman, R.S. Soil Sci. Soc. Am. J., 1984, 16, 250.

Bowman, R.S.; Gibbens, J.F. Difluorobenzoates as Nonreactive Tracers in Soil and Ground Water, Ground Water, 1992, 30, No. 1, 8.

Caldwell, J. Conjugation Reactions in Drug Biotransformation, Aitio, A. Ed.; Elsevier/North Holland Biomedical, 1978, pp 111.

Casarett and Doull's Toxicology, Second ed.; Doull, J.; Klaassen, C.D.; Amdur, M.O.; Eds.; Macmillan, New York, 1980, Chapter 23 and p 72.

Cass, A.E.G.; Ribbons, D.W.; Rossiter, J.T.; Williams, S.R. Biotransformation of Aromatic Compounds: Monitoring Fluorinated Analogues by NMR, Federation of European Biochemical Societies, 1987, 220, No. 2, 353.

Claassen, H.C.; Condes, E.H.; Two-well Recirculating Tracer Test in Fractured Carbonate Rock, Nevada, Hydrological Sciences Bulletin, 1975, Vol XX, No. 3, 367.

Concepts in Drug Metabolism (part A), Jenner, P.; Testa, B. Ed.; Drugs and the Pharmaceutical Sciences, Marcel Dekker, New York, 1980, pp 53-176, 211.

Domgala, J.M.; Bridges, A.J.; Culbertson, T.P.; Gambino, L.; Hagen, S.E.; Karrick, G.; Porter, K.; Sanchez, J.P.; Sesnie, J.A.; Spense, F.G.; Szotek, D.; Wemple, J. Synthesis and Biological Activity of 5-Amino- and 5-Hydroxyquinolones, and the Overwhelming Influence of the Remote $\mathrm{N}_{1}$-Substituent in Determining the Structure-Activity Relationship, Journal of Medicinal Chemistry, 1991, 34, 1142. 
Engesser, K.-H.; Schmidt, E.; Knackmuss, H.-J. Adaption of Alcaligenes eutrophus B9 and Pseudomonas sp. B13 to 2-Fluorobenzoates as Growth Substrate, Applied and Environmental Microbiology, 1980, January, 68.

Freiser, H.; Fernando, Q. Ionic Equilibria in Analytical Chemistry, John Wiley and Sons, New York, 1963, Chapter 5.

Ghauri, F.Y.K.; Wilson, I.D.; Nicholson, J.K. ${ }^{19} \mathrm{~F}^{-}$and ${ }^{1}$ H-NMR Studies of the Metabolism of 4-Trifluoromethylbenzoic Acid in the Rat, Methodological Surveys in Biochemistry and Analysis, 1990, 20, 321.

Goldman, P.; Milne, G.W.A.; Pignataro, M.T. Fluorine Containing Metabolites Formed From 2-Fluorobenzoic Acid by Pseudomonas Species, Archives of Biochemistry and Biophysics, 1967, 118, 178.

Gosselin, R.E.; Smith, R.P.; Hodge, H.C.; Braddock, J.E.; Eds.; Clinical Toxicology of Commercial Products, Fifth ed.; Williams and Wilkins, Baltimore MD, 1984, p II-203.

Hager, G.P.; Starkey, E.B. Fluorine Substituted Aromatic Acids, Journal of the American Pharmaceutical Association, 1943, 32, 44.

Harper, D.B.; Blakley, E.R. The Metabolism of p-Fluorobenzoic Acid by Pseudomonas sp., Canadian Journal of Microbiology, 1971, 17, 1015.

Jones, T.L.; Kelly, V.A.; Pickens, J.F.; Upton, D.T.; Beauheim, R.L.; Davies, P.B. Interpretation of Results of Tracer Tests Performed in the Culebra Dolomite at the Waste Isolation Plant, Sandia National Laboratories: Albuquerque, NM, 1992, SAND92-1579, UC721.

Kelly, V.A.; Pickens, J.F.; Interpretation of the Convergent-Flow Tracer Tests Conducted in the Culebra Dolomite at the $\mathrm{H}-3$ and $\mathrm{H}-4$ Hydropads, Waste Isolation Pilot Plant (WIPP) Southeastern New Mexico, Sandia National Laboratories: Albuquerque, NM, 1986, SAND867161.

Krebs, H.A.; Wiggins, D.; Stubbs, M. Studies on the Mechanism of the Antifungal Action of Benzoate, Journal of Biochemistry, 1983, 214, 657.

Martindale: The Extra Pharmacopia, 29th ed., Reynolds, J.E.F. Ed.; Pharmaceutical Press, London, 1989, pp 1355-1356, 1430.

Matthews, H.B.; Kato, S. The Metabolism and Disposition of Halogenated Aromatics, Health Effects of Halogenated Aromatic Hydrocarbons, Annals of the New York Academy of Sciences, Nicholson, W.J.; Moore, J.A. Eds.; New York Academy of Sciences, New York, 1979, vol 320, 271. 
McCray, J.G.; Nowatzki, E.A.; Van Zyl, D.; Thompson, G.M.; Armstrong, G.; Low-Level Nuclear Waste Shallow Land Burial Trench Isolation; NUREG/CR-3570; Nuclear Regulatory Commission: Washington D.C., September 1983.

Milne, G.W.A.; Goldman, P.; Holtzman, J.L. The Metabolism of 2-Fluorobenzoic Acid, Journal of Biological Chemistry, 1968, 243, No. 20, 5374.

Moffett, R.B.; Tang, A.H. Skeletal Muscle Stimulants. Substituted Benzoic Acids, Journal of Medicinal Chemistry, 1968, 11, 1020.

Neal, R.A. Metabolism of Toxic Substances (chapter 4),Casarett and Doull's Toxicology, Second ed.; Doull, J.; Klaassen, C.D.; Amdur, M.O.; Eds.; Macmillan, New York, 1980, Chapter 4, pp 56.

Nimmo, W.B.; de Wilde, P.C.; Verloop, A. The Degradation of Diflubenzuron and its Chief Metabolites in Soils. Part I. Hydrolytic Cleavage of Diflubenzuron, Pesticide Science, 1984, 15, 574.

Nimmo, W.B.; Joustra, K.D.; Willems, A.G.M. The Degradation of Diflubenzuron and its Chief Metabolites in Soils. Part III. Fate of 2,6-Difluorobenzoic Acid, Pesticide Science, 1990, 29, 39.

O'Reilly, N.J.; Derwin, W.S.; Fertel, L.B.; Lin, H.C. An Expedient Route to the Quinolone Antibacterial Intermediate, 2,4,5-Trifluorobenzoic Acid, Synlett, 1990, October, 609.

Piotrowski, J. Quantitative Evaluation of Exposure to Toluene in Men, Med. Pracy, 1967, $18,213$.

Piotrowski, J.K. Exposure Tests for Organic Compounds in Industrial Toxicology, U.S. Department of Health, Education and Welfare, Cincinnati, OH, 1977, pp 48.

Prescott, L.F. Side Effects of Drugs Annual 1 (Antipyretic Analgesics), Dukes, M.N.G. Ed.; Excerpta Medica, Amsterdam, 1977, Chapter 8.

Remington's Pharmaceutical Sciences, 17th ed., Gennaro, A.R. Ed.; Mack, Easton PA, 1985, pp B1230, B1263.

Schreiber, A.; Hellwig, M.; Dorn, E.; Reineke, W.; Knackmuss, H.-J. Critical Reactions in Fluorobenzoic Acid Degradation by Pseudomonas sp. B13, Applied and Environmental Microbiology, 1980, January, 58.

Sittig, M. Handbook of Toxic and Hazardous Chemicals and Carcinogens, Second ed.; Noyes, Park Ridge, New Jersey, 1985, p 117. 
Srbova, J.; Teisinger, J. Absortion and Elimination of Toluene in Man, Prac. Lek, 1952, 4, 41.

Tester-Dalderup, C.B.M. Side Effects of Drugs Annual 6 (Antihistamines), Dukes, M.N.G.; Elis, J. Eds.; Excerpta Medica, Amsterdam, 1982, Chapter 16.

The Merck Index, Eleventh ed., Budavari, S. Ed.; Merck, Rahway, NJ 1989, pp. 170, 242.

Thompson, G. Ground Water and Transport Characteristics of Flood Basalts as Determined from Tracer Experiments, Unpublished results, 1982.

Thompson, G.; Stetzenbach, K. Assessment and Advances in Tracer Technolgy, A Topical Report to the Nuclear Regulatory Commission, October 1980.

Walter, G.R. Theoretical and Experimental Determination of Matrix Diffusion and Related Solute Transport Properties of Fractured Tuffs from the Nevada Test Site, Los Alamos National Laboratories: Los Alamos, NM, 1982, LA-9471-MS, UC-70.

Wolff, M.S. Body Clearance of Halogenated Hydrocarbons: Workshop Summary, Health Effects of Halogenated Aromatic Hydrocarbons, Annals of the New York Academy of Sciences, Nicholson, W.J. Moore, J.A. Eds.; New York Academy of Sciences, New York, 1979, vol. 320, 271. 
TABLE 1

\section{LIST OF POTENTIAL TRACERS COMPOUNDS for the C-WELL TESTS}

FLUORINATED BENZOIC ACIDS

2,3-Difluorobenzoic acid 2,4-Difluorobenzoic acid 2,5-Difluorobenzoic acid 2,6-Difluorobenzoic acid 3,4-Difluorobenzoic acid 3,5-Difluorobenzoic acid

Pentafluorobenzoic acid
2,3,4-Trifluorobenzoic acid 2,4,5-Trifluorobenzoic acid 3,4,5-Trifluorobenzoic acid

2,3,4,5-Tetrafluorobenzoic acid 2,3,5,6-Tetrafluorobenzoic acid

ortho-Trifluoromethylbenzoic acid (2-trifluoromethyltoluic acid) meta-Trifluoromethylbenzoic acid (3-trifluoromethyltoluic acid) para-Trifluoromethylbenzoic acid (4-trifluoromethyltoluic acid) 
ORGANIC TRACER TOXICITY REPORT

PERFLUORINATED ALIPHATIC ACIDS

DOE Cooperative Agreement

No. DE-FC 08-90NV10972

Tonya Dombrowski

Klaus J. Stetzenbach PhD.

Harry Reid Center For Environmental Studies

University of Nevada - Las Vegas 
Eighteen fluorinated organic acids (table 1) are presently being studied as possible tracers for the Yucca Mountain Site Characterization Project. These have been divided into two separate categories: fluorinated aromatic compounds (poly-fluorinated benzoic acids), and fluorinated aliphatic compounds. Fluorinated organic compounds were selected as potential tracers because of their long term environmental stability and low reactivity. Low reactivity and low toxicity are characteristics of numerous carbon-fluorine compounds. As a general rule, it can be stated that the greater the number of halogen atoms on a molecule, especially fluorine, the greater its stability. Perfluorinated acids such as pentafluoro-benzoic acid (PFBA) and trifluoroacetic acid (TFAA) are therefore extremely resistant to chemical attack.

A complete report detailing the available literature references of the stability and toxicity of the fluorinated aromatic acids, as well as an exposure risk assessment for all tracing compounds during, and immediately prior to the actual tracing tests has been submitted separately. Please refer to this report for further information on these topics.

\section{ALIPHATIC ACIDS}

In addition to the fluorinated aromatic acids mentioned previously, several fluorinated aliphatic acids are being evaluated for use as ground water tracers. These compounds are: trifluoroacetic acid (TFAA), pentafluoropropionic acid (PFPA) and heptafluorobutyric acid (HFBA).

The parent compounds of these acids occur naturally in, or are present as an additive in many food products. Aliphatic acids such as acetic acid (vinegar) and propionic acid are present in many areas of the food industry. The calcium and sodium salts of propionic acid are used effectively against filamentous fungi in breads, cakes and some cheeses. They are also used to inhibit rope formation in bread dough and milk products. Propionates are formed naturally during the production of Swiss cheese, and act as a natural preservative.

Acetic acid is commonly used as an inhibitor of fungal and bacterial growth to preserve meat products, mayonnaise, and catsup. It is also a main ingredient in many salad dressings, tomato sauces, salsas, and relishes.

Butyric acid occurs naturally in butter as an ester at concentrations of up to 4 or $5 \%$. Magnesium butyrate is used in the manufacture of esters which are used in artificial flavorings (Merck, 1989). 


\section{FLUORINATED ALIPHATIC ACIDS}

For the three perfluorinated aliphatic acids being considered, toxicity data is available for TFAA only. TFAA is the perfluorinated derivative of acetic acid. It is also a metabolite of anesthetics such as halothane and fluoroxene in both animal and human systems.

\section{ANIMAL STUDIES WITH TFAA}

Studies have been done in which TFAA was administered to animals directly, either with an injection into the blood stream or muscle tissue, or in their diet. TFAA at $2.1 \mathrm{mmol}$ concentrations (neutralized $\mathrm{pH}$ ) was diluted to $5 \%$ in water and administered intravenously through the tail vein to 10 rats. Serum concentrations of TFAA after 24 hours were found to be $1.71 \mathrm{mmol}$. The intestinal mucosa was analyzed after 24 hours, and TFAA was found to be present at $1.02 \mathrm{micromol} / \mathrm{gram}$. The intestinal mucosa was selected because it is an area where rapid proliferation and cell growth occurs, and therefore would show the effects of toxicity sooner than less rapidly growing tissues. No toxic effects were observed in any of the rats studied when compared to control groups (Fraser, 1988). TFAA (neutralized to $\mathrm{pH} \mathrm{7.0)}$ at concentrations of up to $25 \mathrm{mg} / \mathrm{kg}$ of body weight, was given to male rats in their water. These rats were followed over a course of 3 days, for morphological changes in testicular tissues (an area of rapid cell proliferation). No biologically significant changes were seen in the tissue samples at the dosage concentrations studied, compared to control groups (Lloyd, 1988).

Studies done on mice and guinea pigs show the $\mathrm{LD}_{50}$ for TFAA to be greater than $2000 \mathrm{mg} / \mathrm{kg}$ (intraperitoneal injection) and $1200 \mathrm{mg} / \mathrm{kg}$ intravenous administration (table 2). This same research reports that the TFAA does not appear to block the Krebs cycle like the more toxic monofluoroacetic acid (Airaksinen, 1968). Research to date seems to confirm that TFAA is less harmful when taken orally than intravenously because, at physiological $\mathrm{pH}$, it is ionized and therefore unlikely to penetrate the cellular membranes (Cohen, 1978; Cohen, 1975). Mice were not killed by intraperitoneal doses of $5,000 \mathrm{mg} / \mathrm{kg}$ of sodium fluoroacetate (Blake, et al., 1969) and no effects were seen after $100 \mathrm{mg} / \mathrm{kg}$ of trifluoroethanol ip daily for 18 days except for a failure to gain weight. Histopathological examination did not show any differences between test and control groups in this 18 day study. Trifluoroethanol is more acutely toxic than TFAA $\left(\mathrm{LD}_{s_{0}}=350 \mathrm{mg} / \mathrm{kg}\right.$ by oral and intraperitoneal routes) and is partially converted to TFAA (about 15\%) using the same enzymes which metabolize ethanol (Blake et al., 1969).

\section{CELLULAR EFFECTS OF TFAA}

Research has also been done on the effect of TFAA on cellular systems. Studies were done using C6-murine glioma cells (in vitro) where the TFAA concentrations in the cell media exceeded that of the rodent research listed above. The results indicated that the TFAA had a relatively mild impact on the C6 cells, and only minimally affected the cell's 
energy metabolism (Ma, 1990). Similar studies performed with the anti-influenza virus showed that the virus activity was not affected by TFAA (Harada, 1991).

\section{METABOLIC TFAA IN ANIMALS}

A large body of work has also been done on TFAA as a metabolite in the body. Such a catabolic pathway is known to occur with exposure to certain anesthetics, the ingestion of trifluoroethanol, and the inhalation of certain chlorofluorocarbons.

The anesthetic compounds studied for eventual breakdown to TFAA include halothane, fluoroxene, and desflurane, and isoflurane. Until recently, Halothane was the most widely used anesthetic in the world with the possible exception of nitrous oxide (Greene, 1968). It has been replaced by isoflurane, desflurane, and fluoroxene. All of these anesthetics are commonly referred to as halothane anesthetics, or halothanes. TFAA is the principle oxidative metabolite of halothane anesthesia, and is very stable. As the metabolism of halothane occurs mainly in the liver, concentrations of TFAA in the blood, renal, and hepatic systems reach their peak from 5 to 16 hours after exposure, and then gradually taper off (Ma, 1990).

Recent research on beagle dogs exposed to halothane anesthetics showed that over $80 \%$ of all fluoride inhaled was excreted in the urine as organic fluoride, of which TFAA was a major constituent. As a major metabolite, TFAA is distributed from the liver into either the blood or the bile. TFAA in the blood serum is filtered by the kidneys, and subsequently concentrated in the urine. TFAA which enters the bile can be secreted into the duodenum and be reabsorbed. The TFAA which was in the bile and subsequently reabsorbed would also enter the liver, and, since it is not metabolized further, would go into the kidneys, and then be excreted in the urine. The major percentage of the TFAA produced through the metabolism of halothane anesthetics is therefore eventually excreted in the urine (Sakai, 1991).

Similar research done on guinea pigs (Nakao, 1991), rats (vanDyke, 1965), and rabbits (Steir, 1964; Steir, 1968) also show the major metabolite of halothane anesthetics to be TFAA. Analyses done on mice and dogs (Blake, 1967) exposed to fluoroxene anesthetics show the major metabolite to be TFAA also.

TFAA has also been studied as a metabolite of 2,2,2-Trifluoroethanol (TFE) in rats. TFE is the initial metabolite of the anesthetic agent fluoroxene, which is then further broken down into TFAA. TFE and trifluoroacetaldehyde (TFAld) were administered to rats intravenously, and the blood serum, and intestinal mucosa were monitored for TFAA. TFAA was detected at approximately 1 hour after initial exposure, and levels continued to increase over the next 16 hours, and remained at their peak concentration for another 8 hours. It was noted that within the metabolic pathway from fluoroxene to TFAA, there is a toxic compound formed. However, specific research on this problem has demonstrated that the toxic moiety is a metabolic intermediate and not TFAA. Thus, the toxicity of TFE is mediated by its ultimate metabolism to TFAA (Fraser, 1988, 1987), which is then excreted to a large degree in the urine (Blake, 1969). Administration of TFAA directly did not produce any evidence of toxicity in the bone marrow or small intestine, even though it was 
shown to be distributed to both the blood serum and small intestine mucosa in similar concentrations to those occurring from administration of TFE and TFAld. This result precludes TFAA or any TFAA conjugate from being the toxic metabolite (Fraser, 1988).

Several of the studies cited above (Fraser, 1988; Lloyd, 1988; Airaksinen, 1968; and Blake, 1987) explored the effects of TFAA as a directly introduced compound, and as a metabolite of TFE. These studies showed that TFAA produced no toxic effects when given in a single dose, and no histological or morphological changes in the analyzed tissues compared with control groups at the concentrations studied (Fraser, 1988; Lloyd, 1988; Airaksinen, 1968). However, there have been no long term toxicity studies performed and the hazard of TFAA cannot be assessed from this data.

\section{METABOLIC TFAA IN HUMANS}

Studies of exposure to halothane anesthetics in humans has shown TFAA to be the major metabolic product (Rehder, 1967; Blake, 1972; Cohen, 1975; Witte, 1977). The fact that operating room personnel are continuously exposed to low level concentrations of halothane anesthetics, coupled with the much higher doses received by patients undergoing anesthesia, suggest that the halothane anesthetics are relatively safe at the dosages applied. However, in a small number of cases $(1: 10,000)$ a condition called "halothane hepatitis" occurs and $50 \%$ of those people die from the disease (Goodman and Gilman, 1990). This response may be related to an immune reaction after a protein adduct has formed with some component of the halothane. Possibilities for this component could be the trifluoroacetaldehyde or the trifluoroacetic acid metabolites formed from halothane. In several preliminary studies, most notably Fraser, 1988; TFAA was shown to have no toxic effects in this metabolic pathway. An oxidative intermediate on the pathway between TFAA and trifluoroacetaldehyde is suspected as the toxic moiety; because this intermediate precedes TFAA in the metabolic process, TFAA is not expected to have a toxic capacity in this hepatic condition according to this research.

Initial research using the body fluids of people exposed to halothane anesthesia show a sharp increase in blood and urine TFAA concentrations over a period of about 8 hours, then a gradual increase over 48 hours, where maximum concentration levels are attained at roughly 48 hours after exposure, and then decline slowly over 11 to 14 days. Maximum concentration values ranged from 130 to $300 \mathrm{ug} / \mathrm{ml}$ of TFAA in urine, and 75 to $150 \mathrm{ug} / \mathrm{ml}$ of TFAA in blood serum samples (Witte, 1977). Earlier research shows this same pattern of excretion, with roughly the same concentrations and time frame (Rehder, 1967).

The biliary excretion of TFAA in infants was studied using two babies, one 5 months old, and one two months old. Anesthesia was administered prior to performing a surgical procedure; bile, urine, and faeces samples were collected continuously for five days following surgery and TFAA concentrations were measured. The concentrations monitored in these samples showed that all of the TFAA was excreted in the bile and urine. No TFAA was measured in the faecal samples, which shows an enterohepatic circulation for this metabolite (Wark, 1991). 
Desflurane and isoflurane anesthetics also produce TFAA as the primary metabolite. The major difference between these anesthetics and Halothane is the extent to which they are metabolized. Halothane is metabolized to between 20 and $30 \%$, while desflurane and isofluorane are metabolized to between 1 and $2 \%$, with the bulk of the administered anesthetic being exhaled unmetabolized.

Thirteen volunteers, used as a healthy metabolism control group, and twenty six patients, that did not necessarily have healthy metabolism, were exposed to desflurane anesthesia. The blood serum showed TFAA concentrations around $40 \mathrm{mg} / \mathrm{L}$, and a urinary excretion rate of about 20 ug per hour TFAA, 24 hours after exposure. The levels of TFAA in the blood serum and urine, after similar exposure to isoflurane are approximately 10 times higher than the desflurane results above (Sutton, 1991). It is apparent from the research cited that TFAA is a metabolic byproduct of these anesthetics that is excreted normally by the body without any further metabolism. Metabolism of these anesthetics leads to significant concentrations of TFAA in the body but little is known about the toxic effects of the anesthetics in humans.

The structural similarity of certain chlorofluorocarbons to halothane anesthetics lead to a study of the metabolic products of HCFC-124, a refrigerant substitute. Results indicate that in human subjects, the major metabolites are TFAA and $\mathrm{F}^{-}$(Olsen, 1991). This same pathway is thought to extend to other, structurally similar refrigerant compounds currently in use.

\section{CHLORINATED ACETIC ACIDS}

The chlorinated analog of TFAA, trichloroacetic acid, has been studied because it is a metabolite of two carcinogenic solvents, trichloroethylene and tetrachloroethylene. Although it might be expected to be more extensively metabolized than the fluoroacetic acids, it provides a reference for comparison.

Trichloroacetate was administered to $\mathrm{B} 6 \mathrm{C} 3 \mathrm{~F} 1$ mice at concentrations of 1 or $2 \mathrm{~g} / \mathrm{L}$ for up to 52 weeks (Bull et al., 1990). Trichloroacetate induced hepatoproliferative lesions in male mice, including hepatocellular nodules, adenomas and hepatocellular carcinomas within 12 months. The induction of these lesions was linear with respect to dose. Trichloroacetate did not cause cellular necrosis but rather appeared to increase lipid peroxidation. This suggests that the production of radicals may cause its effects.

\section{ESTIMATED RISK ASSOCIATED WITH TRIFLUOROACETIC ACID EXPOSURE}

\section{Risk from Acute Exposure}

Exposure due to accidents could result in acute effects if the chemical spills on the skin or is accidently ingested. Exposure via skin absorption cannot be estimated for these compounds but their ionic nature makes it unlikely that much will be absorbed. Oral doses 
of trifluoroacetic acid have an $\mathrm{LD}_{50}$ in excess of $5,000 \mathrm{mg} / \mathrm{kg}$ in mice and have $\mathrm{LD}_{50}$ 's in the range of $1,000-2,000 \mathrm{mg} / \mathrm{kg}$ after systemic administration.

Based on the evidence presented, a single dose of tracer of $5 \mathrm{mg} / \mathrm{kg}(350$ $\mathrm{mg} /$ Standard Adult Human (SAH)) should present a minimal risk. To derive that the $\mathrm{LD}_{50}$ of $5,000 \mathrm{mg} / \mathrm{kg}$ was adjusted by a factor of 10 for sensitive human populations, a factor of 10 to adjust for the extrapolation of animals to humans and another factor of 10 to adjust for using an $\mathrm{LD}_{5_{0}}$ value instead of an $L D L_{0}$. This is the equivalent of ingesting $70 \mathrm{~mL}$ of the concentrated injection solution. The chances of someone ingesting concentrated tracer solution are extremely small, as all personnel present would be trained in the proper handling and disposal precautions for these compounds, and the injection apparatus is a closed system. However, this evidence seems to indicate a very low toxicity level for these compounds, even at extremely high concentrations.

\section{Risk from Sub-chronic Exposure}

If the pumping well water was used for drinking water, the exposure would not be for an entire lifetime. Exposure to groundwater would occur only as long as the time it would take for the tracer plume to pass the well. Groundwater moves at the rate of 0.14 to $3.4 \mathrm{~m} /$ day (Claassen and Cordes 1975) and it is expected that persons would be exposed for less than 6 months if they drank from a well which had been used for a tracer test. The average tracer concentration would be $1 \mathrm{ppm}$ based on a conservative dilution factor of 5,000 . If another well was drilled in the pathway of the tracer gradient (approximately 100 - 200 feet from the pumping well), then another dilution factor of 1,000 should be applied. In this case, groundwater from the well would contain $1 \mathrm{ppb}$ tracer concentration. The closest value to a repeated dose toxicity study was the $100 \mathrm{mg} / \mathrm{kg} /$ day $(700 \mathrm{mg} / \mathrm{SAH} /$ day $)$ of trifluoroethanol that was administered to mice for 18 days. That was partially converted (20\%) to TFAA; this would be equivalent to $20 \mathrm{mg} / \mathrm{kg} /$ day $(140 \mathrm{mg} / \mathrm{SAH} /$ day $)$ of TFAA. The daily dose for 6 months would have to be adjusted by a factor of 10,000 to provide any confidence in the number. This would result in a $0.070 \mathrm{ppm}$ drinking water level.

The experience in humans with halothane was extensive and involved people who were not healthy but anesthesia is not given on a repeated dose basis. Operating room personnel would be exposed on a daily basis but the dose would be low. The possibility of an immune response is of concern with the halothane data.

The use of the trichloroacetic acid data involves a carcinogenic endpoint. If other compounds were available for use, as is the case with tracer molecules, they would be chosen instead of one which has the potential to be carcinogenic.

\section{CONCLUSIONS}

Several conclusions can be drawn from the body of research cited above:

(I) TFAA appears to be a fairly non-toxic compound at low to moderate concentrations, with an $\mathrm{LD}_{50}$ several orders of magnitude above the concentrations expected at the downstream end of the tracing tests. 
(II) Ionized compounds do not penetrate cell membranes easily, and at groundwater $\mathrm{pH}$ values, TFAA will be highly ionized. This will make the compound more water soluble, and therefore more easily excreted by mammalian systems. If TFAA in the water was ingested by people or animals down gradient of the test injection area, it would most likely be excreted in the urine, rather than being metabolized.

(III) Significant concentrations of TFAA are present in patients who have undergone halothane anesthesia, or have been exposed to a number of fluorinated hydrocarbon compounds. There was a low incidence of toxicity $(1: 10,000)$ for halothane hepatitis but there was a 50\% likelihood of death in those who developed the illness. On that basis, halothane is no longer generally used as an anesthetic agent.

(IV) Parallels can be drawn from the TFAA to the PFPA and HFBA because of the similar structural properties and ionic character of these compounds.

(V) Trifluoroacetic acid and its congeners may not be the compounds of choice for organic tracer use in cases where sub-chronic or chronic exposure may occur unless further toxicity work is done. Its use in situations which may result in single dose exposures is acceptable.

\section{RECOMMENDATIONS}

These conclusions and recommendations were made using a "worst case scenario" exposure assessment of a tracing test conducted in a densely populated area. The application of this point of view to the actual conditions existing in the proposed tracer testing area should be duly noted when any review of this evaluation is performed.

Before any of these compounds are used in populated areas where sub-chronic exposure is likely, further toxicity studies should be done. These studies should be of 90 day duration as a minimum or of 6 months duration. They should involve two animal species with one species being the rat so the results can be compared with similar compounds. They should be done at three dose levels with one level being low enough to insure that a no effect level would be found.

The existing toxicity data for the proposed compounds are so sketchy that there is a low level of confidence in the levels proposed if repeated human exposure is likely. 


\section{TOXICITY REPORT}

TFAA Reference List:

Airaksinen, M.; Mammisto, T. $\mathbf{L D}_{50}$ and Some Metabolic Effects of Trifluoroethanol and Trifluoroacetic Acid in Mice and Guinea Pigs, Annales Medicinae Experimenatalis et Biologiae Fenniae, 1968, 46, 242.

Blake, D.; Rosman, R.; Cascorbi, H.; Krantz, J. Biotransformation of Fluroxene Metabolism in Mice and Dogs In-vivo, Biochemical Pharmacology, 1967, 16, 1237.

Blake, D.; Cascorbi, H.; Rozman, R.; Meyer, F. Animal Toxicity of 2,2,2-Trifluoroethanol Toxicology and Applied Pharmacology, 1969, 15, 83.

Blake, D.; Barry, J.; Cascorbi, H. Qualitative Analysis of Halothane Metabolites in Man Anesthesiology, 1972, 36, 255.

Claassen, H.C.; Condes, E.H.; Two-well Recirculating Tracer Test in Fractured Carbonate Rock, Nevada, Hydrological Sciences Bulletin, 1975, Vol XX, No. 3, 367.

Cohen, E.; Trudell, J.; Edwards, H.; Watson, E. Urinary Metabolites of Halothane in Man, Anesthesiology, 1975, 43, 392.

Cohen, E. Toxicity of Inhalation Anesthetic Agents, British Journal of Anesthesia, 1978, 50, 665.

Fraser, J.M.; Kaminsky, L.S. Metabolism of 2,2,2-Trifluoroethanol and Its Relationship to Toxicity Toxicology and Applied Pharmacology, 1987, 89, 202.

Fraser, J.M.; Kaminsky, L.S. 2,2,2-Trifluoroethanol Intestinal and Bone Marrow Toxicity: The role of It's Metabolism to 2,2,2-Trifluoroacetaldehyde and Trifluoroacetic Acid, Toxicology and Applied Pharmacology, 1988, 94, 84.

Greene, N. Halothane and Metabolism, Clinical Anesthesia - Halothane, FA Davis, Philadelphia, 1968, p 182.

Lloyd, S.C.; Blackburn, D.M.; Foster, P.M.D. Trifluoroethanol and It's Oxidative Metabolites: Comparison of In-vivo Effects in Rat Testis, Toxicology and Applied Pharmacology, 1988, 92, 390.

Ma, T.G.; Ling, Y.H.; McClure, G.D.; Tseng, M.T.; Effects of TFAA, A Halothane Metabolite, on C-6 Glioma Cells, Journal of Toxicology and Environmental Health, 1990, 31, 147. 
Rehder, K.; Forbes, J.; Alter, H.; Hessler, O.; Steir, A. Halothane Biotransformation in Man - A Quantitative Study, Anesthesiology, 1967, 28, 711.

Steir, A. The Biotransformation of Halothane, Anesthesiology, 1968, 29, 388.

Steir, A. TFAA as a Metabolite of Halothane, Biochemical Pharmacology, 1964, 13, 1544.

vanDyke, P.; Chenoweth, M. Metabolism of Volatile Anesthetics, Anesthesiology, 1965, 26, 348.

Witte, L.; Nau, H.; Fuhrop, J.; Doenicke, A.; Grote, B. Quantitative Analysis of TFAA in Body Fluids of Patients Treated With Halothane, Journal of Chromatography - Biomedical Applications, 1977, 143, 329. 


\section{TABLE 1}

\section{LIST OF POTENTIAL TRACERS COMPOUNDS for the C-WELL TESTS}

\section{FLUORINATED BENZOIC ACIDS}

2,3-Difluorobenzoic acid 2,4-Difluorobenzoic acid 2,5-Difluorobenzoic acid 2,6-Difluorobenzoic acid 3,4-Difluorobenzoic acid 3,5-Difluorobenzoic acid

Pentafluorobenzoic acid
2,3,4-Trifluorobenzoic acid 2,4,5-Trifluorobenzoic acid 3,4,5-Trifluorobenzoic acid

2,3,4,5-Tetrafluorobenzoic acid 2,3,5,6-Tetrafluorobenzoic acid

ortho-Trifluoromethylbenzoic acid (2-trifluoromethyltoluic acid) meta-Trifluoromethylbenzoic acid (3-trifluoromethyltoluic acid) para-Trifluoromethylbenzoic acid (4-trifluoromethyltoluic acid)

\section{PERFLUORINATED ALIPHATIC ACIDS}

Trifluoroacetic acid

Pentafluoropropionic acid

Heptafluorobutyric acid 
APPENDIX C 
C-Well lodide method variability analysis.

This analysis is performed on duplicate data. We divided data into following three catagory:

Lab duplicates

Field duplicates

Lab \& field duplicates

On the basis of concentration, each of the above category is divided into following 3 group

\begin{tabular}{|c|c|c|c|c|c|c|}
\hline - & 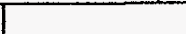 & 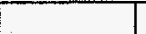 & +2 & 20 & & \\
\hline Group1 & $0-33 \mathrm{ppb}$ & & & & & \\
\hline Group1 & $34-66 \mathrm{ppb}$ & & & & & \\
\hline Group1 & $67-100 \mathrm{ppb}$ & & & & & \\
\hline \multirow{2}{*}{\multicolumn{7}{|c|}{ Analysis results }} \\
\hline & & & & & & \\
\hline & & & & & & \\
\hline \multicolumn{7}{|c|}{ Lab duplicates: } \\
\hline & & & & & & \\
\hline & \# of samples & \multicolumn{2}{|c|}{ \# occurrences } & & \# of samples & \# occurren \\
\hline Group 1 & 12 & 30 & & Group 2 & 18 & 38 \\
\hline & variance $=$ & 4.953876 & & & variance $=$ & 0.599266 \\
\hline & $S D=$ & 2.22573 & & & $S D=$ & 0.774123 \\
\hline & & & & & & \\
\hline
\end{tabular}

Conclusion: Data suggest that there is no significance difference in the duplicate values.

Field duplicates:

\begin{tabular}{|c|c|c|c|c|c|c|}
\hline \\
\hline & & & & & & \\
\hline \multirow[b]{2}{*}{ Group 1} & \# of samples & \multicolumn{2}{|c|}{ \# occurrences } & & \# of samples & \# occurrenc \\
\hline & none & none & & Group 2 & 40 & 86 \\
\hline & & & & & variance $=$ & 1.176028 \\
\hline & & & & & $S D=$ & 1.084448 \\
\hline & & & & & & \\
\hline
\end{tabular}
.

Conclusion: Data suggest that there is no significance difference in the duplicate values.

\begin{tabular}{|l|l|l|l|}
\hline & & & \\
\hline \multicolumn{2}{|l|}{ Lab-field duplicates: } & & \\
\hline & & & \\
\hline & & & \\
\hline Group1 & sig. prob $=$ & 0.488679 & $>.05$ \\
\hline Group2 & sig. prob $=$ & 0.31547 & $>.05$ \\
\hline Group3 & sig. prob $=$ & 0.743794 & $>.05$ \\
\hline
\end{tabular}

Conclusion: Data suggest that there is no significance difference in the duplicate values.

C-well lodide injectate concentrations

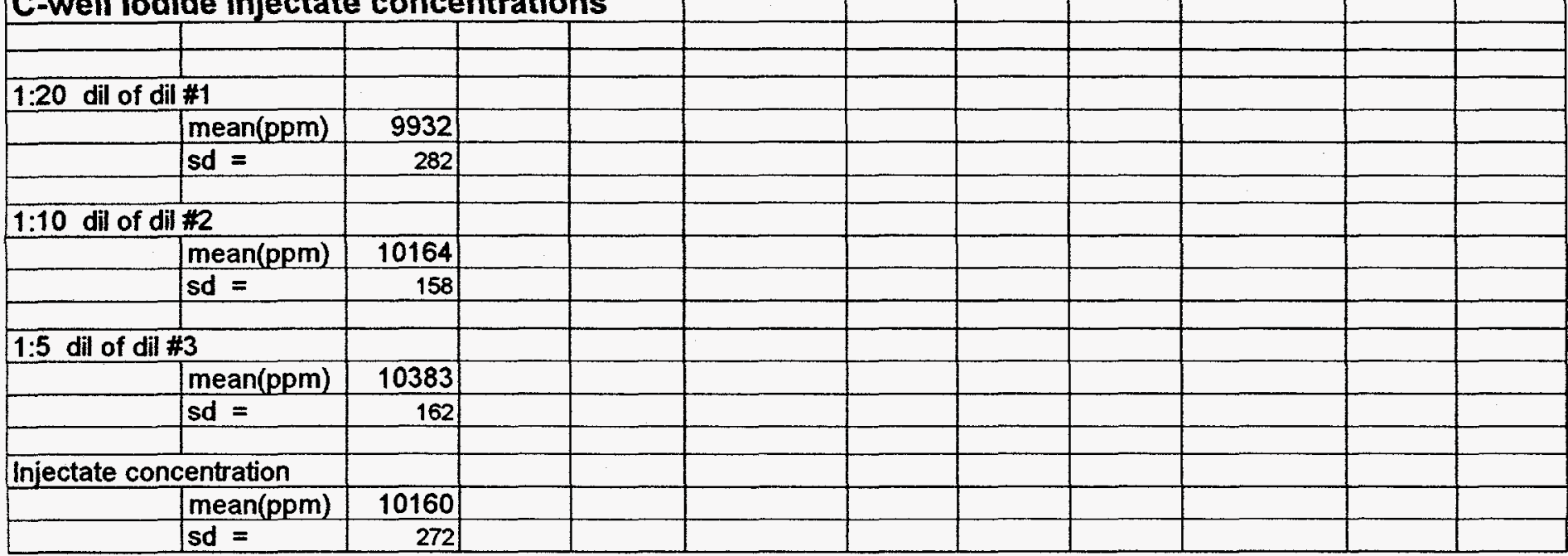




\begin{tabular}{|c|c|c|c|c|c|c|}
\hline Date & Time of Sample & Sample\# & Dup. code & Conc (ppb) & Analysis date & place \\
\hline 2/18/96 & 10:04:37 AM & 893 & & 0.00 & $02 / 18$ & analyzed in field \\
\hline $2 / 18 / 96$ & $10: 14: 49 \mathrm{AM}$ & 894 & & 2.65 & $02 / 18$ & analyzed in field \\
\hline $2 / 18 / 96$ & $10: 25: 02 \mathrm{AM}$ & 895 & & 0.00 & $02 / 18$ & analyzed in field \\
\hline $2 / 18 / 96$ & $10: 35: 23 \mathrm{AM}$ & 896 & & 2.28 & $02 / 18$ & analyzed in field \\
\hline $2 / 18 / 96$ & $10: 45: 36 \mathrm{AM}$ & 897 & & 0.00 & $02 / 18$ & analyzed in field \\
\hline $2 / 18 / 96$ & $10: 55: 49 \mathrm{AM}$ & 898 & & 2.53 & $02 / 18$ & analyzed in field \\
\hline $2 / 18 / 96$ & 11:06:02 AM & 899 & & 4.40 & $02 / 18$ & analyzed in field \\
\hline $2 / 18 / 96$ & $11: 16: 15 \mathrm{AM}$ & 900 & & 2.55 & $02 / 18$ & analyzed in field \\
\hline $2 / 18 / 96$ & 11:26:29 AM & 901 & & 3.05 & $02 / 18$ & analyzed in field \\
\hline $2 / 18 / 96$ & $11: 36: 41 \mathrm{AM}$ & 902 & U/F-D* & 3.32 & & \\
\hline $2 / 18 / 96$ & $11: 46: 54 \mathrm{AM}$ & 903 & & 3.33 & $02 / 18$ & analyzed in field \\
\hline $2 / 18 / 96$ & 11:57:07 AM & 904 & UF $=D^{*}$ & 2.79 & & \\
\hline $2 / 18 / 96$ & 12:07:28 PM & 905 & & 2.93 & $02 / 18$ & analyzed in field \\
\hline $2 / 18 / 96$ & $12: 17: 40 \mathrm{PM}$ & 906 & LF-D* & 2.74 & & \\
\hline $2 / 18 / 96$ & 12:27:53 PM & 907 & & 3.04 & $02 / 18$ & analyzed in field \\
\hline $2 / 18 / 96$ & 12:38:06 PM & 908 & UF-D* & 3.37 & & \\
\hline $2 / 18 / 96$ & 12:48:18 PM & 909 & & 0.00 & $02 / 18$ & analyzed in field \\
\hline $2 / 18 / 96$ & 12:58:31 PM & 910 & UF-D* & 0.00 & & \\
\hline $2 / 18 / 96$ & 1:08:44 PM & 911 & & 3.63 & $02 / 18$ & analyzed in field \\
\hline $2 / 18 / 96$ & 1:18:56 PM & 912 & LF-D & 4.13 & & \\
\hline $2 / 18 / 96$ & 1:29:09 PM & 913 & & 2.31 & $02 / 18$ & analyzed in field \\
\hline $2 / 18 / 96$ & 1:39:30 PM & 914 & UF-D* & 3.03 & & \\
\hline $2 / 18 / 96$ & 1:50:09 PM & 915 & & 3.58 & $02 / 18$ & analyzed in field \\
\hline $2 / 18 / 96$ & $2: 00: 28 \mathrm{PM}$ & 916 & UF-D* & 4.15 & & \\
\hline $2 / 18 / 96$ & $2: 10: 42 \mathrm{PM}$ & 917 & & 3.39 & $02 / 18$ & analyzed in field \\
\hline $2 / 18 / 96$ & 2:20:55 PM & 918 & UF-D & 4.05 & & \\
\hline $2 / 18 / 96$ & $2: 31: 09$ PM & 919 & & 0.00 & $02 / 18$ & analyzed in field \\
\hline $2 / 18 / 96$ & $2: 41: 22 \mathrm{PM}$ & 920 & $U F=D^{*}$ & 4.69 & & \\
\hline $2 / 18 / 96$ & 2:51:35 PM & 921 & LF-D* & 2.97 & & \\
\hline $2 / 18 / 96$ & 3:01:48 PM & 922 & & 6.12 & $03 / 20$ & analyzed in lab \\
\hline $2 / 18 / 96$ & $3: 12: 10 \mathrm{PM}$ & 923 & & & & \\
\hline $2 / 18 / 96$ & $3: 22: 22 \mathrm{PM}$ & 924 & & 6.06 & $03 / 20$ & anabyzed in lab \\
\hline $2 / 18 / 96$ & 3:32:35 PM & 925 & & & & \\
\hline $2 / 18 / 96$ & $3: 42: 48 \mathrm{PM}$ & 926 & & 4.99 & $03 / 20$ & analyzed in lab \\
\hline $2 / 18 / 96$ & 3:53:00 PM & 927 & & & & \\
\hline $2 / 18 / 96$ & 4:03:13 PM & 928 & & 5.98 & $03 / 20$ & analyzed in lab \\
\hline $2 / 18 / 96$ & 4:13:26 PM & 929 & & & & \\
\hline $2 / 18 / 96$ & 4:23:39 PM & 930 & & & & \\
\hline $2 / 18 / 96$ & 4:33:52 PM & 931 & & & & \\
\hline $2 / 18 / 96$ & 4:44:13 PM & 932 & & & & \\
\hline $2 / 18 / 96$ & 4:54:26 PM & 933 & & 6.46 & $03 / 20$ & analyzed in lab \\
\hline $2 / 18 / 96$ & 5:04:44 PM & 934 & & & & \\
\hline $2 / 18 / 96$ & 5:14:57 PM & 935 & & & & \\
\hline $2 / 18 / 96$ & 5:25:10 PM & 936 & & & & \\
\hline $2 / 18 / 96$ & 5:35:23 PM & 937 & & & & \\
\hline $2 / 18 / 96$ & 5:45:36 PM & 938 & & & & \\
\hline $2 / 18 / 96$ & 5:55:49 PM & 939 & & 5.62 & $03 / 20$ & analyzed in lab \\
\hline $2 / 18 / 96$ & 6:06:01 PM & 940 & & & & \\
\hline $2 / 18 / 96$ & 6:16:22 PM & 941 & & & & \\
\hline $2 / 18 / 96$ & 6:26:34 PM & 942 & & 6.39 & $03 / 20$ & anahyzed in lab \\
\hline $2 / 18 / 96$ & 6:36:47 PM & 943 & & & & \\
\hline $2 / 18 / 96$ & 6:47:00 PM & 944 & & & & \\
\hline $2 / 18 / 96$ & 6:57:14 PM & 945 & & 6.79 & $03 / 20$ & analyzed in lab \\
\hline $2 / 18 / 96$ & 7:07:29 PM & 946 & & & & \\
\hline $2 / 18 / 96$ & 7:17:41 PM & 947 & & & & \\
\hline $2 / 18 / 96$ & 7:27:54 PM & 948 & & 7.18 & $03 / 20$ & analyzed in lab \\
\hline $2 / 18 / 96$ & 7:38:07 PM & 949 & & & & \\
\hline $2 / 18 / 96$ & 7:48:28 PM & 950 & & 4.33 & $02 / 19$ & analyzed in field \\
\hline $2 / 18 / 96$ & 7:58:41 PM & 951 & & 7.57 & $03 / 20$ & analyzed in lab \\
\hline $2 / 18 / 96$ & $8: 08: 55$ PM & 952 & & & & \\
\hline $2 / 18 / 96$ & $8: 19: 09 \mathrm{PM}$ & 953 & & & & \\
\hline $2 / 18 / 96$ & $8: 29: 21$ PM & 954 & & 7.39 & $03 / 20$ & analyzed in lab \\
\hline $2 / 18 / 96$ & $8: 39: 33$ PM & 955 & & & & \\
\hline $2 / 18 / 96$ & 8:49:47 PM & 956 & & & & \\
\hline $2 / 18 / 96$ & $9: 00: 01 \mathrm{PM}$ & 957 & & 7.85 & $03 / 20$ & analyzed in lab \\
\hline $2 / 18 / 96$ & $9: 10: 13$ PM & 958 & & & & \\
\hline 2/18/96 & $9: 20: 34$ PM & 959 & & & & \\
\hline $2 / 18 / 96$ & $9: 31: 17 \mathrm{PM}$ & 960 & & & & \\
\hline 2/18/96 & $9: 41: 33 \mathrm{PM}$ & 961 & & 5.71 & $02 / 19$ & analyzed in field \\
\hline $2 / 18 / 96$ & $9: 51: 46 \mathrm{PM}$ & 962 & & & & \\
\hline
\end{tabular}




\begin{tabular}{|c|c|c|c|c|c|c|}
\hline Date & Time of Sample & Sample \# & Dup. code & Conc (ppb) & Analysis date & place \\
\hline $2 / 18 / 96$ & $10: 01: 59 \mathrm{PM}$ & 963 & & 7.55 & $03 / 20$ & analyzed in lab \\
\hline $2 / 18 / 96$ & 10:12:11 PM & 964 & & & & \\
\hline $2 / 18 / 96$ & 10:22:23 PM & 965 & & & & \\
\hline $2 / 18196$ & $10: 32: 37 \mathrm{PM}$ & 966 & & & & \\
\hline $2 / 18 / 96$ & $10: 42: 50 \mathrm{PM}$ & 967 & & & & \\
\hline $2 / 18 / 96$ & 10:53:14 PM & 968 & & & & \\
\hline $2 / 18 / 96$ & 11:03:27 PM & 969 & & 7.95 & $03 / 20$ & analyzed in lab \\
\hline $2 / 18 / 96$ & 11:13:40 PM & 970 & & & & \\
\hline $2 / 18 / 96$ & $11: 23: 53 \mathrm{PM}$ & 971 & & & & \\
\hline $2 / 18 / 96$ & $11: 34: 06 \mathrm{PM}$ & 972 & & & & \\
\hline $2 / 18 / 96$ & $11: 44: 19 \mathrm{PM}$ & 973 & & & & \\
\hline $2 / 18 / 96$ & 11:54:32 PM & 974 & & & & \\
\hline $2 / 19 / 96$ & $12: 04: 45 \mathrm{AM}$ & 975 & & 7.52 & $03 / 20$ & analyzed in lab \\
\hline $2 / 19 / 96$ & 12:14:58 AM & 976 & & & & \\
\hline $2 / 19 / 96$ & 12:25:19 AM & 977 & & 6.27 & $02 / 19$ & analyzed in field \\
\hline $2 / 19 / 96$ & $12: 35: 32 \mathrm{AM}$ & 978 & & & & \\
\hline $2 / 19 / 96$ & $12: 45: 45$ AM & 979 & & & & \\
\hline $2 / 19 / 96$ & 12:55:58 AM & 980 & & & & \\
\hline $2 / 19 / 96$ & 1:06:10 AM & 981 & & 7.29 & $03 / 20$ & analyzed in lab \\
\hline $2 / 19 / 96$ & $1: 16: 23 \mathrm{AM}$ & 982 & & & & \\
\hline $2 / 19 / 96$ & $1: 26: 36 \mathrm{AM}$ & 983 & & & & \\
\hline $2 / 19 / 96$ & 1:36:49 AM & 984 & & & & \\
\hline $2 / 19 / 96$ & 1:47:02 AM & 985 & & & & \\
\hline $2 / 19 / 96$ & 1:57:23 AM & 986 & & & & \\
\hline $2 / 19 / 96$ & $2: 07: 36 \mathrm{AM}$ & 987 & & 7.90 & $03 / 20$ & analyzed in lab \\
\hline $2 / 19 / 96$ & $2: 17: 49 \mathrm{AM}$ & 988 & & & & \\
\hline $2 / 19 / 96$ & $2: 28: 02 \mathrm{AM}$ & 989 & & & & \\
\hline $2 / 19 / 96$ & $2: 38: 15$ AM & 990 & & 8.59 & $03 / 20$ & analyzed in lab \\
\hline $2 / 19 / 96$ & $2: 48: 29 \mathrm{AM}$ & 991 & & & & \\
\hline $2 / 19 / 96$ & $2: 58: 42$ AM & 992 & & & & \\
\hline $2 / 19 / 96$ & $3: 08: 55 \mathrm{AM}$ & 993 & & 8.52 & $03 / 20$ & analyzed in lab \\
\hline 2/19/96 & 3:19:09 AM & 994 & & & & \\
\hline $2119 / 96$ & $3: 29: 29 \mathrm{AM}$ & 995 & & & & \\
\hline $2 / 19 / 96$ & 3:40:08 AM & 996 & & 8.63 & $03 / 20$ & analyzed in lab \\
\hline $2 / 19 / 96$ & $3: 50: 29 \mathrm{AM}$ & 997 & & & & \\
\hline $2 / 19 / 96$ & 4:00:41 AM & 998 & & & & \\
\hline $2 / 19 / 96$ & 4:10:54 AM & 999 & & 8.10 & $03 / 20$ & analyzed in lab \\
\hline $2 / 19 / 96$ & 4:21:07 AM & 1000 & & & & \\
\hline $2 / 19 / 96$ & $4: 31: 20 \mathrm{AM}$ & 1001 & & & & \\
\hline $2 / 19 / 96$ & 4:41:33 AM & 1002 & & 9.11 & $03 / 20$ & analyzed in lab \\
\hline $2 / 19 / 96$ & 4:51:49 AM & 1003 & & & & \\
\hline $2 / 19 / 96$ & 5:02:11 AM & 1004 & & & & \\
\hline $2 / 19 / 96$ & $5: 12: 24 \mathrm{AM}$ & 1005 & LD & 9.03 & & \\
\hline $2 / 19 / 96$ & $5: 22: 38$ AM & 1006 & & & & \\
\hline $2 / 19 / 96$ & $5: 32: 51 \mathrm{AM}$ & 1007 & & & & \\
\hline $2 / 19 / 96$ & $5: 43: 04 \mathrm{AM}$ & 1008 & & $8.7 \pi$ & $03 / 20$ & analyzed in lab \\
\hline $2 / 19 / 96$ & 5:53:17 AM & 1009 & & & & \\
\hline $2 / 19 / 96$ & 6:03:31 AM & 1010 & & & & \\
\hline $2 / 19 / 96$ & $6: 13: 46 \mathrm{AM}$ & 1011 & & 9.42 & $03 / 20$ & analyzed in lab \\
\hline $2 / 19 / 96$ & $6: 23: 59 \mathrm{AM}$ & 1012 & & & & \\
\hline $2 / 19 / 96$ & $6: 34: 22 \mathrm{AM}$ & 1013 & & & & \\
\hline $2 / 19 / 96$ & $6: 44: 35 \mathrm{AM}$ & 1014 & & 8.79 & $03 / 20$ & analyzed in lab \\
\hline $2 / 19 / 96$ & $6: 54: 48 \mathrm{AM}$ & 1015 & & & & \\
\hline $2 / 19 / 96$ & 7:05:01 AM & 1016 & & 8.85 & $03 / 20$ & analyzed in lab \\
\hline $2 / 19 / 96$ & $7: 15: 14 \mathrm{AM}$ & 1017 & & & & \\
\hline $2 / 19 / 96$ & $7: 25: 27 \mathrm{AM}$ & 1018 & & & & \\
\hline $2 / 19 / 96$ & $7: 35: 40 \mathrm{AM}$ & 1019 & & & & \\
\hline $2 / 19 / 96$ & $7: 45: 53 \mathrm{AM}$ & 1020 & & & & \\
\hline $2 / 19 / 96$ & $7: 56: 06 \mathrm{AM}$ & 1021 & & & & \\
\hline $2 / 19 / 96$ & $8: 06: 27 \mathrm{AM}$ & 1022 & & 9.60 & $03 / 20$ & analyzed in lab \\
\hline $2 / 19 / 96$ & $8: 16: 39 \mathrm{AM}$ & 1023 & & 6.44 & $02 / 19$ & analyzed in field \\
\hline $2 / 19 / 96$ & $8: 26: 52 \mathrm{AM}$ & 1024 & & 8.12 & $02 / 19$ & analyzed in field \\
\hline $2 / 19 / 96$ & 8:37:04 AM & 1025 & & 8.01 & $02 / 19$ & analyzed in field \\
\hline $2 / 19 / 96$ & $8: 47: 16 \mathrm{AM}$ & 1026 & & 6.46 & $02 / 19$ & analyzed in field \\
\hline $2 / 19 / 96$ & $8: 57.29 \mathrm{AM}$ & 1027 & & 6.95 & $02 / 19$ & analyzed in field \\
\hline $2 / 19 / 96$ & 9:07:42 AM & 1028 & & 7.07 & $02 / 19$ & analyzed in field \\
\hline $2 / 19 / 96$ & $9: 17: 55 \mathrm{AM}$ & 1029 & & 8.52 & $02 / 19$ & analyzed in field \\
\hline $2 / 19 / 96$ & $9: 28: 08 \mathrm{AM}$ & 1030 & & 7.34 & $02 / 19$ & analyzed in field \\
\hline $2 / 19 / 96$ & $9: 38: 29 \mathrm{AM}$ & 1031 & & 9.16 & $02 / 19$ & analyzed in field \\
\hline $2 / 19 / 96$ & $9: 48: 42$ AM & 1032 & UF-D" & 6.84 & & \\
\hline
\end{tabular}




\begin{tabular}{|c|c|c|c|c|c|c|}
\hline Date & Time of Sample & Sample \# & Dup. code & Conc (ppb) & Analysis date & place \\
\hline $2 / 19 / 96$ & $9: 58: 55 \mathrm{AM}$ & 1033 & & 7.84 & $02 / 19$ & analyzed in field \\
\hline $2 / 19 / 96$ & 10:09:09 AM & 1034 & & 7.54 & $02 / 19$ & analyzed in field \\
\hline $2 / 19 / 96$ & $10: 19: 22$ AM & 1035 & & 8.47 & $02 / 19$ & analyzed in field \\
\hline $2 / 19 / 96$ & $10: 29: 34$ AM & 1036 & & 9.46 & $02 / 19$ & analyzed in field \\
\hline $2 / 19 / 96$ & $10: 39: 47$ AM & 1037 & & 8.36 & $02 / 19$ & analyzed in field \\
\hline $2 / 19 / 96$ & $10: 50: 00 \mathrm{AM}$ & 1038 & & 8.46 & $02 / 19$ & analyzed in field \\
\hline $2 / 19 / 96$ & $11: 00: 13 \mathrm{AM}$ & 1039 & & 8.25 & $02 / 19$ & analyzed in field \\
\hline $2 / 19 / 96$ & $11: 10: 45 \mathrm{AM}$ & 1040 & & 7.93 & $02 / 19$ & analyzed in field \\
\hline $2 / 19 / 96$ & $11: 21: 29 \mathrm{AM}$ & 1041 & & 8.14 & $02 / 19$ & analyzed in field \\
\hline $2 / 19 / 96$ & $11: 31: 43 \mathrm{AM}$ & 1042 & & 8.04 & $02 / 19$ & analyzed in field \\
\hline $2 / 19 / 96$ & $11: 41: 58 \mathrm{AM}$ & 1043 & & 8.56 & $02 / 19$ & analyzed in field \\
\hline $2 / 19 / 96$ & $11: 52: 12 \mathrm{AM}$ & 1044 & & 8.12 & $02 / 19$ & analyzed in field \\
\hline $2 / 19 / 96$ & 12:02:25 PM & 1045 & & 8.16 & $02 / 19$ & analyzed in field \\
\hline $2 / 19 / 96$ & 12:12:38 PM & 1046 & & 8.41 & $02 / 19$ & analyzed in field \\
\hline $2 / 19 / 96$ & 12:22:51 PM & 1047 & & 8.75 & $02 / 19$ & analyzed in field \\
\hline $2 / 19 / 96$ & $12: 33: 03 \mathrm{PM}$ & 1048 & LF-D & 8.79 & & \\
\hline $2 / 19 / 96$ & 12:43:24 PM & 1049 & & 8.64 & $02 / 19$ & analyzed in field \\
\hline $2 / 19 / 96$ & 12:53:38 PM & 1050 & UF-D & 9.33 & & \\
\hline $2 / 19 / 96$ & $1: 03: 50 \mathrm{PM}$ & 1051 & & 9.02 & $02 / 19$ & analyzed in field \\
\hline $2 / 19 / 96$ & 1:14:03 PM & 1052 & L/F-D & 9.8 & & \\
\hline $2 / 19 / 96$ & 1:24:17 PM & 1053 & & & & \\
\hline $2 / 19 / 96$ & 1:34:30 PM & 1054 & & 10.85 & $03 / 20$ & analyzed in lab \\
\hline $2 / 19 / 96$ & 1:44:43 PM & 1055 & & & & \\
\hline $2 / 19 / 96$ & $1: 54: 56 \mathrm{PM}$ & 1056 & LD & 10.93 & & \\
\hline $2 / 19 / 96$ & $2: 05: 09 \mathrm{PM}$ & 1057 & & & & \\
\hline $2 / 19 / 96$ & 2:15:29 PM & 1058 & & 11.4 & $03 / 19$ & analyzed in lab \\
\hline $2 / 19 / 96$ & $2: 25: 42 \mathrm{PM}$ & 1059 & & & & \\
\hline $2 / 19 / 96$ & $2: 35: 55 \mathrm{PM}$ & 1060 & & 11.05 & $03 / 20$ & analyzed in lab \\
\hline $2 / 19 / 96$ & 2:46:08 PM & 1061 & & 9.06 & $02 / 19$ & analyzed in field \\
\hline $2 / 19 / 96$ & $2: 56: 21 \mathrm{PM}$ & 1062 & & 12.07 & $03 / 20$ & analyzed in lab \\
\hline $2 / 19 / 96$ & $3: 06: 35 \mathrm{PM}$ & 1063 & & & & \\
\hline $2 / 19 / 96$ & 3:16:48 PM & 1064 & & 11.7 & $03 / 19$ & anabrzed in lab \\
\hline $2 / 19 / 96$ & 3:27:01 PM & 1065 & & & & \\
\hline $219 / 96$ & 3:37:14 PM & 1066 & & 11.32 & $03 / 20$ & analyzed in lab \\
\hline $2 / 19 / 96$ & 3:47:35 PM & 1067 & & & & \\
\hline $2 / 19 / 96$ & 3.57:48 PM & 1068 & & 11.35 & $03 / 20$ & analyzed in lab \\
\hline $2 / 19 / 96$ & 4:08:01 PM & 1069 & & & & \\
\hline $2 / 19 / 96$ & $4: 18: 14 \mathrm{PM}$ & 1070 & & 12.3 & $03 / 19$ & analyzed in lab \\
\hline $2 / 19 / 96$ & 4:28:27 PM & 1071 & & & & \\
\hline $2 / 19 / 96$ & 4:38:39 PM & 1072 & & 11.51 & $03 / 20$ & analyzed in lab \\
\hline $2 / 19 / 96$ & 4:48:52 PM & 1073 & & & & \\
\hline $2 / 19 / 96$ & 4:59:05 PM & 1074 & LF $-D^{*}$ & 12.37 & $03 / 20$ & analyzed in lab \\
\hline $2 / 19 / 96$ & 5:09:18 PM & 1075 & & & & \\
\hline $219 / 96$ & 5:19:39 PM & 1076 & & 11.5 & $03 / 19$ & analyzed in lab \\
\hline $2 / 19 / 96$ & $5: 29: 52 \mathrm{PM}$ & 1077 & & & & \\
\hline $2 / 19 / 96$ & 5:40:04 PM & 1078 & & 11.97 & $03 / 20$ & analyzed in lab \\
\hline $2 / 19 / 96$ & 5:50:17 PM & 1079 & & & & \\
\hline $2 / 19 / 96$ & $6: 00: 29 \mathrm{PM}$ & 1080 & & 12.57 & $03 / 20$ & analyzed in lab \\
\hline $2 / 19 / 96$ & $6: 10: 42 \mathrm{PM}$ & 1081 & & 10.06 & 02220 & analyzed in field \\
\hline $2 / 19 / 96$ & $6: 20: 55 \mathrm{PM}$ & 1082 & & 12.0 & $03 / 19$ & analyzed in lab \\
\hline $2 / 19 / 96$ & $6: 31: 08 \mathrm{PM}$ & 1083 & & & & \\
\hline $2 / 19 / 96$ & $6: 41: 22 \mathrm{PM}$ & 1084 & & 13.26 & $03 / 20$ & analyzed in lab \\
\hline $2 / 19 / 96$ & $6: 51: 43 \mathrm{PM}$ & 1085 & & & & \\
\hline $2 / 19 / 96$ & $7: 01: 56 \mathrm{PM}$ & 1086 & & 13.21 & $03 / 20$ & analyzed in lab \\
\hline $2 / 19 / 96$ & 7:12:09PM & 1087 & & & & \\
\hline $2 / 19 / 96$ & $7: 22: 22 \mathrm{PM}$ & 1088 & & 13.5 & $03 / 19$ & analyzed in lab \\
\hline $2 / 19 / 96$ & 7:32:35 PM & 1089 & & 9.97 & 02220 & analyzed in field \\
\hline $2 / 19 / 96$ & 7:42:48 PM & 1090 & & 13.06 & $03 / 20$ & analyzed in lab \\
\hline $2 / 19 / 96$ & 7:53:01 PM & 1091 & & & & \\
\hline $2 / 19 / 96$ & 8:03:14 PM & 1092 & LD & 12.45 & & \\
\hline $2 / 19 / 96$ & $8: 14: 02 \mathrm{PM}$ & 1093 & & & & \\
\hline $2 / 19 / 96$ & $8: 24: 48 \mathrm{PM}$ & 1094 & & 13.7 & $03 / 19$ & analyzed in lab \\
\hline $2 / 19 / 96$ & $8: 35: 00 \mathrm{PM}$ & 1095 & & & & \\
\hline $2 / 19 / 96$ & 8:45:13 PM & 1096 & L/F-D* & 14.09 & $03 / 20$ & analyzed in lab \\
\hline $2 / 19 / 96$ & $8: 55: 26 \mathrm{PM}$ & 1097 & & & & \\
\hline $2 / 19 / 96$ & 9:05:39 PM & 1098 & & 13.86 & $03 / 20$ & analyzed in lab \\
\hline $2 / 19 / 96$ & 9:15:52 PM & 1099 & & & & \\
\hline $2 / 19 / 96$ & $9: 26: 05 \mathrm{PM}$ & 1100 & & 13.4 & $03 / 19$ & analyzed in lab \\
\hline $2 / 19 / 96$ & 9:36:18 PM & 1101 & & & & \\
\hline $2 / 19 / 96$ & $9: 46: 30 \mathrm{PM}$ & 1102 & & 12.99 & $03 / 20$ & analyzed in lab \\
\hline
\end{tabular}




\begin{tabular}{|c|c|c|c|c|c|c|}
\hline Date & Time of Sample & Sample \# & Dup. code & Conc (ppb) & Analysis date & place \\
\hline $2 / 19 / 96$ & $9: 56: 52 \mathrm{PM}$ & 1103 & & 11.22 & $02 / 20$ & analyzed in field \\
\hline $2 / 19 / 96$ & $10: 07: 05 \mathrm{PM}$ & 1104 & & 13.64 & $03 / 20$ & analyzed in lab \\
\hline $2 / 19 / 96$ & $10: 17: 17 \mathrm{PM}$ & 1105 & & & & \\
\hline $2 / 19 / 96$ & $10: 27: 30 \mathrm{PM}$ & 1106 & & 14.0 & $03 / 19$ & analyzed in lab \\
\hline $2 / 19 / 96$ & $10: 37: 44 \mathrm{PM}$ & 1107 & & & & \\
\hline $2 / 19 / 96$ & $10: 47: 56 \mathrm{PM}$ & 1108 & & 13.60 & $03 / 20$ & analyzed in lab \\
\hline $2 / 19 / 96$ & $10: 58: 09 \mathrm{PM}$ & 1109 & & & & \\
\hline $2 / 19 / 96$ & $11: 08: 22 \mathrm{PM}$ & 1110 & & 14.38 & $03 / 20$ & analyzed in lab \\
\hline $2 / 19 / 96$ & $11: 18: 35 \mathrm{PM}$ & 1111 & & & & \\
\hline $2 / 19 / 96$ & $11: 28: 56 \mathrm{PM}$ & 1112 & & 13.7 & $03 / 19$ & analyzed in lab \\
\hline $2 / 19 / 96$ & $11: 39: 39 \mathrm{PM}$ & 1113 & & & & \\
\hline $2 / 19 / 96$ & $11: 49: 52 \mathrm{PM}$ & 1114 & & 16.02 & $03 / 20$ & analyzed in lab \\
\hline $2 / 20 / 96$ & $12: 00: 05 \mathrm{AM}$ & 1115 & & & & \\
\hline $2 / 20 / 96$ & $12: 10: 18 \mathrm{AM}$ & 1116 & LF $-D^{*}$ & 13.59 & $03 / 20$ & analyzed in lab \\
\hline $2 / 20 / 96$ & $12: 20: 31 \mathrm{AM}$ & 1117 & & 12.29 & 02220 & analyzed in field \\
\hline $2 / 20 / 96$ & $12: 30: 45 \mathrm{AM}$ & 1118 & & 15.1 & $03 / 19$ & analyzed in lab \\
\hline $2 / 20 / 96$ & $12: 40: 58 \mathrm{AM}$ & 1119 & & & & \\
\hline $2 / 20 / 96$ & $12: 51: 16 \mathrm{AM}$ & 1120 & & 14.96 & $03 / 20$ & analyzed in lab \\
\hline $2 / 20 / 96$ & $1: 01: 38$ AM & 1121 & & & & \\
\hline $2 / 20 / 96$ & $1: 11: 51 \mathrm{AM}$ & 1122 & & 13.55 & $03 / 20$ & analyzed in lab \\
\hline $2 / 20 / 96$ & $1: 22: 04 \mathrm{AM}$ & 1123 & & & & \\
\hline $2 / 20 / 96$ & $1: 32: 25 \mathrm{AM}$ & 1124 & & 15.5 & $03 / 19$ & analyzed in lab \\
\hline $2 / 20 / 96$ & $1: 42: 38 \mathrm{AM}$ & 1125 & & & & \\
\hline $2 / 20 / 96$ & 1:52:51 AM & 1126 & & 14.44 & $03 / 20$ & analyzed in lab \\
\hline $2 / 20 / 96$ & 2:03:04 AM & 1127 & & & & \\
\hline $2 / 20 / 96$ & $2: 13: 17 \mathrm{AM}$ & 1128 & & 15.44 & $03 / 20$ & analyzed in lab \\
\hline $2 / 20 / 96$ & $2: 23: 29$ AM & 1129 & & & & \\
\hline $2 / 20 / 96$ & 2:33:49 AM & 1130 & LD & 14.9 & & \\
\hline $2 / 20 / 96$ & $2: 44: 02 \mathrm{AM}$ & 1131 & & 13.30 & 02220 & analyzed in field \\
\hline $2 / 20 / 96$ & $2: 54: 15$ AM & 1132 & & 14.6 & $03 / 19$ & analyzed in lab \\
\hline $2 / 20 / 96$ & $3: 04: 28$ AM & 1133 & & & & \\
\hline $2 / 20 / 96$ & $3: 14: 41$ AM & 1134 & & 14.7 & $03 / 19$ & analyzed in lab \\
\hline $2 / 20 / 96$ & $3: 24: 54$ AM & 1135 & & & & \\
\hline $2 / 20 / 96$ & $3: 35: 06$ AM & 1136 & & 16.2 & $03 / 19$ & analyzed in lab \\
\hline $2 / 20 / 96$ & $3: 45: 19$ AM & 1137 & & & & \\
\hline $2 / 20 / 96$ & $3.55: 32$ AM & 1138 & & 15.2 & $03 / 19$ & analyzed in lab \\
\hline $2 / 20 / 96$ & 4:05:53 AM & 1139 & & 13.87 & $02 / 20$ & analyzed in field \\
\hline $2 / 20 / 96$ & 4:16:31 AM & 1140 & & 15.8 & $03 / 19$ & analyzed in lab \\
\hline $2 / 20 / 96$ & $4: 27: 11 \mathrm{AM}$ & 1141 & & & & \\
\hline $2 / 20 / 96$ & 4:37:24 AM & 1142 & & 14.4 & $03 / 19$ & anatyzed in lab \\
\hline $2 / 20 / 96$ & 4:47:37 AM & 1143 & & & & \\
\hline $2 / 20196$ & 4:57:50 AM & 1144 & & 16.2 & $03 / 19$ & analyzed in $\mathrm{lab}$ \\
\hline $2 / 20 / 96$ & $5: 08: 03$ AM & 1145 & & & & \\
\hline $2 / 20 / 96$ & 5:18:16 AM & 1146 & & & & \\
\hline $2 / 20 / 96$ & 5:28:29 AM & 1147 & & 15.9 & $03 / 19$ & analyzed in lab \\
\hline $2 / 20 / 96$ & 5:38:50 AM & 1148 & & & & \\
\hline $2 / 20 / 96$ & 5:49:03 AM & 1149 & & & & \\
\hline $2 / 20 / 96$ & $5: 59: 16 \mathrm{AM}$ & 1150 & & 15.0 & $03 / 19$ & analyzed in lab \\
\hline $2 / 20 / 96$ & $6: 09: 29 \mathrm{AM}$ & 1151 & & & & \\
\hline $2 / 20 / 96$ & $6: 19: 42 \mathrm{AM}$ & 1152 & & 15.07 & 02220 & analyzed in field \\
\hline $2 / 20 / 96$ & $6: 30: 03$ AM & 1153 & & 16.3 & $03 / 19$ & analyzed in lab \\
\hline $2 / 20196$ & $6: 40: 17 \mathrm{AM}$ & 1154 & & 14.76 & 0220 & analyzed in field \\
\hline $2 / 20 / 96$ & $6: 50: 30 \mathrm{AM}$ & 1155 & & & & \\
\hline $2 / 20 / 96$ & $7: 00: 42 \mathrm{AM}$ & 1156 & & 17.2 & $03 / 19$ & analyzed in lab \\
\hline $2 / 20 / 96$ & $7: 11: 04 \mathrm{AM}$ & 1157 & & & & \\
\hline $2 / 20 / 96$ & $7: 21: 17 \mathrm{AM}$ & 1158 & & & & \\
\hline $2 / 20 / 96$ & $7: 31: 30 \mathrm{AM}$ & 1159 & & 15.7 & $03 / 19$ & analyzed in lab \\
\hline $2 / 20 / 96$ & $7: 41: 43 \mathrm{AM}$ & 1160 & & & & \\
\hline $2 / 20 / 96$ & $7: 51: 56 \mathrm{AM}$ & 1161 & & & & \\
\hline $2 / 20 / 96$ & $8: 02: 08 \mathrm{AM}$ & 1162 & & 16.9 & $03 / 19$ & analyzed in lab \\
\hline $2 / 20 / 96$ & $8: 12: 21 \mathrm{AM}$ & 1163 & & & & \\
\hline $2 / 20 / 96$ & $8: 22: 34 \mathrm{AM}$ & 1164 & & & & \\
\hline $2 / 20 / 96$ & $8: 32: 47 \mathrm{AM}$ & 1165 & & 16.1 & $03 / 19$ & analyzed in lab \\
\hline $2 / 20 / 96$ & $8: 43: 08$ AM & 1166 & & 15.11 & $02 / 20$ & analyzed in field \\
\hline $2 / 20 / 96$ & $8: 53.21 \mathrm{AM}$ & 1167 & & & & \\
\hline $2 / 20 / 96$ & $9: 03: 34 \mathrm{AM}$ & 1168 & & 15.20 & $02 / 20$ & analyzed in field \\
\hline $2 / 20 / 96$ & $9: 13: 47 \mathrm{AM}$ & 1169 & & & & \\
\hline $2 / 20 / 96$ & $9: 24: 26 \mathrm{AM}$ & 1170 & & 15.55 & $02 / 20$ & analyzed in field \\
\hline $2 / 20 / 96$ & $9: 34: 47$ AM & 1171 & & 15.8 & $03 / 19$ & anahzed in lab \\
\hline $2 / 20 / 96$ & $9: 45: 00 \mathrm{AM}$ & 1172 & & 15.23 & $02 / 20$ & analyzed in field \\
\hline
\end{tabular}




\begin{tabular}{|c|c|c|c|c|c|c|}
\hline Date & Time of Sample & Sample \# & Dup. code & Conc (ppb) & Analysis date & place \\
\hline $2 / 20 / 96$ & 9:55:14 AM & 1173 & & & & \\
\hline $2 / 20 / 96$ & $10: 05: 30 \mathrm{AM}$ & 1174 & & 16.36 & $02 / 20$ & analyzed in field \\
\hline $2 / 20 / 96$ & 10:15:52 AM & 1175 & & 15.85 & $02 / 20$ & analyzed in field \\
\hline $2 / 20 / 96$ & $10: 26: 05 \mathrm{AM}$ & 1176 & & 16.82 & $02 / 20$ & analyzed in field \\
\hline $2 / 20 / 96$ & 10:36:18 AM & 1177 & & 16.22 & $02 / 20$ & analyzed in field \\
\hline $2 / 20 / 96$ & $10: 46: 31 \mathrm{AM}$ & 1178 & & 16.37 & $02 / 20$ & analyzed in field \\
\hline $2 / 20 / 96$ & 10:56:43 AM & 1179 & & 15.82 & $02 / 20$ & analyzed in field \\
\hline $2 / 20 / 96$ & $11: 06: 56 \mathrm{AM}$ & 1180 & & 16.11 & $02 / 20$ & analyzed in field \\
\hline $2 / 20 / 96$ & 11:17:09 AM & 1181 & & 16.71 & $02 / 20$ & analyzed in field \\
\hline $2 / 20 / 96$ & $11: 27: 22 \mathrm{AM}$ & 1182 & & 16.62 & $02 / 20$ & analyzed in field \\
\hline $2 / 20 / 96$ & 11:37:51 AM & 1183 & & 16.69 & $02 / 20$ & analyzed in field \\
\hline $2 / 20 / 96$ & 11:48:11 AM & 1184 & & 15.65 & $02 / 20$ & analyzed in field \\
\hline $2 / 20 / 96$ & $11: 58: 24 \mathrm{AM}$ & 1185 & & 17.07 & $02 / 20$ & analyzed in field \\
\hline $2 / 20 / 96$ & 12:08:37 PM & 1186 & & 17.11 & $02 / 20$ & analyzed in field \\
\hline $2 / 20 / 96$ & $12: 19: 15 \mathrm{PM}$ & 1187 & & 17.79 & $02 / 20$ & analyzed in field \\
\hline $2 / 20 / 96$ & $12: 29: 56 \mathrm{PM}$ & 1188 & & 16.29 & $02 / 20$ & analyzed in field \\
\hline $2 / 20 / 96$ & $12: 40: 09 \mathrm{PM}$ & 1189 & & 16.45 & $02 / 20$ & analyzed in field \\
\hline $2 / 20 / 96$ & 12:50:22 PM & 1190 & & 17.29 & $02 / 20$ & analyzed in field \\
\hline $2 / 20 / 96$ & 1:00:35 PM & 1191 & & 16.91 & $02 / 20$ & analyzed in field \\
\hline $2 / 20 / 96$ & 1:10:48 PM & 1192 & & 17.05 & $02 / 20$ & analyzed in field \\
\hline $2 / 20 / 96$ & 1:21:07 PM & 1193 & & 17.32 & $02 / 20$ & analyzed in field \\
\hline $2 / 20 / 96$ & 1:31:18 PM & 1194 & & 16.58 & $02 / 20$ & analyzed in field \\
\hline $2 / 20 / 96$ & $1: 41: 56 \mathrm{PM}$ & 1195 & & 17.09 & $02 / 20$ & analyzed in field \\
\hline $2 / 20 / 96$ & 1:52:06 PM & 1196 & & 18.12 & $02 / 20$ & analyzed in field \\
\hline $2 / 20 / 96$ & $2: 02: 18 \mathrm{PM}$ & 1197 & & 17.92 & $02 / 20$ & analyzed in field \\
\hline $2 / 20 / 96$ & 2:12:31 PM & 1198 & & 16.99 & $02 / 20$ & analyzed in field \\
\hline $2 / 20 / 96$ & 2:27:44 PM & 1199 & & 17.55 & $02 / 20$ & analyzed in field \\
\hline $2 / 20 / 96$ & $2: 42: 56 \mathrm{PM}$ & 1200 & & 17.53 & $02 / 20$ & analyzed in field \\
\hline $2 / 20 / 96$ & 2:58:10 PM & 1201 & & 17.82 & $02 / 20$ & analyzed in field \\
\hline $2 / 20 / 96$ & 3:13:35 PM & 1202 & & 17.56 & $02 / 20$ & analyzed in field \\
\hline $2 / 20 / 96$ & $3: 28: 47 \mathrm{PM}$ & 1203 & & 15.90 & $02 / 20$ & analyzed in field \\
\hline $2 / 20 / 96$ & 3:44:01 PM & 1204 & & 17.17 & $02 / 20$ & analyzed in field \\
\hline $2 / 20 / 96$ & 3:59:19 PM & 1205 & & 18.37 & $02 / 20$ & analyzed in field \\
\hline $2 / 20 / 96$ & 4:14:37 PM & 1206 & & 18.47 & $02 / 20$ & analyzed in field \\
\hline $2 / 20 / 96$ & 4:29:58 PM & 1207 & & 17.63 & $02 / 20$ & analyzed in field \\
\hline $2 / 20 / 96$ & 4:45:23 PM & 1208 & & 18.10 & $02 / 20$ & analyzed in field \\
\hline $2 / 20 / 96$ & 5:00:41 PM & 1209 & & & & \\
\hline $2 / 20 / 96$ & 5:16:01 PM & 1210 & & 19.9 & $03 / 19$ & analyzed in lab \\
\hline $2 / 20 / 96$ & 5:31:27 PM & 1211 & & & & \\
\hline $2 / 20 / 96$ & 5:47:02 PM & 1212 & & 20.0 & $03 / 19$ & analyzed in lab \\
\hline $2 / 20 / 96$ & 6:02:21 PM & 1213 & & & & \\
\hline $2 / 20 / 96$ & $6: 17: 38 \mathrm{PM}$ & 1214 & LD & 19.6 & & \\
\hline $2 / 20 / 96$ & 6:32:55 PM & 1215 & & & & \\
\hline $2 / 20 / 96$ & 6:48:14 PM & 1216 & & 19.4 & $03 / 19$ & analyzed in lab \\
\hline $2 / 20 / 96$ & 7:03:32 PM & 1217 & & & & \\
\hline $2 / 20 / 96$ & 7:18:50 PM & 1218 & & 20.4 & $03 / 19$ & analyzed in lab \\
\hline $2 / 20 / 96$ & 7:34:12 PM & 1219 & & & & \\
\hline $2 / 20 / 96$ & 7:49:44 PM & 1220 & & 19.3 & $03 / 19$ & analyzed in lab \\
\hline $2 / 20 / 96$ & 8:04:58 PM & 1221 & & & & \\
\hline $2 / 20 / 96$ & 8:20:11 PM & 1222 & & 20.4 & $03 / 19$ & analyzed in lab \\
\hline $2 / 20 / 96$ & 8:35:32 PM & 1223 & & & & \\
\hline $2 / 20 / 96$ & 8:45:59 PM & 1224 & & 19.7 & $03 / 19$ & analyzed in lab \\
\hline $2 / 20 / 96$ & 8:56:12 PM & 1225 & & & & \\
\hline $2 / 20 / 96$ & 9:06:25 PM & 1226 & UD & 20.9 & & \\
\hline $2 / 20 / 96$ & 9:16:37 PM & 1227 & & & & \\
\hline $2 / 20 / 96$ & $9: 26: 50 \mathrm{PM}$ & 1228 & & 17.4 & $03 / 18$ & anahyzed in lab \\
\hline $2 / 20 / 96$ & $9: 37: 12$ PM & 1229 & & & & \\
\hline $2 / 20 / 96$ & 9:47:24 PM & 1230 & & 17.9 & $03 / 18$ & analyzed in lab \\
\hline $2 / 20 / 96$ & 9:57:37 PM & 1231 & & & & \\
\hline $2 / 20 / 96$ & $10: 07: 50 \mathrm{PM}$ & 1232 & & 17.8 & $03 / 18$ & analyzed in lab \\
\hline $2 / 20 / 96$ & 10:18:02 PM & 1233 & & & & \\
\hline $2 / 20 / 96$ & $10: 28: 15 \mathrm{PM}$ & 1234 & & 17.5 & $03 / 18$ & analyzed in lab \\
\hline $2 / 20 / 96$ & 10:38:52 PM & 1235 & & & & \\
\hline $2 / 20 / 96$ & 10:49:17 PM & 1236 & & 18.1 & $03 / 18$ & anatyzed in lab \\
\hline $2 / 20 / 96$ & 10:59:31 PM & 1237 & & & & \\
\hline $2 / 20 / 96$ & 11:09:54 PM & 1238 & & 18.6 & $03 / 18$ & analyzed in tab \\
\hline $2 / 20 / 96$ & $11: 20: 07 \mathrm{PM}$ & 1239 & & & & \\
\hline $2 / 20 / 96$ & 11:30:20 PM & 1240 & & 18.4 & $03 / 18$ & analyzed in lab \\
\hline $2 / 20 / 96$ & 11:40:33 PM & 1241 & & & & \\
\hline $2 / 20 / 96$ & 11:50:46 PM & 1242 & & 19.3 & $03 / 18$ & analyzed in lab \\
\hline
\end{tabular}




\begin{tabular}{|c|c|c|c|c|c|c|}
\hline Date & Time of Sample & Sample \# & Dup. code & Conc (ppb) & Analysis date & place \\
\hline $2 / 21 / 96$ & $12: 00: 59$ AM & 1243 & & & & \\
\hline $2 / 21 / 96$ & 12:11:12 AM & 1244 & & 18.2 & $03 / 18$ & analyzed in lab \\
\hline $2 / 21 / 96$ & $12: 21: 25 \mathrm{AM}$ & 1245 & & & & \\
\hline $2 / 21 / 96$ & $12: 31: 37 \mathrm{AM}$ & 1246 & & 19.7 & $03 / 18$ & analyzed in lab \\
\hline $2 / 21 / 96$ & $12: 41: 58 \mathrm{AM}$ & 1247 & & & & \\
\hline $2 / 21 / 96$ & 12:52:12 AM & 1248 & & 17.9 & $03 / 18$ & analyzed in lab \\
\hline $2 / 21 / 96$ & 1:02:24 AM & 1249 & & & & \\
\hline $2 / 21 / 96$ & 1:12:37 AM & 1250 & & 20.6 & $03 / 18$ & analyzed in lab \\
\hline $2 / 21 / 96$ & 1:22:49 AM & 1251 & & & & \\
\hline $2 / 21 / 96$ & 1:33:02 AM & 1252 & & 19.6 & $03 / 18$ & analyzed in lab \\
\hline $2 / 21 / 96$ & 1:43:15 AM & 1253 & & & & \\
\hline $2 / 21 / 96$ & 1:53:28 AM & 1254 & & 20.0 & $03 / 18$ & analyzed in lab \\
\hline $2 / 21 / 96$ & 2:03:42 AM & 1255 & & & & \\
\hline $2 / 21 / 96$ & 2:14:04 AM & 1256 & & 20.1 & $03 / 18$ & analyzed in lab \\
\hline $2 / 21 / 96$ & $2: 24: 50$ AM & 1257 & & & & \\
\hline $2 / 21 / 96$ & $2: 35: 28$ AM & 1258 & & 18.6 & $03 / 18$ & analyzed in lab \\
\hline $2 / 21 / 96$ & 2:45:41 AM & 1259 & & & & \\
\hline $2 / 21 / 96$ & $2: 55: 57$ AM & 1260 & $\mathrm{LD}^{*}$ & 19.6 & $03 / 18$ & analyzed in lab \\
\hline $2 / 21 / 96$ & $3: 06: 12$ AM & 1261 & & & & \\
\hline $2 / 21 / 96$ & $3: 16: 24$ AM & 1262 & & 21.4 & $03 / 18$ & analyzed in lab \\
\hline $2 / 21 / 96$ & $3: 26: 38$ AM & 1263 & & & & \\
\hline $2 / 21 / 96$ & $3: 37: 14$ AM & 1264 & & 20.7 & $03 / 18$ & analyzed in lab \\
\hline $2 / 21 / 96$ & $3: 47: 45$ AM & 1265 & & & & \\
\hline $2 / 21 / 96$ & $3: 57: 57$ AM & 1266 & & 20.4 & $03 / 18$ & analyzed in lab \\
\hline $2 / 21 / 96$ & 4:08:10 AM & 1267 & & & & \\
\hline $2 / 21 / 96$ & 4:18:23 AM & 1268 & & 20.6 & $03 / 18$ & analyzed in lab \\
\hline $221 / 96$ & 4:28:36 AM & 1269 & & & & \\
\hline $2 / 21 / 96$ & 4:38:50 AM & 1270 & & 21.4 & $03 / 18$ & analyzed in lab \\
\hline $2 / 21 / 96$ & 4:49:04 AM & 1271 & & & & \\
\hline $2 / 21 / 96$ & 4:59:17 AM & 1272 & & 20.8 & $03 / 18$ & analyzed in lab \\
\hline $2 / 21 / 96$ & $5: 09: 30 \mathrm{AM}$ & 1273 & & & & \\
\hline $2 / 21 / 96$ & 5:19:52 AM & 1274 & & 21.5 & $03 / 18$ & analyzed in lab \\
\hline $2 / 21 / 96$ & 5:30:05 AM & 1275 & & & & \\
\hline $2 / 21 / 96$ & 5:40:18 AM & 1276 & & 19.6 & $03 / 18$ & analyzed in lab \\
\hline $2 / 21 / 96$ & $5: 50: 31 \mathrm{AM}$ & 1277 & & & & \\
\hline $2 / 21 / 96$ & $6: 00: 45 \mathrm{AM}$ & 1278 & & 21.6 & $03 / 18$ & analyzed in lab \\
\hline $2 / 21 / 96$ & $6: 10: 58$ AM & 1279 & & & & \\
\hline $2 / 21 / 96$ & $6: 21: 11$ AM & 1280 & & 21.8 & $03 / 18$ & analyzed in lab \\
\hline $2 / 21 / 96$ & $6: 31: 25$ AM & 1281 & & & & \\
\hline $2 / 21 / 96$ & $6: 41: 49 \mathrm{AM}$ & 1282 & & 21.5 & $03 / 18$ & analyzed in lab \\
\hline $2 / 21 / 96$ & 6:52:10 AM & 1283 & & 20.6 & $03 / 18$ & analyzed in lab \\
\hline $2 / 21 / 96$ & $7: 02: 23 \mathrm{AM}$ & 1284 & & 21.7 & $03 / 18$ & analyzed in lab \\
\hline $2 / 21 / 96$ & $7: 12: 36 \mathrm{AM}$ & 1285 & & & & \\
\hline $2 / 21 / 96$ & $7: 22: 49 \mathrm{AM}$ & 1286 & UD & 23.1 & & \\
\hline $2 / 21 / 96$ & $7: 33: 02 \mathrm{AM}$ & 1287 & & & & \\
\hline $2 / 21 / 96$ & $7: 43: 21$ AM & 1288 & & 21.2 & $03 / 18$ & analyzed in lab \\
\hline $2 / 21 / 96$ & 7:53:35 AM & 1289 & & 22.0 & $03 / 18$ & analyzed in lab \\
\hline $2 / 21 / 96$ & $8: 03: 51$ AM & 1290 & & & & \\
\hline $2 / 21 / 96$ & 8:14:04 AM & 1291 & & & & \\
\hline $2 / 21 / 96$ & 8:24:28 AM & 1292 & UD* & 21.8 & $03 / 18$ & analyzed in lab \\
\hline $221 / 96$ & $8: 34: 41$ AM & 1293 & & & & \\
\hline $2 / 21 / 96$ & $8: 45: 18$ AM & 1294 & & 22.3 & $03 / 18$ & analyzed in lab \\
\hline $2 / 21 / 96$ & $8: 55: 31$ AM & 1295 & & 22.3 & $03 / 18$ & analyzed in $l a b$ \\
\hline $2 / 21 / 96$ & $9: 05: 46$ AM & 1296 & UF-D* & 22.4 & $03 / 18$ & analyzed in lab \\
\hline $221 / 96$ & $9: 16: 01$ AM & 1297 & UF-D & 22.9 & & \\
\hline $2 / 21 / 96$ & 9:26:14 AM & 1298 & & 27.2 & $02 / 21$ & analyzed in field \\
\hline $2 / 21 / 96$ & $9: 36: 27$ AM & 1299 & & 25.8 & 0221 & analyzed in field \\
\hline $221 / 96$ & 9:46:39 AM & 1300 & & 25.1 & $02 / 21$ & analyzed in field \\
\hline $2 / 21 / 96$ & 9:57:00 AM & 1301 & & 26.0 & 0221 & analyzed in field \\
\hline $2 / 21 / 96$ & $10: 07: 13 \mathrm{AM}$ & 1302 & & 26.7 & 0221 & analyzed in fieid \\
\hline $2 / 21 / 96$ & $10: 17: 26 \mathrm{AM}$ & 1303 & & 27.2 & $02 / 21$ & analyzed in field \\
\hline $2 / 21 / 96$ & $10: 27: 38 \mathrm{AM}$ & 1304 & & 26.9 & $02 / 21$ & analyzed in field \\
\hline $2 / 21 / 96$ & $10: 37: 50 \mathrm{AM}$ & 1305 & & 27.4 & 02221 & analyzed in field \\
\hline $2 / 21 / 96$ & $10: 48: 03 \mathrm{AM}$ & 1306 & & 27.4 & $02 / 21$ & analyzed in field \\
\hline $2 / 21 / 96$ & $10: 58: 17$ AM & 1307 & & 25.5 & $02 / 21$ & analyzed in field \\
\hline $2 / 21 / 96$ & $11: 08: 30 \mathrm{AM}$ & 1308 & & 27.8 & 0221 & analyzed in field \\
\hline $2 / 21196$ & $11: 18: 43 \mathrm{AM}$ & 1309 & & 25.8 & $02 / 21$ & analyzed in field \\
\hline $2 / 21 / 96$ & $11: 30: 04$ AM & 1310 & & 26.6 & $02 / 21$ & analyzed in field \\
\hline 221196 & $11: 40: 17 \mathrm{AM}$ & 1311 & & 29.0 & $02 / 21$ & analyzed in field \\
\hline $2 / 21 / 96$ & $11: 50: 29 \mathrm{AM}$ & 1312 & & 29.8 & $02 / 21$ & analyzed in field \\
\hline
\end{tabular}




\begin{tabular}{|c|c|c|c|c|c|c|}
\hline Date & Time of Sample & Sample \# & Dup. code & Conc (ppb) & Analysis date & place \\
\hline $2 / 21 / 96$ & 12:00:42 PM & 1313 & & 24.6 & $02 / 21$ & analyzed in field \\
\hline $2 / 21 / 96$ & $12: 10: 55 \mathrm{PM}$ & 1314 & & 27.8 & $02 / 21$ & analyzed in field \\
\hline $2 / 21 / 96$ & $12: 21: 08 \mathrm{PM}$ & 1315 & & 28.5 & $02 / 21$ & anabyzed in field \\
\hline $2 / 21 / 96$ & 12:36:21 PM & 1316 & & 27.4 & $02 / 21$ & analyzed in field \\
\hline $2 / 21 / 96$ & $12: 51: 41 \mathrm{PM}$ & 1317 & & 27.5 & $02 / 21$ & analyzed in field \\
\hline $2 / 21 / 96$ & 1:07:03 PM & 1318 & & 26.1 & $02 / 21$ & anabyzed in field \\
\hline $2 / 21 / 96$ & 1:22:38 PM & 1319 & & 27.5 & $02 / 21$ & analyzed in field \\
\hline $2 / 21 / 96$ & $1: 37: 52 \mathrm{PM}$ & 1320 & & 29.3 & $02 / 21$ & analyzed in field \\
\hline $2 / 21 / 96$ & 1:53:27 PM & 1321 & & 28.4 & 0221 & analyzed in field \\
\hline $2 / 21 / 96$ & 2:08:45 PM & 1322 & & 28.5 & 0221 & analyzed in field \\
\hline $2 / 21 / 96$ & $2: 24: 05$ PM & 1323 & & 26.8 & $02 / 21$ & analyzed in field \\
\hline $2 / 21 / 96$ & 2:39:23 PM & 1324 & & 27.7 & 0221 & analyzed in field \\
\hline $2 / 21 / 96$ & 2:54:46 PM & 1325 & & 30.6 & $02 / 21$ & analyzed in field \\
\hline $2 / 21 / 96$ & 3:10:04 PM & 1326 & & 28.1 & $02 / 21$ & analyzed in field \\
\hline $2 / 21 / 96$ & $3: 25: 22 \mathrm{PM}$ & 1327 & & 27.7 & $02 / 21$ & analyzed in field \\
\hline $2 / 21 / 96$ & $3: 41: 02 \mathrm{PM}$ & 1328 & & 28.2 & $02 / 21$ & analyzed in field \\
\hline $2 / 21 / 96$ & $3: 56: 15 \mathrm{PM}$ & 1329 & & 27.4 & 0221 & analyzed in field \\
\hline $2 / 21 / 96$ & 4:11:28 PM & 1330 & & 28.3 & $02 / 21$ & analyzed in field \\
\hline $2 / 21 / 96$ & 4:26:47 PM & 1331 & & 29.6 & $02 / 21$ & analyzed in field \\
\hline $2 / 21 / 96$ & 4:42:05 PM & 1332 & & 29.3 & $02 / 21$ & analyzed in field \\
\hline $2 / 21 / 96$ & 4:57:39 PM & 1333 & LD* & 28.3 & $03 / 18$ & analyzed in lab \\
\hline $2 / 21 / 96$ & 5:12:56 PM & 1334 & & 25.3 & $03 / 18$ & analyzed in lab \\
\hline $2 / 21 / 96$ & 5:28:17 PM & 1335 & & 25.3 & $03 / 18$ & analyzed in lab \\
\hline $2 / 21 / 96$ & 5:43:38 PM & 1336 & & 25.7 & $03 / 18$ & analyzed in lab \\
\hline $2 / 21 / 96$ & 5:59:29 PM & 1337 & & 27.3 & $03 / 18$ & analyzed in lab \\
\hline 2/21/96 & $6: 14: 42$ PM & 1338 & & 25.3 & $03 / 18$ & analyzed in lab \\
\hline $2 / 21 / 96$ & $6: 29: 55 \mathrm{PM}$ & 1339 & & 25.6 & $03 / 18$ & analyzed in lab \\
\hline $2 / 21 / 96$ & $6: 45: 15$ PM & 1340 & & 27.8 & $03 / 18$ & analyzed in lab \\
\hline $2 / 21 / 96$ & 7:00:27 PM & 1341 & & 26.6 & $03 / 18$ & analyzed in lab \\
\hline $2 / 21 / 96$ & $7: 15: 40 \mathrm{PM}$ & 1342 & & 27.5 & $03 / 18$ & analyzed in lab \\
\hline $2 / 21 / 96$ & $7: 30: 53 \mathrm{PM}$ & 1343 & & 27.1 & $03 / 18$ & analyzed in lab \\
\hline $2 / 21 / 96$ & 7:46:06 PM & 1344 & & 26.3 & $03 / 18$ & analyzed in lab \\
\hline $2 / 21 / 96$ & $8: 01: 29 \mathrm{PM}$ & 1345 & & 28.7 & $03 / 18$ & anatyzed in lab \\
\hline $2 / 21 / 96$ & $8: 17: 08$ PM & 1346 & & 29.0 & $03 / 18$ & analyzed in lab \\
\hline $2 / 21 / 96$ & 8:32:21 PM & 1347 & & 27.8 & $03 / 18$ & analyzed in lab \\
\hline $2 / 21 / 96$ & $8: 47: 34$ PM & 1348 & & 27.3 & $03 / 18$ & analyzed in lab \\
\hline $2 / 21 / 96$ & 9:03:07 PM & 1349 & & 31.2 & $03 / 18$ & analyzed in lab \\
\hline $2 / 21 / 96$ & 9:18:29 PM & 1350 & LD* & 30.8 & $03 / 18$ & analyzed in lab \\
\hline $2 / 21 / 96$ & 9:34:48 PM & 1351 & & 27.5 & $03 / 18$ & analyzed in lab \\
\hline $2 / 21 / 96$ & $9: 50: 26 \mathrm{PM}$ & 1352 & & 28.5 & $03 / 18$ & analyzed in lab \\
\hline $2 / 21 / 96$ & $10: 05: 49 \mathrm{PM}$ & 1353 & & 28.9 & $03 / 18$ & analyzed in lab \\
\hline $2 / 21 / 96$ & 10:21:09 PM & 1354 & & 29.6 & $03 / 18$ & analyzed in lab \\
\hline $2 / 21 / 96$ & $10: 36: 58 \mathrm{PM}$ & 1355 & & 29.0 & $03 / 18$ & analyzed in lab \\
\hline $2 / 21 / 96$ & 10:52:11 PM & 1356 & & 28.9 & $03 / 18$ & analyzed in $\mathrm{tab}$ \\
\hline $2 / 21 / 96$ & 11:07:25 PM & 1357 & & 34.5 & $03 / 18$ & analyzed in lab \\
\hline $2 / 21 / 96$ & $11: 22: 43 \mathrm{PM}$ & 1358 & & 34.0 & $03 / 18$ & analyzed in lab \\
\hline $2 / 21 / 96$ & 11:38:01 PM & 1359 & & 32.4 & $03 / 18$ & analyzed in lab \\
\hline $2 / 21 / 96$ & 11:53:14 PM & 1360 & & 33.1 & $03 / 18$ & analyzed in $\mathrm{lab}$ \\
\hline $2 / 22 / 96$ & $12: 08: 27$ AM & 1361 & & 32.7 & $03 / 18$ & analyzed in lab \\
\hline $2 / 22 / 96$ & $12: 23: 39 \mathrm{AM}$ & 1362 & & 33.1 & $03 / 18$ & analyzed in lab \\
\hline $2 / 22 / 96$ & 12:38:56 AM & 1363 & & 34.1 & $03 / 18$ & analyzed in $\mathrm{lab}$ \\
\hline $2 / 22 / 96$ & $12: 54: 48 \mathrm{AM}$ & 1364 & & 32.5 & $03 / 18$ & analyzed in lab \\
\hline $2 / 22 / 96$ & $1: 10: 00 \mathrm{AM}$ & 1365 & & 32.5 & $03 / 18$ & analyzed in lab \\
\hline $2 / 22 / 96$ & 1:25:13 AM & 1366 & & 32.1 & $03 / 18$ & analyzed in lab \\
\hline $2 / 22 / 96$ & $1: 40: 32$ AM & 1367 & & 33.5 & $03 / 18$ & analyzed in lab \\
\hline $2 / 22 / 96$ & 1:56:10 AM & 1368 & & 32.2 & $03 / 18$ & analyzed in $\mathrm{tab}$ \\
\hline $2 / 22 / 96$ & $2: 11: 30 \mathrm{AM}$ & 1369 & & 33.3 & $03 / 18$ & analyzed in lab \\
\hline $2 / 22196$ & $2: 26: 51$ AM & 1370 & & 33.1 & $03 / 18$ & analyzed in lab \\
\hline $2 / 22 / 96$ & $2: 42: 15$ AM & 1371 & & 33.3 & $03 / 18$ & analyzed in lab \\
\hline $2 / 22 / 96$ & $2: 57: 49$ AM & 1372 & & 31.7 & $03 / 18$ & analyzed in lab \\
\hline $2 / 22 / 96$ & 3:13:21 AM & 1373 & & 32.6 & $03 / 18$ & analyzed in lab \\
\hline $2 / 22 / 96$ & $3: 28: 35 \mathrm{AM}$ & 1374 & & 37.0 & $03 / 18$ & analyzed in lab \\
\hline $2 / 22 / 96$ & 3:43:48 AM & 1375 & & 33.8 & $03 / 18$ & analyzed in lab \\
\hline $2 / 22 / 96$ & $3: 59: 26$ AM & 1376 & & 34.5 & $03 / 18$ & analyzed in lab \\
\hline $2 / 22 / 96$ & $4: 14: 46 \mathrm{AM}$ & 1377 & LD* & 34.1 & $03 / 18$ & analyzed in lab \\
\hline $2 / 22 / 96$ & 4:30:05 AM & 1378 & & 32.4 & $03 / 18$ & analyzed in lab \\
\hline $2 / 22 / 96$ & 4:45:28 AM & 1379 & & 32.2 & $03 / 18$ & analyzed in lab \\
\hline $2 / 22 / 96$ & 5:00:41 AM & 1380 & & 33.2 & $03 / 18$ & analyzed in lab \\
\hline $2 / 22 / 96$ & 5:15:54 AM & 1381 & & 35.8 & $02 / 22$ & analyzed in field \\
\hline $2 / 22 / 96$ & 5:31:27 AM & 1382 & & 36.5 & $02 / 22$ & analyzed in field \\
\hline
\end{tabular}




\begin{tabular}{|c|c|c|c|c|c|c|}
\hline Date & Time of Sample & Sample \# & Dup. code & Conc (ppb) & Analysis date & place \\
\hline $2 / 22 / 96$ & $5: 46: 40 \mathrm{AM}$ & 1383 & & 34.3 & $02 / 22$ & analyzed in field \\
\hline $2 / 22 / 96$ & $6: 02: 14$ AM & 1384 & & 37.4 & $02 / 22$ & analyzed in field \\
\hline $2 / 22 / 96$ & $6: 17: 36 \mathrm{AM}$ & 1385 & & 34.8 & 0222 & analyzed in field \\
\hline $2 / 22 / 96$ & $6: 32: 58$ AM & 1386 & & 36.5 & $02 / 22$ & analyzed in field \\
\hline $2 / 22 / 96$ & $6: 48: 18$ AM & 1387 & & 36.7 & $02 / 22$ & analyzed in field \\
\hline $2 / 22 / 96$ & $7: 03: 58$ AM & 1388 & & 34.8 & $02 / 22$ & analyzed in field \\
\hline $2 / 22 / 96$ & 7:19:19 AM & 1389 & & 35.0 & 02122 & analyzed in field \\
\hline $2 / 22 / 96$ & $7: 34: 36$ AM & 1390 & & 37.5 & $02 / 22$ & analyzed in field \\
\hline $2 / 22196$ & $7: 50: 28$ AM & 1391 & & 39.8 & $02 / 22$ & analyzed in field \\
\hline $2 / 22 / 96$ & $8: 05: 41$ AM & 1392 & & 35.6 & $02 / 22$ & analyzed in freld \\
\hline $2 / 22 / 96$ & $8: 20: 54$ AM & 1393 & & 35.1 & $02 / 22$ & analyzed in field \\
\hline $2 / 22 / 96$ & $8: 36: 17 \mathrm{AM}$ & 1394 & & 35.8 & $02 / 22$ & analyzed in field \\
\hline $2 / 22 / 96$ & $8: 51: 37$ AM & 1395 & & 35.4 & 02222 & analyzed in field \\
\hline $2 / 22 / 96$ & $9: 07: 15 \mathrm{AM}$ & 1396 & & & & \\
\hline $2 / 22 / 96$ & $9: 22: 42$ AM & 1397 & & 37.7 & $02 / 22$ & analyzed in field \\
\hline $2 / 22 / 96$ & $9: 38: 03 \mathrm{AM}$ & 1398 & & 37.9 & $02 / 22$ & analyzed in field \\
\hline $2 / 22 / 96$ & $9: 53: 22 \mathrm{AM}$ & 1399 & & 38.7 & $02 / 22$ & analyzed in field \\
\hline $2 / 22 / 96$ & $10: 09: 01 \mathrm{AM}$ & 1400 & & 38.0 & 02122 & analyzed in field \\
\hline $2 / 22 / 96$ & $10: 24: 14 \mathrm{AM}$ & 1401 & & 36.7 & 02122 & analyzed in field \\
\hline $2 / 22 / 96$ & $10: 39: 26 \mathrm{AM}$ & 1402 & & 38.6 & $02 / 22$ & analyzed in field \\
\hline $2 / 22 / 96$ & $10: 54: 45 \mathrm{AM}$ & 1403 & & 38.1 & $02 / 22$ & analyzed in field \\
\hline $2 / 22 / 96$ & $11: 10: 13 \mathrm{AM}$ & 1404 & & 37.5 & 02122 & analyzed in field \\
\hline $2 / 22 / 96$ & $11: 25: 34 \mathrm{AM}$ & 1405 & & 39.3 & $02 / 22$ & analyzed in field \\
\hline $2 / 22 / 96$ & $11: 40: 55 \mathrm{AM}$ & 1406 & & 38.9 & 02122 & anabyzed in field \\
\hline $2 / 22 / 96$ & $11: 56: 12 \mathrm{AM}$ & 1407 & & 38.9 & $02 / 22$ & analyzed in field \\
\hline $2 / 22 / 96$ & $12: 11: 50 \mathrm{PM}$ & 1408 & & 41.6 & $02 / 22$ & analyzed in field \\
\hline $2 / 22 / 96$ & $12: 27: 22 \mathrm{PM}$ & 1409 & & 41.6 & 0222 & analyzed in field \\
\hline $2 / 22 / 96$ & $12: 43: 31 \mathrm{PM}$ & 1410 & & 40.0 & $02 / 22$ & analyzed in field \\
\hline $2 / 22 / 96$ & $12: 59: 08 \mathrm{PM}$ & 1411 & & 38.9 & $02 / 22$ & analyzed in field \\
\hline $2 / 22 / 96$ & $1: 14: 26 \mathrm{PM}$ & 1412 & & 38.0 & $02 / 22$ & analyzed in field \\
\hline $2 / 22 / 96$ & $1: 29: 45$ PM & 1413 & & 39.8 & $02 / 22$ & analyzed in field \\
\hline $2 / 22 / 96$ & 1:45:07 PM & 1414 & & 40.0 & $02 / 22$ & analyzed in field \\
\hline $2 / 22 / 96$ & $2: 00: 20$ PM & 1415 & & 39.6 & $02 / 22$ & analyzed in field \\
\hline $2 / 22 / 96$ & 2:15:33 PM & 1416 & & 39.1 & $02 / 22$ & analyzed in freid \\
\hline $2 / 22 / 96$ & $2: 30: 47$ PM & 1417 & & 40.1 & 0222 & analyzed in field \\
\hline $2 / 22 / 96$ & $2: 46: 35 P M$ & 1418 & & 41.0 & $02 / 22$ & analyzed in fieid \\
\hline $2 / 22 / 96$ & 3:01:48 PM & 1419 & & 41.0 & 0222 & analyzed in field \\
\hline $2 / 22 / 96$ & 3:17:01 PM & 1420 & & 41.0 & $02 / 22$ & analyzed in field \\
\hline $2 / 22 / 96$ & 3:32:18 PM & 1421 & & 41.3 & $02 / 22$ & analyzed in field \\
\hline $2 / 22 / 96$ & 3:47:34 PM & 1422 & & 39.4 & 02122 & analyzed in field \\
\hline $2 / 22196$ & 4:03:12PM & 1423 & & 41.4 & 0222 & analyzed in field \\
\hline $2 / 22 / 96$ & 4:18:33 PM & 1424 & & 39.7 & 0222 & analyzed in field \\
\hline $2 / 22 / 96$ & 4:33:57 PM & 1425 & & 41.9 & 02122 & analyzed in field \\
\hline $2 / 22 / 96$ & 4:49:17 PM & 1426 & & 38.7 & $03 / 15$ & analyzed in lab \\
\hline $2 / 22 / 96$ & 5:05:10 PM & 1427 & & 39.8 & $03 / 15$ & analyzed in lab \\
\hline $2 / 22 / 96$ & $5: 20: 23$ PM & 1428 & & 39.1 & $03 / 15$ & analyzed in lab \\
\hline $2 / 22 / 96$ & $5: 35: 35$ PM & 1429 & & 39.5 & $03 / 15$ & analyzed in lab \\
\hline $2 / 22 / 96$ & 5:50:58 PM & 1430 & & 40.0 & $03 / 15$ & anabyed in tab \\
\hline $2 / 22 / 96$ & 6:06:37 PM & 1431 & & 39.9 & $03 / 15$ & analyzed in lab \\
\hline $2 / 22 / 96$ & $6: 22: 01$ PM & 1432 & & 41.2 & $03 / 15$ & analyzed in lab \\
\hline $2 / 22196$ & $6: 37: 21$ PM & 1433 & & 39.8 & $03 / 15$ & analyzed in lab \\
\hline $2 / 22 / 96$ & $6: 52: 42$ PM & 1434 & & 40.9 & $03 / 15$ & analyzed in lab \\
\hline $2 / 22 / 96$ & $7: 07: 55 \mathrm{PM}$ & 1435 & & 40.5 & $03 / 15$ & analyzed in lab \\
\hline $2 / 22196$ & $7: 23: 16$ PM & 1436 & & 41.3 & $03 / 15$ & analyzed in lab \\
\hline $2 / 22 / 96$ & 7:38:28 PM & 1437 & & 41.1 & $03 / 15$ & analyzed in lab \\
\hline 222296 & $7: 53: 52 \mathrm{PM}$ & 1438 & & 39.6 & $03 / 15$ & anahred in lab \\
\hline $2 / 22 / 96$ & $8: 09: 16$ PM & 1439 & & 41.6 & $03 / 15$ & analyzed in lab \\
\hline $2 / 22 / 96$ & $8: 24: 35$ PM & 1440 & UD & 40.8 & & \\
\hline $2 / 22 / 96$ & $8: 39: 56$ PM & 1441 & & 40.9 & $03 / 15$ & analyzed in lab \\
\hline $2 / 22 / 96$ & $8: 55: 24$ PM & 1442 & & 41.7 & $03 / 15$ & analyzed in lab \\
\hline $2 / 22 / 96$ & $9: 10: 45 \mathrm{PM}$ & 1443 & & 42.5 & $03 / 15$ & analyzed in lab \\
\hline $2 / 22 / 96$ & $9: 26: 02 \mathrm{PM}$ & 1444 & & 41.5 & $03 / 15$ & analyzed in lab \\
\hline $2 / 22 / 96$ & $9: 41: 29 \mathrm{PM}$ & 1445 & & 41.7 & $03 / 15$ & analyzed in lab \\
\hline $2 / 22 / 96$ & 9:57:04 PM & 1446 & & 41.4 & $03 / 15$ & analyzed in lab \\
\hline 222296 & $10: 12: 23 \mathrm{PM}$ & 1447 & & 42.7 & $03 / 15$ & analyzed in lab \\
\hline $2 / 22 / 96$ & $10: 27: 46 \mathrm{PM}$ & 1448 & & 41.2 & $03 / 15$ & analyzed in lab \\
\hline $2 / 22 / 96$ & $10: 43: 03 \mathrm{PM}$ & 1449 & & 42.4 & $03 / 15$ & anahzed in lab \\
\hline $2 / 22 / 96$ & 10:58:16 PM & 1450 & & 41.3 & $03 / 15$ & analyzed in lab \\
\hline $2 / 22 / 96$ & $11: 14: 00 \mathrm{PM}$ & 1451 & & 42.5 & $03 / 15$ & analyzed in lab \\
\hline $2 / 22 / 96$ & $11: 29: 26 \mathrm{PM}$ & 1452 & & 43.1 & $03 / 15$ & analyzed in lab \\
\hline
\end{tabular}




\begin{tabular}{|c|c|c|c|c|c|c|}
\hline Date & Time of Sample & Sample \# & Dup. code & Conc (ppb) & Analysis date & place \\
\hline $2 / 22 / 96$ & $11: 44: 49 \mathrm{PM}$ & 1453 & & 41.6 & $03 / 15$ & analyzed in lab \\
\hline $2 / 23 / 96$ & $12: 00: 11 \mathrm{AM}$ & 1454 & & 42.5 & $03 / 15$ & analyzed in lab \\
\hline $2 / 23 / 96$ & $12: 15: 51 \mathrm{AM}$ & 1455 & & 41.5 & $03 / 15$ & analyzed in lab \\
\hline $2 / 23 / 96$ & $12: 31: 10 \mathrm{AM}$ & 1456 & & 41.6 & $03 / 15$ & analyzed in lab \\
\hline $2 / 23 / 96$ & $12: 46: 37 \mathrm{AM}$ & 1457 & & 42.3 & $03 / 15$ & anabzed in lab \\
\hline $2 / 23 / 96$ & $1: 01: 51 \mathrm{AM}$ & 1458 & & 42.6 & $03 / 15$ & analyzed in lab \\
\hline $2 / 23 / 96$ & $1: 17: 40 \mathrm{AM}$ & 1459 & & 42.7 & $03 / 15$ & analyzed in lab \\
\hline $2 / 23 / 96$ & $1: 32: 59$ AM & 1460 & UD & 42.7 & & \\
\hline $2 / 23 / 96$ & 1:48:19 AM & 1461 & & 42.6 & $03 / 15$ & anatyzed in lab \\
\hline $2 / 23 / 96$ & $2: 03: 32$ AM & 1462 & & 42.4 & $03 / 15$ & analyzed in lab \\
\hline $2 / 23 / 96$ & $2: 19: 29$ AM & 1463 & & 43.5 & $03 / 15$ & analyzed in lab \\
\hline $2 / 23 / 96$ & $2: 34: 41$ AM & 1464 & & 42.9 & $03 / 15$ & analyzed in lab \\
\hline $2 / 23 / 96$ & $2: 49: 59$ AM & 1465 & & 43.7 & $03 / 15$ & analyzed in lab \\
\hline $2 / 23 / 96$ & $3: 05: 12$ AM & 1466 & & 43.6 & $03 / 15$ & analyzed in lab \\
\hline $2 / 23 / 96$ & $3: 21: 03$ AM & 1467 & & 44.1 & $03 / 15$ & analyzed in lab \\
\hline $2 / 23 / 96$ & $3: 36: 20 \mathrm{AM}$ & 1468 & & 45.5 & $02 / 23$ & analyzed in fielo \\
\hline $2 / 23 / 96$ & $3: 51: 40 \mathrm{AM}$ & 1469 & & 46.5 & $02 / 23$ & analyzed in field \\
\hline $2 / 23 / 96$ & 4:06:53 AM & 1470 & & 46.4 & $02 / 23$ & analyzed in fielo \\
\hline $2 / 23 / 96$ & $4: 22: 48 \mathrm{AM}$ & 1471 & & 46.2 & $02 / 23$ & analyzed in fielo \\
\hline $2 / 23 / 96$ & 4:38:14 AM & 1472 & & 46.2 & $02 / 23$ & analyzed in fielo \\
\hline $2 / 23 / 96$ & $4: 54: 51$ AM & 1473 & & 47.0 & $02 / 23$ & analyzed in field \\
\hline $2 / 23 / 96$ & $5: 10: 29 \mathrm{AM}$ & 1474 & & 47.3 & $02 / 23$ & analyzed in fieid \\
\hline $2 / 23 / 96$ & $5: 25: 51$ AM & 1475 & & 54.6 & $02 / 23$ & analyzed in field \\
\hline $2 / 23 / 96$ & $5: 41: 15$ AM & 1476 & & 48.4 & $02 / 23$ & analyzed in fielo \\
\hline $2 / 23 / 96$ & 5:56:36 AM & 1477 & & 50.1 & $02 / 23$ & analyzed in fieid \\
\hline $2 / 23 / 96$ & $6: 12: 12 \mathrm{AM}$ & 1478 & & 48.6 & $02 / 23$ & analyzed in field \\
\hline $2 / 23 / 96$ & $6: 27: 44 \mathrm{AM}$ & 1479 & & 49.9 & $02 / 23$ & analyzed in field \\
\hline $2 / 23 / 96$ & $6: 43: 02 \mathrm{AM}$ & 1480 & & 47.6 & $02 / 23$ & analyzed in field \\
\hline $2 / 23 / 96$ & $6: 58: 33 \mathrm{AM}$ & 1481 & & 49.1 & $02 / 23$ & analyzed in fielo \\
\hline $2 / 23 / 96$ & $7: 14: 10 \mathrm{AM}$ & 1482 & & 50.2 & $02 / 23$ & analyzed in fielo \\
\hline $2 / 23 / 96$ & $7: 29: 28 \mathrm{AM}$ & 1483 & & 47.9 & $02 / 23$ & analyzed in field \\
\hline $2 / 23 / 96$ & $7: 44: 45 \mathrm{AM}$ & 1484 & & 45.0 & $02 / 23$ & analyzed in fielo \\
\hline $2 / 23 / 96$ & $8: 00: 06$ AM & 1485 & & 50.9 & $02 / 23$ & analyzed in field \\
\hline $2 / 23 / 96$ & $8: 15: 46 \mathrm{AM}$ & 1486 & & 47.9 & $02 / 23$ & analyzed in fielc \\
\hline $2 / 23 / 96$ & $8: 31: 07$ AM & 1487 & & 49.2 & $02 / 23$ & analyzed in field \\
\hline $2 / 23 / 96$ & $8: 46: 27 \mathrm{AM}$ & 1488 & & 48.7 & $02 / 23$ & analyzed in field \\
\hline $2 / 23 / 96$ & $9: 01: 47 \mathrm{AM}$ & 1489 & & 49.4 & $02 / 23$ & analyzed in field \\
\hline $2 / 23 / 96$ & $9: 17: 08 \mathrm{AM}$ & 1490 & & 47.8 & $02 / 23$ & analyzed in fielo \\
\hline $2 / 23 / 96$ & 9:32:21 AM & 1491 & & 46.6 & $02 / 23$ & analyzed in field \\
\hline $2 / 23 / 96$ & $9: 47: 34$ AM & 1492 & & 49.7 & $02 / 23$ & anabred in fielo \\
\hline $2 / 23 / 96$ & $10: 02: 58 \mathrm{AM}$ & 1493 & & 49.3 & $02 / 23$ & analyzed in field \\
\hline $2 / 23 / 96$ & $10: 18: 17 \mathrm{AM}$ & 1494 & & 50.2 & $02 / 23$ & analyzed in field \\
\hline $2 / 23 / 96$ & $10: 33: 38 \mathrm{AM}$ & 1495 & & 50.7 & $02 / 23$ & analyzed in field \\
\hline $2 / 23 / 96$ & $10: 48: 57 \mathrm{AM}$ & 1496 & & 48.7 & $02 / 23$ & analyzed in field \\
\hline $2 / 23 / 96$ & $11: 04: 29 \mathrm{AM}$ & 1497 & & 48.8 & $02 / 23$ & analyzed in field \\
\hline & & & & 50.9 & $02 / 23$ & analyzed in field \\
\hline & & & & 51.6 & $02 / 23$ & analyzed in field \\
\hline & & & & 49.4 & $02 / 23$ & analyzed in field \\
\hline & & & & 47.3 & $02 / 24$ & analyzed in field \\
\hline & & & & 53.1 & $02 / 24$ & anabyzed in field \\
\hline $2 / 23 / 96$ & $12: 53: 25 \mathrm{PM}$ & 1503 & & 47.1 & $03 / 15$ & analyzed in $\mathrm{ab}$ \\
\hline $2 / 23 / 96$ & $1: 08: 49 \mathrm{PM}$ & 1504 & & 48.7 & $03 / 15$ & anahyzed in lab \\
\hline $2 / 23 / 96$ & 1:24:10 PM & 1505 & & 48.5 & $03 / 15$ & analyzed in lab \\
\hline $2 / 23 / 96$ & 1:39:35 PM & 1506 & & 48.7 & $03 / 15$ & analyzed in lab \\
\hline $2 / 23 / 96$ & 1:54:48 PM & 1507 & & 48.5 & $03 / 15$ & analyzed in lab \\
\hline $2 / 23 / 96$ & 2:10:09 PM & 1508 & & 48.4 & $03 / 15$ & analyzed in lab \\
\hline $2 / 23 / 96$ & $2: 25: 28 \mathrm{PM}$ & 1509 & & 54.7 & $03 / 15$ & analyzed in lab \\
\hline $2 / 23 / 96$ & $2: 40: 46$ PM & 1510 & & 52.8 & $03 / 15$ & anahyzed in lab \\
\hline $2 / 23 / 96$ & $2: 56: 05$ PM & 1511 & & 52.9 & $03 / 15$ & analyzed in lab \\
\hline $2 / 23 / 96$ & 3:11:49 PM & 1512 & & 54.8 & $03 / 15$ & analyzed in lab \\
\hline $2 / 23 / 96$ & $3: 27: 02$ PM & 1513 & & 51.2 & $03 / 15$ & anahyzed in $\mathrm{lab}$ \\
\hline $2 / 23 / 96$ & 3:42:15 PM & 1514 & & 53.8 & $03 / 15$ & analyzed in lab \\
\hline $2 / 23 / 96$ & $3: 57: 31 \mathrm{PM}$ & 1515 & & 53.2 & $03 / 15$ & analyzed in lab \\
\hline $2 / 23 / 96$ & 4:12:49 PM & 1516 & & 49.1 & $03 / 15$ & analyzed in lab \\
\hline $2 / 23 / 96$ & $4: 28: 10 \mathrm{PM}$ & 1517 & & 53.3 & $03 / 15$ & analyzed in lab \\
\hline $2 / 23 / 96$ & 4:43:31 PM & 1518 & & 55.3 & $03 / 15$ & anahzed in lab \\
\hline $2 / 23 / 96$ & 4:58:51 PM & 1519 & & 53.1 & $03 / 15$ & analyzed in $\mathrm{tab}$ \\
\hline $2 / 23 / 96$ & 5:14:13 PM & 1520 & & 55.9 & $03 / 15$ & analyzed in lab \\
\hline $2 / 23 / 96$ & 5:29:48 PM & 1521 & & 55.9 & $03 / 15$ & analyzed in lab \\
\hline $2 / 23 / 96$ & 5:45:01 PM & 1522 & & 54.2 & $03 / 15$ & analyzed in lab \\
\hline
\end{tabular}




\begin{tabular}{|c|c|c|c|c|c|c|}
\hline Date & Time of Sample & Sample \# & Dup. code & Conc (ppb) & Analysis date & place \\
\hline $2 / 23 / 96$ & $6: 00: 14 \mathrm{PM}$ & 1523 & & 54.7 & $03 / 15$ & analyzed in lab \\
\hline $2 / 23 / 96$ & $6: 15: 28 \mathrm{PM}$ & 1524 & & 52.0 & $03 / 15$ & anatyzed in lab \\
\hline $2 / 23 / 96$ & $6: 30: 47 \mathrm{PM}$ & 1525 & & 55.3 & $03 / 15$ & analyzed in lab \\
\hline $2 / 23 / 96$ & $6: 46: 10 P M$ & 1526 & $\angle D^{\circ}$ & 54.7 & $03 / 15$ & analyzed in lab \\
\hline $2 / 23 / 96$ & 7:01:32 PM & 1527 & & 54.2 & $03 / 15$ & analyzed in lab \\
\hline $2 / 23 / 96$ & 7:16:52 PM & 1528 & & 56.2 & $03 / 15$ & analyzed in lab \\
\hline $2 / 23 / 96$ & $7: 32: 14 \mathrm{PM}$ & 1529 & & 54.4 & $03 / 15$ & anatyzed in lab \\
\hline $2 / 23 / 96$ & $7: 47: 54 \mathrm{PM}$ & 1530 & & 59.7 & $03 / 15$ & anahyed in lab \\
\hline $2 / 23 / 96$ & 8:03:07 PM & 1531 & & 53.8 & $03 / 15$ & analyzed in lab \\
\hline $2 / 23 / 96$ & $8: 18: 20 \mathrm{PM}$ & 1532 & & 55.0 & $03 / 15$ & analyzed in lab \\
\hline $2 / 23 / 96$ & $8: 33: 38 \mathrm{PM}$ & 1533 & & 58.7 & $03 / 15$ & analyzed in lab \\
\hline $2 / 23 / 96$ & 8:48:57 PM & 1534 & & 57.5 & $03 / 15$ & analyzed in lab \\
\hline $2 / 23 / 96$ & 9:04:16 PM & 1535 & & 58.0 & $03 / 15$ & analyzed in lab \\
\hline $2 / 23 / 96$ & 9:19:37 PM & 1536 & & 60.3 & $03 / 15$ & analyzed in lab \\
\hline $2 / 23 / 96$ & $9: 34: 58 \mathrm{PM}$ & 1537 & & 56.7 & $03 / 15$ & analyzed in lab \\
\hline $2 / 23 / 96$ & 9:50:17 PM & 1538 & & 62.7 & $03 / 15$ & analyzed in $\mathrm{kb}$ \\
\hline $2 / 23 / 96$ & $10: 05: 50 \mathrm{PM}$ & 1539 & & 58.4 & $03 / 15$ & analyzed in $\mathrm{lab}$ \\
\hline $2 / 23 / 96$ & 10:21:04 PM & 1540 & & 58.6 & $03 / 15$ & analyzed in $\mathrm{lab}$ \\
\hline $2 / 23 / 96$ & $10: 36: 17 \mathrm{PM}$ & 1541 & & 58.5 & $03 / 15$ & analyzed in $\mathrm{ab}$ \\
\hline $2 / 23 / 96$ & $10: 51: 36 \mathrm{PM}$ & 1542 & & 57.0 & $03 / 15$ & analyzed in lab \\
\hline $2 / 23 / 96$ & $11: 06: 54 \mathrm{PM}$ & 1543 & & 58.3 & $03 / 15$ & analyzed in $\mathrm{lab}$ \\
\hline $2 / 23 / 96$ & $11: 22: 16 \mathrm{PM}$ & 1544 & & 59.1 & $03 / 15$ & anahyzed in lab \\
\hline $2 / 23 / 96$ & $11: 37: 34 \mathrm{PM}$ & 1545 & & 62.1 & $03 / 15$ & analyzed in lab \\
\hline $2 / 23 / 96$ & $11: 52: 57 \mathrm{PM}$ & 1546 & & 57.7 & $03 / 15$ & anabyzed in lab \\
\hline $2 / 24 / 96$ & $12: 08: 18 \mathrm{AM}$ & 1547 & & 59.8 & $03 / 15$ & analyzed in lab \\
\hline $2 / 24 / 96$ & $12: 23: 55 \mathrm{AM}$ & 1548 & & 60.9 & $03 / 15$ & anatyzed in lab \\
\hline $2 / 24 / 96$ & $12: 39: 08 \mathrm{AM}$ & 1549 & & 59.6 & $03 / 15$ & analyzed in lab \\
\hline $2 / 24 / 96$ & $12: 54: 20 \mathrm{AM}$ & 1550 & & 59.4 & $03 / 15$ & analyzed in lab \\
\hline $2 / 24 / 96$ & $1: 09: 44 \mathrm{AM}$ & 1551 & & 60.1 & $03 / 15$ & analyzed in lab \\
\hline $2 / 24 / 96$ & 1:25:05 AM & 1552 & & 60.2 & $03 / 15$ & analyzed in lab \\
\hline $2 / 24 / 96$ & 1:40:27 AM & 1553 & LD & 58.8 & & \\
\hline $2 / 24 / 96$ & 1:55:50 AM & 1554 & & 60.5 & $03 / 15$ & analyzed in lab \\
\hline $2 / 24 / 96$ & $2: 11: 06 \mathrm{AM}$ & 1555 & & 64.4 & $03 / 15$ & analyzed in lab \\
\hline $2 / 24 / 96$ & $2: 26: 28 \mathrm{AM}$ & 1556 & & 62.2 & $03 / 15$ & analyzed in lab \\
\hline $2 / 24 / 96$ & $2: 42: 02 \mathrm{AM}$ & 1557 & & 64.0 & $03 / 14$ & analyzed in lab \\
\hline $2 / 24 / 96$ & $2: 57: 15 \mathrm{AM}$ & 1558 & & 63.9 & $03 / 14$ & analyzed in $\mathrm{kb}$ \\
\hline $2 / 24 / 96$ & $3: 12: 28$ AM & 1559 & & 64.6 & $03 / 14$ & anahyzed in lab \\
\hline $2 / 24 / 96$ & $3: 27: 49$ AM & 1560 & & 64.4 & $03 / 14$ & analyzed in lab \\
\hline $2 / 24 / 96$ & 3:43:11 AM & 1561 & & 64.4 & $03 / 14$ & analyzed in lab \\
\hline $2 / 24 / 96$ & 3:58:34 AM & 1562 & & 64.4 & $03 / 14$ & analyzed in lab \\
\hline $2 / 24 / 96$ & 4:13:56 AM & 1563 & & 63.4 & $03 / 14$ & analyzed in lab \\
\hline $2 / 24 / 96$ & 4:29:14 AM & 1564 & & 61.1 & $02 / 24$ & analyzed in field \\
\hline $2 / 24 / 96$ & 4:44:33 AM & 1565 & & 61.5 & $02 / 24$ & analyzed in field \\
\hline $2 / 24 / 96$ & 5:00:10 AM & 1566 & & 60.8 & $02 / 24$ & analyzed in field \\
\hline $2 / 24 / 96$ & $5: 15: 23$ AM & 1567 & & & & \\
\hline $2 / 24 / 96$ & 5:30:37 AM & 1568 & & 61.0 & $02 / 24$ & analyzed in field \\
\hline $2 / 24 / 96$ & $5: 45: 55$ AM & 1569 & & 59.8 & $02 / 24$ & analyzed in field \\
\hline $2 / 24 / 96$ & $6: 01: 15$ AM & 1570 & & 60.2 & $02 / 24$ & analyzed in field \\
\hline 2/24/96 & $6: 16: 36 \mathrm{AM}$ & 1571 & & 59.6 & $02 / 24$ & analyzed in field \\
\hline $2 / 24 / 96$ & 6:31:59 AM & 1572 & & 61.6 & $02 / 24$ & analyzed in field \\
\hline $2 / 24 / 96$ & $6: 47: 19$ AM & 1573 & & 62.4 & $02 / 24$ & analyzed in field \\
\hline $2 / 24 / 96$ & 7:02:37 AM & 1574 & & 61.0 & $02 / 24$ & analyzed in field \\
\hline $2 / 24 / 96$ & 7:18:13 AM & 1575 & & 62.8 & $02 / 24$ & anabyzed in field \\
\hline $2 / 24 / 96$ & 7:33:26 AM & 1576 & & 62.3 & $02 / 24$ & analyzed in field \\
\hline 2/24/96 & 7:48:39 AM & 1577 & & 60.8 & $02 / 24$ & analyzed in field \\
\hline $2 / 24 / 96$ & $8: 03: 58 \mathrm{AM}$ & 1578 & & 60.8 & $02 / 24$ & analyzed in field \\
\hline 2/24/96 & $8: 19: 16$ AM & 1579 & & 60.6 & $02 / 24$ & analyzed in field \\
\hline $2 / 24 / 96$ & $8: 34: 39 \mathrm{AM}$ & 1580 & & 61.9 & $02 / 24$ & anabyzed in field \\
\hline $2 / 24 / 96$ & $8: 50: 01 \mathrm{AM}$ & 1581 & & 60.9 & $02 / 24$ & analyzed in field \\
\hline $2 / 24 / 96$ & 9:05:21 AM & 1582 & & 61.2 & $02 / 24$ & analyzed in field \\
\hline $2 / 24 / 96$ & $9: 20: 40 \mathrm{AM}$ & 1583 & & 63.4 & $02 / 24$ & analyzed in field \\
\hline $2 / 24 / 96$ & 9:36:15 AM & 1584 & & 62.7 & $02 / 24$ & analyzed in field \\
\hline $2 / 24 / 96$ & $9: 51: 28 \mathrm{AM}$ & 1585 & & 63.1 & $02 / 24$ & analyzed in field \\
\hline $2 / 24 / 96$ & $10: 06: 41 \mathrm{AM}$ & 1586 & & 63.3 & $02 / 24$ & analyzed in field \\
\hline $2 / 24 / 96$ & $10: 21: 57 \mathrm{AM}$ & 1587 & & 62.1 & $02 / 24$ & analyzed in field \\
\hline $2 / 24 / 96$ & $10: 37: 16 \mathrm{AM}$ & 1588 & & 63.3 & $02 / 24$ & anabyzed in field \\
\hline $2 / 24 / 96$ & $10: 52: 38 \mathrm{AM}$ & 1589 & & 61.6 & $02 / 24$ & analyzed in field \\
\hline $2 / 24 / 96$ & 11:07:58 AM & 1590 & & 61.5 & $02 / 24$ & analyzed in field \\
\hline $2 / 24 / 96$ & $11: 23: 16 \mathrm{AM}$ & 1591 & & 63.6 & $02 / 24$ & analyzed in field \\
\hline $2 / 24 / 96$ & $11: 38: 38 \mathrm{AM}$ & 1592 & & 62.3 & $02 / 24$ & analyzed in field \\
\hline
\end{tabular}




\begin{tabular}{|c|c|c|c|c|c|c|}
\hline Date & Time of Sample & Sample \# & Dup. code & Conc (ppb) & Analysis date & place \\
\hline $2 / 24 / 96$ & 11:54:17 AM & 1593 & & 63.6 & $02 / 24$ & analyzed in field \\
\hline $2 / 24 / 96$ & 12:09:31 PM & 1594 & & 64.2 & $02 / 24$ & analyzed in field \\
\hline $2 / 24 / 96$ & $12: 24: 43 \mathrm{PM}$ & 1595 & & 63.7 & $02 / 24$ & analyzed in field \\
\hline $2 / 24 / 96$ & 12:40:03 PM & 1596 & & 62.5 & $02 / 24$ & analyzed in field \\
\hline $224 / 96$ & 12:55:26 PM & 1597 & F/D & 62.6 & & \\
\hline $2 / 24 / 96$ & $1: 10: 43 \mathrm{PM}$ & 1598 & & 63.2 & $02 / 24$ & analyzed in field \\
\hline $2 / 24 / 96$ & 1:26:02 PM & 1599 & & 62.5 & $02 / 24$ & analyzed in field \\
\hline $2 / 24 / 96$ & 1:41:22 PM & 1600 & & 68.2 & $03 / 14$ & analyzed in lab \\
\hline 224196 & 1:56:43 PM & 1601 & & 68.7 & $03 / 14$ & analyzed in lab \\
\hline $2 / 24 / 96$ & $2: 12: 24 \mathrm{PM}$ & 1602 & & 67.9 & $03 / 14$ & analyzed in lab \\
\hline 2/24/96 & 2:27:37 PM & 1603 & & 68.2 & $03 / 14$ & analyzed in lab \\
\hline $2 / 24 / 96$ & $2: 42: 50 \mathrm{PM}$ & 1604 & & 69.3 & $03 / 14$ & analyzed in lab \\
\hline $2 / 24 / 96$ & $2: 58: 12 \mathrm{PM}$ & 1605 & & 72.1 & $03 / 14$ & analyzed in lab \\
\hline $2 / 24 / 96$ & 3:13:34 PM & 1606 & & 68.7 & $03 / 14$ & analyzed in lab \\
\hline $2 / 24 / 96$ & $3: 28: 56$ PM & 1607 & & 67.6 & $03 / 14$ & analyzed in lab \\
\hline $2 / 24 / 96$ & 3:44:13 PM & 1608 & & 69.7 & $03 / 14$ & analyzed in lab \\
\hline $2 / 24 / 96$ & 3:59:32 PM & 1609 & & 70.8 & $03 / 14$ & analyzed in lab \\
\hline 2/24/96 & 4:14:53PM & 1610 & & 69.4 & $03 / 14$ & analyzed in lab \\
\hline $2 / 24196$ & 4:30:29 PM & 1611 & & 70.6 & $03 / 14$ & analyzed in lab \\
\hline $2 / 24 / 96$ & 4:45:42 PM & 1612 & & 68.9 & $03 / 14$ & analyzed in lab \\
\hline $2 / 24 / 96$ & $5: 00: 56 \mathrm{PM}$ & 1613 & & 68.2 & $03 / 14$ & analyzed in lab \\
\hline $2 / 24 / 96$ & 5:16:18 PM & 1614 & & 70.0 & $03 / 14$ & analyzed in lab \\
\hline $2 / 24 / 96$ & 5:31:37 PM & 1615 & & 69.2 & $03 / 14$ & analyzed in lab \\
\hline $2 / 24 / 96$ & 5:46:55 PM & 1616 & & 69.9 & $03 / 14$ & analyzed in lab \\
\hline $2 / 24 / 96$ & 6:02:16 PM & 1617 & $\mathrm{LD}^{*}$ & 72.3 & $03 / 14$ & analyzed in lab \\
\hline $2 / 24 / 96$ & 6:17:37 PM & 1618 & LD & 73.5 & & \\
\hline $2 / 24 / 96$ & $6: 32: 54$ PM & 1619 & LD & 73.6 & & \\
\hline $2 / 24 / 96$ & 6:48:29 PM & 1620 & L/D & 73.8 & & \\
\hline $2 / 24 / 96$ & 7:03:42 PM & 1621 & LD & 74.3 & & \\
\hline $2 / 24 / 96$ & 7:18:55 PM & 1622 & & 73.1 & $03 / 14$ & analyzed in lab \\
\hline $2 / 24 / 96$ & 7:34:16 PM & 1623 & & 76.1 & $03 / 14$ & analyzed in lab \\
\hline $2 / 24 / 96$ & 7:49:39 PM & 1624 & & 73.1 & $03 / 14$ & anatyzed in lab \\
\hline $2 / 24 / 96$ & 8:05:03 PM & 1625 & & 74.5 & $03 / 14$ & analyzed in lab \\
\hline $2 / 24 / 96$ & $8: 20: 25 \mathrm{PM}$ & 1626 & & 73.8 & $03 / 14$ & analyzed in lab \\
\hline $2 / 24 / 96$ & $8: 35: 42$ PM & 1627 & & 75.0 & $03 / 14$ & analyzed in lab \\
\hline $2 / 24 / 96$ & 8:51:03 PM & 1628 & & 73.1 & $03 / 14$ & analyzed in lab \\
\hline $2 / 24196$ & 9:06:39 PM & 1629 & & 74.4 & $03 / 14$ & analyzed in lab \\
\hline $2 / 24 / 96$ & $9: 21: 52 \mathrm{PM}$ & 1630 & & 74.8 & $03 / 14$ & analyzed in lab \\
\hline $2 / 24 / 96$ & 9:37:05 PM & 1631 & & 74.1 & $03 / 14$ & analyzed in lab \\
\hline $2 / 24 / 96$ & $9: 52: 25 \mathrm{PM}$ & 1632 & & 71.9 & $03 / 14$ & analyzed in lab \\
\hline $2 / 24 / 96$ & $10: 07: 43 \mathrm{PM}$ & 1633 & & 74.7 & $03 / 14$ & analyzed in lab \\
\hline $2 / 24 / 96$ & 10:23:04 PM & 1634 & & 77.8 & $03 / 14$ & analyzed in lab \\
\hline $2 / 2496$ & 10:38:23 PM & 1635 & & & & \\
\hline $2 / 24 / 96$ & 10:53:46 PM & 1636 & & 74.8 & $03 / 14$ & analyzed in lab \\
\hline $2 / 24 / 96$ & 11:09:06 PM & 1637 & & 75.3 & $03 / 14$ & analyzed in lab \\
\hline $2 / 24 / 96$ & 11:24:37 PM & 1638 & & 73.0 & $03 / 14$ & analyzed in lab \\
\hline $2 / 24 / 96$ & $11: 39: 50 \mathrm{PM}$ & 1639 & & 75.7 & $03 / 14$ & analyzed in lab \\
\hline $2 / 24 / 96$ & $11: 55: 04 \mathrm{PM}$ & 1640 & & 73.3 & $03 / 14$ & analyzed in lab \\
\hline $2 / 25 / 96$ & 12:10:26 AM & 1641 & & 69.5 & $03 / 13$ & anatyzed in lab \\
\hline $2 / 25 / 96$ & $12: 25: 47 \mathrm{AM}$ & 1642 & & 69.9 & $03 / 13$ & analyzed in lab \\
\hline $2 / 25196$ & $12: 41: 06 \mathrm{AM}$ & 1643 & & 69.7 & $03 / 13$ & analyzed in lab \\
\hline $2 / 25 / 96$ & $12: 56: 24 \mathrm{AM}$ & 1644 & & 69.5 & $03 / 13$ & analyzed in lab \\
\hline $2 / 25 / 96$ & $1: 11: 45$ AM & 1645 & & 70.2 & $03 / 13$ & analyzed in lab \\
\hline $2 / 25 / 96$ & 1:27:04 AM & 1646 & & 70.9 & $03 / 13$ & analyzed in lab \\
\hline $2 / 25 / 96$ & 1:42:35 AM & 1647 & & 72.3 & $03 / 13$ & analyzed in lab \\
\hline $2 / 25196$ & 1:57:49 AM & 1648 & & 71.5 & $03 / 13$ & analyzed in lab \\
\hline $2 / 25 / 96$ & $2: 13: 02 \mathrm{AM}$ & 1649 & & 71.4 & $03 / 13$ & analyzed in lab \\
\hline $2 / 25 / 96$ & 2:28:15 AM & 1650 & & 72.3 & $03 / 13$ & anabyzed in lab \\
\hline $2 / 25 / 96$ & 2:43:35 AM & 1651 & & 72.7 & $03 / 13$ & analyzed in lab \\
\hline $2 / 25 / 96$ & $2: 58: 52 \mathrm{AM}$ & 1652 & & 72.7 & $03 / 13$ & analyzed in lab \\
\hline $2 / 25196$ & 3:14:15 AM & 1653 & & 72.4 & $03 / 13$ & analyzed in lab \\
\hline $2 / 25 / 96$ & $3: 29: 34$ AM & 1654 & & 70.8 & $03 / 13$ & analyzed in lab \\
\hline $2 / 25 / 96$ & $3: 44: 51$ AM & 1655 & & 72.1 & $03 / 13$ & analyzed in lab \\
\hline $2 / 25 / 96$ & 4:00:24 AM & 1656 & & 72.4 & $03 / 13$ & analyzed in lab \\
\hline 2/25/96 & 4:15:36 AM & 1657 & & 71.8 & $03 / 13$ & anatyzed in lab \\
\hline $2 / 25 / 96$ & 4:30:49 AM & 1658 & & 71.3 & $03 / 13$ & anahyzed in lab \\
\hline $2 / 25 / 96$ & 4:46:07 AM & 1659 & & 72.3 & $03 / 13$ & analyzed in lab \\
\hline $2 / 25196$ & 5:01:27 AM & 1660 & & 72.2 & $03 / 13$ & analyzed in lab \\
\hline $2 / 25 / 96$ & 5:16:49 AM & 1661 & & 72.9 & $03 / 13$ & analyzed in lab \\
\hline $2 / 25 / 96$ & 5:32:09 AM & 1662 & & 73.4 & $03 / 13$ & analyzed in lab \\
\hline
\end{tabular}


Yucca Mountain tracer test; 12

\begin{tabular}{|c|c|c|c|c|c|c|}
\hline Date & Time of Sample & Sample \# & Dup, code & Conc (ppb) & Analysis date & place \\
\hline $2 / 25 / 96$ & $5: 47: 26$ AM & 1663 & & 72.5 & $03 / 13$ & analyzed in lab \\
\hline $2 / 25 / 96$ & $6: 02: 44$ AM & 1664 & & 72.6 & $03 / 13$ & analyzed in lab \\
\hline $2 / 25 / 96$ & 6:18:17 AM & 1665 & L/ & 72.8 & $03 / 27$ & analyzed in lab \\
\hline $2 / 25 / 96$ & 6:33:30 AM & 1666 & LD & 72.7 & & \\
\hline $2 / 25 / 96$ & $6: 48: 43 \mathrm{AM}$ & 1667 & LO & 75.6 & & \\
\hline $2 / 25 / 96$ & 7:04:01 AM & 1668 & LD & 73.7 & & \\
\hline $2 / 25 / 96$ & 7:19:23 AM & 1669 & LD & 73.9 & & \\
\hline $2 / 25 / 96$ & $7: 34: 43 \mathrm{AM}$ & 1670 & UD" & 73.3 & & \\
\hline $2 / 25 / 96$ & $7: 50: 00 \mathrm{AM}$ & 1671 & $\mathrm{UD}^{*}$ & 74.6 & & \\
\hline $2 / 25 / 96$ & $8: 05: 20 \mathrm{AM}$ & 1672 & LD & 71.8 & & \\
\hline $2 / 25 / 96$ & $8: 20: 41 \mathrm{AM}$ & 1673 & LD* & 74.4 & & \\
\hline $2 / 25 / 96$ & $8: 36: 13 \mathrm{AM}$ & 1674 & $\mathrm{UO}^{*}$ & 74.6 & & \\
\hline $2 / 25 / 96$ & $8: 51: 27 \mathrm{AM}$ & 1675 & UD & 74.8 & & \\
\hline $2 / 25 / 96$ & $9: 06: 39$ AM & 1676 & LD & 75.1 & & \\
\hline $2 / 25 / 96$ & $9: 21: 59 \mathrm{AM}$ & 1677 & UD* & 75.4 & & \\
\hline $2 / 25 / 96$ & 9:37:19 AM & 1678 & LD* & 75.6 & & \\
\hline $2 / 25 / 96$ & $9: 52: 40 \mathrm{AM}$ & 1679 & UD* & 76.0 & & \\
\hline $2 / 25 / 96$ & $10: 08: 01 \mathrm{AM}$ & 1680 & UD & 81.5 & & \\
\hline $2 / 25 / 96$ & $10: 23: 23 \mathrm{AM}$ & 1681 & UD & 75.3 & & \\
\hline $2 / 25 / 96$ & $10: 38: 42$ AM & 1682 & UD & 76.6 & & \\
\hline $2 / 25 / 96$ & $10: 54: 18 \mathrm{AM}$ & 1683 & UD & 80.1 & & \\
\hline $2 / 25 / 96$ & $11: 09: 32 \mathrm{AM}$ & 1684 & LD & 80.1 & & \\
\hline $2 / 25 / 96$ & $11: 24: 45$ AM & 1685 & UD & 79.5 & & \\
\hline $2 / 25 / 96$ & $11: 40: 03 \mathrm{AM}$ & 1686 & UD & 81.3 & & \\
\hline $2 / 25 / 96$ & $11: 55: 22$ AM & 1687 & UD & 80.5 & & \\
\hline $2 / 25 / 96$ & 12:10:41 PM & 1688 & UD & 80.7 & & \\
\hline $2 / 25 / 96$ & 12:26:02 PM & 1689 & UD & 72.3 & $03 / 13$ & analyzed in lab \\
\hline $2 / 25 / 96$ & $12: 41: 22 \mathrm{PM}$ & 1690 & & 74.4 & $03 / 13$ & analyzed in lab \\
\hline $2 / 25 / 96$ & $12: 56: 40 \mathrm{PM}$ & 1691 & & 74.2 & $03 / 13$ & analyzed in lab \\
\hline $2 / 25 / 96$ & 1:12:16 PM & 1692 & & 73.7 & $03 / 13$ & analyzed in lab \\
\hline $2 / 25 / 96$ & 1:27:30 PM & 1693 & & 74.3 & $03 / 13$ & analyzed in lab \\
\hline $2 / 25 / 96$ & 1:42:43 PM & 1694 & & 75.4 & $03 / 13$ & analyzed in lab \\
\hline $2 / 25 / 96$ & 1:57:58 PM & 1695 & & 73.5 & $03 / 13$ & analyzed in lab \\
\hline $2 / 25 / 96$ & 2:13:20 PM & 1696 & & 73.9 & $03 / 13$ & analyzed in lab \\
\hline $2 / 25 / 96$ & $2: 28: 39 \mathrm{PM}$ & 1697 & & 74.8 & $03 / 13$ & analyzed in lab \\
\hline $2 / 25 / 96$ & 2:43:59 PM & 1698 & & 75.8 & $03 / 13$ & analyzed in $\mathrm{lab}$ \\
\hline $2 / 25 / 96$ & 2:59:17 PM & 1699 & & 75.0 & $03 / 13$ & analyzed in lab \\
\hline $2 / 25 / 96$ & 3:14:37 PM & 1700 & & 75.1 & $03 / 13$ & analyzed in lab \\
\hline $2 / 25 / 96$ & $3: 30: 11$ PM & 1701 & & 74.5 & $03 / 13$ & analyzed in lab \\
\hline $2 / 25 / 96$ & 3:45:24 PM & 1702 & & 75.6 & $03 / 13$ & analyzed in lab \\
\hline $2 / 25 / 96$ & 4:00:37 PM & 1703 & & 77.5 & $03 / 13$ & analyzed in lab \\
\hline $2 / 25 / 96$ & 4:15:53 PM & 1704 & & 77.0 & $03 / 13$ & analyzed in lab \\
\hline $2 / 25 / 96$ & 4:31:11 PM & 1705 & & 78.6 & $03 / 13$ & analyzed in lab \\
\hline $2 / 25 / 96$ & 4:46:30 PM & 1706 & & 77.4 & $03 / 13$ & analyzed in lab \\
\hline $2 / 25 / 96$ & 5:01:49 PM & 1707 & & 76.4 & $03 / 13$ & analyzed in lab \\
\hline $2 / 25 / 96$ & 5:17:08 PM & 1708 & & 76.2 & $03 / 13$ & analyzed in lab \\
\hline $2 / 25 / 96$ & 5:32:25 PM & 1709 & & 76.5 & $03 / 13$ & analyzed in lab \\
\hline $2 / 25 / 96$ & 5:47:59 PM & 1710 & & 75.7 & $02 / 27$ & analyzed in field \\
\hline $2 / 25 / 96$ & 6:03:12 PM & 1711 & & 75.3 & $03 / 13$ & anahzed in lab \\
\hline $2 / 25 / 96$ & 6:18:26 PM & 1712 & & 79.0 & $03 / 13$ & analyzed in lab \\
\hline $2 / 25 / 96$ & 6:33:43 PM & 1713 & & 80.3 & $03 / 12$ & analyzed in lab \\
\hline $2 / 25 / 96$ & 6:49:04 PM & 1714 & & 82.2 & $03 / 12$ & analyzed in lab \\
\hline $2 / 25 / 96$ & 7:04:22 PM & 1715 & & 81.8 & $03 / 12$ & analyzed in lab \\
\hline $2 / 25 / 96$ & 7:19:42 PM & 1716 & & 82.8 & $03 / 12$ & analyzed in lab \\
\hline $2 / 25 / 96$ & 7:35:01 PM & 1717 & & 81.8 & $03 / 12$ & analyzed in lab \\
\hline $2 / 25 / 96$ & 7:50:21 PM & 1718 & & 81.6 & $03 / 12$ & analyzed in lab \\
\hline $2 / 25 / 96$ & 8:06:00 PM & 1749 & & 80.6 & $03 / 12$ & analyzed in lab \\
\hline $2 / 25 / 96$ & 8:21:13 PM & 1720 & & 81.1 & $03 / 12$ & analyzed in lab \\
\hline $2 / 25 / 96$ & 8:36:29 PM & 1721 & & 80.9 & $03 / 12$ & anahzed in $\mathrm{ab}$ \\
\hline $2 / 25 / 96$ & 8:51:51 PM & 1722 & & 80.2 & $03 / 12$ & analyzed in $\mathrm{lab}$ \\
\hline $2 / 25 / 96$ & 9:07:11 PM & 1723 & & 80.4 & $03 / 12$ & analyzed in lab \\
\hline $2 / 25 / 96$ & 9:22:30 PM & 1724 & & 80.1 & $03 / 12$ & analyzed in $\mathrm{lab}$ \\
\hline $2 / 25 / 96$ & 9:37:47 PM & 1725 & & 78.8 & $03 / 13$ & analyzed in lab \\
\hline $2 / 25 / 96$ & 9:53:07 PM & 1726 & & 80.2 & $03 / 13$ & analyzed in $\mathrm{lab}$ \\
\hline $2 / 25 / 96$ & 10:08:28 PM & 1727 & & 73.9 & $03 / 13$ & analyzed in lab \\
\hline $2 / 25 / 96$ & $10: 24: 05 \mathrm{PM}$ & 1728 & & 78.1 & $03 / 13$ & analyzed in lab \\
\hline $2 / 25 / 96$ & $10: 39: 18 \mathrm{PM}$ & 1729 & & 78.7 & $03 / 13$ & analyzed in lab \\
\hline $2 / 25 / 96$ & 10:54:31 PM & 1730 & LD* & 77.7 & $03 / 13$ & analyzed in $l a b$ \\
\hline $2 / 25 / 96$ & 11:09:47 PM & 1731 & & 79.9 & $03 / 13$ & analyzed in lab \\
\hline $2 / 25 / 96$ & $11: 25: 07 \mathrm{PM}$ & 1732 & & 79.8 & $03 / 13$ & analyzed in lab \\
\hline
\end{tabular}




\begin{tabular}{|c|c|c|c|c|c|c|}
\hline Date & Time of Sample & Sample \# & Dup. code & Conc (ppb) & Analysis date & place \\
\hline $2 / 25 / 96$ & $11: 40: 27 \mathrm{PM}$ & 1733 & & 80.8 & $03 / 13$ & analyzed in lab \\
\hline $2 / 25 / 96$ & $11: 55: 46 \mathrm{PM}$ & 1734 & & 80.7 & $03 / 13$ & analyzed in lab \\
\hline $2 / 26 / 96$ & $12: 11: 07 \mathrm{AM}$ & 1735 & & 82.0 & $03 / 13$ & analyzed in lab \\
\hline $2 / 26 / 96$ & $12: 26: 28 \mathrm{AM}$ & 1736 & & 77.0 & $03 / 13$ & anahyzed in lab \\
\hline $2 / 26 / 96$ & $12: 42: 01 \mathrm{AM}$ & 1737 & & 80.8 & $03 / 13$ & analyzed in lab \\
\hline $2 / 26 / 96$ & $12: 57: 14 \mathrm{AM}$ & 1738 & & 80.5 & $03 / 13$ & analyzed in lab \\
\hline $2 / 26 / 96$ & $1: 12: 27 \mathrm{AM}$ & 1739 & & 79.6 & $03 / 13$ & analyzed in lab \\
\hline $2 / 26 / 96$ & $1: 27: 44$ AM & 1740 & & 79.4 & $03 / 13$ & analyzed in lab \\
\hline $2 / 26 / 96$ & $1: 43: 04 \mathrm{AM}$ & 1741 & & 79.4 & $03 / 13$ & analyzed in lab \\
\hline $2 / 26 / 96$ & 1:58:26 AM & 1742 & & 79.6 & $03 / 13$ & analyzed in lab \\
\hline $2 / 26 / 96$ & 2:13:47 AM & 1743 & & 80.9 & $03 / 13$ & analyzed in lab \\
\hline $2 / 26 / 96$ & 2:29:07 AM & 1744 & & 79.5 & $03 / 13$ & analyzed in lab \\
\hline $2 / 26 / 96$ & $2: 44: 26 \mathrm{AM}$ & 1745 & & 78.9 & $03 / 13$ & analyzed in lab \\
\hline $2 / 26 / 96$ & $3: 00: 02$ AM & 1746 & & 80.6 & $03 / 13$ & analyzed in lab \\
\hline $2 / 26 / 96$ & $3: 15: 14 A M$ & 1747 & & 80.5 & $03 / 13$ & analyzed in lab \\
\hline $2 / 26 / 96$ & $3: 30: 27 \mathrm{AM}$ & 1748 & & 80.8 & $03 / 13$ & analyzed in lab \\
\hline $2 / 26 / 96$ & 3:45:47 AM & 1749 & & 79.7 & $03 / 13$ & analyzed in lab \\
\hline $2 / 26 / 96$ & 4:01:07 AM & 1750 & LD* & 80.3 & $03 / 13$ & analyzed in lab \\
\hline $2 / 26 / 96$ & 4:16:23 AM & 1751 & & 80.6 & $03 / 13$ & analyzed in lab \\
\hline $2 / 26 / 96$ & $4: 31: 43 \mathrm{AM}$ & 1752 & LD* & 80.9 & $03 / 13$ & analyzed in lab \\
\hline $2 / 26 / 96$ & 4:47:01 AM & 1753 & & 80.4 & $03 / 13$ & analyzed in lab \\
\hline $2 / 26 / 96$ & 5:02:18 AM & 1754 & & 79.6 & $03 / 13$ & analyzed in lab \\
\hline $2 / 26 / 96$ & 5:17:55 AM & 1755 & & 81.9 & $03 / 13$ & analyzed in lab \\
\hline $2 / 26 / 96$ & 5:33:08 AM & 1756 & & 80.5 & $03 / 13$ & analyzed in lab \\
\hline $2 / 26 / 96$ & 5:48:22 AM & 1757 & & 81.1 & $03 / 13$ & analyzed in lab \\
\hline $2 / 26 / 96$ & $6: 03: 37 \mathrm{AM}$ & 1758 & & 81.6 & $03 / 13$ & analyzed in lab \\
\hline $2 / 26 / 96$ & $6: 18: 56 \mathrm{AM}$ & 1759 & & 81.1 & $03 / 13$ & analyzed in lab \\
\hline $2 / 26 / 96$ & $6: 34: 17 \mathrm{AM}$ & 1760 & & 81.8 & $03 / 13$ & analyzed in lab \\
\hline $2 / 26 / 96$ & $6: 49: 35$ AM & 1761 & & 85.2 & $03 / 12$ & analyzed in lab \\
\hline $2 / 26 / 96$ & $7: 04: 54 \mathrm{AM}$ & 1762 & & 85.6 & $03 / 12$ & analyzed in lab \\
\hline $2 / 26 / 96$ & $7: 20: 12 \mathrm{AM}$ & 1763 & & 85.1 & $03 / 12$ & analyzed in lab \\
\hline $2 / 26 / 96$ & $7: 35: 48$ AM & 1764 & & 84.0 & $03 / 12$ & analyzed in lab \\
\hline $2 / 26 / 90$ & $7: 51: 00 \mathrm{AM}$ & 1765 & & 85.4 & $03 / 12$ & analyzed in lab \\
\hline $2 / 26 / 96$ & $8: 06: 13$ AM & 1766 & & 85.4 & $03 / 12$ & analyzed in lab \\
\hline $2 / 26 / 96$ & $8: 21: 34$ AM & 1767 & & 84.4 & $03 / 12$ & analyzed in lab \\
\hline $2 / 26 / 96$ & $8: 36: 57 \mathrm{AM}$ & 1768 & & 84.8 & $03 / 12$ & analyzed in lab \\
\hline $2 / 26 / 96$ & $8: 52: 17$ AM & 1769 & & 85.3 & $03 / 12$ & analyzed in lab \\
\hline $2 / 26 / 96$ & 9:07:34 AM & 1770 & & 83.9 & $03 / 12$ & analyzed in lab \\
\hline $2 / 26 / 96$ & $9: 22: 53 \mathrm{AM}$ & 1771 & & 85.0 & $03 / 12$ & analyzed in lab \\
\hline $2 / 26 / 96$ & $9: 38: 14$ AM & 1772 & & 85.0 & $03 / 12$ & analyzed in lab \\
\hline $2 / 26 / 96$ & $9: 53: 48$ AM & 1773 & & 86.1 & $03 / 12$ & analyzed in lab \\
\hline $2 / 26 / 96$ & $10: 09: 02 \mathrm{AM}$ & 1774 & & 85.4 & $03 / 12$ & analyzed in lab \\
\hline $2 / 26 / 96$ & $10: 24: 15 \mathrm{AM}$ & 1775 & & 87.6 & $03 / 12$ & analyzed in lab \\
\hline $2 / 26 / 96$ & $10: 39: 31 \mathrm{AM}$ & 1776 & & 86.4 & $03 / 12$ & analyzed in lab \\
\hline $2 / 26 / 96$ & $10: 54: 50 \mathrm{AM}$ & 1777 & & 84.4 & $03 / 12$ & analyzed in lab \\
\hline $2 / 26 / 96$ & $11: 10: 12 \mathrm{AM}$ & 1778 & & 85.0 & $03 / 12$ & analyzed in lab \\
\hline $2 / 26 / 96$ & $11: 25: 30 \mathrm{AM}$ & 1779 & & 86.7 & $03 / 12$ & analyzed in lab \\
\hline $2 / 26 / 96$ & $11: 40: 51 \mathrm{AM}$ & 1780 & & 84.8 & $03 / 12$ & anailyzed in lab \\
\hline $2 / 26 / 96$ & $11: 56: 10 \mathrm{AM}$ & 1781 & & 85.8 & $03 / 12$ & analyzed in $\mathrm{kb}$ \\
\hline $2 / 26 / 96$ & $12: 11: 46 \mathrm{PM}$ & 1782 & & 80.1 & $02 / 27$ & anahred in field \\
\hline $2 / 26 / 96$ & $12: 26: 59 \mathrm{PM}$ & 1783 & & 86.3 & $03 / 12$ & analyzed in lab \\
\hline $2 / 26 / 96$ & $12: 42: 13 \mathrm{PM}$ & 1784 & & 85.5 & $03 / 12$ & analyzed in lab \\
\hline $2 / 26 / 96$ & $12: 57: 33 \mathrm{PM}$ & 1785 & LD & 86.6 & & \\
\hline $2 / 26 / 96$ & $1: 12: 54 \mathrm{PM}$ & 1786 & & 86.6 & $03 / 12$ & analyzed in lab \\
\hline $2 / 26 / 96$ & $1: 28: 16 \mathrm{PM}$ & 1787 & & 87.0 & $03 / 12$ & analyzed in lab \\
\hline $2 / 26 / 96$ & 1:43:36 PM & 1788 & & 87.1 & $03 / 12$ & analyzed in $\mathrm{lab}$ \\
\hline $2 / 26 / 96$ & 1:58:55 PM & 1789 & & 87.4 & $03 / 12$ & analyzed in lab \\
\hline $2 / 26 / 96$ & $2: 14: 20 \mathrm{PM}$ & 1790 & & 87.2 & $03 / 12$ & analyzed in $\mathrm{ab}$ \\
\hline $2 / 26 / 96$ & $2: 30: 03$ PM & 1791 & & 85.1 & $03 / 12$ & analyzed in lab \\
\hline $2 / 26196$ & 2:45:17 PM & 1792 & & 86.8 & $03 / 12$ & analyzed in lab \\
\hline $2 / 26 / 96$ & 3:00:30 PM & 1793 & & 86.4 & $03 / 12$ & analyzed in lab \\
\hline $2 / 26 / 96$ & 3:15:52 PM & 1794 & & 87.0 & $03 / 12$ & analyzed in lab \\
\hline $2 / 26 / 96$ & $3: 31: 12 \mathrm{PM}$ & 1795 & & 88.2 & $03 / 12$ & analyzed in lab \\
\hline $2 / 26 / 96$ & $3: 46: 34 \mathrm{PM}$ & 1796 & & 85.3 & $03 / 12$ & analyzed in lab \\
\hline $2 / 26 / 96$ & 4:02:00 PM & 1797 & LD & 88.0 & & \\
\hline $2 / 26 / 96$ & 4:17:21 PM & 1798 & & 85.8 & $03 / 12$ & analyzed in lab \\
\hline $2 / 26 / 96$ & 4:32:41 PM & 1799 & & & & \\
\hline $2 / 26 / 96$ & 4:48:14 PM & 1800 & & 87.9 & $03 / 12$ & analyzed in lab \\
\hline $2 / 26 / 96$ & 5:03:28 PM & 1801 & & 88.5 & $03 / 12$ & analyzed in $\mathrm{kb}$ \\
\hline $2 / 26 / 96$ & 5:18:41 PM & 1802 & & 87.5 & $03 / 12$ & analyzed in lab \\
\hline
\end{tabular}




\begin{tabular}{|c|c|c|c|c|c|c|}
\hline Date & Time of Sample & Sample \# & Dup. code & Conc (ppb) & Analysis date & place \\
\hline $2 / 26 / 96$ & $5: 33: 58 \mathrm{PM}$ & 1803 & & 87.2 & $03 / 12$ & analyzed in lab \\
\hline $2 / 26 / 96$ & 5:48:18 PM & 1804 & & 89.4 & $03 / 12$ & analyzed in lab \\
\hline $2 / 26 / 96$ & 6:04:38 PM & 1805 & & 88.1 & $03 / 12$ & analyzed in lab \\
\hline $2 / 26 / 96$ & $6: 20: 00 \mathrm{PM}$ & 1806 & & 84.2 & $02 / 27$ & analyzed in field \\
\hline $2 / 26 / 96$ & 6:35:21 PM & 1807 & & 88.4 & $03 / 12$ & analyzed in lab \\
\hline $2 / 26 / 96$ & $6: 50: 41 \mathrm{PM}$ & 1808 & & 89.0 & $03 / 12$ & analyzed in lab \\
\hline $2 / 26 / 96$ & 7:06:15 PM & 1809 & & 92.5 & $03 / 12$ & analyzed in lab \\
\hline $2 / 26 / 96$ & $7: 21: 28 \mathrm{PM}$ & 1810 & & 90.9 & $03 / 12$ & analyzed in lab \\
\hline $2 / 26 / 96$ & 7:36:41 PM & 1811 & & 92.4 & $03 / 12$ & analyzed in lab \\
\hline $2 / 26 / 96$ & $7: 51: 56 \mathrm{PM}$ & 1812 & & 90.1 & $03 / 12$ & analyzed in lab \\
\hline $2 / 26 / 96$ & $8: 07: 17 \mathrm{PM}$ & 1813 & & 91.6 & $03 / 12$ & analyzed in lab \\
\hline $2 / 26 / 96$ & $8: 22: 36 \mathrm{PM}$ & 1814 & & 91.4 & $03 / 12$ & analyzed in lab \\
\hline $2 / 26 / 96$ & $8: 37: 52$ PM & 1815 & & 89.8 & $03 / 12$ & analyzed in lab \\
\hline $2 / 26 / 96$ & 8:53:11 PM & 1816 & & 91.2 & $03 / 12$ & analyzed in lab \\
\hline $2 / 26 / 96$ & 9:08:38 PM & 1817 & & 91.3 & $03 / 12$ & analyzed in lab \\
\hline $2 / 26 / 96$ & $9: 24: 09 \mathrm{PM}$ & 1818 & & 91.2 & $03 / 12$ & analyzed in lab \\
\hline $2 / 26 / 96$ & 9:39:23 PM & 1819 & UD* & 90.0 & $03 / 12$ & analyzed in lab \\
\hline $2 / 26 / 96$ & 9:54:36 PM & 1820 & & 90.7 & $03 / 12$ & analyzed in lab \\
\hline $2 / 26 / 96$ & $10: 09: 56 \mathrm{PM}$ & 1821 & & 91.0 & $03 / 12$ & analyzed in lab \\
\hline $2 / 26 / 96$ & $10: 25: 18 \mathrm{PM}$ & 1822 & & 92.1 & $03 / 12$ & analyzed in lab \\
\hline $2 / 26 / 96$ & $10: 40: 37 \mathrm{PM}$ & 1823 & & 90.6 & $03 / 12$ & analyzed in lab \\
\hline $2 / 26 / 96$ & $10: 55: 57 \mathrm{PM}$ & 1824 & & 91.4 & $03 / 12$ & analyzed in lab \\
\hline $2 / 26 / 96$ & $11: 11: 15 \mathrm{PM}$ & 1825 & & 90.8 & $03 / 12$ & analyzed in lab \\
\hline $2 / 26 / 96$ & $11: 26: 40 \mathrm{PM}$ & 1826 & & 90.3 & $03 / 12$ & analyzed in lab \\
\hline $2 / 26 / 96$ & $11: 42: 20 \mathrm{PM}$ & 1827 & & 92.0 & $03 / 12$ & analyzed in lab \\
\hline $2 / 26 / 96$ & 11:57:32 PM & 1828 & & 90.9 & $03 / 12$ & analyzed in lab \\
\hline $2 / 27 / 96$ & $12: 12: 45 \mathrm{AM}$ & 1829 & & 91.8 & $03 / 12$ & analyzed in lab \\
\hline $2 / 27 / 96$ & 12:28:01 AM & 1830 & & 90.6 & $03 / 12$ & analyzed in lab \\
\hline $2 / 27 / 96$ & $12: 43: 20 \mathrm{AM}$ & 1831 & & 90.8 & $03 / 12$ & analyzed in lab \\
\hline $2 / 27 / 96$ & $12: 58: 41 \mathrm{AM}$ & 1832 & & 91.0 & $03 / 12$ & analyzed in lab \\
\hline $2 / 27 / 96$ & $1: 14: 00 \mathrm{AM}$ & 1833 & & 91.6 & $03 / 12$ & analyzed in lab \\
\hline $2 / 27 / 96$ & 1:29:19 AM & 1834 & & 91.9 & $03 / 12$ & analyzed in lab \\
\hline $2 / 27 / 96$ & $1: 44: 40 \mathrm{AM}$ & 1835 & & 90.1 & $03 / 12$ & analyzed in lab \\
\hline $2 / 27 / 96$ & $2: 00: 16$ AM & 1836 & & 90.8 & $03 / 12$ & analyzed in lab \\
\hline $2 / 27 / 96$ & 2:15:29 AM & 1837 & & 90.6 & $03 / 12$ & analyzed in lab \\
\hline $2 / 27 / 96$ & $2: 30: 43$ AM & 1838 & & 89.5 & $03 / 12$ & analyzed in lab \\
\hline $2 / 27 / 96$ & 2:45:59 AM & 1839 & & 90.2 & $03 / 12$ & analyzed in lab \\
\hline $2 / 27 / 96$ & 3:01:16 AM & 1840 & & 88.7 & $03 / 12$ & analyzed in lab \\
\hline $2 / 27 / 96$ & 3:16:34 AM & 1841 & & 91.9 & $03 / 12$ & analyzed in lab \\
\hline $2 / 27196$ & $3: 31: 53 \mathrm{AM}$ & 1842 & & 90.3 & $03 / 12$ & analyzed in $1 \mathrm{ab}$ \\
\hline $2 / 27 / 96$ & $3: 47: 13 \mathrm{AM}$ & 1843 & & 81.8 & $03 / 12$ & analyzed in lab \\
\hline $2 / 27 / 96$ & 4:02:33 AM & 1844 & & 88.9 & $03 / 12$ & analyzed in lab \\
\hline $2 / 27 / 96$ & 4:18:09 AM & 1845 & & 91.7 & $03 / 12$ & analyzed in lab \\
\hline $2 / 27 / 96$ & 4:33:22 AM & 1846 & & 91.5 & $03 / 12$ & analyzed in lab \\
\hline $2 / 27 / 96$ & 4:48:35 AM & 1847 & & 91.9 & $03 / 12$ & analyzed in lab \\
\hline $2 / 27 / 96$ & 5:03:55 AM & 1848 & & 91.1 & $03 / 12$ & analyzed in lab \\
\hline $2 / 27 / 96$ & 5:19:16 AM & 1849 & & 93.0 & $03 / 12$ & analyzed in lab \\
\hline $2 / 27 / 96$ & 5:34:35 AM & 1850 & & 91.8 & $03 / 12$ & analyzed in lab \\
\hline $2 / 27 / 96$ & 5:49:54 AM & 1851 & & 90.8 & $03 / 12$ & analyzed in lab \\
\hline $2 / 27196$ & 6:05:16 AM & 1852 & & 90.6 & $03 / 12$ & analyzed in lab \\
\hline $2 / 27 / 96$ & $6: 20: 36 \mathrm{AM}$ & 1853 & & 88.7 & $02 / 27$ & analyzed in field \\
\hline $2 / 27 / 96$ & 6:36:11 AM & 1854 & & 86.3 & $02 / 27$ & analyzed in field \\
\hline $2 / 27 / 96$ & $6: 51: 24 \mathrm{AM}$ & 1855 & & 85.2 & $02 / 27$ & analyzed in field \\
\hline $2 / 27 / 96$ & 7:06:38 AM & 1856 & & 86.3 & $02 / 27$ & analyzed in field \\
\hline $2 / 27 / 96$ & $7: 21: 53 \mathrm{AM}$ & 1857 & & 88.8 & $02 / 27$ & analyzed in field \\
\hline $2 / 27 / 96$ & 7:37:12 AM & 1858 & & 85.2 & $02 / 27$ & analyzed in field \\
\hline $2 / 27 / 96$ & 7:52:32 AM & 1859 & & 87.7 & $02 / 27$ & analyzed in field \\
\hline $2 / 27 / 96$ & $8: 07: 50 \mathrm{AM}$ & 1860 & & 87.1 & $02 / 27$ & analyzed in field \\
\hline $2 / 27 / 96$ & 8:23:09 AM & 1861 & & 85.5 & $02 / 27$ & analyzed in field \\
\hline $2 / 27 / 96$ & $8: 38: 29 \mathrm{AM}$ & 1862 & & 87.4 & $02 / 27$ & analyzed in field \\
\hline $2 / 27 / 96$ & $8: 54: 03 \mathrm{AM}$ & 1863 & & 86.4 & $02 / 27$ & analyzed in field \\
\hline $2 / 27 / 96$ & $9: 09: 16$ AM & 1864 & & 85.7 & $02 / 27$ & anahred in field \\
\hline $2 / 27 / 96$ & $9: 24: 29 \mathrm{AM}$ & 1865 & & 85.1 & $02 / 27$ & analyzed in field \\
\hline $2 / 27 / 96$ & $9: 39: 53 \mathrm{AM}$ & 1866 & & 83.9 & $02 / 27$ & analyzed in field \\
\hline $2 / 27 / 96$ & 9:55:11 AM & 1867 & & 86.6 & $02 / 27$ & analyzed in field \\
\hline $2 / 27 / 96$ & $10: 10: 31 \mathrm{AM}$ & 1868 & & 85.6 & $02 / 27$ & analyzed in field \\
\hline $2 / 27 / 96$ & $10: 25: 53 \mathrm{AM}$ & 1869 & & 84.8 & $02 / 27$ & analyzed in field \\
\hline $2 / 27 / 96$ & $10: 41: 12 \mathrm{AM}$ & 1870 & & 84.6 & $02 / 27$ & analyzed in field \\
\hline $2 / 27 / 96$ & $10: 56: 32 \mathrm{AM}$ & 1871 & & 84.8 & $02 / 27$ & analyzed in field \\
\hline $2 / 27 / 96$ & $11: 12: 08 \mathrm{AM}$ & 1872 & & 86.3 & 02227 & analyzed in field \\
\hline
\end{tabular}




\begin{tabular}{|c|c|c|c|c|c|c|}
\hline Date & Time of Sample & Sample \# & Dup. code & Conc (ppb) & Analysis date & place \\
\hline $2 / 27 / 96$ & $11: 27: 21 \mathrm{AM}$ & 1873 & & 84.3 & $02 / 27$ & analyzed in field \\
\hline $2 / 27 / 96$ & $11: 47: 34 \mathrm{AM}$ & 1874 & & 84.6 & $02 / 27$ & analyzed in field \\
\hline $2 / 27 / 96$ & $12: 08: 00 \mathrm{PM}$ & 1875 & & 86.7 & 0227 & analyzed in field \\
\hline $2 / 27 / 96$ & 12:28:27 PM & 1876 & & 86.6 & $02 / 27$ & analyzed in field \\
\hline $2 / 27 / 96$ & $12: 48: 58 \mathrm{PM}$ & 1877 & & 86.5 & $02 / 27$ & analyzed in field \\
\hline $2 / 27 / 96$ & 1:09:25 PM & 1878 & & 87.4 & $02 / 27$ & analyzed in field \\
\hline $2 / 27 / 96$ & 1:29:52 PM & 1879 & & 86.9 & $02 / 27$ & analyzed in field \\
\hline $2 / 27 / 96$ & 1:50:21 PM & 1880 & & 92.2 & $03 / 12$ & analyzed in lab \\
\hline $2 / 27 / 96$ & 2:11:08 PM & 1881 & & 92.5 & $03 / 12$ & analyzed in lab \\
\hline $2 / 27 / 96$ & $2: 31: 20 \mathrm{PM}$ & 1882 & & 92.9 & $03 / 12$ & analyzed in lab \\
\hline $2 / 27 / 96$ & $2: 51: 36$ PM & 1883 & & 92.0 & $03 / 12$ & analyzed in $\mathrm{lab}$ \\
\hline $2 / 27 / 96$ & 3:12:01 PM & 1884 & & 90.4 & $03 / 13$ & analyzed in lab \\
\hline $2 / 27 / 96$ & 3:32:28 PM & 1885 & & 89.3 & $03 / 13$ & analyzed in lab \\
\hline $2 / 27 / 96$ & $3: 52: 55 \mathrm{PM}$ & 1886 & & 90.6 & $03 / 13$ & analyzed in lab \\
\hline $2 / 27 / 96$ & 4:13:21 PM & 1887 & & 89.9 & $03 / 13$ & analyzed in lab \\
\hline $2 / 27 / 96$ & 4:33:47 PM & 1888 & & 91.0 & $03 / 13$ & analyzed in lab \\
\hline $2 / 27 / 96$ & 4:54:11 PM & 1889 & & 92.6 & $03 / 13$ & analyzed in lab \\
\hline $2 / 27196$ & 5:14:57 PM & 1890 & & 89.9 & $03 / 13$ & analyzed in lab \\
\hline $2 / 27 / 96$ & 5:35:10 PM & 1891 & & 93.1 & $03 / 13$ & analyzed in lab \\
\hline $2 / 27 / 96$ & 5:55:26 PM & 1892 & & 89.8 & $03 / 13$ & analyzed in lab \\
\hline $2 / 27 / 96$ & 6:15:54 PM & 1893 & & 90.3 & $03 / 13$ & analyzed in lab \\
\hline $2 / 27 / 96$ & $6: 36: 26 \mathrm{PM}$ & 1894 & & 90.1 & $03 / 13$ & analyzed in lab \\
\hline $2 / 27 / 96$ & 6:56:53 PM & 1895 & & 86.8 & $03 / 13$ & analyzed in lab \\
\hline $2 / 27 / 96$ & 7:17:21 PM & 1896 & & 89.5 & $03 / 07$ & analyzed in lab \\
\hline $2 / 27 / 96$ & $7: 37: 47$ PM & 1897 & & 89.1 & $03 / 07$ & analyzed in lab \\
\hline $2 / 27 / 96$ & 7:58:14 PM & 1898 & & 91.4 & $03 / 07$ & analyzed in lab \\
\hline $2 / 27 / 96$ & 8:19:04 PM & 1899 & & 89.9 & $03 / 07$ & analyzed in lab \\
\hline $2 / 27 / 96$ & $8: 39: 17 \mathrm{PM}$ & 1900 & & 89.4 & $03 / 07$ & analyzed in lab \\
\hline $2 / 27 / 96$ & 8:59:34 PM & 1901 & & 88.5 & $03 / 07$ & analyzed in lab \\
\hline $2 / 27 / 96$ & 9:20:04 PM & 1902 & & 89.5 & $03 / 07$ & analyzed in tab \\
\hline $2 / 27 / 96$ & $9: 40: 28 \mathrm{PM}$ & 1903 & & 90.4 & $03 / 07$ & analyzed in lab \\
\hline $2 / 27 / 96$ & $10: 00: 59 \mathrm{PM}$ & 1904 & & 89.8 & $03 / 07$ & analyzed in lab \\
\hline $2 / 27 / 96$ & $10: 21: 31 \mathrm{PM}$ & 1905 & & 90.6 & $03 / 07$ & analyzed in lab \\
\hline $2 / 27 / 96$ & 10:42:00 PM & 1906 & & 90.5 & $03 / 07$ & analyzed in lab \\
\hline $2 / 27 / 96$ & 11:02:27 PM & 1907 & & 91.8 & $03 / 07$ & analyzed in lab \\
\hline $2 / 27 / 96$ & $11: 23: 19 \mathrm{PM}$ & 1908 & & 90.2 & $03 / 13$ & analyzed in lab \\
\hline $2 / 27 / 96$ & 11:43:32 PM & 1909 & & 90.9 & $03 / 13$ & analyzed in lab \\
\hline $2 / 28 / 96$ & $12: 03: 54 \mathrm{AM}$ & 1910 & & 92.0 & $03 / 13$ & analyzed in lab \\
\hline $2 / 28 / 96$ & 12:24:20 AM & 1911 & & 87.7 & $03 / 13$ & analyzed in lab \\
\hline $2 / 28 / 96$ & $12: 44: 49 \mathrm{AM}$ & 1912 & & 93.2 & $03 / 13$ & analyzed in lab \\
\hline $2 / 28 / 96$ & $1: 05: 15 \mathrm{AM}$ & 1913 & & 90.4 & $03 / 13$ & analyzed in lab \\
\hline $2 / 28 / 96$ & $1: 25: 42$ AM & 1914 & & 90.6 & $03 / 13$ & analyzed in lab \\
\hline $2 / 28 / 96$ & 1:46:09 AM & 1915 & & 92.9 & $03 / 13$ & analyzed in lab \\
\hline $2 / 28 / 96$ & 2:06:36 AM & 1916 & LD & 91.4 & & \\
\hline $2 / 28 / 96$ & $2: 27: 24 \mathrm{AM}$ & 1917 & & 90.7 & $03 / 13$ & analyzed in lab \\
\hline $2 / 28 / 96$ & $2: 47: 36$ AM & 1918 & & 89.8 & $03 / 13$ & analyzed in $\mathrm{lab}$ \\
\hline $2 / 28 / 96$ & 3:07:53 AM & 1919 & & 90.7 & $03 / 13$ & analyzed in lab \\
\hline $2 / 28 / 96$ & $3: 28: 20 \mathrm{AM}$ & 1920 & & 92.6 & $03 / 11$ & analyzed in lab \\
\hline $2 / 28 / 96$ & 3:48:47 AM & 1921 & & 92.8 & $03 / 11$ & analyzed in lab \\
\hline $2 / 28 / 96$ & 4:09:15 AM & 1922 & & 92.2 & $03 / 11$ & analyzed in lab \\
\hline $2 / 28 / 96$ & $4: 29: 43 \mathrm{AM}$ & 1923 & & 92.8 & $03 / 11$ & analyzed in lab \\
\hline $2 / 28 / 96$ & 4:50:12 AM & 1924 & & 93.4 & $03 / 11$ & analyzed in lab \\
\hline $2 / 28 / 96$ & $5: 10: 40$ AM & 1925 & & 91.8 & $03 / 11$ & analyzed in lab \\
\hline $2 / 28 / 96$ & 5:31:32 AM & 1926 & & 93.1 & $03 / 11$ & analyzed in lab \\
\hline $2 / 28 / 96$ & $5: 51: 46$ AM & 1927 & & 92.8 & $03 / 11$ & analyzed in lab \\
\hline $2 / 28 / 96$ & 6:12:02 AM & 1928 & & 92.8 & $03 / 11$ & analyzed in $\mathrm{lab}$ \\
\hline $2 / 28196$ & 6:32:28 AM & 1929 & & 93.8 & $03 / 11$ & analyzed in lab \\
\hline $2 / 28 / 96$ & 6:52:52 AM & 1930 & & 92.6 & $03 / 11$ & analyzed in lab \\
\hline $2 / 28 / 96$ & 7:13:23 AM & 1931 & & 92.6 & $03 / 11$ & analyzed in lab \\
\hline $2 / 28 / 96$ & 7:33:51 AM & 1932 & & & & \\
\hline $2 / 28 / 96$ & $7: 54: 17 \mathrm{AM}$ & 1933 & & 95.1 & $03 / 06$ & analyzed in lab \\
\hline $2 / 28 / 96$ & $8: 14: 40 \mathrm{AM}$ & 1934 & & 95.1 & $03 / 06$ & analyzed in lab \\
\hline $2 / 28 / 96$ & $8: 35: 22 \mathrm{AM}$ & 1935 & & 96.1 & $03 / 06$ & analyzed in lab \\
\hline $2 / 28 / 96$ & $8: 55: 35 \mathrm{AM}$ & 1936 & & 93.5 & $03 / 06$ & analyzed in lab \\
\hline $2 / 28 / 96$ & $9: 15: 58 \mathrm{AM}$ & 1937 & & 97.5 & $03 / 06$ & analyzed in lab \\
\hline $2 / 28 / 96$ & 9:36:27 AM & 1938 & & 96.5 & $03 / 06$ & analyzed in lab \\
\hline $2 / 28 / 96$ & 9:56:54 AM & 1939 & & 93.7 & $03 / 06$ & analyzed in lab \\
\hline $2 / 28 / 96$ & $10: 17: 23 \mathrm{AM}$ & 1940 & & 95.5 & $03 / 06$ & analyzed in lab \\
\hline $2 / 28 / 96$ & $10: 37: 47 \mathrm{AM}$ & 1941 & & 94.2 & $03 / 06$ & analyzed in lab \\
\hline $2 / 28 / 96$ & $10: 58: 15 \mathrm{AM}$ & 1942 & & 95.5 & $03 / 06$ & analyzed in lab \\
\hline
\end{tabular}


Yucca Mountain tracer test; 16

\begin{tabular}{|c|c|c|c|c|c|c|}
\hline Date & Time of Sample & Sample \# & Dup. code & Conc (ppb) & Analysis date & place \\
\hline $2 / 28 / 96$ & $11: 18: 42$ AM & 1943 & & 95.7 & $03 / 06$ & analyzed in lab \\
\hline $2 / 28 / 96$ & $11: 39: 28 \mathrm{AM}$ & 1944 & & 91.1 & $03 / 13$ & analyzed in lab \\
\hline $2 / 28 / 96$ & $11: 59: 41 \mathrm{AM}$ & 1945 & & 91.2 & $03 / 13$ & anahyzed in lab \\
\hline $2 / 28 / 96$ & $12: 19: 58 \mathrm{PM}$ & 1946 & & 91.8 & $03 / 13$ & analyzed in lab \\
\hline $2 / 28196$ & $12: 40: 23 \mathrm{PM}$ & 1947 & & 90.7 & $03 / 13$ & analyzed in lab \\
\hline 2128196 & $1: 00: 50 \mathrm{PM}$ & 1948 & & 91.7 & $03 / 13$ & analyzed in lab \\
\hline $2 / 28 / 96$ & $1: 21: 29 \mathrm{PM}$ & 1949 & & 91.8 & $03 / 13$ & analyzed in lab \\
\hline $2 / 28 / 96$ & $1: 41: 40 \mathrm{PM}$ & 1950 & & 90.5 & $03 / 13$ & analyzed in lab \\
\hline $2 / 28 / 96$ & $2: 02: 09 \mathrm{PM}$ & 1951 & & 92.0 & $03 / 13$ & analyzed in $\mathrm{ab}$ \\
\hline $2 / 28 / 96$ & $2: 22: 35 \mathrm{PM}$ & 1952 & & 92.4 & $03 / 13$ & anatyzed in lab \\
\hline $2 / 28 / 96$ & 2:43:18 PM & 1953 & & 91.3 & $03 / 13$ & analyzed in lab \\
\hline $2 / 28 / 96$ & 3:03:32 PM & 1954 & & 92.3 & $03 / 13$ & analyzed in lab \\
\hline $2 / 28 / 96$ & 3:23:52 PM & 1955 & & 91.1 & $03 / 13$ & analyzed in lab \\
\hline $2 / 28 / 96$ & $3: 44: 18 \mathrm{PM}$ & 1956 & & 97.4 & $03 / 12$ & analyzed in lab \\
\hline $2 / 28 / 96$ & 4:04:44 PM & 1957 & & 95.8 & $03 / 12$ & analyzed in lab \\
\hline $2 / 28196$ & 4:25:09 PM & 1958 & & 96.9 & $03 / 12$ & analyzed in lab \\
\hline $2 / 28 / 96$ & $4: 45: 35$ PM & 1959 & & 93.3 & $03 / 12$ & analyzed in $\mathrm{kb}$ \\
\hline $2 / 28 / 96$ & 5:06:02 PM & 1960 & & 96.3 & $03 / 12$ & analyzed in lab \\
\hline $2 / 28 / 96$ & 5:26:26 PM & 1961 & & 95.7 & $03 / 12$ & analyzed in lab \\
\hline $2 / 28 / 96$ & 5:47:18 PM & 1962 & & 96.9 & $03 / 12$ & analyzed in lab \\
\hline $2 / 28 / 96$ & 6:07:31 PM & 1963 & & 95.3 & $03 / 12$ & analyzed in lab \\
\hline $2 / 28 / 96$ & $6: 27: 49 \mathrm{PM}$ & 1964 & & 95.4 & $03 / 12$ & analyzed in lab \\
\hline $2 / 28 / 96$ & $6: 48: 12 \mathrm{PM}$ & 1965 & & 97.1 & $03 / 12$ & analyzed in lab \\
\hline $2 / 28 / 96$ & 7:08:35 PM & 1966 & & 97.2 & $03 / 12$ & analyzed in lab \\
\hline $2 / 28 / 96$ & $7: 29: 01 \mathrm{PM}$ & 1967 & & 97.0 & $03 / 12$ & analyzed in lab \\
\hline $2 / 28 / 96$ & $7: 49: 28 \mathrm{PM}$ & 1968 & & 93.4 & $03 / 06$ & analyzed in lab \\
\hline $2 / 28 / 96$ & $8: 09: 55 \mathrm{PM}$ & 1969 & & 93.7 & $03 / 06$ & analyzed in lab \\
\hline $2 / 28 / 96$ & $8: 30: 21 \mathrm{PM}$ & 1970 & & 92.9 & $03 / 06$ & analyzed in lab \\
\hline $2 / 28 / 96$ & $8: 51: 11 \mathrm{PM}$ & 1971 & & 92.6 & $03 / 06$ & analyzed in lab \\
\hline $2 / 28 / 96$ & 9:11:24 PM & 1972 & & 92.6 & $03 / 06$ & analyzed in lab \\
\hline $2 / 28 / 96$ & 9:31:44 PM & 1973 & & 93.8 & $03 / 06$ & analyzed in lab \\
\hline $2 / 28 / 96$ & 9:52:13 PM & 1974 & & 94.3 & $03 / 06$ & analyzed in lab \\
\hline $2 / 28 / 96$ & $10: 12: 40 \mathrm{PM}$ & 1975 & LD & 97.1 & & \\
\hline $2 / 28 / 96$ & $10: 33: 08 \mathrm{PM}$ & 1976 & & 95.4 & $03 / 06$ & analyzed in lab \\
\hline $2 / 28 / 96$ & $10: 53: 34 \mathrm{PM}$ & 1977 & & 95.6 & $03 / 06$ & analyzed in lab \\
\hline $2 / 28 / 96$ & $11: 14: 03 \mathrm{PM}$ & 1978 & & 96.3 & $03 / 06$ & analyzed in lab \\
\hline $2 / 28 / 96$ & $11: 34: 26$ PM & 1979 & & 99.7 & $03 / 06$ & analyzed in lab \\
\hline $2 / 28 / 96$ & $11: 55: 14 \mathrm{PM}$ & 1980 & & 97.8 & $03 / 06$ & analyzed in lab \\
\hline $2 / 29 / 96$ & $12: 15: 27$ AM & 1981 & LD* & 100.4 & 03.06 & analyzed in lab \\
\hline $2 / 29 / 96$ & $12: 35: 46 \mathrm{AM}$ & 1982 & & 99.7 & $03 / 06$ & analyzed in lab \\
\hline $2 / 29 / 96$ & $12: 56: 12 \mathrm{AM}$ & 1983 & & 102.2 & $03 / 06$ & analyzed in lab \\
\hline $2 / 29196$ & $1: 16: 42 \mathrm{AM}$ & 1984 & & 100.8 & $03 / 06$ & analyzed in lab \\
\hline $2 / 29 / 96$ & 1:37:09 AM & 1985 & & 98.0 & $03 / 06$ & analyzed in lab \\
\hline $2 / 29 / 96$ & $1: 57: 30 \mathrm{AM}$ & 1986 & & 99.7 & $03 / 06$ & analyzed in lab \\
\hline $2 / 29 / 96$ & $2: 17: 56$ AM & 1987 & & 99.3 & $03 / 06$ & analyzed in lab \\
\hline $2 / 29 / 96$ & $2: 38: 25$ AM & 1988 & LD & 98.2 & & \\
\hline $2 / 29 / 96$ & $2: 59: 15 \mathrm{AM}$ & 1989 & & 97.8 & $03 / 06$ & analyzed in lab \\
\hline $2 / 29196$ & $3: 19: 28 \mathrm{AM}$ & 1990 & & 103.8 & $03 / 06$ & analyzed in lab \\
\hline $2 / 29 / 96$ & $3: 39: 46$ AM & 1991 & & 100.1 & $03 / 06$ & analyzed in lab \\
\hline $2 / 29196$ & 4:00:15 AM & 1992 & & 103.3 & 03106 & analyzed in lab \\
\hline $2 / 29 / 96$ & $4: 20: 42$ AM & 1993 & & 100.6 & $03 / 06$ & analyzed in $\mathrm{lab}$ \\
\hline $2 / 29 / 96$ & $4: 41: 08 \mathrm{AM}$ & 1994 & & 99.5 & 03106 & analyzed in lab \\
\hline $2 / 29 / 96$ & 5:01:34 AM & 1995 & & 98.9 & 03106 & analyzed in lab \\
\hline $2 / 29 / 96$ & $5: 22: 06$ AM & 1996 & & 98.0 & 03106 & analyzed in lab \\
\hline $2 / 29 / 96$ & $5: 42: 32$ AM & 1997 & & 98.8 & $03 / 06$ & analyzed in lab \\
\hline $2 / 29 / 96$ & $6: 03: 20 \mathrm{AM}$ & 1998 & $\mathrm{LO}^{*}$ & 98.5 & $03 / 06$ & analyzed in $\mathrm{lab}$ \\
\hline $2 / 29 / 96$ & $6: 23: 34 \mathrm{AM}$ & 1999 & & 91.2 & $03 / 07$ & analyzed in lab \\
\hline $2 / 29 / 96$ & $6: 43: 51 \mathrm{AM}$ & 2000 & & 92.0 & $03 / 07$ & analyzed in lab \\
\hline $2 / 29 / 96$ & 7:04:17 AM & 2001 & & 92.5 & $03 / 07$ & analyzed in lab \\
\hline $2 / 29 / 96$ & $7: 24: 41 \mathrm{AM}$ & 2002 & & 91.3 & $03 / 07$ & analyzed in lab \\
\hline $2 / 29 / 96$ & $7: 45: 06 \mathrm{AM}$ & 2003 & & 92.0 & $03 / 07$ & analyzed in lab \\
\hline $2 / 29 / 96$ & $8: 05: 31$ AM & 2004 & & 100.1 & 03104 & analyzed in lab \\
\hline $2 / 29 / 96$ & $8: 25: 54$ AM & 2005 & & 98.6 & $03 / 04$ & analyzed in lab \\
\hline $2 / 29 / 96$ & $8: 46: 17$ AM & 2006 & & 96.9 & $03 / 04$ & analyzed in lab \\
\hline $2 / 29 / 96$ & 9:07:02 AM & 2007 & & 99.2 & $03 / 04$ & analyzed in lab \\
\hline $2 / 29 / 96$ & 9:27:24 AM & 2008 & & 96.4 & $03 / 05$ & analyzed in lab \\
\hline & & & & 94.6 & $03 / 05$ & analyzed in lab \\
\hline $2 / 29 / 96$ & $10: 40: 39 \mathrm{AM}$ & 2010 & & 95.8 & $03 / 05$ & analyzed in lab \\
\hline $2 / 29 / 96$ & $11: 01: 08 \mathrm{AM}$ & 2011 & & 97.2 & 03104 & analyzed in lab \\
\hline $2 / 29 / 96$ & $11: 21: 33$ AM & 2012 & & 96.4 & $03 / 05$ & analyzed in lab \\
\hline
\end{tabular}




\begin{tabular}{|c|c|c|c|c|c|c|}
\hline Date & Time of Sample & Sample \# & Dup. code & Conc (ppb) & Analysis date & place \\
\hline $2 / 29 / 96$ & $11: 41: 55 \mathrm{AM}$ & 2013 & & 94.6 & 03105 & analyzed in lab \\
\hline $229 / 96$ & $12: 02: 23 \mathrm{PM}$ & 2014 & & 96.9 & 03105 & analyzed in lab \\
\hline $2 / 29 / 96$ & $12: 22: 47 \mathrm{PM}$ & 2015 & & 96.4 & 0305 & analyzed in lab \\
\hline $2 / 29 / 96$ & $12: 43: 16 \mathrm{PM}$ & 2016 & & 92.7 & $03 / 19$ & analyzed in lab \\
\hline $2 / 29 / 96$ & $1: 03: 42 \mathrm{PM}$ & 2017 & LD & 95.8 & & \\
\hline $2 / 29 / 96$ & 1:24:11 PM & 2018 & & 98.2 & 03104 & analyzed in lab \\
\hline $2 / 29 / 96$ & 1:44:56 PM & 2019 & & 95.0 & 0304 & analyzed in lab \\
\hline $2 / 29 / 96$ & 2:05:10 PM & 2020 & & 98.3 & 03104 & analyzed in lab \\
\hline $2 / 29 / 96$ & 2:25:28 PM & 2021 & & 99.2 & 03104 & analyzed in lab \\
\hline $2 / 29 / 96$ & $2: 45: 53 \mathrm{PM}$ & 2022 & & 95.0 & 03104 & analyzed in lab \\
\hline $2 / 29 / 96$ & 3:06:17 PM & 2023 & & 97.7 & 03104 & analyzed in lab \\
\hline $2 / 29 / 96$ & 3:26:40 PM & 2024 & & 96.3 & $03 / 04$ & analyzed in lab \\
\hline $2 / 29 / 96$ & 3:47:06 PM & 2025 & & 97.0 & 03104 & analyzed in lab \\
\hline $2 / 29 / 96$ & 4:07:34 PM & 2026 & & 95.8 & $03 / 04$ & analyzed in lab \\
\hline $2 / 29 / 96$ & 4:27:58 PM & 2027 & & 97.7 & 03104 & analyzed in lab \\
\hline $2 / 29 / 96$ & 4:48:51 PM & 2028 & & 98.1 & 03104 & analyzed in $\mathrm{ab}$ \\
\hline $2 / 29 / 96$ & 5:09:04 PM & 2029 & & 97.0 & 03104 & analyzed in lab \\
\hline $2 / 29 / 96$ & 5:29:22 PM & 2030 & & 98.5 & 0304 & analyzed in lab \\
\hline $2 / 29 / 96$ & 5:49:50 PM & 2031 & & 99.4 & 03104 & analyzed in lab \\
\hline $2 / 29 / 96$ & $6: 10: 14 P M$ & 2032 & & 98.3 & 03104 & analyzed in lab \\
\hline $2 / 29 / 96$ & 6:30:37 PM & 2033 & & 99.0 & 03104 & anahzed in lab \\
\hline $2 / 29 / 96$ & 6:51:00 PM & 2034 & & 97.2 & 03,04 & analyzed in $\mathrm{ab}$ \\
\hline $2 / 29 / 96$ & $7: 11: 31 \mathrm{PM}$ & 2035 & & 94.8 & $03 / 04$ & analyzed in lab \\
\hline $2 / 29 / 96$ & 7:31:59 PM & 2036 & & 98.4 & 03104 & analyzed in lab \\
\hline $2 / 29 / 96$ & $7: 52: 45 \mathrm{PM}$ & 2037 & & 97.6 & $03 / 04$ & anabzed in lab \\
\hline $2 / 29 / 96$ & $8: 12: 58 \mathrm{PM}$ & 2038 & & 94.2 & 03104 & analyzed in lab \\
\hline $2 / 29 / 96$ & $8: 33: 18 \mathrm{PM}$ & 2039 & & 100.3 & 03104 & analyzed in lab \\
\hline $2 / 29 / 96$ & $8: 53: 40 \mathrm{PM}$ & 2040 & & 97.3 & $03 / 04$ & analyzed in lab \\
\hline $2 / 29 / 96$ & 9:14:09 PM & 2041 & & 100.6 & $03 / 04$ & analyzed in lab \\
\hline $2 / 29 / 96$ & 9:34:38 PM & 2042 & & 98.9 & $03 / 04$ & analyzed in lab \\
\hline $2 / 29 / 96$ & 9:55:06 PM & 2043 & & 98.4 & $03 / 04$ & analyzed in lab \\
\hline $2 / 29 / 96$ & $10: 15: 33 \mathrm{PM}$ & 2044 & & 97.2 & $03 / 04$ & analyzed in lab \\
\hline $2 / 29 / 96$ & $10: 35: 59 \mathrm{PM}$ & 2045 & & & & \\
\hline $2 / 29 / 96$ & $10: 56: 49 \mathrm{PM}$ & 2046 & & 93.1 & $03 / 26$ & analyzed in lab \\
\hline $2 / 29 / 96$ & $11: 17: 02 \mathrm{PM}$ & 2047 & & & & \\
\hline $2 / 29 / 96$ & 11:37:20 PM & 2048 & & & & \\
\hline $2 / 29 / 96$ & $11: 57: 46 \mathrm{PM}$ & 2049 & & 93.5 & $03 / 19$ & analyzed in lab \\
\hline $3 / 1 / 96$ & 12:18:13 AM & 2050 & & & & \\
\hline $3 / 1 / 96$ & $12: 38: 40$ AM & 2051 & & & & \\
\hline $3 / 1 / 96$ & $12: 59: 07$ AM & 2052 & LD & 95.2 & & \\
\hline $3 / 1 / 96$ & $1: 19: 35 \mathrm{AM}$ & 2053 & & & & \\
\hline $3 / 1 / 96$ & 1:40:03 AM & 2054 & & & & \\
\hline $3 / 1 / 96$ & 2:00:50 AM & 2055 & & 97.0 & $03 / 19$ & analyzed in lab \\
\hline $3 / 1 / 96$ & $2: 21: 03 \mathrm{AM}$ & 2056 & & & & \\
\hline $3 / 1 / 96$ & $2: 41: 23$ AM & 2057 & & & & \\
\hline $3 / 1 / 96$ & 3:01:52 AM & 2058 & UD & 96.7 & & \\
\hline $3 / 1 / 96$ & 3:22:19 AM & 2059 & & & & \\
\hline $3 / 1 / 96$ & $3: 42: 49$ AM & 2060 & & & & \\
\hline $3 / 1 / 96$ & 4:03:19 AM & 2061 & & 95.1 & $03 / 19$ & analyzed in lab \\
\hline $3 / 1 / 96$ & 4:23:44 AM & 2062 & & & & \\
\hline $3 / 1 / 96$ & 4:44:14 AM & 2063 & & & & \\
\hline $3 / 1 / 96$ & 5:05:02 AM & 2064 & LD* & 94.1 & $03 / 19$ & analyzed in lab \\
\hline $3 / 1 / 96$ & 5:25:15 AM & 2065 & & & & \\
\hline $3 / 1 / 96$ & $5: 45: 33$ AM & 2066 & & & & \\
\hline $3 / 1 / 96$ & $6: 05: 58$ AM & 2067 & & 94.8 & $03 / 19$ & analyzed in lab \\
\hline $3 / 1 / 96$ & $6: 26: 25 \mathrm{AM}$ & 2068 & & & & \\
\hline $3 / 1 / 96$ & $6: 46: 52 \mathrm{AM}$ & 2069 & & & & \\
\hline $3 / 1 / 96$ & $7: 07: 15$ AM & 2070 & $\mathrm{LD}^{*}$ & 94.7 & $03 / 19$ & analyzed in lab \\
\hline $3 / 1 / 96$ & 7:27:39 AM & 2071 & & & & \\
\hline $3 / 1 / 96$ & $7: 48: 07$ AM & 2072 & & & & \\
\hline $3 / 1 / 96$ & 8:08:57 AM & 2073 & & 93.1 & $03 / 19$ & analyzed in lab \\
\hline $3 / 1 / 96$ & $8: 29: 11 \mathrm{AM}$ & 2074 & & & & \\
\hline $3 / 1 / 96$ & $8: 49: 30 \mathrm{AM}$ & 2075 & & & & \\
\hline $3 / 1 / 96$ & 9:09:57 AM & 2076 & UD & 98.7 & & \\
\hline $3 / 1 / 96$ & $9: 30: 23$ AM & 2077 & & & & \\
\hline $3 / 1 / 96$ & $9: 50: 49 \mathrm{AM}$ & 2078 & & & & \\
\hline $3 / 1 / 96$ & $10: 11: 14$ AM & 2079 & LD & 95.3 & & \\
\hline $3 / 1 / 96$ & $10: 31: 35 \mathrm{AM}$ & 2080 & & & & \\
\hline $3 / 1 / 96$ & $10: 51: 59$ AM & 2081 & & & & \\
\hline $3 / 1 / 96$ & $11: 12: 43 \mathrm{AM}$ & 2082 & UD & 99.3 & & \\
\hline
\end{tabular}


Yucca Mountain tracer test; 18

\begin{tabular}{|c|c|c|c|c|c|c|}
\hline Date & Time of Sample & Sample \# & Dup. code & Conc (ppb) & Analysis date & place \\
\hline $3 / 1 / 96$ & $11: 32: 55 \mathrm{AM}$ & 2083 & & & & \\
\hline $3 / 1 / 96$ & 11:53:16 AM & 2084 & & & & \\
\hline $3 / 1 / 96$ & $12: 13: 42 \mathrm{PM}$ & 2085 & & 96.0 & $03 / 19$ & analyzed in lab \\
\hline $3 / 1 / 96$ & 12:34:06 PM & 2086 & & & & \\
\hline $3 / 1 / 96$ & 12:54:29 PM & 2087 & & & & \\
\hline $3 / 1 / 96$ & $1: 14: 54 \mathrm{PM}$ & 2088 & UD & 97.9 & & \\
\hline $3 / 1 / 96$ & 1:35:27 PM & 2089 & & & & \\
\hline $3 / 1 / 96$ & 1:55:46 PM & 2090 & & & & \\
\hline $3 / 1 / 96$ & 2:16:35 PM & 2091 & & 95.8 & $03 / 19$ & analyzed in lab \\
\hline $3 / 1 / 96$ & 2:36:48 PM & 2092 & & & & \\
\hline $3 / 1 / 96$ & 2:57:05 PM & 2093 & & & & \\
\hline $3 / 1 / 96$ & 3:17:33 PM & 2094 & UD & 96.9 & & \\
\hline $3 / 1 / 96$ & 3:37:59 PM & 2095 & & & & \\
\hline $3 / 1 / 96$ & 3:58:30 PM & 2096 & & 97.4 & $03 / 19$ & analyzed in lab \\
\hline $3 / 1 / 96$ & 4:18:58 PM & 2097 & & 95.3 & $03 / 04$ & analyzed in lab \\
\hline $3 / 1 / 96$ & 4:39:24 PM & 2098 & & 98.9 & $03 / 04$ & analyzed in lab \\
\hline $3 / 1 / 96$ & 4:59:50 PM & 2099 & & 94.8 & $03 / 04$ & anahzed in lab \\
\hline $3 / 1 / 96$ & $5: 20: 47 \mathrm{PM}$ & 2100 & & 98.0 & 03104 & analyzed in lab \\
\hline $3 / 1 / 96$ & 5:41:00 PM & 2101 & & 99.1 & $03 / 04$ & analyzed in lab \\
\hline $3 / 1 / 96$ & 6:01:21 PM & 2102 & & 95.2 & $03 / 04$ & analyzed in lab \\
\hline $3 / 1 / 96$ & 6:21:47 PM & 2103 & & 98.8 & $03 / 04$ & analyzed in lab \\
\hline $3 / 1 / 96$ & 6:42:13 PM & 2104 & & 98.2 & $03 / 04$ & analyzed in lab \\
\hline $3 / 1 / 96$ & 7:02:40 PM & 2105 & & 99.4 & $03 / 04$ & analyzed in lab \\
\hline $3 / 1 / 96$ & 7:23:11 PM & 2106 & & 99.7 & $03 / 04$ & analyzed in lab \\
\hline $3 / 1 / 96$ & $7: 43: 42 \mathrm{PM}$ & 2107 & & 99.8 & $03 / 04$ & analyzed in lab \\
\hline $3 / 1 / 96$ & 8:04:10 PM & 2108 & & 99.0 & $03 / 04$ & analyzed in lab \\
\hline $3 / 1 / 96$ & $8: 24: 57$ PM & 2109 & & & & \\
\hline $3 / 1 / 96$ & $8: 45: 11 P M$ & 2110 & LD & 97.4 & & \\
\hline $3 / 1 / 96$ & 9:05:30 PM & 2111 & & 97.0 & $03 / 04$ & analyzed in lab \\
\hline $3 / 1 / 96$ & $9: 25: 56 \mathrm{PM}$ & 2112 & & 99.9 & $03 / 04$ & analyzed in lab \\
\hline $3 / 1 / 96$ & $9: 46: 22 \mathrm{PM}$ & 2113 & & 95.8 & $03 / 04$ & analyzed in lab \\
\hline $3 / 1 / 96$ & 10:06:51 PM & 2114 & & 96.1 & $03 / 04$ & analyzed in lab \\
\hline $3 / 1 / 96$ & $10: 27: 20 \mathrm{PM}$ & 2115 & & 98.2 & $03 / 04$ & analyzed in lab \\
\hline $3 / 1 / 96$ & $10: 47: 46 \mathrm{PM}$ & 2116 & & 98.2 & $03 / 04$ & analyzed in lab \\
\hline $3 / 1 / 96$ & 11:08:15 PM & 2117 & & 96.9 & $03 / 04$ & analyzed in lab \\
\hline $3 / 1 / 96$ & $11: 29: 06 \mathrm{PM}$ & 2118 & & 96.6 & $03 / 04$ & analyzed in lab \\
\hline $3 / 1 / 96$ & $11: 49: 19 \mathrm{PM}$ & 2119 & & 96.9 & $03 / 04$ & analyzed in lab \\
\hline $3 / 2 / 96$ & 12:09:39 AM & 2120 & & 97.2 & $03 / 04$ & analyzed in lab \\
\hline $3 / 2 / 96$ & 12:30:09 AM & 2121 & & 98.4 & $03 / 04$ & analyzed in lab \\
\hline $3 / 2 / 96$ & 12:50:36 AM & 2122 & & 98.2 & $03 / 04$ & anaiyzed in lab \\
\hline $3 / 2 / 96$ & $1: 11: 02 \mathrm{AM}$ & 2123 & & 98.4 & $03 / 04$ & anatyzed in lab \\
\hline $3 / 2 / 96$ & 1:31:29 AM & 2124 & & 100.0 & $03 / 04$ & analyzed in lab \\
\hline $3 / 2 / 96$ & 1:51:56 AM & 2125 & & 99.7 & $03 / 04$ & analyzed in lab \\
\hline $3 / 2 / 96$ & 2:12:22 AM & 2126 & & 99.2 & $03 / 04$ & analyzed in lab \\
\hline $3 / 2 / 96$ & 2:33:08 AM & 2127 & & 91.9 & $03 / 04$ & analyzed in lab \\
\hline $3 / 2 / 96$ & 2:53:21 AM & 2128 & & 97.3 & $03 / 04$ & analyzed in $\mathrm{tab}$ \\
\hline $3 / 2 / 96$ & 3:13:38 AM & 2129 & & 99.2 & $03 / 08$ & analyzed in lab \\
\hline $3 / 2 / 96$ & 3:34:06 AM & 2130 & & 96.0 & $03 / 08$ & analyzed in lab \\
\hline $3 / 2 / 96$ & 3:54:33 AM & 2131 & & 97.4 & $03 / 08$ & analyzed in lab \\
\hline $3 / 2 / 96$ & 4:14:58 AM & 2132 & & 96.9 & $03 / 08$ & analyzed in $\mathrm{lab}$ \\
\hline $3 / 2 / 96$ & 4:35:22 AM & 2133 & & 98.1 & $03 / 08$ & analyzed in lab \\
\hline $3 / 2 / 96$ & 4:55:50 AM & 2134 & & 95.8 & $03 / 08$ & analyzed in lab \\
\hline $3 / 2 / 96$ & 5:16:17 AM & 2135 & & 94.4 & $03 / 08$ & analyzed in lab \\
\hline $3 / 2 / 96$ & 5:37:06 AM & 2136 & & 97.7 & $03 / 05$ & analyzed in lab \\
\hline $3 / 2 / 96$ & 5:57:18 AM & 2137 & & 98.1 & $03 / 05$ & analyzed in lab \\
\hline $3 / 2 / 96$ & 6:17:39 AM & 2138 & & 98.2 & $03 / 05$ & analyzed in lab \\
\hline $3 / 2 / 96$ & 6:38:05 AM & 2139 & & 96.8 & $03 / 05$ & analyzed in lab \\
\hline $3 / 2 / 96$ & $6: 58: 32$ AM & 2140 & L/D & 98.3 & & \\
\hline $3 / 2 / 96$ & $7: 18: 58 \mathrm{AM}$ & 2141 & & 97.1 & $03 / 05$ & analyzed in lab \\
\hline $3 / 2 / 96$ & 7:39:26 AM & 2142 & & 98.5 & $03 / 19$ & analyzed in lab \\
\hline $3 / 2 / 96$ & $7: 59: 52$ AM & 2143 & & & & \\
\hline $3 / 2 / 96$ & $8: 20: 21$ AM & 2144 & & & & \\
\hline $3 / 2 / 96$ & $8: 41: 06$ AM & 2145 & & 98.6 & $03 / 19$ & analyzed in lab \\
\hline $3 / 2 / 96$ & 9:01:19 AM & 2146 & L/O & 95.3 & & \\
\hline $3 / 2 / 96$ & 9:21:38 AM & 2147 & LD & 95.9 & & \\
\hline $3 / 2 / 96$ & $9: 42: 16 \mathrm{AM}$ & 2148 & & 95.9 & $03 / 19$ & analyzed in lab \\
\hline $3 / 2 / 96$ & 10:02:33 AM & 2149 & & 94.4 & $03 / 19$ & analyzed in lab \\
\hline $3 / 2 / 96$ & 10:22:56 AM & 2150 & & 95.5 & $03 / 19$ & analyzed in lab \\
\hline $3 / 2 / 96$ & 10:43:20 AM & 2151 & & 95.3 & $03 / 19$ & analyzed in lab \\
\hline $3 / 2 / 96$ & $11: 03: 48 \mathrm{AM}$ & 2152 & & 98.2 & $03 / 19$ & analyzed in lab \\
\hline
\end{tabular}




\begin{tabular}{|c|c|c|c|c|c|c|}
\hline Date & Time of Sample & Sample \# & Dup. code & Conc (ppb) & Analysis date & place \\
\hline $3 / 2 / 96$ & 11:24:17 AM & 2153 & & 94.5 & $03 / 19$ & analyzed in lab \\
\hline $3 / 2 / 96$ & $11: 45: 08 \mathrm{AM}$ & 2154 & & 94.8 & $03 / 19$ & analyzed in lab \\
\hline $3 / 2 / 96$ & $12: 05: 21 \mathrm{PM}$ & 2155 & & 97.8 & 03305 & anałyzed in lab \\
\hline $3 / 2 / 96$ & 12:25:38 PM & 2156 & & 98.2 & $03 / 05$ & analyzed in lab \\
\hline $3 / 2 / 96$ & 12:46:01 PM & 2157 & & 98.2 & $03 / 05$ & analyzed in lab \\
\hline $3 / 2196$ & 1:06:31 PM & 2158 & & 98.3 & $03 / 05$ & analyzed in lab \\
\hline $3 / 2 / 96$ & 1:27:00 PM & 2159 & & 97.3 & $03 / 05$ & analyzed in lab \\
\hline $3 / 2 / 96$ & 1:47:27 PM & 2160 & & 99.7 & $03 / 05$ & analyzed in lab \\
\hline $3 / 2 / 96$ & 2:07:56 PM & 2161 & & 98.9 & $03 / 05$ & analyzed in lab \\
\hline $3 / 2 / 96$ & 2:28:24 PM & 2162 & & 98.2 & $03 / 05$ & analyzed in $1 \mathrm{ab}$ \\
\hline $3 / 2 / 96$ & 2:49:11 PM & 2103 & & 98.4 & $03 / 05$ & anahyzed in lab \\
\hline $3 / 2 / 96$ & 3:09:24 PM & 2164 & & 99.8 & $03 / 05$ & analyzed in lab \\
\hline $3 / 2 / 96$ & $3: 29: 42 \mathrm{PM}$ & 2165 & & 101.4 & $03 / 05$ & analyzed in lab \\
\hline $3 / 2 / 96$ & 3:50:12 PM & 2166 & & 100.3 & $03 / 05$ & analyzed in lab \\
\hline $3 / 2 / 96$ & 4:10:40 PM & 2167 & & 99.0 & $03 / 05$ & analyzed in lab \\
\hline $3 / 2 / 96$ & 4:31:08 PM & 2168 & & 99.8 & $03 / 05$ & analyzed in lab \\
\hline $3 / 2 / 96$ & 4.51:35 PM & 2169 & & 99.9 & $03 / 05$ & analyzed in lab \\
\hline $3 / 2 / 96$ & 5:12:02 PM & 2170 & & 98.8 & $03 / 05$ & analyzed in lab \\
\hline $3 / 2 / 96$ & 5:32:26 PM & 2171 & & 98.5 & $03 / 05$ & analyzed in lab \\
\hline $3 / 2 / 96$ & 5:53:12 PM & 2172 & & 101.2 & $03 / 05$ & analyzed in lab \\
\hline $3 / 2 / 96$ & 6:13:25 PM & 2173 & & 98.3 & 03,05 & analyzed in lab \\
\hline $3 / 2 / 96$ & 6:33:44 PM & 2174 & & 97.3 & $03 / 05$ & analyzed in lab \\
\hline $3 / 2 / 96$ & 6:54:15 PM & 2175 & & 97.9 & $03 / 105$ & analyzed in lab \\
\hline $3 / 2 / 96$ & 7:14:41 PM & 2176 & & 99.1 & $03 / 05$ & analyzed in lab \\
\hline $3 / 2 / 96$ & 7:35:09 PM & 2177 & & 96.8 & $03 / 05$ & analyzed in lab \\
\hline $3 / 2 / 96$ & 7:55:36 PM & 2178 & & 98.7 & $03 / 05$ & analyzed in lab \\
\hline $3 / 2 / 96$ & 8:16:04 PM & 2179 & & 99.2 & $03 / 05$ & analyzed in lab \\
\hline $3 / 2 / 96$ & $8: 36: 30 \mathrm{PM}$ & 2180 & & 98.5 & $03 / 05$ & analyzed in lab \\
\hline $3 / 2 / 96$ & 8:57:21 PM & 2181 & LD & 98.3 & & \\
\hline $3 / 2 / 96$ & 9:17:34 PM & 2182 & & 97.3 & $03 / 05$ & analyzed in lab \\
\hline $3 / 2 / 96$ & 9:37:52 PM & 2183 & & 98.3 & $03 / 05$ & analyzed in lab \\
\hline $3 / 2 / 96$ & $9: 58: 18 \mathrm{PM}$ & 2184 & & 98.3 & $03 / 05$ & anabyzed in lab \\
\hline $3 / 2 / 96$ & 10:18:43 PM & 2185 & & 97.9 & $03 / 05$ & analyzed in lab \\
\hline $3 / 2 / 96$ & 10:39:10 PM & 2186 & & 98.4 & $03 / 05$ & analyzed in lab \\
\hline $3 / 2 / 96$ & 10:59:35 PM & 2187. & & 98.1 & $03 / 05$ & analyzed in lab \\
\hline $3 / 2 / 96$ & $11: 19: 57$ PM & 2188 & & 97.9 & $03 / 05$ & anahyzed in lab \\
\hline $3 / 2 / 96$ & $11: 40: 23 \mathrm{PM}$ & 2189 & & 98.3 & $03 / 05$ & analyzed in lab \\
\hline $3 / 3 / 96$ & $12: 01: 10 \mathrm{AM}$ & 2190 & & 98.6 & $03 / 05$ & anahrzed in lab \\
\hline $3 / 3 / 96$ & $12: 21: 23 \mathrm{AM}$ & 2191 & & 97.6 & $03 / 05$ & analyzed in lab \\
\hline $3 / 3 / 96$ & 12:41:41 AM & 2192 & & 99.4 & $03 / 05$ & analyzed in lab \\
\hline $3 / 3 / 96$ & 1:02:08 AM & 2193 & & 97.8 & $03 / 05$ & anahzed in lab \\
\hline $3 / 3 / 96$ & 1:22:34 AM & 2194 & & 98.2 & $03 / 05$ & analyzed in lab \\
\hline $3 / 3 / 96$ & $1: 43: 01 \mathrm{AM}$ & 2195 & & 97.8 & $03 / 05$ & analyzed in lab \\
\hline $3 / 3 / 96$ & $2: 03: 29$ AM & 2196 & & 97.5 & $03 / 05$ & analyzed in lab \\
\hline $3 / 3 / 96$ & $2: 23: 55 \mathrm{AM}$ & 2197 & $L D^{*}$ & 98.3 & $03 / 05$ & analyzed in lab \\
\hline $3 / 3 / 96$ & $2: 44: 22 \mathrm{AM}$ & 2198 & & 97.2 & $03 / 05$ & anabzed in lab \\
\hline $3 / 3 / 96$ & 3:05:13 AM & 2199 & & 98.6 & $03 / 05$ & analyzed in lab \\
\hline $3 / 3 / 96$ & $3: 25: 26 \mathrm{AM}$ & 2200 & & 98.8 & $03 / 05$ & analyzed in lab \\
\hline $3 / 3 / 96$ & $3: 45: 43 \mathrm{AM}$ & 2201 & & 98.5 & $03 / 05$ & analyzed in lab \\
\hline $3 / 3 / 96$ & 4:06:10 AM & 2202 & & 99.4 & $03 / 05$ & analyzed in lab \\
\hline $3 / 3 / 96$ & $4: 26: 36 \mathrm{AM}$ & 2203 & & 96.5 & $03 / 05$ & analyzed in lab \\
\hline $3 / 3 / 96$ & 4:47:02 AM & 2204 & & 96.5 & $03 / 05$ & analyzed in lab \\
\hline $3 / 3 / 96$ & $5: 07: 28 \mathrm{AM}$ & 2205 & & 98.0 & 03105 & anabrzed in lab \\
\hline $3 / 3 / 96$ & 5:27:59 AM & 2206 & & 95.2 & $03 / 05$ & analyzed in lab \\
\hline $3 / 3 / 96$ & $5: 48: 43$ AM & 2207 & & 97.0 & 03105 & analyzed in lab \\
\hline $3 / 3 / 96$ & $6: 09: 21$ AM & 2208 & & 98.1 & $03 / 105$ & analyzed in lab \\
\hline $3 / 3 / 96$ & $6: 29: 34 \mathrm{AM}$ & 2209 & $U D^{*}$ & 96.4 & $03 / 05$ & analyzed in lab \\
\hline $3 / 3 / 96$ & $6: 49: 52 \mathrm{AM}$ & 2210 & & 97.3 & $03 / 105$ & analyzed in lab \\
\hline $3 / 3 / 96$ & $7: 10: 17 \mathrm{AM}$ & 2211 & & 95.8 & 03105 & analyzed in lab \\
\hline $3 / 3 / 96$ & $7: 30: 42 \mathrm{AM}$ & 2212 & & 96.8 & $03 / 05$ & analyzed in lab \\
\hline $3 / 3 / 96$ & $7: 51: 12 \mathrm{AM}$ & 2213 & & 97.0 & $03 / 05$ & analyzed in lab \\
\hline $3 / 3 / 96$ & $8: 11: 36 \mathrm{AM}$ & 2214 & & 94.5 & $03 / 05$ & analyzed in lab \\
\hline $3 / 3 / 96$ & $8: 31: 59 \mathrm{AM}$ & 2215 & & 95.1 & 03105 & analyzed in lab \\
\hline $3 / 3 / 96$ & $8: 52: 28$ AM & 2216 & & 96.8 & $03 / 05$ & analyzed in lab \\
\hline $3 / 3 / 96$ & $9: 13: 14 \mathrm{AM}$ & 2217 & & 97.4 & 03305 & analyzed in lab \\
\hline 3/3/96 & $9: 33: 27 \mathrm{AM}$ & 2218 & & 96.6 & $03 / 05$ & analyzed in lab \\
\hline $3 / 3 / 96$ & $9: 53: 46 \mathrm{AM}$ & 2219 & & 96.2 & $03 / 05$ & analyzed in lab \\
\hline $3 / 3 / 96$ & 10:14:10 AM & 2220 & & 95.8 & $03 / 05$ & analyzed in lab \\
\hline $3 / 3 / 96$ & 10:34:33 AM & 2221 & & 95.1 & $03 / 105$ & analyzed in lab \\
\hline $3 / 3 / 96$ & $10: 54: 59$ AM & 2222 & & 92.5 & $03 / 05$ & analyzed in lab \\
\hline
\end{tabular}




\begin{tabular}{|c|c|c|c|c|c|c|}
\hline Date & Time of Sample & Sample \# & Dup. code & Conc (ppb) & Analysis date & place \\
\hline $3 / 3 / 96$ & $11: 15: 24 \mathrm{AM}$ & 2223 & & 95.6 & $03 / 05$ & analyzed in lab \\
\hline $3 / 3 / 96$ & $11: 35: 47 \mathrm{AM}$ & 2224 & & 95.5 & $03 / 05$ & analyzed in $\mathrm{lab}$ \\
\hline $3 / 3 / 96$ & $11: 56: 15 \mathrm{AM}$ & 2225 & & 95.7 & $03 / 05$ & analyzed in lab \\
\hline $3 / 3 / 96$ & 12:17:12 PM & 2226 & & 95.6 & $03 / 05$ & analyzed in lab \\
\hline $3 / 3 / 96$ & 12:37:25 PM & 2227 & & 95.5 & $03 / 05$ & analyzed in lab \\
\hline $3 / 3 / 96$ & $12: 57: 42 \mathrm{PM}$ & 2228 & & 94.4 & $03 / 05$ & analyzed in lab \\
\hline $3 / 3 / 96$ & 1:18:04 PM & 2229 & & 95.9 & $03 / 05$ & analyzed in lab \\
\hline 3/3/96 & 1:38:31 PM & 2230 & & 96.3 & $03 / 05$ & analyzed in lab \\
\hline $3 / 3 / 96$ & 1:58:57 PM & 2231 & & 95.1 & $03 / 05$ & analyzed in lab \\
\hline $3 / 3 / 96$ & 2:19:23 PM & 2232 & & 94.6 & $03 / 05$ & analyzed in lab \\
\hline $3 / 3 / 96$ & $2: 39: 51$ PM & 2233 & & 94.5 & $03 / 05$ & analyzed in lab \\
\hline $3 / 3 / 96$ & 3:00:16 PM & 2234 & LD* & 95.7 & 03105 & analyzed in lab \\
\hline $3 / 3 / 96$ & $3: 21: 06 \mathrm{PM}$ & 2235 & & 97.3 & $03 / 05$ & analyzed in lab \\
\hline $3 / 3 / 96$ & 3:41:19 PM & 2236 & & 99.5 & $03 / 05$ & analyzed in lab \\
\hline $3 / 3 / 96$ & 4:01:38 PM & 2237 & & 97.7 & $03 / 05$ & analyzed in lab \\
\hline $3 / 3 / 96$ & 4:22:06 PM & 2238 & & 97.2 & $03 / 05$ & analyzed in lab \\
\hline $3 / 3 / 96$ & 4:42:36 PM & 2239 & & 96.6 & $03 / 05$ & analyzed in lab \\
\hline $3 / 3 / 96$ & 5:03:02 PM & 2240 & & 98.1 & $03 / 05$ & analyzed in lab \\
\hline $3 / 3 / 96$ & $5: 23: 29 \mathrm{PM}$ & 2241 & & 96.0 & $03 / 05$ & analyzed in $\mathrm{kb}$ \\
\hline $3 / 3 / 96$ & $5: 43: 56 \mathrm{PM}$ & 2242 & & 97.0 & $03 / 05$ & analyzed in lab \\
\hline $3 / 3 / 96$ & 6:04:22 PM & 2243 & & 96.2 & $03 / 05$ & analyzed in lab \\
\hline $3 / 3 / 96$ & 6:25:09 PM & 2244 & & 96.2 & $03 / 05$ & analyzed in lab \\
\hline $3 / 3 / 96$ & 6:45:22 PM & 2245 & & 96.0 & $03 / 06$ & analyzed in lab \\
\hline $3 / 3 / 96$ & 7:05:43 PM & 2246 & & 99.6 & $03 / 06$ & analyzed in lab \\
\hline $3 / 3 / 96$ & $7: 26: 07 \mathrm{PM}$ & 2247 & & 96.8 & $03 / 06$ & analyzed in lab \\
\hline $3 / 3 / 96$ & $7: 46: 35 \mathrm{PM}$ & 2248 & & 97.7 & $03 / 06$ & analyzed in lab \\
\hline $3 / 3 / 96$ & 8:07:00 PM & 2249 & $\angle D^{*}$ & 97.0 & $03 / 06$ & analyzed in lab \\
\hline $3 / 3 / 96$ & 8:27:31 PM & 2250 & & 99.5 & $03 / 06$ & analyzed in lab \\
\hline $3 / 3 / 96$ & $8: 47: 55 \mathrm{PM}$ & 2251 & & 97.2 & $03 / 06$ & analyzed in lab \\
\hline $3 / 3 / 96$ & 9:08:22 PM & 2252 & & 99.4 & $03 / 06$ & analyzed in lab \\
\hline $3 / 3 / 96$ & 9:29:07 PM & 2253 & & 97.6 & $03 / 06$ & analyzed in lab \\
\hline $3 / 3 / 96$ & 9:49:20 PM & 2254 & & 98.3 & $03 / 06$ & analyzed in lab \\
\hline $3 / 3 / 96$ & 10:09:36 PM & 2255 & & 97.9 & $03 / 06$ & analyzed in lab \\
\hline $3 / 3 / 96$ & 10:30:05 PM & 2256 & & 97.9 & $03 / 06$ & analyzed in lab \\
\hline $3 / 3 / 96$ & 10:50:30 PM & 2257 & & 96.5 & $03 / 06$ & analyzed in lab \\
\hline $3 / 3 / 96$ & 11:10:55 PM & 2258 & & 98.3 & $03 / 06$ & analyzed in lab \\
\hline $3 / 3 / 96$ & $11: 31: 23 \mathrm{PM}$ & 2259 & & 97.8 & $03 / 06$ & analyzed in lab \\
\hline $3 / 3 / 96$ & $11: 51: 47 \mathrm{PM}$ & 2260 & & 99.2 & $03 / 06$ & analyzed in lab \\
\hline $3 / 4 / 96$ & 12:12:10 AM & 2261 & & 97.6 & $03 / 06$ & analyzed in lab \\
\hline $3 / 4 / 96$ & 12:32:55 AM & 2262 & & 100.0 & $03 / 06$ & analyzed in lab \\
\hline $3 / 4 / 96$ & 12:53:08 AM & 2263 & & 97.6 & $03 / 06$ & analyzed in lab \\
\hline $3 / 4 / 96$ & 1:13:28 AM & 2264 & & 101.2 & $03 / 06$ & analyzed in lab \\
\hline $3 / 4 / 96$ & 1:33:56 AM & 2265 & & 96.5 & $03 / 06$ & analyzed in lab \\
\hline $3 / 4 / 96$ & $1: 54: 43 \mathrm{AM}$ & 2266 & & 99.4 & $03 / 06$ & analyzed in lab \\
\hline $3 / 4 / 96$ & $2: 14: 56$ AM & 2267 & & 97.4 & $03 / 06$ & analyzed in lab \\
\hline $3 / 4 / 96$ & $2: 35: 18 \mathrm{AM}$ & 2268 & & 98.8 & $03 / 06$ & analyzed in lab \\
\hline $3 / 4 / 96$ & $2: 55: 47$ AM & 2269 & UD & 93.6 & & \\
\hline $3 / 4 / 96$ & $3: 16: 15 \mathrm{AM}$ & 2270 & & 95.1 & $03 / 08$ & analyzed in lab \\
\hline $3 / 4 / 96$ & 3:37:02 AM & 2271 & & 94.8 & $03 / 08$ & analyzed in lab \\
\hline $3 / 4 / 96$ & $3: 57: 15 \mathrm{AM}$ & 2272 & & 95.6 & $03 / 08$ & analyzed in lab \\
\hline $3 / 4 / 96$ & 4:17:35 AM & 2273 & & 94.4 & $03 / 08$ & analyzed in lab \\
\hline $3 / 4 / 96$ & 4:38:02 AM & 2274 & & 91.9 & $03 / 11$ & analyzed in lab \\
\hline $3 / 4 / 96$ & 4:58:32 AM & 2275 & & 92.6 & $03 / 11$ & anabyzed in lab \\
\hline $3 / 4 / 96$ & 5:19:01 AM & 2276 & & 94.9 & $03 / 08$ & analyzed in lab \\
\hline $3 / 4 / 96$ & 5:39:28 AM & 2277 & & 101.4 & $03 / 08$ & analyzed in lab \\
\hline $3 / 4 / 96$ & 5:59:54 AM & 2278 & & 93.9 & $03 / 08$ & analyzed in lab \\
\hline $3 / 4 / 96$ & $6: 20: 20 \mathrm{AM}$ & 2279 & & 94.8 & $03 / 08$ & anatyzed in lab \\
\hline $3 / 4 / 96$ & $6: 41: 08 \mathrm{AM}$ & 2280 & & 94.4 & $03 / 08$ & analyzed in lab \\
\hline $3 / 4 / 96$ & 7:01:21 AM & 2281 & & 95.0 & $03 / 08$ & analyzed in lab \\
\hline $3 / 4 / 96$ & 7:21:39 AM & 2282 & & 95.2 & $03 / 08$ & analyzed in lab \\
\hline $3 / 4 / 96$ & 7:42:06 AM & 2283 & & 94.5 & $03 / 08$ & analyzed in lab \\
\hline $3 / 4 / 96$ & 8:02:35 AM & 2284 & & 95.7 & $03 / 08$ & analyzed in lab \\
\hline $3 / 4 / 96$ & $8: 22: 58 \mathrm{AM}$ & 2285 & & 93.6 & $03 / 08$ & analyzed in lab \\
\hline $3 / 4 / 96$ & $8: 43: 24 \mathrm{AM}$ & 2286 & & 92.3 & $03 / 08$ & analyzed in $\mathrm{lab}$ \\
\hline $3 / 4 / 96$ & 9:03:51 AM & 2287 & & 94.1 & $03 / 08$ & analyzed in lab \\
\hline $3 / 4 / 96$ & 9:24:16 AM & 2288 & & 91.5 & $03 / 08$ & analyzed in lab \\
\hline $3 / 4 / 96$ & 9:45:01 AM & 2289 & LF-D* & 91.5 & $03 / 19$ & analyzed in lab \\
\hline $3 / 4 / 96$ & 10:05:14 AM & 2290 & LF-D* & 94.0 & $03 / 19$ & analyzed in lab \\
\hline $3 / 4 / 96$ & $10: 25: 30 \mathrm{AM}$ & 2291 & L/F-D* & 93.3 & $03 / 19$ & analyzed in lab \\
\hline $3 / 4 / 96$ & $10: 45: 54 \mathrm{AM}$ & 2292 & & 98.5 & $03 / 04$ & analyzed in field \\
\hline
\end{tabular}




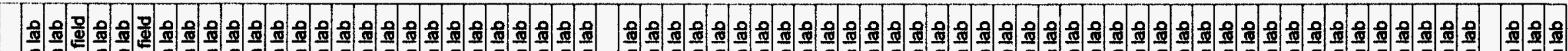

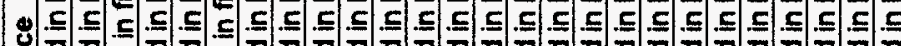

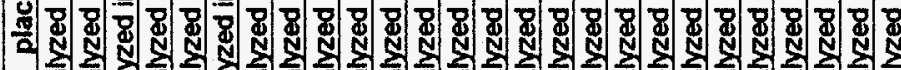

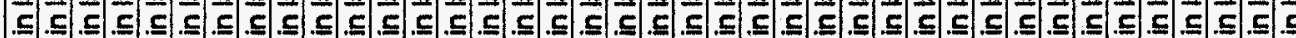

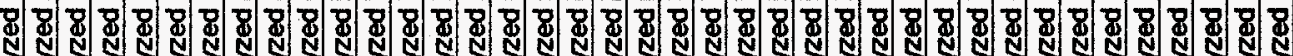

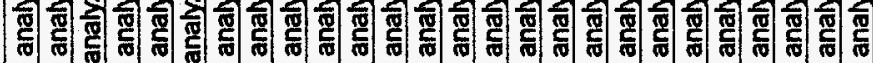

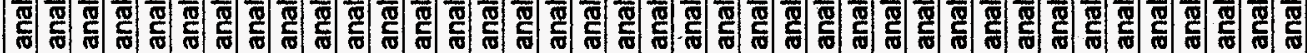

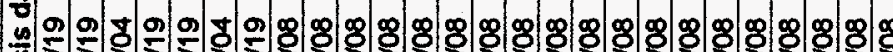

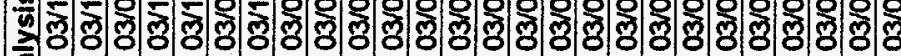

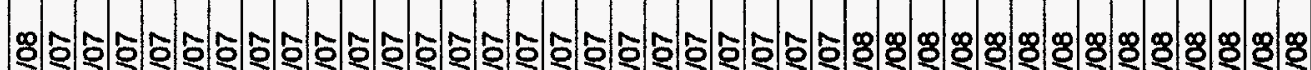

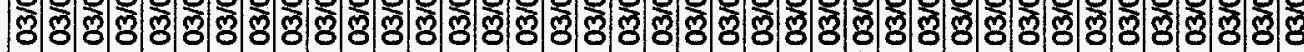

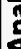

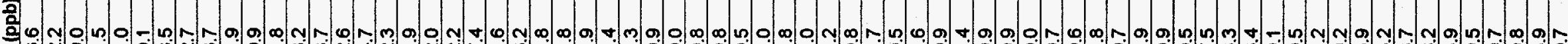

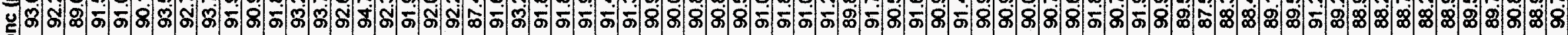

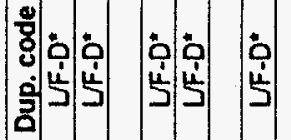

5

$\grave{\mathrm{S}}$

S

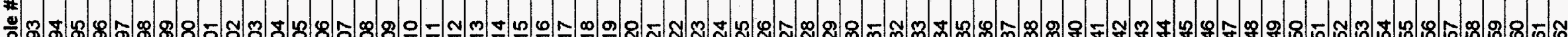

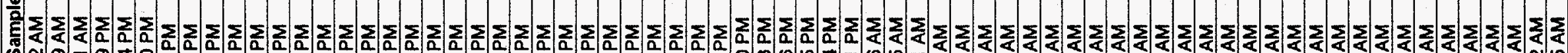

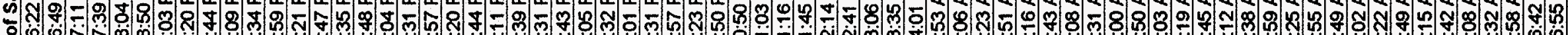

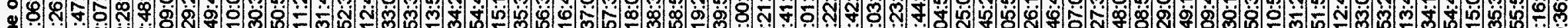

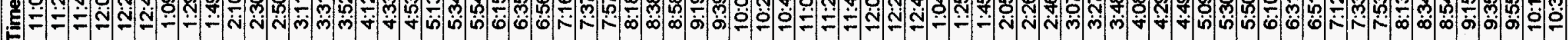

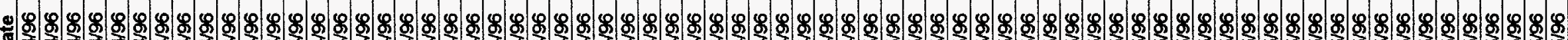

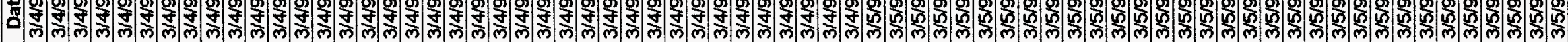


Yucca Mountain tracer test; 22

\begin{tabular}{|c|c|c|c|c|c|c|}
\hline Date & Time of Sample & Sample \# & Dup. code & Conc (ppb) & Analysis date & place \\
\hline $3 / 5 / 96$ & $10: 57: 10 \mathrm{AM}$ & 2363 & & 90.9 & $03 / 08$ & analyzed in lab \\
\hline $3 / 5 / 96$ & $11: 17: 38 \mathrm{AM}$ & 2364 & & 89.4 & $03 / 08$ & analyzed in lab \\
\hline $3 / 5 / 96$ & $11: 38: 02 \mathrm{AM}$ & 2365 & & 90.0 & $03 / 08$ & analyzed in lab \\
\hline $3 / 5 / 96$ & 11:58:31 AM & 2366 & & 88.7 & $03 / 08$ & analyzed in lab \\
\hline $3 / 5 / 96$ & $12: 19: 01 \mathrm{PM}$ & 2367 & & 88.7 & $03 / 08$ & analyzed in lab \\
\hline $3 / 5 / 96$ & $12: 39: 26 \mathrm{PM}$ & 2368 & & 90.2 & $03 / 08$ & analyzed in lab \\
\hline $3 / 5 / 96$ & 12:59:52 PM & 2369 & & 90.4 & $03 / 07$ & analyzed in lab \\
\hline $3 / 5 / 96$ & $1: 20: 41 \mathrm{PM}$ & 2370 & & 90.6 & $03 / 07$ & analyzed in lab \\
\hline $3 / 5 / 96$ & $1: 40: 54 \mathrm{PM}$ & 2371 & & 88.8 & $03 / 07$ & analyzed in lab \\
\hline $3 / 5 / 96$ & 2:01:12 PM & 2372 & & 89.8 & $03 / 07$ & analyzed in lab \\
\hline $3 / 5 / 96$ & $2: 21: 43 \mathrm{PM}$ & 2373 & & 89.7 & $03 / 07$ & analyzed in lab \\
\hline $3 / 5 / 96$ & 2:42:09 PM & 2374 & & 88.2 & $03 / 07$ & analyzed in lab \\
\hline $3 / 5 / 96$ & $3: 02: 36 \mathrm{PM}$ & 2375 & & 89.8 & $03 / 07$ & analyzed in lab \\
\hline $3 / 5 / 96$ & $3: 23: 00$ PM & 2376 & & 89.9 & $03 / 07$ & analyzed in lab \\
\hline $3 / 5 / 96$ & $3: 43: 24$ PM & 2377 & & 87.1 & $03 / 07$ & analyzed in lab \\
\hline $3 / 5 / 96$ & 4:03:55 PM & 2378 & & 87.2 & $03 / 07$ & analyzed in lab \\
\hline $3 / 5 / 96$ & 4:24:41 PM & 2379 & & 86.3 & $03 / 07$ & analyzed in lab \\
\hline $3 / 5 / 96$ & 4:44:53 PM & 2380 & LD & 85.1 & & \\
\hline $3 / 5 / 96$ & 5:05:14 PM & 2381 & & 88.0 & $03 / 07$ & analyzed in $\mathrm{lab}$ \\
\hline $3 / 5 / 96$ & 5:25:41 PM & 2382 & & 85.0 & $03 / 07$ & analyzed in lab \\
\hline $3 / 5 / 96$ & $5: 46: 06 \mathrm{PM}$ & 2383 & & 86.6 & $03 / 07$ & analyzed in lab \\
\hline $3 / 5 / 96$ & $6: 06: 57$ PM & 2384 & & 86.9 & 03107 & analyzed in lab \\
\hline $3 / 5 / 96$ & $6: 27: 10 \mathrm{PM}$ & 2385 & & 89.9 & $03 / 07$ & analyzed in lab \\
\hline $3 / 5 / 96$ & 6:47:30 PM & 2386 & & 85.8 & 03107 & analyzed in lab \\
\hline $3 / 5 / 96$ & 7:07:59 PM & 2387 & & 87.3 & $03 / 07$ & analyzed in lab \\
\hline $3 / 5 / 96$ & $7: 28: 53 \mathrm{PM}$ & 2388 & & 85.0 & $03 / 08$ & analyzed in lab \\
\hline $3 / 5 / 96$ & $7: 49: 06 \mathrm{PM}$ & 2389 & & 84.0 & $03 / 08$ & analyzed in lab \\
\hline $3 / 5 / 96$ & $8: 09: 23 \mathrm{PM}$ & 2390 & & 84.8 & $03 / 08$ & analyzed in lab \\
\hline $3 / 5 / 96$ & $8: 29: 48$ PM & 2391 & & 85.0 & $03 / 08$ & analyzed in lab \\
\hline $3 / 5 / 96$ & $8: 50: 13 P M$ & 2392 & & 81.1 & $03 / 08$ & analyzed in lab \\
\hline $3 / 5 / 96$ & $9: 10: 43 \mathrm{PM}$ & 2393 & & 85.5 & $03 / 07$ & analyzed in lab \\
\hline $3 / 5 / 96$ & $9: 31: 08 \mathrm{PM}$ & 2394 & & 85.7 & $03 / 07$ & analyzed in lab \\
\hline $3 / 5 / 96$ & $9: 51: 33 \mathrm{PM}$ & 2395 & & 86.0 & $03 / 07$ & analyzed in lab \\
\hline $3 / 5 / 96$ & $10: 11: 58 \mathrm{PM}$ & 2396 & & 85.3 & $03 / 07$ & anahyzed in lab \\
\hline $3 / 5 / 96$ & $10: 32: 50 \mathrm{PM}$ & 2397 & & 85.7 & $03 / 07$ & analyzed in lab \\
\hline $3 / 5 / 96$ & $10: 53: 03 \mathrm{PM}$ & 2398 & & 85.9 & $03 / 07$ & analyzed in lab \\
\hline $3 / 5 / 96$ & $11: 13: 23 \mathrm{PM}$ & 2399 & & 87.4 & $03 / 07$ & analyzed in lab \\
\hline $3 / 5 / 96$ & 11:33:47 PM & 2400 & & 86.4 & $03 / 07$ & analyzed in lab \\
\hline $3 / 5 / 96$ & $11: 54: 15 \mathrm{PM}$ & 2401 & & 87.9 & $03 / 07$ & analyzed in lab \\
\hline $3 / 6 / 96$ & $12: 14: 41 \mathrm{AM}$ & 2402 & & 88.7 & $03 / 07$ & analyzed in lab \\
\hline $3 / 6 / 96$ & $12: 35: 08 \mathrm{AM}$ & 2403 & & 86.8 & $03 / 07$ & analyzed in lab \\
\hline $3 / 6 / 96$ & $12: 55: 36 \mathrm{AM}$ & 2404 & & 88.1 & $03 / 07$ & analyzed in lab \\
\hline $3 / 6 / 96$ & $1: 16: 04 \mathrm{AM}$ & 2405 & UF-D & 88.1 & & \\
\hline $3 / 6 / 96$ & $1: 36: 57$ AM & 2406 & & 86.5 & $03 / 06$ & analyzed in field \\
\hline $3 / 6 / 96$ & $1: 57: 09 \mathrm{AM}$ & 2407 & UF-D & 88.5 & & \\
\hline $3 / 6 / 96$ & $2: 17: 30$ AM & 2408 & UF-D & 88.7 & & \\
\hline $3 / 6 / 96$ & $2: 37: 59 \mathrm{AM}$ & 2409 & & 82.3 & $03 / 06$ & anatyzed in field \\
\hline $3 / 6 / 96$ & $2: 58: 26$ AM & 2410 & & 87.7 & $03 / 11$ & analyzed in lab \\
\hline $3 / 6 / 96$ & 3:18:53 AM & 2411 & & 87.6 & $03 / 11$ & analyzed in lab \\
\hline $3 / 6 / 96$ & 3:39:19 AM & 2412 & & 87.9 & $03 / 11$ & analyzed in lab \\
\hline $3 / 6 / 96$ & 3:59:52 AM & 2413 & & 86.8 & $03 / 11$ & analyzed in lab \\
\hline $3 / 6 / 96$ & $4: 20: 19 \mathrm{AM}$ & 2414 & & 86.7 & $03 / 11$ & analyzed in lab \\
\hline $3 / 6 / 96$ & 4:41:11 AM & 2415 & & 85.1 & $03 / 06$ & analyzed in field \\
\hline $3 / 6 / 96$ & $5: 01: 25$ AM & 2416 & LF-D & 85.0 & & \\
\hline $3 / 6 / 96$ & $5: 21: 43$ AM & 2417 & LF $-D^{*}$ & 87.1 & $03 / 06$ & analyzed in field \\
\hline $3 / 6 / 96$ & $5: 42: 15$ AM & 2418 & & 86.0 & $03 / 06$ & analyzed in field \\
\hline $3 / 6 / 96$ & $6: 02: 46 \mathrm{AM}$ & 2419 & LF-D & 87.2 & & \\
\hline $3 / 6 / 96$ & $6: 23: 14 \mathrm{AM}$ & 2420 & LF-D* & 85.3 & $04 / 19$ & analyzed in lab \\
\hline $3 / 6 / 96$ & $6: 43: 43 \mathrm{AM}$ & 2421 & & 85.8 & $03 / 06$ & analyzed in field \\
\hline $3 / 6 / 96$ & 7:04:10 AM & 2422 & LF $-D^{*}$ & 86.7 & $03 / 19$ & analyzed in lab \\
\hline $3 / 6 / 96$ & $7: 24: 36$ AM & 2423 & UF-D & 87.4 & & \\
\hline $3 / 6 / 96$ & $7: 45: 28 \mathrm{AM}$ & 2424 & & 89.4 & $03 / 06$ & analyzed in field \\
\hline $3 / 6 / 96$ & 8:05:41 AM & 2425 & LF-D & 86.6 & & \\
\hline $3 / 6 / 96$ & 8:26:01 AM & 2426 & & 86.5 & $03 / 06$ & analyzed in field \\
\hline $3 / 6 / 96$ & $8: 46: 28 \mathrm{AM}$ & 2427 & & 87.0 & $03 / 06$ & analyzed in field \\
\hline $3 / 6 / 96$ & $9: 06: 56 \mathrm{AM}$ & 2428 & & 83.3 & $03 / 06$ & analyzed in field \\
\hline $3 / 6 / 96$ & 9:27:17 AM & 2429 & & 84.6 & $03 / 06$ & analyzed in field \\
\hline $3 / 6 / 96$ & 9:47:45 AM & 2430 & & 85.6 & $03 / 06$ & analyzed in field \\
\hline $3 / 6196$ & 10:08:12 AM & 2431 & & 87.8 & $03 / 06$ & anahzed in field \\
\hline $3 / 6 / 96$ & 10:28:37 AM & 2432 & & 84.1 & $03 / 06$ & anabyzed in field \\
\hline
\end{tabular}




\begin{tabular}{|c|c|c|c|c|c|c|}
\hline Date & Time of Sample & Sample \# & Dup. code & Conc (ppb) & Analysis date & place \\
\hline $3 / 6 / 96$ & $10: 49: 29 \mathrm{AM}$ & 2433 & & 85.8 & $03 / 106$ & analyzed in field \\
\hline $3 / 6 / 96$ & $11: 09: 42$ AM & 2434 & & 83.9 & $03 / 06$ & analyzed in field \\
\hline $3 / 6 / 96$ & 11:30:02 AM & 2435 & & 84.7 & $03 / 06$ & analyzed in field \\
\hline $3 / 6 / 96$ & $11: 50: 28 \mathrm{AM}$ & 2436 & & 84.0 & $03 / 06$ & analyzed in field \\
\hline $3 / 6 / 96$ & 12:10:57 PM & 2437 & & 87.0 & 03106 & analyzed in field \\
\hline $3 / 6 / 96$ & 12:31:24 PM & 2438 & & 85.6 & $03 / 06$ & analyzed in field \\
\hline $3 / 6 / 96$ & $12: 51: 50 \mathrm{PM}$ & 2439 & & 84.3 & $03 / 06$ & analyzed in field \\
\hline $3 / 6 / 96$ & 1:12:17 PM & 2440 & & 83.9 & $03 / 06$ & analyzed in field \\
\hline $3 / 6 / 96$ & 1:32:47 PM & 2441 & & 86.0 & $03 / 06$ & analyzed in field \\
\hline $3 / 6 / 96$ & 1:53:37 PM & 2442 & & 85.8 & $03 / 11$ & analyzed in lab \\
\hline $3 / 6 / 96$ & 2:14:15 PM & 2443 & & 85.5 & $03 / 11$ & analyzed in lab \\
\hline $3 / 6 / 96$ & $2: 34: 28 \mathrm{PM}$ & 2444 & & 85.4 & $03 / 11$ & analyzed in lab \\
\hline $3 / 6 / 96$ & 2:54:40 PM & 2445 & & 85.9 & $03 / 11$ & analyzed in lab \\
\hline $3 / 6 / 96$ & 3:15:08 PM & 2446 & & 84.8 & $03 / 11$ & analyzed in lab \\
\hline $3 / 6 / 96$ & 3:35:36 PM & 2447 & & 87.1 & $03 / 11$ & analyzed in lab \\
\hline $3 / 6 / 96$ & 3:56:01 PM & 2448 & & 87.6 & $03 / 11$ & analyzed in lab \\
\hline $3 / 6 / 96$ & 4:16:31 PM & 2449 & & 87.1 & $03 / 11$ & analyzed in lab \\
\hline $3 / 6 / 96$ & 4:36:57 PM & 2450 & & 87.7 & $03 / 11$ & analyzed in lab \\
\hline $3 / 6 / 96$ & 4:57:39 PM & 2451 & & 87.8 & $03 / 11$ & analyzed in lab \\
\hline $3 / 6 / 96$ & $5: 17: 52 \mathrm{PM}$ & 2452 & & 87.7 & $03 / 11$ & analyzed in lab \\
\hline $3 / 6 / 96$ & 5:38:09 PM & 2453 & & 86.3 & $03 / 11$ & analyzed in lab \\
\hline $3 / 6 / 96$ & 5:58:35 PM & 2454 & & 86.7 & $03 / 11$ & analyzed in lab \\
\hline $3 / 6 / 96$ & 6:19:02 PM & 2455 & UD & 87.6 & & \\
\hline $3 / 6 / 96$ & $6: 39: 26 \mathrm{PM}$ & 2456 & & 87.1 & $03 / 11$ & analyzed in lab \\
\hline $3 / 6 / 96$ & 6:59:56 PM & 2457 & & 86.7 & $03 / 11$ & analyzed in lab \\
\hline $3 / 6 / 96$ & 7:20:21 PM & 2458 & & 86.8 & $03 / 11$ & analyzed in lab \\
\hline $3 / 6 / 96$ & $7: 40: 50 \mathrm{PM}$ & 2459 & & 86.7 & $03 / 11$ & analyzed in lab \\
\hline $3 / 6 / 96$ & $8: 01: 42 \mathrm{PM}$ & 2460 & & 86.4 & $03 / 11$ & analyzed in lab \\
\hline $3 / 6 / 96$ & 8:21:54 PM & 2461 & & 88.0 & $03 / 20$ & analyzed in lab \\
\hline $3 / 6 / 96$ & 8:42:14 PM & 2462 & & 83.8 & $03 / 20$ & analyzed in lab \\
\hline $3 / 6 / 96$ & 9:02:41 PM & 2463 & & 86.3 & $03 / 20$ & analyzed in lab \\
\hline $3 / 6 / 96$ & 9:23:08 PM & 2464 & & 85.6 & $03 / 20$ & analyzed in lab \\
\hline $3 / 6 / 96$ & $9: 43: 35 \mathrm{PM}$ & 2465 & & 86.9 & $03 / 20$ & analyzed in lab \\
\hline $3 / 6 / 96$ & $10: 03.59 \mathrm{PM}$ & 2466 & & 86.3 & $03 / 20$ & analyzed in lab \\
\hline 3/6/96 & 10:24:28 PM & 2467 & & 82.5 & $03 / 20$ & analyzed in lab \\
\hline $3 / 6 / 96$ & 10:44:56 PM & 2468 & & 85.4 & $03 / 20$ & analyzed in lab \\
\hline $3 / 6 / 96$ & 11:05:48 PM & 2469 & & 87.2 & $03 / 20$ & analyzed in lab \\
\hline $3 / 6 / 96$ & $11: 26: 02 \mathrm{PM}$ & 2470 & & 84.7 & $03 / 20$ & analyzed in lab \\
\hline $3 / 6196$ & 11:46:21 PM & 2471 & & 85.2 & $03 / 20$ & analyzed in lab \\
\hline $3 / 7 / 96$ & $12: 06: 48 \mathrm{AM}$ & 2472 & & 84.1 & $03 / 20$ & analyzed in lab \\
\hline $3 / 7 / 96$ & 12:27:18 AM & 2473 & & 83.8 & $03 / 20$ & analyzed in lab \\
\hline $3 / 7 / 96$ & $12: 47: 44 \mathrm{AM}$ & 2474 & & 85.0 & $03 / 20$ & analyzed in lab \\
\hline $3 \sqrt{7196}$ & 1:08:14 AM & 2475 & & 84.9 & $03 / 20$ & analyzed in lab \\
\hline $3 / 7 / 96$ & 1:28:38 AM & 2476 & & 84.3 & $03 / 20$ & analyzed in lab \\
\hline $3 / 7 / 96$ & 1:49:15 AM & 2477 & & 83.1 & $03 / 20$ & analyzed in lab \\
\hline $3 / 7 / 96$ & $2: 10: 01$ AM & 2478 & LD & 81.0 & & \\
\hline $3 / 7 / 96$ & $2: 30: 14$ AM & 2479 & & 82.1 & $03 / 20$ & analyzed in lab \\
\hline $3 / 7 / 96$ & $2: 50: 34$ AM & 2480 & & 81.5 & $03 / 20$ & analyzed in lab \\
\hline $3 / 7 / 96$ & $3: 10: 59$ AM & 2481 & & 81.0 & $03 / 20$ & analyzed in lab \\
\hline $3 / 7 / 96$ & 3:31:24 AM & 2482 & & 81.0 & $03 / 20$ & analyzed in lab \\
\hline $3 / 7 / 96$ & 3:51:52 AM & 2483 & & 82.4 & $03 / 20$ & analyzed in $\mathrm{lab}$ \\
\hline $3 / 7 / 96$ & 4:12:18 AM & 2484 & & 82.8 & $03 / 20$ & analyzed in lab \\
\hline $37 / 96$ & 4:32:41 AM & 2485 & & 80.4 & $03 / 20$ & analyzed in lab \\
\hline $3 / 7 / 96$ & 4:53:12 AM & 2486 & & 82.4 & $03 / 20$ & analyzed in lab \\
\hline $3 / 7 / 96$ & $5: 14: 02$ AM & 2487 & UD & 79.8 & & \\
\hline $3 / 796$ & $5: 34: 15 \mathrm{AM}$ & 2488 & & 79.9 & $03 / 20$ & analyzed in lab \\
\hline $3 / 7 / 96$ & $5: 54: 37$ AM & 2489 & & 83.8 & $03 / 20$ & analyzed in lab \\
\hline $3 / 7 / 96$ & $6: 15: 01 \mathrm{AM}$ & 2490 & & 82.0 & $03 / 20$ & anahyed in lab \\
\hline $3 / 7 / 96$ & 6:35:28 AM & 2491 & & 81.1 & $03 / 20$ & analyzed in lab \\
\hline $37 / 96$ & $6: 56: 00 \mathrm{AM}$ & 2492 & & 79.8 & $03 / 20$ & analyzed in lab \\
\hline $3 / 7 / 96$ & $7: 16: 28 \mathrm{AM}$ & 2493 & & 79.1 & $03 / 20$ & analyzed in lab \\
\hline $3 / 7 / 96$ & $7: 36: 55$ AM & 2494 & & 81.4 & $03 / 20$ & anatyzed in lab \\
\hline $3 / 7 / 96$ & 7:57:22 AM & 2495 & & 79.0 & $03 / 20$ & analyzed in lab \\
\hline $3 / 7 / 96$ & $8: 18: 12$ AM & 2496 & & 80.1 & $03 / 20$ & analyzed in lab \\
\hline $3 / 7 / 96$ & $8: 38: 25$ AM & 2497 & LD & 83.7 & & \\
\hline $3 / 7 / 96$ & 8:58:42 AM & 2498 & & 80.3 & $03 / 20$ & analyzed in lab \\
\hline $3 / 7 / 96$ & 9:19:07 AM & 2499 & & 82.0 & $03 / 20$ & analyzed in lab \\
\hline $3 / 7 / 96$ & 9:39:32 AM & 2500 & & 83.0 & $03 / 20$ & analyzed in lab \\
\hline $3 / 7 / 96$ & 9:59:58 AM & 2501 & & 81.0 & $03 / 20$ & anahyed in lab \\
\hline & & & & 82.4 & $03 / 20$ & analyzed in lab \\
\hline
\end{tabular}


Yucca Mountain tracer test; 24

\begin{tabular}{|c|c|c|c|c|c|c|}
\hline Date & Time of Sample & Sample \# & Dup. code & Conc (ppb) & Analysis date & place \\
\hline & & & & 80.6 & $03 / 20$ & analyzed in lab \\
\hline $3 / 7 / 96$ & $1: 02: 28 \mathrm{PM}$ & 2504 & & 83.6 & $03 / 20$ & analyzed in lab \\
\hline $3 / 7 / 96$ & 1:09:47 PM & 2504 & & & & \\
\hline $3 / 7 / 96$ & 1:15:27 PM & 2505 & & 81.5 & $03 / 20$ & analyzed in lab \\
\hline $3 / 796$ & $1: 35: 40 \mathrm{PM}$ & 2506 & & 85.0 & $03 / 20$ & analyzed in lab \\
\hline $3 / 7 / 96$ & $1: 55: 58 \mathrm{PM}$ & 2507 & & 82.6 & $03 / 20$ & analyzed in lab \\
\hline $3 / 7 / 96$ & $2: 16: 24 \mathrm{PM}$ & 2508 & & 84.9 & $03 / 20$ & analyzed in lab \\
\hline $3 / 7 / 96$ & $2: 36: 48 \mathrm{PM}$ & 2509 & & 84.1 & $03 / 11$ & analyzed in lab \\
\hline $3 / 7 / 96$ & $2: 57: 12 \mathrm{PM}$ & 2510 & & 85.3 & $03 / 11$ & analyzed in lab \\
\hline $3 / 7 / 96$ & 3:17:37 PM & 2511 & & 83.8 & $03 / 11$ & analyzed in lab \\
\hline $3 / 7 / 96$ & 3:38:04 PM & 2512 & & 83.5 & $03 / 11$ & analyzed in lab \\
\hline $3 \pi / 96$ & 3:58:51 PM & 2513 & & 84.5 & $03 / 11$ & analyzed in lab \\
\hline $3 / 7 / 96$ & 4:19:03 PM & 2514 & & 85.5 & $03 / 11$ & analyzed in lab \\
\hline $3 / 7 / 96$ & $4: 39: 22 \mathrm{PM}$ & 2515 & & 84.9 & $03 / 11$ & analyzed in lab \\
\hline $3 / 7 / 96$ & 4:59:54 PM & 2516 & & 84.7 & $03 / 11$ & analyzed in lab \\
\hline $3 / 7 / 96$ & $5: 20: 22 \mathrm{PM}$ & 2517 & & 85.2 & $03 / 11$ & analyzed in tab \\
\hline $37 / 96$ & 5:40:53 PM & 2518 & & 85.4 & $03 / 11$ & analyzed in lab \\
\hline $3 / 7 / 96$ & 6:01:16 PM & 2519 & & 85.6 & $03 / 11$ & analyzed in lab \\
\hline $3 / 7 / 96$ & $6: 21: 39 \mathrm{PM}$ & 2520 & & 85.5 & $03 / 11$ & analyzed in lab \\
\hline $3 / 7 / 96$ & $6: 42: 07 \mathrm{PM}$ & 2521 & & 86.0 & $03 / 11$ & analyzed in lab \\
\hline $3 / 7 / 96$ & $7: 02: 58 \mathrm{PM}$ & 2522 & & 85.1 & $03 / 11$ & analyzed in lab \\
\hline $3 / 7 / 96$ & $7: 23: 11 \mathrm{PM}$ & 2523 & & 85.4 & $03 / 11$ & analyzed in $1 a b$ \\
\hline $3 / 7 / 96$ & $7: 43: 29 \mathrm{PM}$ & 2524 & & 86.0 & $03 / 11$ & analyzed in $\mathrm{lab}$ \\
\hline $3 / 7 / 96$ & 8:04:00 PM & 2525 & & 84.7 & $03 / 11$ & analyzed in lab \\
\hline $37 / 96$ & $8: 24: 26$ PM & 2526 & & 84.9 & $03 / 11$ & analyzed in lab \\
\hline $3 / 7 / 96$ & 8:44:54 PM & 2527 & & 85.0 & $03 / 11$ & analyzed in lab \\
\hline $37 / 96$ & $9: 05: 21$ PM & 2528 & & 85.4 & $03 / 11$ & analyzed in lab \\
\hline $3 / 7 / 96$ & $9: 25: 47 \mathrm{PM}$ & 2529 & $L / D$ & 84.6 & & \\
\hline $3 / 7 / 96$ & $9: 46: 15 \mathrm{PM}$ & 2530 & & 83.1 & $03 / 11$ & analyzed in lab \\
\hline $3 / 7 / 96$ & $10: 07: 12 \mathrm{PM}$ & 2531 & & 85.3 & $03 / 11$ & analyzed in lab \\
\hline $3 / 7 / 96$ & $10: 27: 25 \mathrm{PM}$ & 2532 & & 84.2 & $03 / 11$ & analyzed in lab \\
\hline $3 / 7 / 96$ & $10: 47: 42 \mathrm{PM}$ & 2533 & & 83.2 & $03 / 11$ & analyzed in lab \\
\hline $3 / 7 / 96$ & 11:08:07 PM & 2534 & & 82.9 & $03 / 11$ & analyzed in lab \\
\hline $3 / 7 / 96$ & $11: 28: 33 \mathrm{PM}$ & 2535 & & 83.0 & $03 / 11$ & analyzed in lab \\
\hline $3 / 7 / 96$ & 11:49:00 PM & 2536 & & 83.0 & $03 / 11$ & analyzed in $\mathrm{lab}$ \\
\hline $3 / 8 / 96$ & 12:09:30 AM & 2537 & & 82.6 & $03 / 11$ & analyzed in lab \\
\hline $3 / 8 / 96$ & $12: 29: 57$ AM & 2538 & & 84.0 & $03 / 11$ & analyzed in lab \\
\hline $3 / 8 / 96$ & $12: 50: 23 \mathrm{AM}$ & 2539 & & 82.9 & $03 / 11$ & analyzed in tab \\
\hline $3 / 8 / 96$ & $1: 11: 13 \mathrm{AM}$ & 2540 & & 82.5 & $03 / 11$ & analyzed in lab \\
\hline $3 / 8 / 96$ & 1:31:26 AM & 2541 & & 78.7 & $03 / 11$ & analyzed in lab \\
\hline $3 / 8 / 96$ & 1:51:44 AM & 2542 & & 82.9 & $03 / 11$ & analyzed in lab \\
\hline $3 / 8 / 96$ & 2:12:11 AM & 2543 & & 83.1 & $03 / 11$ & analyzed in lab \\
\hline $3 / 8 / 96$ & 2:32:40 AM & 2544 & & 82.1 & $03 / 11$ & analyzed in lab \\
\hline $3 / 8 / 96$ & $2: 53: 05$ AM & 2545 & & 83.5 & $03 / 11$ & analyzed in lab \\
\hline $3 / 8 / 96$ & 3:13:32 AM & 2546 & & 87.2 & $03 / 11$ & analyzed in lab \\
\hline $3 / 8 / 96$ & 3:34:07 AM & 2547 & & 82.0 & $03 / 11$ & analyzed in lab \\
\hline $3 / 8 / 96$ & 3:54:37 AM & 2548 & LD & 83.7 & & \\
\hline $3 / 8 / 96$ & 4:15:26 AM & 2549 & & 82.1 & $03 / 11$ & analyzed in lab \\
\hline $3 / 8 / 96$ & 4:35:38 AM & 2550 & & 79.9 & $03 / 11$ & analyzed in lab \\
\hline $3 / 8 / 96$ & 4:55:55 AM & 2551 & & 80.7 & $03 / 11$ & analyzed in lab \\
\hline $3 / 8 / 96$ & $5: 16: 20 \mathrm{AM}$ & 2552 & & 84.1 & $03 / 11$ & analyzed in lab \\
\hline $3 / 8 / 96$ & $5: 36: 47$ AM & 2553 & & 81.8 & $03 / 11$ & analyzed in lab \\
\hline $3 / 8 / 96$ & 5:57:13 AM & 2554 & & 80.8 & $03 / 11$ & analyzed in lab \\
\hline $3 / 8 / 96$ & $6: 17: 43 \mathrm{AM}$ & 2555 & & 83.1 & $03 / 11$ & analyzed in lab \\
\hline $3 / 8 / 96$ & $6: 38: 10 \mathrm{AM}$ & 2556 & & 82.7 & 03111 & analyzed in $\mathrm{ab}$ \\
\hline $3 / 8 / 96$ & $6: 58: 33 \mathrm{AM}$ & 2557 & & 77.7 & $03 / 20$ & analyzed in lab \\
\hline $3 / 8196$ & 7:19:24 AM & 2558 & & 78.9 & $03 / 20$ & analyzed in lab \\
\hline $3 / 8 / 96$ & 7:39:37 AM & 2559 & & 78.9 & $03 / 20$ & analyzed in lab \\
\hline $3 / 8 / 96$ & 7:59:56 AM & 2560 & & 80.1 & $03 / 08$ & analyzed in field \\
\hline $3 / 8 / 96$ & 8:20:27 AM & 2561 & F/D & 78.6 & & \\
\hline $3 / 8 / 96$ & 8:41:03 AM & 2562 & & 78.9 & $03 / 08$ & analyzed in field \\
\hline $3 / 8 / 96$ & $9: 02: 06 \mathrm{AM}$ & 2563 & & 79.0 & $03 / 08$ & analyzed in field \\
\hline $3 / 8 / 96$ & 9:22:19 AM & 2564 & & 80.1 & $03 / 08$ & analyzed in field \\
\hline $3 / 8 / 96$ & $9: 42: 31$ AM & 2565 & & 78.7 & $03 / 08$ & analyzed in field \\
\hline $3 / 8196$ & $10: 02: 53 \mathrm{AM}$ & 2566 & & 80.6 & $03 / 08$ & analyzed in field \\
\hline $3 / 8 / 96$ & $10: 23: 45 \mathrm{AM}$ & 2567 & & 80.5 & $03 / 08$ & analyzed in field \\
\hline $3 / 8 / 96$ & $10: 43: 58 \mathrm{AM}$ & 2568 & & 78.1 & $03 / 08$ & analyzed in field \\
\hline $3 / 8 / 96$ & $11: 04: 16 \mathrm{AM}$ & 2569 & & 76.8 & $03 / 08$ & analyzed in field \\
\hline $3 / 8 / 96$ & $11: 24: 46 \mathrm{AM}$ & 2570 & & 80.0 & $03 / 08$ & analyzed in fietd \\
\hline $3 / 8 / 96$ & 11:45:14 AM & $\frac{2571}{2571}$ & & 79.9 & $03 / 08$ & analyzed in field \\
\hline
\end{tabular}




\begin{tabular}{|c|c|c|c|c|c|c|}
\hline Date & Time of Sample & Sample \# & Dup. code & Conc (ppb) & Analysis date & place \\
\hline $3 / 8 / 96$ & 12:05:37 PM & 2572 & & 78.4 & $03 / 08$ & analyzed in field \\
\hline $3 / 8 / 96$ & 12:26:03 PM & 2573 & & 74.4 & $03 / 08$ & analyzed in field \\
\hline $3 / 8 / 96$ & $12: 46: 29 \mathrm{PM}$ & 2574 & & 78.9 & $03 / 08$ & analyzed in field \\
\hline $3 / 8 / 96$ & 1:06:55 PM & 2575 & & 78.5 & 03108 & analyzed in field \\
\hline $3 / 8 / 96$ & 1:27:51 PM & 2576 & & 78.0 & $03 / 08$ & analyzed in field \\
\hline $3 / 8 / 96$ & 1:48:04 PM & 2577 & & 76.7 & $03 / 20$ & analyzed in lab \\
\hline $3 / 8 / 96$ & 2:08:20 PM & 2578 & & 76.0 & $03 / 20$ & analyzed in lab \\
\hline $3 / 8 / 96$ & 2:38:47 PM & 2579 & & 78.4 & $03 / 20$ & analyzed in lab \\
\hline $3 / 8 / 96$ & 3:09:27 PM & 2580 & & 77.3 & $03 / 20$ & analyzed in lab \\
\hline $3 / 8 / 96$ & 3:40:09 PM & 2581 & & 76.9 & $03 / 20$ & analyzed in lab \\
\hline $3 / 8 / 96$ & 4:10:46 PM & 2582 & & 78.4 & $03 / 20$ & analyzed in lab \\
\hline $3 / 8 / 96$ & 4:41:24PM & 2583 & UD & 78.0 & & \\
\hline $3 / 8 / 96$ & 5:12:02 PM & 2584 & & 75.2 & $03 / 20$ & analyzed in lab \\
\hline $3 / 8 / 96$ & 5:43:18 PM & 2585 & & 77.8 & $03 / 20$ & analyzed in lab \\
\hline $3 / 8 / 96$ & 6:13:31 PM & 2586 & & 79.2 & $03 / 20$ & analyzed in lab \\
\hline $3 / 8 / 96$ & 6:44:08 PM & 2587 & & 78.8 & $03 / 20$ & analyzed in lab \\
\hline $3 / 8 / 96$ & 7:14:48 PM & 2588 & & 77.1 & $03 / 20$ & analyzed in lab \\
\hline $3 / 8 / 96$ & 7:45:30 PM & 2589 & & 77.7 & $03 / 20$ & analyzed in lab \\
\hline $3 / 8 / 96$ & 8:16:09 PM & 2590 & & 77.6 & $03 / 20$ & analyzed in lab \\
\hline $3 / 8 / 96$ & $8: 46: 48 \mathrm{PM}$ & 2591 & & 77.4 & $03 / 20$ & analyzed in lab \\
\hline 3/8/96 & 9:17:26 PM & 2592 & & 77.3 & $03 / 20$ & analyzed in lab \\
\hline $3 / 8 / 96$ & 9:48:10 PM & 2593 & & 76.6 & $03 / 20$ & analyzed in lab \\
\hline $3 / 8 / 96$ & 10:18:58 PM & 2594 & & 75.9 & $03 / 20$ & analyzed in lab \\
\hline $3 / 8 / 96$ & 10:49:35 PM & 2595 & & 78.0 & $03 / 20$ & analyzed in lab \\
\hline $3 / 8 / 96$ & 11:20:18 PM & 2596 & & 75.0 & $03 / 20$ & analyzed in lab \\
\hline $3 / 8 / 96$ & 11:50:30 PM & 2597 & & 76.6 & $03 / 20$ & analyzed in lab \\
\hline $3 / 9 / 96$ & 12:20:56 AM & 2598 & & 81.4 & $03 / 12$ & analyzed in lab \\
\hline $3 / 9 / 96$ & $12: 51: 36 \mathrm{AM}$ & 2599 & & 80.1 & $03 / 12$ & analyzed in lab \\
\hline $3 / 9 / 96$ & 1:22:19 AM & 2600 & & 82.9 & $03 / 12$ & analyzed in lab \\
\hline $3 / 9 / 96$ & 1:53:00 AM & 2601 & & 83.2 & $03 / 12$ & analyzed in lab \\
\hline $3 / 9 / 96$ & 2:23:41 AM & 2602 & & 82.0 & $03 / 12$ & analyzed in lab \\
\hline $3 / 9 / 96$ & 2:54:27 AM & 2603 & & 83.3 & $03 / 12$ & analyzed in lab \\
\hline $3 / 9 / 96$ & 3:25:01 AM & 2604 & & 82.0 & $03 / 12$ & analyzed in lab \\
\hline $3 / 9 / 96$ & 3:55:42 AM & 2605 & & 81.0 & $03 / 12$ & analyzed in lab \\
\hline $3 / 9 / 96$ & 4:26:21 AM & 2606 & & 81.2 & $03 / 12$ & analyzed in lab \\
\hline $3 / 9 / 96$ & 4:56:34 AM & 2607 & & 80.8 & $03 / 12$ & analyzed in lab \\
\hline $3 / 9 / 96$ & 5:26:58 AM & 2608 & & 80.7 & $03 / 12$ & analyzed in lab \\
\hline $3 / 9 / 96$ & 5:57:41 AM & 2609 & & 82.3 & $03 / 12$ & analyzed in lab \\
\hline $3 / 9 / 96$ & $6: 28: 23$ AM & 2610 & & 77.0 & 04102 & analyzed in field \\
\hline $3 / 9 / 96$ & $6: 59: 01 \mathrm{AM}$ & 2611 & & 76.8 & 04102 & analyzed in field \\
\hline $3 / 9 / 96$ & 7:30:18 AM & 2612 & & 76.8 & $04 / 02$ & analyzed in field \\
\hline $3 / 9 / 96$ & 8:00:31 AM & 2613 & & 76.1 & $04 / 02$ & analyzed in field \\
\hline $3 / 9 / 96$ & 8:31:06 AM & 2614 & & 76.7 & $04 / 02$ & analyzed in field \\
\hline $3 / 9 / 96$ & $9: 01: 44$ AM & 2615 & & 76.6 & $04 / 02$ & analyzed in field \\
\hline $3 / 9 / 96$ & 9:32:23 AM & 2616 & & 75.7 & 04102 & analyzed in field \\
\hline $3 / 9 / 96$ & 10:03:01 AM & 2617 & & 75.8 & 04102 & anahyed in field \\
\hline $3 / 9 / 96$ & 10:33:44 AM & 2618 & F/D & 76.5 & & \\
\hline $3 / 9 / 96$ & 11:04:20 AM & 2619 & & 75.6 & 0402 & analyzed in field \\
\hline $3 / 9 / 96$ & $11: 34: 59 \mathrm{AM}$ & 2620 & & 76.2 & $04 / 02$ & analyzed in field \\
\hline $3 / 9 / 96$ & 12:05:25 PM & 2621 & & 76.8 & 0402 & analyzed in field \\
\hline $3 / 9 / 96$ & 12:35:38 PM & 2622 & & 80.1 & $03 / 12$ & analyzed in lab \\
\hline $3 / 9 / 96$ & 1:06:12 PM & 2623 & & 79.2 & $03 / 12$ & analyzed in lab \\
\hline $3 / 9 / 96$ & 1:36:55 PM & 2624 & & 79.6 & $03 / 12$ & analyzed in lab \\
\hline $3 / 9 / 96$ & 2:07:32 PM & 2625 & & 80.6 & $03 / 12$ & analyzed in lab. \\
\hline $3 / 9 / 96$ & 2:38:12 PM & 2626 & & 78.9 & $03 / 12$ & anatyzed in lab \\
\hline $3 / 9 / 96$ & 3:08:50 PM & 2627 & & 82.9 & $03 / 12$ & analyzed in lab \\
\hline 3/9/96 & 3:39:03 PM & 2628 & & 79.7 & $03 / 12$ & analyzed in lab \\
\hline $3 / 9 / 96$ & 4:09:39 PM & 2629 & & 79.3 & $03 / 12$ & analyzed in lab \\
\hline $3 / 9 / 96$ & 4:40:07 PM & 2630 & & 80.6 & $03 / 12$ & analyzed in lab \\
\hline $3 / 9 / 96$ & 5:10:34 PM & 2631 & & 80.0 & $03 / 12$ & analyzed in lab \\
\hline 3/9/96 & 5:41:13 PM & 2632 & & 80.7 & $03 / 12$ & analyzed in lab \\
\hline 3/9/96 & 6:11:53 PM & 2633 & & 81.0 & $03 / 12$ & analyzed in lab \\
\hline $3 / 9 / 96$ & 6:42:32 PM & 2634 & & 76.1 & $03 / 12$ & analyzed in lab \\
\hline $3 / 9 / 96$ & 7:13:16 PM & 2635 & & 81.5 & $03 / 12$ & analyzed in lab \\
\hline $3 / 9 / 96$ & 7:45:08 PM & 2636 & & 79.8 & $03 / 12$ & anabrzed in lab \\
\hline $3 / 9 / 96$ & 8:15:45 PM & 2637 & & 79.8 & $03 / 12$ & anabzed in lab \\
\hline $3 / 9 / 96$ & 8:46:24 PM & 2638 & & 79.5 & $03 / 12$ & analyzed in lab \\
\hline $3 / 9 / 96$ & 9:17:12 PM & 2639 & & 80.4 & $03 / 12$ & analyzed in lab \\
\hline $3 / 9 / 96$ & 9:47:54 PM & 2640 & & 79.6 & $03 / 12$ & analyzed in lab \\
\hline $3 / 9196$ & 10:18:35 PM & 2641 & & 80.5 & $03 / 12$ & analyzed in lab \\
\hline
\end{tabular}




\begin{tabular}{|c|c|c|c|c|c|c|}
\hline Date & Time of Sample & Sample \# & Dup. code & Conc (ppb) & Analysis date & place \\
\hline $3 / 9 / 96$ & $10: 49: 12 \mathrm{PM}$ & 2642 & UD & 79.9 & & analyzed in lab \\
\hline $3 / 9 / 96$ & $11: 19: 26 \mathrm{PM}$ & 2643 & & 79.1 & $03 / 12$ & analyzed in $l a b$ \\
\hline $3 / 9 / 96$ & $11: 49: 58 \mathrm{PM}$ & 2644 & & 75.0 & $03 / 12$ & analyzed in lab \\
\hline $3 / 10 / 96$ & $12: 20: 16 \mathrm{AM}$ & 2645 & & 76.6 & $03 / 12$ & analyzed in lab \\
\hline $3 / 10 / 96$ & $12: 50: 30 \mathrm{AM}$ & 2646 & & 71.9 & $03 / 20$ & analyzed in lab \\
\hline $3 / 10 / 96$ & $1: 21: 05 \mathrm{AM}$ & 2647 & LD & 72.7 & & \\
\hline $3 / 10 / 96$ & 1:51:50 AM & 2648 & & 72.2 & $03 / 20$ & analyzed in lab \\
\hline $3 / 10 / 96$ & $2: 22: 21$ AM & 2649 & & 73.1 & $03 / 20$ & analyzed in lab \\
\hline $3 / 10 / 96$ & 2:53:00 AM & 2650 & & 70.0 & $03 / 20$ & analyzed in lab \\
\hline $3 / 10 / 96$ & 3:23:40 AM & 2651 & & 72.4 & $03 / 20$ & analyzed in lab \\
\hline $3 / 10 / 96$ & 3:54:18 AM & 2652 & & 71.5 & $03 / 20$ & analyzed in lab \\
\hline $3 / 10 / 96$ & 4:25:00 AM & 2653 & & 72.1 & $03 / 20$ & analyzed in lab \\
\hline $3 / 10 / 96$ & 4:55:40 AM & 2654 & & 74.7 & $03 / 20$ & analyzed in lab \\
\hline $3 / 10 / 96$ & 5:26:24 AM & 2655 & & 71.0 & $03 / 20$ & anatyzed in lab \\
\hline $3 / 10 / 96$ & $5: 56: 37$ AM & 2656 & & 74.1 & $03 / 20$ & analyzed in lab \\
\hline $3 / 10 / 96$ & $6: 27: 43 \mathrm{AM}$ & 2657 & & 68.8 & $03 / 20$ & analyzed in lab \\
\hline $3 / 10 / 96$ & $6: 57: 57 \mathrm{AM}$ & 2658 & & 72.3 & $03 / 20$ & analyzed in lab \\
\hline $3 / 10 / 96$ & $7: 28: 30 \mathrm{AM}$ & 2659 & & 71.8 & $03 / 20$ & analyzed in lab \\
\hline $3 / 10 / 96$ & 7:59:11 AM & 2660 & & 71.1 & $03 / 20$ & analyzed in lab \\
\hline $3 / 10 / 96$ & $8: 29: 52$ AM & 2661 & & 72.4 & $03 / 20$ & analyzed in lab \\
\hline $3 / 10 / 96$ & $9: 00: 36$ AM & 2662 & & 72.0 & $03 / 20$ & analyzed in lab \\
\hline $3 / 10 / 96$ & $9: 31: 12$ AM & 2663 & & 73.2 & 0320 & analyzed in lab \\
\hline $3 / 10 / 96$ & $10: 01: 52 \mathrm{AM}$ & 2664 & & 72.5 & 0320 & analyzed in lab \\
\hline $3 / 10 / 96$ & $10: 32: 29 \mathrm{AM}$ & 2665 & & 70.0 & $03 / 20$ & analyzed in lab \\
\hline $3 / 10 / 96$ & $11: 03: 16 \mathrm{AM}$ & 2666 & & 71.9 & $03 / 20$ & analyzed in lab \\
\hline $3 / 10 / 96$ & $11: 33: 56 \mathrm{AM}$ & 2667 & & 69.6 & $03 / 20$ & analyzed in lab \\
\hline $3 / 10 / 96$ & $12: 04: 38 \mathrm{PM}$ & 2668 & & 72.0 & $03 / 20$ & analyzed in lab \\
\hline $3 / 10 / 96$ & $12: 35: 16 \mathrm{PM}$ & 2669 & & 71.0 & $03 / 20$ & analyzed in lab \\
\hline $3 / 10 / 96$ & $1: 05: 56 \mathrm{PM}$ & 2670 & & 72.2 & 0402 & analyzed in field \\
\hline $3 / 10 / 96$ & 1:36:35 PM & 2671 & & 71.6 & 0402 & analyzed in field \\
\hline $3 / 10 / 96$ & 2:07:14 PM & 2672 & & 73.6 & $04 / 02$ & analyzed in field \\
\hline $3 / 10 / 96$ & 2:37:53 PM & 2673 & & 72.9 & $04 / 02$ & analyzed in field \\
\hline $3 / 10 / 96$ & 3:08:35 PM & 2674 & & 73.2 & 0402 & analyzed in field \\
\hline $3 / 10 / 96$ & 3:39:26 PM & 2675 & & 73.3 & 04,02 & analyzed in field \\
\hline $3 / 10 / 96$ & 4:09:39 PM & 2676 & & 72.8 & 04102 & analyzed in field \\
\hline $3 / 10 / 96$ & 4:39:59 PM & 2677 & & 72.2 & $04 / 02$ & analyzed in field \\
\hline $3 / 10 / 96$ & 5:10:39 PM & 2678 & & 72.7 & 04102 & analyzed in field \\
\hline $3 / 10 / 96$ & 5:41:16 PM & 2679 & & 72.7 & $04 / 02$ & analyzed in field \\
\hline $3 / 10 / 96$ & $6: 11: 56 \mathrm{PM}$ & 2680 & & 72.8 & 04102 & analyzed in field \\
\hline $3 / 10 / 96$ & $6: 42: 36 \mathrm{PM}$ & 2681 & & 72.6 & 0402 & analyzed in field \\
\hline $3 / 10 / 96$ & 7:13:17 PM & 2682 & & 71.9 & $03 / 11$ & analyzed in field \\
\hline $3 / 10 / 96$ & 7:43:57 PM & 2683 & & 71.7 & $03 / 11$ & analyzed in field \\
\hline $3 / 10 / 96$ & $8: 15: 10 \mathrm{PM}$ & 2684 & & 72.7 & $03 / 11$ & analyzed in field \\
\hline $3 / 10 / 96$ & 8:45:23 PM & 2685 & $F / D$ & 72.4 & & \\
\hline $3 / 10 / 90$ & 9:15:36 PM & 2686 & & 71.6 & $03 / 11$ & analyzed in field \\
\hline $3 / 10 / 96$ & 9:46:01 PM & 2687 & & 70.6 & $03 / 11$ & analyzed in field \\
\hline $3 / 10 / 96$ & 10:16:41 PM & 2688 & & 71.9 & $03 / 11$ & analyzed in field \\
\hline $3 / 10 / 96$ & 10:47:18 PM & 2689 & & 68.3 & $03 / 11$ & analyzed in field \\
\hline $3 / 10 / 96$ & 11:17:55 PM & 2690 & & 71.6 & $03 / 11$ & analyzed in field \\
\hline $3 / 10 / 96$ & 11:48:15 PM & 2691 & & 71.0 & $03 / 11$ & analyzed in field \\
\hline $3 / 11 / 96$ & 12:18:28 AM & 2692 & & 68.8 & $03 / 11$ & analyzed in field \\
\hline $3 / 11 / 96$ & 12:49:44 AM & 2693 & & 71.1 & $03 / 11$ & analyzed in field \\
\hline $3 / 11 / 96$ & $1: 20: 16 \mathrm{AM}$ & 2694 & & 72.4 & $03 / 11$ & analyzed in field \\
\hline $3 / 11 / 96$ & 1:50:29 AM & 2695 & & 70.8 & $03 / 11$ & analyzed in field \\
\hline $3 / 11 / 96$ & $2: 20: 43$ AM & 2696 & & 70.5 & $03 / 11$ & analyzed in field \\
\hline $3 / 11 / 96$ & $2: 51: 19$ AM & 2697 & & 71.8 & $03 / 11$ & anabyzed in field \\
\hline $3 / 11 / 96$ & 3:22:01 AM & 2698 & & 68.1 & $03 / 11$ & analyzed in field \\
\hline $3 / 11 / 96$ & 3:52:44 AM & 2699 & & 71.4 & $03 / 11$ & analyzed in field \\
\hline $3 / 11 / 96$ & 4:23:22 AM & 2700 & & 69.0 & $03 / 11$ & analyzed in field \\
\hline $3 / 11 / 96$ & 4:53:58 AM & 2701 & & 69.3 & $03 / 11$ & analyzed in field \\
\hline $3 / 11 / 96$ & 5:24:42 AM & 2702 & & 69.8 & $03 / 11$ & analyzed in field \\
\hline $3 / 11 / 96$ & $5: 55: 24$ AM & 2703 & F/D & 67.7 & & \\
\hline $3 / 11 / 96$ & $6: 26: 05 \mathrm{AM}$ & 2704 & & 68.8 & $03 / 11$ & analyzed in field \\
\hline $3 / 11 / 96$ & $6: 56: 45 \mathrm{AM}$ & 2705 & & 67.0 & $03 / 11$ & analyzed in field \\
\hline $3 / 11 / 96$ & $7: 26: 58 \mathrm{AM}$ & 2706 & & 72.0 & $03 / 11$ & analyzed in field \\
\hline $3 / 11 / 96$ & $7: 57: 28$ AM & 2707 & & 69.2 & $03 / 11$ & anatyzed in field \\
\hline $3 / 11 / 96$ & $8: 28: 09$ AM & 2708 & & 69.7 & $03 / 11$ & anahzed in field \\
\hline $3 / 11 / 96$ & 8:59:53 AM & 2709 & & 70.0 & $03 / 11$ & analyzed in field \\
\hline $3 / 11 / 96$ & 9:30:33 AM & 2710 & & 67.5 & $03 / 11$ & analyzed in field \\
\hline $3 / 11 / 96$ & $10: 01: 18 \mathrm{AM}$ & 2711 & & 69.8 & $03 / 11$ & analyzed in field \\
\hline
\end{tabular}


Yucca Mountain tracer test; 27

\begin{tabular}{|c|c|c|c|c|c|c|}
\hline Date & Time of Sample & Sample \# & Dup. code & Conc (ppb) & Analysis date & place \\
\hline $3 / 11 / 96$ & $10: 31: 49$ AM & 2712 & & \begin{tabular}{|l|}
69.7 \\
\end{tabular} & $03 / 11$ & analyzed in field \\
\hline $3 / 11 / 96$ & $11: 02: 31$ AM & 2713 & & 70.0 & $03 / 11$ & analyzed in field \\
\hline $3 / 11 / 96$ & $11: 33: 13 \mathrm{AM}$ & 2714 & & 69.5 & $03 / 11$ & analyzed in field \\
\hline $3 / 11 / 96$ & 12:03:54 PM & 2715 & & 70.4 & $03 / 11$ & analyzed in field \\
\hline $3 / 11 / 96$ & 12:34:34 PM & 2716 & & 68.6 & $03 / 11$ & analyzed in field \\
\hline $3 / 11 / 96$ & 1:05:14 PM & 2717 & & 66.8 & $03 / 11$ & analyzed in field \\
\hline $3 / 11 / 96$ & 1:35:51 PM & 2718 & & 69.2 & $03 / 11$ & analyzed in field \\
\hline $3 / 11 / 96$ & 2:06:30 PM & 2719 & & 65.8 & $03 / 11$ & analyzed in field \\
\hline $3 / 11 / 96$ & $2: 36: 55 \mathrm{PM}$ & 2720 & & 69.1 & $03 / 11$ & analyzed in field \\
\hline $3 / 11 / 96$ & 3:07:07 PM & 2721 & & 67.6 & $03 / 14$ & analyzed in lab \\
\hline $3 / 11 / 96$ & 3:37:38 PM & 2722 & & 72.2 & $03 / 14$ & analyzed in lab \\
\hline $3 / 11 / 96$ & 4:08:20 PM & 2723 & & 72.0 & $03 / 14$ & analyzed in lab \\
\hline $3 / 11 / 96$ & 4:39:00 PM & 2724 & & 70.4 & $03 / 14$ & analyzed in lab \\
\hline $3 / 11 / 96$ & 5:09:13PM & 2725 & & 70.0 & $03 / 14$ & analyzed in lab \\
\hline $3 / 11 / 96$ & 5:39:40 PM & 2726 & & 69.4 & $03 / 14$ & analyzed in lab \\
\hline $3 / 11 / 96$ & $6: 10: 19$ PM & 2727 & & 75.3 & $03 / 14$ & analyzed in lab \\
\hline $3 / 11 / 96$ & $6: 41: 00 \mathrm{PM}$ & 2728 & & 71.8 & $03 / 14$ & anabyzed in $\mathrm{lab}$ \\
\hline $3 / 11 / 96$ & $7: 11: 53 \mathrm{PM}$ & 2729 & & 68.9 & $03 / 14$ & analyzed in lab \\
\hline $3 / 11 / 96$ & 7:42:25 PM & 2730 & & 70.1 & $03 / 14$ & analyzed in lab \\
\hline $3 / 11 / 96$ & 8:13:07 PM & 2731 & & 70.5 & $03 / 14$ & analyzed in lab \\
\hline $3 / 11 / 96$ & 8:43:47 PM & 2732 & & 68.8 & $03 / 14$ & analyzed in lab \\
\hline $3 / 11 / 96$ & 9:14:26 PM & 2733 & & 69.2 & $03 / 14$ & analyzed in lab \\
\hline $3 / 11 / 96$ & 9:45:06 PM & 2734 & & 70.5 & $03 / 14$ & analyzed in lab \\
\hline $3 / 11 / 96$ & $10: 15: 19 \mathrm{PM}$ & 2735 & LD & 70.0 & & \\
\hline $3 / 11 / 96$ & $10: 45: 51 \mathrm{PM}$ & 2736 & & 68.8 & $03 / 14$ & analyzed in lab \\
\hline $3 / 11 / 96$ & $11: 16: 07 \mathrm{PM}$ & 2737 & & 68.2 & $03 / 14$ & analyzed in lab \\
\hline $3 / 11 / 96$ & $11: 46: 33 \mathrm{PM}$ & 2738 & & 68.0 & $03 / 14$ & analyzed in lab \\
\hline $3 / 12 / 96$ & $12: 17: 01 \mathrm{AM}$ & 2739 & & 64.4 & $03 / 14$ & analyzed in lab \\
\hline $3 / 12 / 96$ & $12: 47: 43 \mathrm{AM}$ & 2740 & & 67.2 & $03 / 14$ & analyzed in lab \\
\hline $3 / 12 / 96$ & $1: 18: 19 \mathrm{AM}$ & 2741 & & 69.2 & $03 / 14$ & analyzed in lab \\
\hline $3 / 12 / 96$ & 1:49:03 AM & 2742 & & 65.4 & $03 / 14$ & analyzed in lab \\
\hline $3 / 12 / 96$ & $2: 19: 46$ AM & 2743 & & 69.6 & $03 / 14$ & analyzed in lab \\
\hline $3 / 12 / 96$ & $2: 50: 24$ AM & 2744 & & 68.5 & $03 / 14$ & analyzed in lab \\
\hline $3 / 12 / 96$ & $3: 20: 37$ AM & 2745 & & 65.1 & $03 / 13$ & analyzed in lab \\
\hline $3 / 12 / 96$ & 3:51:11 AM & 2746 & & 66.2 & $03 / 13$ & analyzed in lab \\
\hline $3 / 12 / 96$ & 4:21:34 AM & 2747 & & 63.2 & $03 / 13$ & analyzed in lab \\
\hline $3 / 12 / 96$ & 4:51:46 AM & 2748 & & 64.6 & $03 / 13$ & analyzed in lab \\
\hline $3 / 12 / 96$ & $5: 22: 24$ AM & 2749 & & 66.2 & $03 / 13$ & analyzed in lab \\
\hline $3 / 12 / 96$ & 5:52:59 AM & 2750 & & 65.0 & $03 / 13$ & analyzed in lab \\
\hline $3 / 12 / 96$ & $6: 23: 11 \mathrm{AM}$ & 2751 & & 65.4 & $03 / 13$ & analyzed in lab \\
\hline $3 / 12 / 96$ & $6: 53: 27$ AM & 2752 & & 65.5 & $03 / 13$ & analyzed in lab \\
\hline $3 / 12 / 96$ & $7: 24: 06 \mathrm{AM}$ & 2753 & & 66.0 & $03 / 13$ & analyzed in lab \\
\hline $3 / 12 / 96$ & $7: 54: 42 \mathrm{AM}$ & 2754 & & 64.4 & $03 / 13$ & analyzed in lab \\
\hline $3 / 12 / 96$ & $8: 24: 58$ AM & 2755 & & 68.2 & $03 / 13$ & analyzed in lab \\
\hline $3 / 12 / 96$ & $8: 56: 11$ AM & 2756 & & 64.5 & $03 / 13$ & analyzed in lab \\
\hline $3 / 12 / 96$ & 9:26:24 AM & 2757 & & 63.7 & $03 / 13$ & analyzed in lab \\
\hline $3 / 12 / 96$ & $9: 56: 56 \mathrm{AM}$ & 2758 & & 64.1 & $03 / 13$ & analyzed in lab \\
\hline $3 / 12 / 96$ & $10: 27: 35 \mathrm{AM}$ & 2759 & & 64.0 & $03 / 13$ & analyzed in lab \\
\hline $3 / 12 / 96$ & 10:58:17 AM & 2760 & & 65.2 & $03 / 13$ & analyzed in lab \\
\hline $3 / 12 / 96$ & $11: 28: 54 \mathrm{AM}$ & 2761 & & 63.8 & $03 / 13$ & analyzed in lab \\
\hline $3 / 12 / 96$ & 11:59:31 AM & 2762 & LD & 64.8 & & \\
\hline $3 / 12 / 96$ & $12: 30: 10 \mathrm{PM}$ & 2763 & & 63.1 & $03 / 13$ & analyzed in lab \\
\hline $3 / 12 / 96$ & $1: 00: 53 \mathrm{PM}$ & 2764 & & 65.4 & $03 / 13$ & analyzed in lab \\
\hline $3 / 12 / 96$ & 1:31:23PM & 2765 & & 64.0 & $03 / 13$ & analyzed in lab \\
\hline $3 / 12 / 96$ & 2:01:55 PM & 2766 & & 64.8 & $03 / 13$ & analyzed in lab \\
\hline $3 / 12 / 96$ & $2: 32: 08 \mathrm{PM}$ & 2767 & & 65.4 & $03 / 13$ & analyzed in lab \\
\hline $3 / 12 / 96$ & 3:02:49 PM & 2768 & & 65.0 & $03 / 13$ & analyzed in lab \\
\hline $3 / 12 / 96$ & 3:33:03 PM & 2769 & & 66.5 & $03 / 13$ & analyzed in lab \\
\hline $3 / 12 / 96$ & 4:03:23 PM & 2770 & & 65.1 & $03 / 13$ & analyzed in lab \\
\hline $3 / 12 / 96$ & 4:34:02 PM & 2771 & & 64.9 & $03 / 13$ & analyzed in lab \\
\hline $3 / 12 / 96$ & 5:04:39 PM & 2772 & & 64.5 & $03 / 13$ & analyzed in lab \\
\hline $3 / 12 / 96$ & 5:34:52 PM & 2773 & & 66.5 & $03 / 13$ & analyzed in $\mathrm{lab}$ \\
\hline $3 / 12 / 96$ & 6:05:24 PM & 2774 & & 65.6 & $03 / 13$ & analyzed in $\mathrm{lab}$ \\
\hline $3 / 12 / 96$ & 6:35:37 PM & 2775 & & 63.2 & $03 / 13$ & analyzed in lab \\
\hline $3 / 12 / 96$ & 7:05:57 PM & 2776 & & 63.9 & $03 / 13$ & analyzed in lab \\
\hline $3 / 12 / 96$ & 7:36:36 PM & 2777 & & 64.1 & $03 / 13$ & analyzed in lab \\
\hline $3 / 12 / 96$ & $8: 07: 15 \mathrm{PM}$ & 2778 & & 64.8 & $03 / 13$ & analyzed in lab \\
\hline $3 / 12 / 96$ & $8: 37: 28 \mathrm{PM}$ & 2779 & & 66.4 & $03 / 13$ & analyzed in field \\
\hline $3 / 12 / 96$ & 9:07:49 PM & 2780 & & 67.3 & $03 / 13$ & analyzed in field \\
\hline $3 / 12 / 96$ & 9:38:27 PM & 2781 & & 65.5 & $03 / 13$ & analyzed in field \\
\hline
\end{tabular}




\begin{tabular}{|c|c|c|c|c|c|c|}
\hline Date & Time of Sample & Sample \# & Dup. code & Conc (ppb) & Analysis date & place \\
\hline $3 / 12 / 96$ & $10: 09: 08 \mathrm{PM}$ & 2782 & & 66.4 & $03 / 13$ & analyzed in field \\
\hline $3 / 12 / 96$ & $10: 39: 35 \mathrm{PM}$ & 2783 & & 64.6 & $03 / 13$ & analyzed in field \\
\hline $3 / 12 / 96$ & $11: 09: 48 \mathrm{PM}$ & 2784 & & 67.3 & $03 / 13$ & analyzed in field \\
\hline $3 / 12 / 96$ & $11: 40: 01 \mathrm{PM}$ & 2785 & & 64.6 & $03 / 13$ & analyzed in field \\
\hline $3 / 13 / 96$ & $12: 10: 19 \mathrm{AM}$ & 2786 & & 65.1 & $03 / 13$ & analyzed in field \\
\hline $3 / 13 / 96$ & $12: 40: 58 \mathrm{AM}$ & 2787 & & 66.6 & $03 / 13$ & analyzed in field \\
\hline $3 / 13 / 96$ & $1: 11: 11 \mathrm{AM}$ & 2788 & & 69.5 & $03 / 13$ & analyzed in field \\
\hline $3 / 13 / 96$ & $1: 41: 34 \mathrm{AM}$ & 2789 & & 64.7 & $03 / 13$ & analyzed in field \\
\hline $3 / 13 / 96$ & $2: 12: 13$ AM & 2790 & & 67.9 & $03 / 13$ & analyzed in field \\
\hline $3 / 13 / 96$ & $2: 42: 51$ AM & 2791 & & 68.8 & $03 / 13$ & analyzed in field \\
\hline $3 / 13 / 96$ & $3: 13: 37$ AM & 2792 & & 65.2 & $03 / 13$ & analyzed in field \\
\hline $3 / 13 / 96$ & $3: 43: 49$ AM & 2793 & & 64.8 & $03 / 13$ & analyzed in field \\
\hline $3 / 13 / 96$ & $4: 14: 05 \mathrm{AM}$ & 2794 & & 65.4 & $03 / 13$ & analyzed in field \\
\hline $3 / 13196$ & 4:44:18 AM & 2795 & & 64.0 & $03 / 13$ & analyzed in field \\
\hline $3 / 13 / 96$ & $5: 14: 56$ AM & 2796 & & 65.1 & $03 / 13$ & analyzed in field \\
\hline $3 / 13 / 96$ & 5:45:09 AM & 2797 & & 61.6 & $03 / 13$ & analyzed in field \\
\hline $3 / 13 / 96$ & $6: 15: 22 \mathrm{AM}$ & 2798 & F/D & 66.7 & & \\
\hline $3 / 13 / 96$ & $6: 46: 01$ AM & 2799 & & 62.2 & $03 / 13$ & analyzed in field \\
\hline $3 / 13 / 96$ & $7: 16: 14 \mathrm{AM}$ & 2800 & & 67.3 & $03 / 13$ & analyzed in field \\
\hline $3 / 13 / 96$ & $7: 46: 45$ AM & 2801 & & 65.7 & $03 / 13$ & analyzed in field \\
\hline $3 / 13 / 96$ & $8: 17: 18 \mathrm{AM}$ & 2802 & & 62.4 & $03 / 13$ & analyzed in field \\
\hline $3 / 13 / 96$ & $8: 47: 31$ AM & 2803 & & 66.0 & $03 / 13$ & analyzed in field \\
\hline $3 / 13 / 96$ & $9: 17: 47$ AM & 2804 & & 64.2 & $03 / 13$ & analyzed in field \\
\hline $3 / 13 / 96$ & 9:48:00 AM & 2805 & & 63.0 & $03 / 13$ & analyzed in field \\
\hline $3 / 13 / 96$ & $10: 18: 20 \mathrm{AM}$ & 2806 & & 63.7 & $03 / 13$ & analyzed in field \\
\hline $3 / 13 / 96$ & $10: 49: 02 \mathrm{AM}$ & 2807 & & 63.0 & $03 / 13$ & analyzed in field \\
\hline $3 / 13 / 96$ & $11: 19: 41 \mathrm{AM}$ & 2808 & & 63.1 & $03 / 13$ & analyzed in field \\
\hline $3 / 13 / 96$ & $11: 50: 21 \mathrm{AM}$ & 2809 & & 64.7 & $03 / 13$ & analyzed in field \\
\hline $3 / 13 / 96$ & $12: 22: 11 \mathrm{PM}$ & 2810 & & 64.0 & $03 / 13$ & analyzed in field \\
\hline $3 / 13 / 96$ & $12: 52: 51 \mathrm{PM}$ & 2811 & & 62.3 & $03 / 13$ & analyzed in field \\
\hline $3 / 13 / 96$ & $1: 23: 31 \mathrm{PM}$ & 2812 & & 63.4 & $03 / 13$ & analyzed in field \\
\hline $3 / 13 / 96$ & 1:54:10 PM & 2813 & & 60.8 & $03 / 13$ & analyzed in field \\
\hline $3 / 13 / 96$ & $2: 24: 23 \mathrm{PM}$ & 2814 & & 62.8 & $03 / 27$ & analyzed in lab \\
\hline $3 / 13 / 96$ & $2: 55: 01 \mathrm{PM}$ & 2815 & & 63.1 & $03 / 27$ & analyzed in lab \\
\hline $3 / 13 / 96$ & $3: 25: 14 \mathrm{PM}$ & 2816 & & 64.6 & $03 / 27$ & analyzed in lab \\
\hline $3 / 13 / 96$ & $3: 55: 30 \mathrm{PM}$ & 2817 & LD & 63.8 & & \\
\hline $3 / 13 / 96$ & 4:26:09 PM & 2818 & & 64.8 & $03 / 27$ & analyzed in field \\
\hline $3 / 13 / 96$ & $4: 56: 56 \mathrm{PM}$ & 2819 & & 65.1 & $03 / 27$ & analyzed in field \\
\hline $3 / 13 / 96$ & $5: 27: 28 \mathrm{PM}$ & 2820 & & 64.8 & $03 / 27$ & analyzed in field \\
\hline $3 / 13 / 96$ & $5: 58: 09$ PM & 2821 & & 64.9 & $03 / 27$ & analyzed in field \\
\hline $3 / 13 / 96$ & $6: 28: 30 \mathrm{PM}$ & 2822 & & 64.7 & $03 / 27$ & analyzed in field \\
\hline $3 / 13 / 96$ & $6: 58: 43$ PM & 2823 & & 64.8 & $03 / 27$ & analyzed in field \\
\hline $3 / 13 / 96$ & $7: 28: 56 \mathrm{PM}$ & 2824 & & 65.0 & $03 / 27$ & analyzed in field \\
\hline $3 / 13 / 96$ & $7: 59: 35$ PM & 2825 & & 64.5 & $03 / 27$ & analyzed in field \\
\hline $3 / 13 / 96$ & $8: 29: 48$ PM & 2826 & & 64.1 & $03 / 27$ & analyzed in field \\
\hline $3 / 13 / 96$ & $9: 00: 03$ PM & 2827 & & 65.0 & $03 / 28$ & analyzed in field \\
\hline $3 / 13 / 96$ & $9: 30: 38 \mathrm{PM}$ & 2828 & F/D & 64.5 & & \\
\hline $3 / 13 / 96$ & $10: 00: 50 \mathrm{PM}$ & 2829 & & 64.9 & $03 / 28$ & analyzed in field \\
\hline $3 / 13 / 96$ & $10: 31: 27 \mathrm{PM}$ & 2830 & & 63.7 & $03 / 28$ & analyzed in field \\
\hline $3 / 13 / 96$ & $11: 01: 40 \mathrm{PM}$ & 2831 & & 64.4 & $03 / 28$ & analyzed in field \\
\hline $3 / 13 / 96$ & $11: 32: 09 \mathrm{PM}$ & 2832 & & 64.0 & $03 / 28$ & analyzed in field \\
\hline $3 / 14 / 96$ & 12:02:49 AM & 2833 & & 64.5 & $03 / 28$ & analyzed in field \\
\hline $3 / 14 / 96$ & $12: 33: 03 \mathrm{AM}$ & 2834 & & 64.2 & $03 / 28$ & analyzed in field \\
\hline $3 / 14 / 96$ & $1: 03: 42 \mathrm{AM}$ & 2835 & & 64.0 & $03 / 28$ & analyzed in field \\
\hline $3 / 14 / 96$ & $1: 33: 55 \mathrm{AM}$ & 2836 & & 65.2 & $03 / 28$ & analyzed in field \\
\hline $3 / 14 / 96$ & $2: 04: 18 \mathrm{AM}$ & 2837 & & 64.0 & $03 / 28$ & analyzed in field \\
\hline $3 / 14 / 96$ & $2: 34: 54$ AM & 2838 & & 64.3 & $03 / 29$ & analyzed in field \\
\hline $3 / 14 / 96$ & $3: 05: 07$ AM & 2839 & & 64.6 & $03 / 29$ & analyzed in field \\
\hline $3 / 14 / 96$ & $3: 35: 34$ AM & 2840 & & 63.0 & $04 / 01$ & analyzed in field \\
\hline $3 / 14 / 96$ & 4:06:16 AM & 2841 & & 63.7 & $04 / 01$ & analyzed in field \\
\hline $3 / 14 / 96$ & $4: 36: 29 \mathrm{AM}$ & 2842 & & 64.0 & $04 / 01$ & analyzed in field \\
\hline $3 / 14 / 96$ & $5: 06: 45 \mathrm{AM}$ & 2843 & & 63.3 & $04 / 01$ & analyzed in field \\
\hline $3 / 14 / 96$ & $5: 37: 02 \mathrm{AM}$ & 2844 & & 63.7 & $04 / 01$ & analyzed in field \\
\hline $3 / 14 / 96$ & $6: 07: 35 \mathrm{AM}$ & 2845 & & 62.8 & $04 / 01$ & analyzed in field \\
\hline $3 / 14 / 96$ & $6: 38: 07$ AM & 2846 & & 64.2 & $04 / 01$ & analyzed in field \\
\hline $3 / 14 / 96$ & $7: 08: 20 \mathrm{AM}$ & 2847 & $F / D$ & 63.4 & & \\
\hline $3 / 14 / 96$ & $7: 38: 59 \mathrm{AM}$ & 2848 & UF-D* & 63.3 & $04 / 01$ & analyzed in field \\
\hline $3 / 14 / 96$ & $8: 09: 37$ AM & 2849 & & 62.8 & $04 / 01$ & analyzed in field \\
\hline $3 / 14 / 96$ & $8: 39: 50 \mathrm{AM}$ & 2850 & UF-D & 61.9 & & \\
\hline $3 / 14 / 96$ & $9: 10: 18 \mathrm{AM}$ & 2851 & & 62.8 & $04 / 01$ & analyzed in field \\
\hline
\end{tabular}




\begin{tabular}{|c|c|c|c|c|c|c|}
\hline Date & Time of Sample & Sample \# & Dup. code & Conc (ppb) & Analysis date & place \\
\hline $3 / 14 / 96$ & $9: 41: 02 \mathrm{AM}$ & 2852 & & 62.1 & $04 / 01$ & analyzed in field \\
\hline $3 / 14 / 96$ & 10:11:44 AM & 2853 & & 62.4 & $04 / 01$ & analyzed in field \\
\hline $3 / 14 / 96$ & 10:41:57 AM & 2854 & & 60.9 & $04 / 01$ & analyzed in lab \\
\hline $3 / 14 / 96$ & 11:12:42 AM & 2855 & & 60.6 & $04 / 01$ & analyzed in lab \\
\hline $3 / 14 / 96$ & $11: 42: 54 \mathrm{AM}$ & 2856 & & 58.5 & $04 / 01$ & analyzed in lab \\
\hline $3 / 14 / 96$ & 12:13:16 PM & 2857 & & 56.2 & $04 / 01$ & analyzed in lab \\
\hline $3 / 14 / 96$ & 12:43:29 PM & 2858 & LF -D & 60.6 & & \\
\hline $3 / 14 / 96$ & 1:13:53 PM & 2859 & & 59.1 & $03 / 29$ & analyzed in lab \\
\hline $3 / 14 / 96$ & 1:44:18 PM & 2860 & & 59.8 & $03 / 29$ & analyzed in lab \\
\hline $3 / 14 / 96$ & $2: 14: 32 \mathrm{PM}$ & 2861 & & 59.5 & $03 / 29$ & analyzed in lab \\
\hline $3 / 14 / 96$ & $2: 44: 45 \mathrm{PM}$ & 2862 & & 59.8 & $03 / 29$ & analyzed in lab \\
\hline $3 / 14 / 96$ & 3:45:11 PM & 2863 & & 58.8 & $03 / 29$ & analyzed in lab \\
\hline $3 / 14 / 96$ & 4:46:05 PM & 2864 & & 60.5 & $04 / 19$ & analyzed in lab \\
\hline $3 / 14 / 96$ & $5: 46: 18 \mathrm{PM}$ & 2865 & & 55.4 & $03 / 29$ & analyzed in lab \\
\hline $3 / 14 / 96$ & $6: 46: 59 \mathrm{PM}$ & 2866 & & 55.5 & $03 / 29$ & analyzed in lab \\
\hline $3 / 14 / 96$ & 7:47:13 PM & 2867 & & 55.1 & $0,3 / 29$ & analyzed in lab \\
\hline $3 / 14 / 96$ & $8: 47: 51 \mathrm{PM}$ & 2868 & & 58.0 & $0,03 / 29$ & analyzed in lab \\
\hline $3 / 14 / 96$ & 9:48:05 PM & 2869 & & 55.9 & $03 / 29$ & analyzed in lab \\
\hline $3 / 14 / 96$ & 10:48:32 PM & 2870 & & 58.6 & $03 / 29$ & analyzed in lab \\
\hline $3 / 14 / 96$ & 11:49:11 PM & 2871 & & 54.5 & $03 / 29$ & analyzed in lab \\
\hline $3 / 15 / 96$ & 12:49:48 AM & 2872 & & 54.0 & $03 / 29$ & analyzed in lab \\
\hline $3 / 15 / 96$ & 1:50:29 AM & 2873 & & 54.0 & $03 / 29$ & analyzed in lab \\
\hline $3 / 15 / 96$ & $2: 51: 08 \mathrm{AM}$ & 2874 & & 55.0 & $03 / 29$ & analyzed in lab \\
\hline $3 / 15 / 96$ & $3: 51: 47 \mathrm{AM}$ & 2875 & & 54.1 & $03 / 29$ & analyzed in lab \\
\hline $3 / 15 / 96$ & 4:52:23 AM & 2876 & & 55.4 & $03 / 29$ & analyzed in lab \\
\hline $3 / 15 / 96$ & $5: 53: 04 \mathrm{AM}$ & 2877 & & 58.4 & $03 / 29$ & analyzed in lab \\
\hline $3 / 15 / 96$ & $6: 53: 41 \mathrm{AM}$ & 2878 & & 58.2 & $03 / 29$ & analyzed in lab \\
\hline $3 / 15 / 96$ & $7: 54: 06 \mathrm{AM}$ & 2879 & & 56.7 & $03 / 29$ & analyzed in lab \\
\hline $3 / 15 / 96$ & $8: 54: 19$ AM & 2880 & & 59.2 & $03 / 29$ & analyzed in lab \\
\hline $3 / 15 / 96$ & $9: 54: 43 \mathrm{AM}$ & 2881 & UD* & 57.8 & $03 / 29$ & analyzed in lab \\
\hline $3 / 15 / 96$ & 10:55:21 AM & 2882 & & 58.9 & $03 / 29$ & analyzed in lab \\
\hline $3 / 15 / 96$ & $11: 55: 43 \mathrm{AM}$ & 2883 & & 58.0 & $03 / 29$ & analyzed in lab \\
\hline $3 / 15 / 96$ & 12:55:57 PM & 2884 & & 61.1 & 04104 & analyzed in field \\
\hline $3 / 15 / 96$ & 1:56:35 PM & 2885 & & 59.6 & 04101 & analyzed in field \\
\hline $3 / 15 / 96$ & 2:57:04 PM & 2886 & & 59.5 & $04 / 01$ & analyzed in field \\
\hline $3 / 15 / 96$ & $3: 57: 17 \mathrm{PM}$ & 2887 & & 60.1 & 04101 & analyzed in field \\
\hline $3 / 15 / 96$ & 4:57:30 PM & 2888 & & 59.5 & $04 / 01$ & analyzed in field \\
\hline $3 / 15 / 96$ & 5:57:49 PM & 2889 & & 60.0 & 04101 & analyzed in field \\
\hline $3 / 15 / 96$ & $6: 58: 30 \mathrm{PM}$ & 2890 & & 59.5 & $04 / 01$ & analyzed in field \\
\hline $3 / 15 / 96$ & 7:59:20 PM & 2891 & & 59.7 & 04101 & analyzed in field \\
\hline $3 / 15 / 96$ & $8: 59: 32 \mathrm{PM}$ & 2892 & & 59.5 & $04 / 101$ & anahyed in field \\
\hline $3 / 15 / 96$ & $9: 59: 46$ PM & 2893 & & 59.2 & $04 / 01$ & analyzed in field \\
\hline $3 / 15 / 96$ & $11: 00: 18 \mathrm{PM}$ & 2894 & & 59.4 & $04 / 01$ & analyzed in field \\
\hline $3 / 16 / 96$ & 12:01:01 AM & 2895 & FID & 59.4 & & \\
\hline $3 / 16 / 96$ & 1:01:44 AM & 2896 & & 58.8 & $04 / 01$ & analyzed in field \\
\hline $3 / 16 / 96$ & $2: 01: 57 \mathrm{AM}$ & 2897 & & 58.4 & 04101 & analyzed in field \\
\hline $3 / 16 / 96$ & 3:02:28 AM & 2898 & & 57.9 & $04 / 01$ & analyzed in field \\
\hline $3 / 16 / 96$ & 4:03:05 AM & 2899 & & 58.0 & $04 / 01$ & analyzed in field \\
\hline $3 / 16 / 96$ & $5: 03: 52 \mathrm{AM}$ & 2900 & & 58.2 & 04101 & analyzed in field \\
\hline $3 / 16 / 96$ & $6: 04: 05 \mathrm{AM}$ & 2901 & & 58.3 & 04101 & analyzed in field \\
\hline $3 / 16 / 96$ & $7: 04: 28 \mathrm{AM}$ & 2902 & & 57.9 & $04 / 01$ & analyzed in field \\
\hline $3 / 16 / 96$ & 8:04:48 AM & 2903 & & 57.5 & $04 / 01$ & anahzed in field \\
\hline $3 / 16 / 96$ & 9:05:01 AM & 2904 & & 58.1 & $04 / 01$ & anablyzed in field \\
\hline $3 / 16 / 96$ & $10: 05: 13$ AM & 2905 & & 57.8 & $04 / 01$ & analyzed in field \\
\hline $3 / 16 / 96$ & 11:05:45 AM & 2906 & & 57.5 & 04101 & analyzed in field \\
\hline $3 / 16 / 96$ & 12:06:23 PM & 2907 & $F / D$ & 58.0 & & \\
\hline $3 / 16 / 96$ & 1:06:37 PM & 2908 & & 57.0 & $03 / 28$ & analyzed in field \\
\hline $3 / 16 / 96$ & 2:07:12 PM & 2009 & & 56.3 & $03 / 28$ & analyzed in field \\
\hline $3 / 16 / 96$ & $3: 07: 25 \mathrm{PM}$ & 2910 & & 58.0 & $03 / 28$ & analyzed in field \\
\hline 3/16/96 & 4:07:55 PM & 2911 & & 56.6 & $03 / 28$ & analyzed in field \\
\hline 3/16/96 & 5:08:33 PM & 2912 & & 56.8 & $03 / 28$ & analyzed in field \\
\hline $3 / 16 / 96$ & 6:08:51 PM & 2913 & F/D & 57.2 & & \\
\hline $3 / 16 / 96$ & $7: 09: 33 \mathrm{PM}$ & 2914 & & 56.0 & $03 / 28$ & analyzed in field \\
\hline $3 / 16 / 96$ & $8: 09: 46 \mathrm{PM}$ & 2915 & & 56.4 & $03 / 29$ & analyzed in field \\
\hline $3 / 16 / 96$ & 9:10:03 PM & 2916 & & 56.1 & $03 / 29$ & analyzed in field \\
\hline 3/16/96 & 10:10:16 PM & 2917 & & 57.4 & $03 / 29$ & analyzed in field \\
\hline $3 / 16 / 96$ & 11:11:07 PM & 2918 & F/D* & 57.1 & $03 / 29$ & analyzed in field \\
\hline $3 / 17 / 96$ & $12: 11: 35 \mathrm{AM}$ & 2919 & & 58.8 & $03 / 29$ & analyzed in field \\
\hline $3 / 17 / 96$ & 1:12:11 AM & 2920 & & 48.9 & $03 / 29$ & analyzed in lab \\
\hline $3 / 17 / 96$ & $2: 12: 26 \mathrm{AM}$ & 2921 & & 53.1 & $03 / 29$ & analyzed in lab \\
\hline
\end{tabular}


Yucca Mountain tracer test; 30

\begin{tabular}{|c|c|c|c|c|c|c|}
\hline Date & Time of Sample & Sample \# & Dup. code & Conc (ppb) & Analysis date & place \\
\hline $3 / 17 / 96$ & $3: 12: 39$ AM & 2922 & & 48.4 & $03 / 29$ & analyzed in lab \\
\hline $3 / 17 / 96$ & 4:13:05 AM & 2923 & UD & 49.2 & & \\
\hline $3 / 17 / 96$ & $5: 13: 18 \mathrm{AM}$ & 2924 & & 49.4 & $03 / 29$ & analyzed in lab \\
\hline $3 / 17 / 96$ & $6: 13: 58 \mathrm{AM}$ & 2925 & & 49.7 & $03 / 29$ & analyzed in lab \\
\hline $3 / 17 / 96$ & $7: 14: 35 \mathrm{AM}$ & 2926 & & 47.5 & $03 / 29$ & analyzed in lab \\
\hline $3 / 17 / 96$ & $8: 15: 20 \mathrm{AM}$ & 2927 & & 47.2 & $03 / 29$ & analyzed in lab \\
\hline $3 / 17 / 96$ & $9: 15: 32 \mathrm{AM}$ & 2928 & & 48.2 & $03 / 29$ & analyzed in lab \\
\hline $3 / 17 / 96$ & $10: 15: 45 \mathrm{AM}$ & 2929 & UD & 51.5 & & \\
\hline $3 / 17 / 96$ & $11: 16: 01 \mathrm{AM}$ & 2930 & UD & 52.4 & & \\
\hline $3 / 17 / 96$ & 12:16:39 PM & 2931 & UD & 51.9 & & \\
\hline $3 / 17 / 96$ & $1: 17: 21 \mathrm{PM}$ & 2932 & $F / D^{*}$ & 52.6 & $04 / 02$ & \\
\hline $3 / 17 / 96$ & $2: 17: 35 \mathrm{PM}$ & 2933 & & 55.2 & $03 / 18$ & analyzed in field \\
\hline $3 / 17 / 96$ & 3:18:12 PM & 2934 & $\mathrm{~F} / \mathrm{D}^{*}$ & 55.7 & $03 / 18$ & \\
\hline $3 / 17 / 96$ & 4:18:26 PM & 2935 & & 55.8 & $03 / 18$ & analyzed in field \\
\hline $3 / 17 / 96$ & 5:19:08 PM & 2936 & $F / D^{*}$ & 56.8 & $03 / 18$ & \\
\hline $3 / 17 / 96$ & 6:19:21 PM & 2937 & & 56.1 & $03 / 18$ & analyzed in field \\
\hline $3 / 17 / 96$ & $7: 20: 04 \mathrm{PM}$ & 2938 & F/D & 52.9 & & \\
\hline $3 / 17 / 96$ & $8: 20: 34 \mathrm{PM}$ & 2939 & & 52.4 & $03 / 18$ & analyzed in field \\
\hline $3 / 17 / 96$ & $9: 20: 47 \mathrm{PM}$ & 2940 & $F / D^{*}$ & 52.2 & $04 / 02$ & \\
\hline $3 / 17 / 96$ & $10: 21: 00 \mathrm{PM}$ & 2941 & & 53.9 & $03 / 18$ & analyzed in field \\
\hline $3 / 17 / 96$ & $11: 21: 40 \mathrm{PM}$ & 2942 & $\mathrm{~F} / \mathrm{D}^{*}$ & 53.8 & $03 / 18$ & \\
\hline $3 / 18 / 96$ & $12: 22: 19 \mathrm{AM}$ & 2943 & & 54.2 & $03 / 18$ & analyzed in field \\
\hline $3 / 18 / 96$ & $1: 22: 31 \mathrm{AM}$ & 2944 & $\mathrm{~F}^{*} \mathrm{D}^{*}$ & 54.0 & $03 / 18$ & \\
\hline $3 / 18 / 96$ & 2:23:07 AM & 2945 & & 54.0 & $03 / 18$ & analyzed in field \\
\hline $3 / 18 / 96$ & $3: 23: 20 \mathrm{AM}$ & 2946 & F/D & 52.4 & & \\
\hline $3 / 18 / 96$ & 4:23:58 AM & 2947 & & 53.0 & $03 / 18$ & analyzed in field \\
\hline $3 / 18 / 96$ & 5:24:11 AM & 2948 & F/D & 51.5 & & \\
\hline $3 / 18 / 96$ & $6: 24: 40$ AM & 2949 & & 51.5 & $03 / 18$ & analyzed in field \\
\hline $3 / 18 / 96$ & $7: 24: 54$ AM & 2950 & F/D & 51.0 & & \\
\hline $3 / 18 / 96$ & 8:25:07 AM & 2951 & & 52.5 & $03 / 18$ & analyzed in field \\
\hline $3 / 18 / 96$ & $9: 49: 40 \mathrm{AM}$ & 2952 & F/D & 51.6 & & \\
\hline $3 / 18 / 96$ & 10:49:56 AM & 2953 & & 52.9 & $03 / 18$ & analyzed in field \\
\hline $3 / 18 / 96$ & $11: 31: 53 \mathrm{AM}$ & 2954 & F/D & 51.1 & & \\
\hline $3 / 18 / 96$ & 12:32:07 PM & 2955 & & 52.4 & $03 / 18$ & analyzed in field \\
\hline $3 / 18 / 96$ & $1: 32: 19 \mathrm{PM}$ & 2956 & LF-D & 50.5 & & \\
\hline $3 / 18 / 96$ & $2: 32: 50 \mathrm{PM}$ & 2957 & LF-D & 50.1 & & \\
\hline $3 / 18 / 96$ & 3:33:03 PM & 2958 & & 49.2 & $04 / 01$ & analyzed in lab \\
\hline $3 / 18 / 96$ & $4: 33: 15 \mathrm{PM}$ & 2959 & & 48.4 & $04 / 01$ & analyzed in lab \\
\hline $3 / 18 / 96$ & 5:33:29 PM & 2960 & & 51.5 & $04 / 01$ & analyzed in lab \\
\hline $3 / 18 / 96$ & 6:33:42 PM & 2961 & & 50.8 & 04101 & analyzed in lab \\
\hline $3 / 18 / 96$ & 7:33:55 PM & 2962 & & 48.4 & $04 / 01$ & analyzed in lab \\
\hline $3 / 18 / 96$ & 8:34:23 PM & 2963 & & 50.7 & $04 / 01$ & analyzed in lab \\
\hline $3 / 18 / 96$ & 9:34:37 PM & 2964 & LD & 49.5 & & \\
\hline $3 / 18 / 96$ & $10: 34: 51 \mathrm{PM}$ & 2965 & & 54.0 & $04 / 01$ & analyzed in field \\
\hline $3 / 18 / 96$ & $11: 35: 06 \mathrm{PM}$ & 2966 & & 51.8 & 04101 & analyzed in field \\
\hline $3 / 19 / 96$ & 12:35:29 AM & 2967 & & 54.1 & $04 / 01$ & analyzed in field \\
\hline $3 / 19 / 96$ & 1:35:47 AM & 2968 & & 52.1 & $04 / 01$ & analyzed in field \\
\hline $3 / 19 / 96$ & 2:36:23 AM & 2969 & & 52.4 & $04 / 01$ & analyzed in field \\
\hline $3 / 19 / 96$ & 3:36:36 AM & 2970 & & 51.5 & $04 / 01$ & analyzed in field \\
\hline $3 / 19 / 96$ & $4: 36: 57$ AM & 2971 & & 52.4 & $04 / 01$ & analyzed in field \\
\hline $3 / 19 / 96$ & $5: 37: 34 \mathrm{AM}$ & 2972 & & 53.0 & $04 / 01$ & analyzed in field \\
\hline $3 / 19 / 96$ & $6: 37: 47$ AM & 2973 & & 52.6 & $04 / 01$ & analyzed in field \\
\hline $3 / 19 / 96$ & 7:38:12 AM & 2974 & & 54.0 & $04 / 01$ & analyzed in field \\
\hline $3 / 19 / 96$ & 8:38:26 AM & 2975 & & 50.4 & $04 / 01$ & analyzed in field \\
\hline $3 / 19 / 96$ & $9: 38: 43 \mathrm{AM}$ & 2976 & & 54.4 & $04 / 01$ & analyzed in field \\
\hline $3 / 19 / 96$ & 10:39:07 AM & 2977 & & 51.6 & $04 / 01$ & analyzed in field \\
\hline $3 / 19 / 96$ & 11:39:20 AM & 2978 & F/D* & 50.6 & $04 / 01$ & anabyed in field \\
\hline $3 / 19 / 96$ & 12:39:41 PM & 2979 & & 50.2 & $04 / 19$ & analyzed in lab \\
\hline $3 / 19 / 96$ & $1: 39: 55 \mathrm{PM}$ & 2980 & & 48.9 & $04 / 02$ & analyzed in field \\
\hline $3 / 19 / 96$ & 2:40:25 PM & 2981 & & 48.4 & 04102 & analyzed in field \\
\hline $3 / 19 / 96$ & 3:40:38 PM & 2982 & & 48.8 & 04102 & analyzed in field \\
\hline $3 / 19 / 96$ & 4:40:51 PM & 2983 & & 48.6 & 04102 & anahyzed in field \\
\hline $3 / 19 / 96$ & 5:41:12 PM & 2984 & & 48.4 & $04 / 02$ & analyzed in field \\
\hline $3 / 19 / 96$ & 6:41:25 PM & 2985 & $F / D$ & 48.0 & & \\
\hline $3 / 19 / 96$ & 7:41:43 PM & 2986 & & 48.3 & $04 / 02$ & analyzed in field \\
\hline $3 / 19 / 96$ & 8:42:01 PM & 2987 & F/D & 48.3 & & \\
\hline $3 / 19 / 96$ & 9:42:25 PM & 2988 & F/D & 47.5 & & \\
\hline $3 / 19 / 96$ & 10:42:56 PM & 2989 & F/D* & 47.5 & & \\
\hline $3 / 19 / 96$ & 11:43:24 PM & 2990 & F/D & 46.9 & & \\
\hline $3 / 20 / 96$ & $12: 43: 37 \mathrm{AM}$ & 2991 & $F / D^{*}$ & 46.8 & & \\
\hline
\end{tabular}




\begin{tabular}{|c|c|c|c|c|c|c|}
\hline Date & Time of Sample & Sample \# & Dup. code & Conc (ppb) & Analysis date & place \\
\hline $3 / 20 / 96$ & $1: 43: 55 \mathrm{AM}$ & 2992 & LF-D & 48.0 & $04 / 02$ & analyzed in field \\
\hline $3 / 20 / 96$ & $2: 44: 17$ AM & 2993 & $F / D^{*}$ & 47.7 & $04 / 02$ & analyzed in field \\
\hline $3 / 20 / 96$ & $3: 44: 48$ AM & 2994 & F/D: & 47.5 & $04 / 02$ & analyzed in field \\
\hline $3 / 20 / 96$ & 4:45:02 AM & 2995 & $F / D^{\circ}$ & 47.4 & $04 / 02$ & analyzed in field \\
\hline $3 / 20 / 96$ & 5:45:22 AM & 2996 & $F / D^{*}$ & 47.2 & $04 / 02$ & analyzed in field \\
\hline $3 / 20 / 96$ & $6: 45: 41$ AM & 2997 & $F / D^{*}$ & 47.0 & $03 / 20$ & analyzed in field \\
\hline $3 / 20 / 96$ & 7:46:02 AM & 2998 & $F / D^{*}$ & 47.1 & $04 / 02$ & analyzed in field \\
\hline $3 / 20 / 96$ & $8: 46: 42 \mathrm{AM}$ & 2999 & $F / D^{*}$ & 46.6 & 04102 & analyzed in field \\
\hline $3 / 20 / 96$ & $9: 46: 55 \mathrm{AM}$ & 3000 & $F / D^{*}$ & 46.2 & $04 / 02$ & analyzed in field \\
\hline $3 / 20 / 96$ & 10:47:09 AM & 3001 & $F / D^{*}$ & 46.1 & $04 / 02$ & analyzed in field \\
\hline $3 / 20 / 96$ & $11: 47: 31 \mathrm{AM}$ & 3002 & $\mathrm{~F} / \mathrm{D}^{*}$ & 46.6 & $04 / 02$ & analyzed in field \\
\hline $3 / 20 / 96$ & $12: 47: 51 \mathrm{PM}$ & 3003 & $F / D^{*}$ & 45.9 & $04 / 02$ & analyzed in field \\
\hline $3 / 20 / 96$ & $1: 48: 04 \mathrm{PM}$ & 3004 & LF-D* & 45.8 & $03 / 20$ & analyzed in field \\
\hline $3 / 20196$ & 2:48:17 PM & 3005 & & 45.5 & $03 / 26$ & analyzed in lab \\
\hline $3 / 20 / 96$ & 3:48:33 PM & 3006 & & 48.5 & $03 / 26$ & analyzed in lab \\
\hline $3 / 20 / 96$ & 4:48:54 PM & 3007 & & 45.0 & $03 / 26$ & analyzed in lab \\
\hline $3 / 20 / 96$ & 5:49:30 PM & 3008 & & 49.4 & $03 / 26$ & analyzed in lab \\
\hline $3 / 20 / 96$ & 6:49:44 PM & 3009 & & 51.0 & $03 / 26$ & analyzed in lab \\
\hline $3 / 20 / 96$ & 7:49:59 PM & 3010 & & 50.9 & $03 / 26$ & analyzed in lab \\
\hline $3 / 20 / 96$ & $8: 50: 18 \mathrm{PM}$ & 3011 & & 50.7 & $03 / 26$ & analyzed in lab \\
\hline $3 / 20 / 96$ & $9: 50: 39 \mathrm{PM}$ & 3012 & & 50.2 & $03 / 26$ & analyzed in lab \\
\hline $3 / 20 / 96$ & $10: 51: 03 \mathrm{PM}$ & 3013 & & 50.3 & $03 / 26$ & analyzed in lab \\
\hline $3 / 20 / 96$ & $11: 51: 34 \mathrm{PM}$ & 3014 & LD* & 50.7 & & \\
\hline $3 / 21 / 96$ & $12: 51: 47 \mathrm{AM}$ & 3015 & & 50.1 & $03 / 26$ & analyzed in lab \\
\hline $3 / 21 / 96$ & $1: 52: 04 \mathrm{AM}$ & 3016 & & 49.1 & $03 / 26$ & analyzed in lab \\
\hline $3 / 21 / 96$ & $2: 52: 34$ AM & 3017 & & 49.8 & $03 / 26$ & analyzed in lab \\
\hline $3 / 21 / 96$ & 3:52:47 AM & 3018 & & 49.0 & $03 / 26$ & analyzed in lab \\
\hline $3 / 21 / 96$ & 4:53:05 AM & 3019 & & 48.7 & $03 / 26$ & analyzed in lab \\
\hline $3 / 21 / 96$ & 5:53:18 AM & 3020 & & 49.9 & $03 / 26$ & analyzed in lab \\
\hline $3 / 21 / 96$ & $6: 53: 34$ AM & 3021 & & 48.9 & $03 / 26$ & analyzed in lab \\
\hline $3 / 21 / 96$ & 7:53:55 AM & 3022 & & 49.3 & $03 / 26$ & analyzed in lab \\
\hline $3 / 21 / 96$ & $8: 54: 22$ AM & 3023 & L/D & 50.3 & & \\
\hline $3 / 21 / 96$ & $9: 54: 44$ AM & 3024 & & 51.6 & $03 / 26$ & analyzed in lab \\
\hline $3 / 21 / 96$ & $10.54: 59 \mathrm{AM}$ & 3025 & & 50.1 & $03 / 26$ & analyzed in lab \\
\hline $3 / 21 / 96$ & $11: 55: 37 \mathrm{AM}$ & 3026 & & 49.0 & $03 / 26$ & analyzed in lab \\
\hline $3 / 21 / 96$ & 12:55:51 PM & 3027 & & 49.4 & $03 / 26$ & analyzed in lab \\
\hline $3 / 21 / 96$ & $1: 56: 04 \mathrm{PM}$ & 3028 & & 48.7 & $03 / 26$ & analyzed in lab \\
\hline $3 / 21 / 96$ & 2:56:17 PM & 3029 & & 50.3 & $03 / 26$ & analyzed in lab \\
\hline $3 / 21 / 96$ & 3:56:29 PM & 3030 & & 49.1 & $03 / 26$ & analyzed in lab \\
\hline $3 / 21 / 96$ & 4:56:42PM & 3031 & & 48.5 & $03 / 26$ & analyzed in lab \\
\hline $3 / 21 / 96$ & 5:56:58 PM & 3032 & & 50.6 & $03 / 26$ & analyzed in lab \\
\hline $3 / 21 / 96$ & 6:57:14 PM & 3033 & & 48.9 & $03 / 26$ & analyzed in lab \\
\hline $3 / 21 / 96$ & 7:57:34 PM & 3034 & $L D^{*}$ & 48.1 & & \\
\hline $3 / 21 / 96$ & 8:58:03 PM & 3035 & & 45.0 & $04 / 19$ & analyzed in lab \\
\hline $3 / 21 / 96$ & 9:58:15 PM & 3036 & & 43.3 & $03 / 27$ & analyzed in lab \\
\hline $3 / 21 / 96$ & $10: 58: 28 \mathrm{PM}$ & 3037 & & 44.0 & $03 / 27$ & analyzed in lab \\
\hline $3 / 21 / 96$ & $11: 58: 41 \mathrm{PM}$ & 3038 & & 44.7 & $03 / 27$ & analyzed in lab \\
\hline $3 / 22 / 96$ & $12: 58: 58 \mathrm{AM}$ & 3039 & & 44.9 & $03 / 27$ & analyzed in lab \\
\hline $3 / 22 / 96$ & 1:59:11 AM & 3040 & & 46.1 & $03 / 27$ & analyzed in lab \\
\hline $3 / 22 / 96$ & 2:59:27 AM & 3041 & & 44.3 & $03 / 27$ & analyzed in lab \\
\hline $3 / 22 / 96$ & $3: 59: 42 \mathrm{AM}$ & 3042 & UF-D & 44.0 & & \\
\hline $3 / 22 / 96$ & 4:59:59 AM & 3043 & UF-D & 44.5 & & \\
\hline $3 / 22 / 96$ & $6: 00: 29$ AM & 3044 & LF $-D^{*}$ & 43.5 & & \\
\hline $3 / 22 / 96$ & 7:00:42 AM & 3045 & LF-D* & 43.7 & & \\
\hline $3 / 22 / 96$ & $8: 00: 55$ AM & 3046 & LF $-D^{*}$ & 45.0 & & \\
\hline $3 / 22 / 96$ & $9: 01: 08 \mathrm{AM}$ & 3047 & LF $-D^{*}$ & 45.1 & & \\
\hline $3 / 22 / 96$ & $10: 01: 28 \mathrm{AM}$ & 3048 & $\mathrm{~L} / \mathrm{F}-\mathrm{D}^{*}$ & 43.6 & & \\
\hline $3 / 22 / 96$ & $11: 01: 58 \mathrm{AM}$ & 3049 & & 44.3 & $03 / 27$ & analyzed in lab \\
\hline $3 / 22 / 96$ & $1: 02: 12 \mathrm{PM}$ & 3050 & & 42.5 & $03 / 27$ & analyzed in lab \\
\hline $3 / 22 / 96$ & 3:02:54 PM & 3051 & & 42.8 & $03 / 27$ & analyzed in lab \\
\hline $3 / 22 / 96$ & 5:03:31 PM & 3052 & & 43.1 & $03 / 27$ & analyzed in field \\
\hline $3 / 22 / 96$ & 7:04:22 PM & 3053 & & 40.6 & $03 / 27$ & analyzed in field \\
\hline $3 / 22 / 96$ & 9:05:15 PM & 3054 & & 41.3 & $03 / 27$ & analyzed in field \\
\hline $3 / 22 / 96$ & $11: 05: 29 \mathrm{PM}$ & 3055 & & 41.2 & $03 / 27$ & analyzed in field \\
\hline $3 / 23 / 96$ & $1: 06: 12 \mathrm{AM}$ & 3056 & & 41.9 & $03 / 27$ & analyzed in field \\
\hline $3 / 23 / 96$ & $3: 06: 55$ AM & 3057 & & 42.2 & $03 / 27$ & anatyzed in field \\
\hline $3 / 23 / 96$ & 5:07:33 AM & 3058 & & 41.7 & $03 / 27$ & analyzed in field \\
\hline $3 / 23 / 96$ & 7:08:09 AM & 3059 & & 41.8 & $03 / 27$ & analyzed in field \\
\hline $3 / 23 / 96$ & 9:08:51 AM & 3060 & & 41.8 & $03 / 27$ & analyzed in field \\
\hline $3 / 23 / 96$ & $11: 09: 22 \mathrm{AM}$ & 3061 & & 42.0 & $03 / 27$ & analyzed in field \\
\hline
\end{tabular}




\begin{tabular}{|c|c|c|c|c|c|c|}
\hline Date & Time of Sample & Sample \# & Dup. code & Conc (ppb) & Analysis date & place \\
\hline $3 / 23 / 96$ & $1: 10: 34 \mathrm{PM}$ & 3062 & & 40.0 & $03 / 27$ & analyzed in field \\
\hline $3 / 23 / 96$ & $3: 10: 47 \mathrm{PM}$ & 3063 & F/D & 40.5 & & \\
\hline $3 / 23 / 96$ & $5: 11: 16 \mathrm{PM}$ & 3064 & & 40.5 & $03 / 27$ & analyzed in field \\
\hline $3 / 23 / 96$ & 7:11:53 PM & 3065 & & 40.0 & $03 / 27$ & analyzed in field \\
\hline $3 / 23 / 96$ & $9: 12: 29 \mathrm{PM}$ & 3066 & & 40.4 & $03 / 27$ & analyzed in field \\
\hline $3 / 23 / 96$ & $11: 12: 43 \mathrm{PM}$ & 3067 & & 40.7 & $03 / 27$ & analyzed in field \\
\hline $3 / 24 / 96$ & $1: 12: 57 \mathrm{AM}$ & 3068 & & 40.3 & $03 / 27$ & analyzed in field \\
\hline $3 / 24 / 96$ & 3:13:23 AM & 3069 & & 40.1 & $03 / 27$ & analyzed in field \\
\hline $3 / 24 / 96$ & 5:13:55 AM & 3070 & & 40.3 & $03 / 27$ & analyzed in field \\
\hline $3 / 24 / 96$ & $7: 14: 59$ AM & 3071 & & 41.7 & $03 / 27$ & analyzed in field \\
\hline $3 / 24 / 96$ & $9: 15: 12 \mathrm{AM}$ & 3072 & & 40.3 & $03 / 27$ & analyzed in field \\
\hline $3 / 24 / 96$ & $11: 15: 45 \mathrm{AM}$ & 3073 & & 40.0 & $03 / 27$ & analyzed in field \\
\hline $3 / 24 / 96$ & 1:16:19 PM & 3074 & & 39.2 & $03 / 27$ & analyzed in field \\
\hline $3 / 24 / 96$ & 3:17:00 PM & 3075 & $F / D^{*}$ & 39.9 & & \\
\hline $3 / 24 / 96$ & 5:17:38 PM & 3076 & & 39.0 & $03 / 25$ & analyzed in lab \\
\hline $3 / 24 / 96$ & 7:18:14 PM & 3077 & & 38.6 & $03 / 25$ & analyzed in lab \\
\hline $3 / 24 / 96$ & 9:18:54 PM & 3078 & & 38.1 & $03 / 25$ & analyzed in $\mathrm{lab}$ \\
\hline $3 / 24 / 96$ & 11:19:07 PM & 3079 & & 37.6 & $03 / 25$ & analyzed in lab \\
\hline $3 / 25 / 96$ & $1: 19: 35 \mathrm{AM}$ & 3080 & & 37.9 & $03 / 25$ & anahyed in lab \\
\hline $3 / 25 / 96$ & $3: 20: 12$ AM & 3081 & & 36.9 & $03 \sqrt{25}$ & analyzed in $\mathrm{ab}$ \\
\hline $3 / 25 / 96$ & $5: 20: 54 \mathrm{AM}$ & 3082 & & 37.8 & $03 / 25$ & anahyed in $\mathrm{tab}$ \\
\hline $3 / 25 / 96$ & $7: 21: 52 \mathrm{AM}$ & 3083 & & 37.8 & $03 / 25$ & analyzed in lab \\
\hline $3 / 25 / 96$ & $9: 22: 06 \mathrm{AM}$ & 3084 & & 37.8 & $03 / 25$ & analyzed in lab \\
\hline $3 / 25 / 96$ & $11: 22: 47 \mathrm{AM}$ & 3085 & $\mathrm{UD}^{*}$ & 37.1 & & \\
\hline $3 / 25 / 96$ & $1: 23: 27 \mathrm{PM}$ & 3086 & UF-D* & 40.6 & & \\
\hline $3 / 25 / 96$ & 3:24:11 PM & 3087 & UF $-D^{*}$ & 37.2 & & \\
\hline $3 / 25 / 96$ & 5:25:04 PM & 3088 & LF-D* & 36.1 & & \\
\hline $3 / 25 / 96$ & $7: 25: 29 \mathrm{PM}$ & 3089 & $\mathrm{~L} / \mathrm{F}-\mathrm{D}^{*}$ & 37.4 & & \\
\hline $3 / 25 / 96$ & 9:26:02 PM & 3090 & LF-D* & 39.0 & & \\
\hline $3 / 25 / 96$ & $11: 26: 43 \mathrm{PM}$ & 3091 & & 38.8 & $03 / 29$ & analyzed in field \\
\hline $3 / 26 / 96$ & $1: 27: 24 \mathrm{AM}$ & 3092 & & 39.0 & $03 / 29$ & anahreed in field \\
\hline $3 / 26 / 96$ & 3:28:06 AM & 3093 & & 39.7 & $03 / 29$ & analyzed in field \\
\hline $3 / 26 / 96$ & 5:28:47 AM & 3094 & & 37.2 & $03 / 29$ & analyzed in field \\
\hline $3 / 26 / 96$ & 7:29:23 AM & 3095 & & 39.1 & $03 / 29$ & analyzed in field \\
\hline $3 / 26 / 96$ & $9: 30: 03 \mathrm{AM}$ & 3096 & & 39.2 & $03 / 29$ & analyzed in field \\
\hline $3 / 26 / 96$ & $11: 30: 38 \mathrm{AM}$ & 3097 & & 38.3 & $03 / 29$ & analyzed in field \\
\hline $3 / 26 / 96$ & $1: 31: 43 \mathrm{PM}$ & 3098 & & 38.2 & $03 / 28$ & analyzed in field \\
\hline $3 / 26 / 96$ & 3:32:01 PM & 3099 & & 36.3 & $03 / 28$ & anahyed in field \\
\hline $3 / 26196$ & 5:32:41 PM & 3100 & & 37.1 & $03 / 28$ & analyzed in field \\
\hline $3 / 26 / 96$ & 7:33:06 PM & 3101 & & 37.0 & $03 / 28$ & analyzed in field \\
\hline $3 / 26 / 96$ & $9: 33: 50 \mathrm{PM}$ & 3102 & & 37.6 & $03 / 28$ & analyzed in field \\
\hline $3 / 26 / 96$ & $11: 34: 50 \mathrm{PM}$ & 3103 & & 37.9 & $03 / 28$ & analyzed in field \\
\hline $3 / 27 / 96$ & $1: 35: 04 \mathrm{AM}$ & 3104 & & 37.2 & $03 / 28$ & analyzed in field \\
\hline $3 / 27 / 96$ & 3:35:41 AM & 3105 & & 37.5 & $03 / 28$ & anahzed in field \\
\hline $3 / 27 / 96$ & 5:35:54 AM & 3106 & & 37.7 & $03 / 28$ & analyzed in field \\
\hline $3 / 27 / 96$ & $7: 36: 18$ AM & 3107 & F/D* & 37.6 & & \\
\hline \multirow[t]{3}{*}{$3 / 27 / 96$} & $9: 36: 50 \mathrm{AM}$ & 3108 & $F / D^{*}$ & 37.1 & $03 / 28$ & analyzed in field \\
\hline & & & & 37.2 & $03 / 29$ & anabzed in field \\
\hline & & & & 35.5 & $03 / 29$ & anahzed in field \\
\hline & & & & & & \\
\hline & & & & & & \\
\hline $3 / 27 / 96$ & 2:43:19 PM & 3111 & & 36.1 & $03 / 29$ & analyzed in field \\
\hline $3 / 27 / 96$ & $4: 43.56 \mathrm{PM}$ & 3112 & & 36.8 & 0329 & anatyzed in field \\
\hline $3 / 27 / 96$ & $6: 44: 32 \mathrm{PM}$ & 3113 & & 36.2 & $03 / 29$ & analyzed in field \\
\hline $3 / 27 / 96$ & $8: 44: 45 \mathrm{PM}$ & 3114 & & 35.2 & $03 / 29$ & analyzed in field \\
\hline $3 / 27 / 96$ & $10: 44: 58 \mathrm{PM}$ & 3115 & & 36.5 & $03 / 29$ & anatyzed in field \\
\hline $3 / 28 / 96$ & $12: 45: 37 \mathrm{AM}$ & 3116 & & 35.4 & $03 / 29$ & analyzed in field \\
\hline $3 / 28 / 96$ & $2: 45: 50 \mathrm{AM}$ & 3117 & & 36.0 & $03 / 29$ & analyzed in field \\
\hline $3 / 28 / 96$ & 4:46:03 AM & 3118 & & 36.0 & $03 / 29$ & analyzed in field \\
\hline $3 / 28 / 96$ & $6: 46: 40 \mathrm{AM}$ & 3119 & & 35.0 & $03 / 29$ & analyzed in field \\
\hline $3 / 28 / 96$ & $8: 47: 50 \mathrm{AM}$ & 3120 & & 36.3 & $03 / 29$ & anahyed in field \\
\hline $3 / 28 / 96$ & 10:48:04 AM & 3121 & & 35.9 & $03 / 29$ & anabyed in $\mathrm{lab}$ \\
\hline $3 / 28 / 96$ & 12:48:37 PM & 3122 & & 33.7 & $03 / 29$ & analyzed in lab \\
\hline $3 / 28 / 96$ & 2:49:17 PM & 3123 & & 35.5 & $03 / 29$ & analyzed in lab \\
\hline $3 / 28 / 96$ & 4:49:55 PM & 3124 & & 34.0 & $03 \sqrt{29}$ & anabyed in $\mathrm{kb}$ \\
\hline $3 / 28 / 96$ & 6:50:27 PM & 3125 & & 32.9 & $03 / 29$ & analyzed in lab \\
\hline $3 / 28 / 96$ & $8: 51: 05$ PM & 3126 & & 34.3 & $03 \sqrt{29}$ & analyzed in lab \\
\hline $3 / 28 / 96$ & $10: 51: 43 \mathrm{PM}$ & 3127 & & 33.9 & $03 / 29$ & analyzed in lab \\
\hline $3 / 29 / 96$ & $12: 51: 56 \mathrm{AM}$ & 3128 & & 33.0 & $03 / 29$ & analyzed in lab \\
\hline $3 / 29 / 96$ & $2: 52: 27 \mathrm{AM}$ & 3129 & LF-D* & 34.0 & $03 / 29$ & analyzed in field \\
\hline
\end{tabular}


Yucca Mountain tracer test; 33

\begin{tabular}{|c|c|c|c|c|c|c|}
\hline Date & Time of Sample & Sample \# & Dup. code & Conc (ppb) & Analysis date & place \\
\hline $3 / 29 / 96$ & $4: 53: 09$ AM & 3130 & & 34.3 & $04 / 02$ & analyzed in field \\
\hline $3 / 29 / 96$ & $6: 53: 39 \mathrm{AM}$ & 3131 & & 33.9 & $04 / 02$ & analyzed in field \\
\hline $3 / 29 / 96$ & $8: 54: 15 \mathrm{AM}$ & 3132 & & 33.7 & $04 / 02$ & analyzed in field \\
\hline $3 / 29 / 96$ & $10: 54: 51 \mathrm{AM}$ & 3133 & & 33.9 & $04 / 02$ & analyzed in field \\
\hline $3 / 29 / 96$ & $12: 55: 27 \mathrm{PM}$ & 3134 & & 33.9 & $04 / 02$ & analyzed in field \\
\hline & & & & & & \\
\hline & & & & & & \\
\hline & & & & & & \\
\hline & & & & & & LD= analyzed in duplicate in lab; \\
\hline & & & & & & F/D=analyzed in duplicate in field; \\
\hline & & & & & & LF.OF analyzed in duplicate in lab and fiel \\
"= only one of the values is used.
\end{tabular}




\section{Yucca Mountain Tracer pattern}

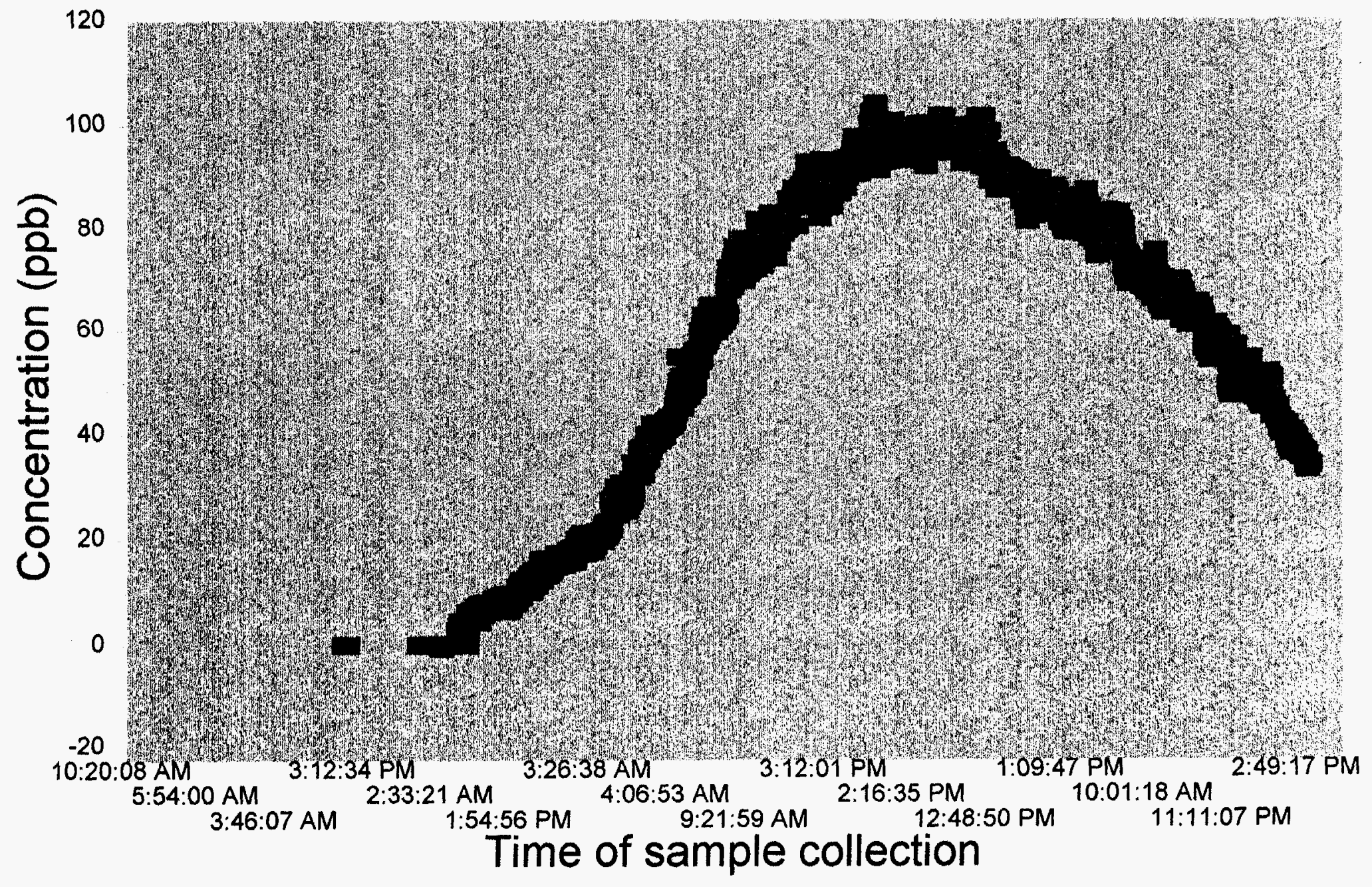


Data analysis books entitled, Chemical Analysis of Water from Ash Meadows Springs and Chemical Analysis of Water from Death Valley Springs can be issued upon request. Please call 895-1357 and ask for Sally Hamilton. 